\title{
Deportability, Labour and Health in Canada's Late Capitalism
}

\author{
by
}

Hector Eloy Rivas Sánchez

A thesis submitted to the Faculty of Graduate and Postdoctoral Affairs in partial fulfillment of the requirements for the degree of

Doctor of Philosophy

in

Sociology

with a specialization in Political Economy

\author{
Carleton University \\ Ottawa, Ontario \\ (C)2019 \\ Hector Eloy Rivas Sanchez
}




\begin{abstract}
This dissertation explores the political economy of the physical and mental illnesses that the migrant workers experience while living and working under conditions of illegality in Canada's late capitalism. The dissertation is divided into three parts. The first part locates four social determinants of health underpinning the structural vulnerability to which the Latin American undocumented workers are subjected in this particular context. Based on the data gathered on the ground, this part shows that, for this particular population, the condition of being "subjects of administration," "subjects of deportability," "subjects of racialization" and "subjects of exploitation," work as primary sources of physical and mental illnesses.
\end{abstract}

The second part describes the mental and physical health illnesses that the undocumented workers develop while living and working in Canada without authorization, according to the type of industry they work in (1.-Multinational Corporations, 2.-Medium-size local industries and 3.- Underground workers' cooperatives) and to the type of work they do. The empirical evidence illustrates that the undocumented immigrants who work for medium-size local enterprises, those who have been affected by deportability and deportation, as well as those who lost their legal status after being engaged in refugee claimant applications, are more likely to develop the most dramatic forms of physical and mental health diseases, such as suicidal thoughts, incapacitating bodily injuries and several disorders arguably linked to what is called here "shortterm historical trauma." In contrast, those who work for underground workers' cooperatives are more likely to report better physical and mental health outcomes. This happens mainly, the third part explores, because living under conditions of what will be called "clandestine solidarity" prevents them from being exposed to the effects of deportability, exploitation and racial domination, and exposes them to diverse forms of solidarity from Canadian grassroots organizations. Overall, this thesis indicates that, under the current social, labour and institutional conditions organized by the precarity-inducing dynamics of late capitalism, social solidarity and engagement in non-waged cooperative labour constitute social mechanisms by which undocumented migrants can access to forms of refuge, care, solidarity and social recognition that partially emancipate them from illnesses, suffering and social death.

This thesis is based on an ethnographic work that I carried out over 24 months in Montreal and surrounding communities. During that period of time, I lived and worked side by side with Latin American undocumented workers in slaughterhouses and meat packing factories, construction and home renovation companies, employment agencies, and as industrial cleaner for multinational corporations, spaces where I carried out direct empirical observation in the points of production and conducted 47 in-depth interviews on illegality, labour and health. I also conducted interviews and did empirical observation while providing support and mealtime company to ill and incarcerated undocumented workers in hospitals and deportation centers. 


\section{Dedication}

To Federico Arcos and Francisca Zepeda Sosa, for having taught me so much about freedom, solidarity, hope and patience.

To my parents, for having taught me to value education and scientific knowledge, despite not having had access to formal education themselves. And for having taught so much about respect and recognition for all my fellow human beings. 


\section{Acknowledgments}

The completion of my doctoral studies, and of this dissertation, in particular, were possible because of the support I received from an important number of people, organizations, and institutions to whom I want to express my gratitude. First of all, I want to thank all the workers who trusted me, shared their time and stories with me, and provided me with ideas throughout the research process. Among them, I learned that when one lives in a context of deep precarity and engaged in a daily struggle to survive deportability, alienation, suffering, and exploitation, it is very difficult to trust in others. Despite this, the workers I interviewed generously overcome mistrust and patiently spent part of their valuable time telling me their stories. Their participation made the very existence of this work possible. Gracias, de veras.

Alma, Raquel, Laura, Raul, Robert, Alejandra, and my compadres Toño and José, were particularly generous throughout the research process. They do not only provided me with housing and mealtime company, but also encouraged me to get things done when I was low in batteries. My compañeras: Romina Hernandez, Carmelo Monge, Noe Arteaga, Mary Foster and all the members of the Comité de Soutien of Solidarity Across Borders provided also encouragement and support during my fieldwork. Their tireless work providing support to migrant workers was a continuous source of inspiration for me.

The organizations Mexicanos Unidos por la Regularización, Solidarity Across Borders and the Centre des travailleurs et travailleuses immigrants / Immigrant Workers Centre (CTI-IWC) allowed me to attend meetings in their spaces and some members of those organizations helped me to get in contact with workers and other people who provided valuable input to this research.

Many thanks to Dr. Aaron Doyle, Chair of the Department of Sociology and Anthropology at Carleton University, and to Paula Whissell, Stephanie LeBlanc, Darlene Moss, Kimberley Séguin, Kim Mitchell for all their help throughout my doctoral studies. Many thanks as well to the "mighty writers' team from the graduate writing seminar and to my colleagues from the "tertulias chez Justin' team for the valuable feedback they provided to my writing.

I feel enormous gratitude to my supervisor, Dr. Justin Paulson, and to my advisors Dr. Hugh Armstrong, Dr. Tanya Basok and Dr. Wallace Clement. Their guidance, teachings and advise throughout the process of designing my research project, collecting data, and writing the research results were fundamental not only for completing this project but also for enriching my academic training itself. Dr. Leah F. Vosko and Dr. Lisa Mills, my external examiners, also contributed with important insights and feedback to this thesis. Being all of them giant academic figures, it was a real honour for me having them in my committee. Their academic rigor, generosity, and kindness have been an incredible source of inspiration for me and I will carry their teachings with me like a precious treasure for the rest of my life.

Professors Bruce Curtis, Xiaobei Chen, Laura McDonald, and Alexis Shotwell played an important role in my academic training as well. They taught me important concepts, theories, writing techniques that informed my research and writing. Alexis Shotwell, in particular, taught me and provided invaluable support in a critical moment within and outside classes. 
Thank you to Viviana Shotwell, who helped me with the copy-editing process of this thesis.

The Social Sciences and Humanities Research Council of Canada provided me with a doctoral studies scholarship which was critical to complete my doctoral studies and to conduct the research process which was the basis of this dissertation. The material support that I also received from the Department of Sociology and Anthropology and from the Faculty of Graduate and Postdoctoral Affairs in the forms of research grants and teaching grants were fundamental as well to complete my doctoral studies at Carleton University and to present my work in several academic events I Canada and abroad.

Finally, I want to express my deep gratitude to Genevieve Tousignant for her loving support, company, and encouragement. The joyful company of Evan, Leo and Nicolas were also fundamental to get things done throughout this journey. Thank you so very much for being always there on my side. 


\section{Table of Contents}

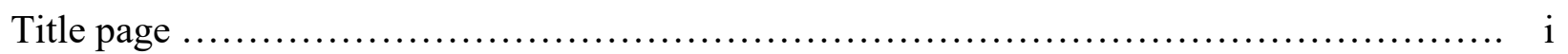

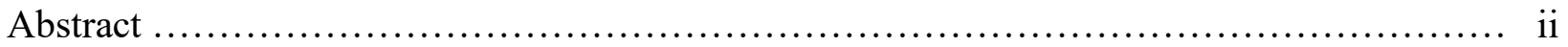

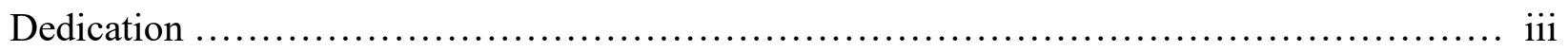

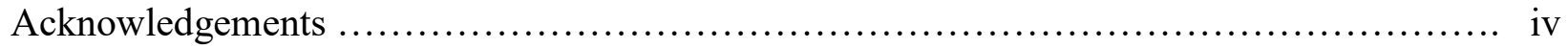

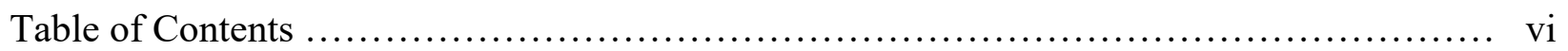

\section{Part I: The Problem and Method}

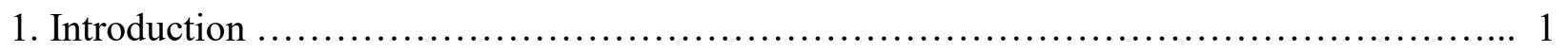

2. Undocumented Immigrants and the Master Determinants of Health ................... 57

\section{Part II: The Wounds of Labour}

3. Wounded Subjectivities: Abstract Labour, Uprootedness and Mental Suffering ........... 95

4. Mental and Physical Health in the Local, Medium-Sized Enterprises ................. 148

5. Mental and Physical Health in the Multinational Corporations ..................... 222

6. Mental and Physical Health in the Underground Workers' Cooperatives ............... 252

\section{Part III: The Seeds of a New Society}

7. Social Solidarity, Social Struggles and Health ................................ 269

8. Conclusions .......................................................... 296

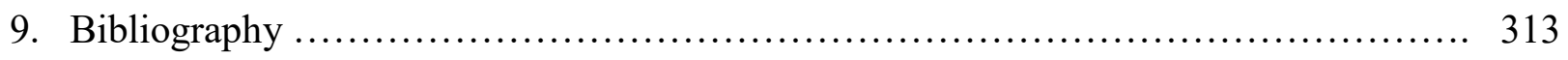




\section{Part I:}

\section{The Problem and Method}

"The method consists of knowing how to situate oneself in the position of the poor and, from there, to carry out a diagnosis of the pathology of the State."

-Hermann Cohen, The Religion of Reason- 


\section{Introduction}

This dissertation offers a sociological analysis of the physical and mental health conditions of undocumented immigrants who live and work in Canada. Although the research was carried out in the Greater Montreal area (GM), this work will also make broader claims, via the extended case

method approach proposed by Burawoy (1998). For those purposes, where appropriate, I will extrapolate the links that exist among apparently disconnected fragments-seeing them as constellations which may be ethnographically scrutinized, and providing reflexive explanations that hypothesize how and to what extent the research results gathered throughout 24 months of field work may be generalizable and extended out to a broader scale. An exercise of critical sociology and critical political economy demands such a scope.

Drawing from a variety of perspectives in the sociology of labour and the political economy of health, the research process - upon which the theses and arguments presented here were developed - consisted in studying the health conditions that undocumented immigrants experience while living in Canada under conditions of "illegality" and restricted mobility. This research was carried out at the micro and macro level, and in three different phases. In a first phase, the "microlevel moment," I entered the field and observed the object of study from an acute angle, at a very close distance, because I myself took on the role of an unauthorized migrant worker. From that perspective, situated at the bottom and on the side of the workers, I registered on a daily basis the social relations in the workplace and the ways in which health is moulded in the factories and in the everyday life, while life is lived at the margins of society. I also interrogated the social etiology of their illnesses, as well as the way suffering is experienced within that context. After spending a significant period of time tracking the workers' daily life from that angle at that first stage, my 
registering soon became a "standpoint" in the sense defined by Dorothy Smith $(2007 ; 2010)$; that is, it became a form of sociological inquiry which comes from below, from the very standpoint of the oppressed subjects. Written in the underground, quite often at the end of a strenuous working day, after visiting an incarcerated migrant worker in a deportation center, or following a significant event, such as the arrest or deportation of a coworker, a political protest, or while doing support work for a migrant worker experiencing a health crisis, the notes in my diary are a testimony to the material social processes through which the will for detached thinking becomes transformed into a will for building up socially engaged knowledge aimed at documenting the roots of oppression and stimulating critical change. Then, at a second phase, the "macro-level moment," I took distance and observed the object of study from a wider focus. From that perspective, I looked at the labour processes and the undocumented immigrants' health as a whole and tried to analyze it within the context of the social system in which all that occurs and resides. I carried out this exercise in solitude: out of the field, the factories, the daily life in the underground, and out of my networks of friends. I read my notes, my diaries, and the recorded interviews. At the beginning, the process of interpreting the data was a difficult task. Within my files, there were a mixture of moving, chilling, and exciting stories, but I was able to see just "cases," and dispersed anecdotes. It took me time to see that the individual wounds, pain, life under exploitation and bondage could be viewed as part of a linked constellation. It was not easy to behold my people's gashes at the time I was working on the ones I myself have gotten in the field. How could this be otherwise? Despite the mechanisms I put in practice throughout the research process to avoid conflict of interest (such as not interviewing coworkers, or friends), some of the "subjects" and "research participants" had become my coworkers, my compañeros. It was grim to see some falling — getting sick, tired, injured, persecuted, caged, or deported. That is why it took some time to see those 
"cases" as a whole, and as interrelated parts of a system. In the third phase, I worked through texts and put my observations in conversation with theory and concepts. I also revisited the stories with which I was entrusted, and the stories that I wrote in my diary. It was only at that time that I started a process of abstraction and extrapolation which allowed me to see the stories and cases I had collected as interrelated parts of a same whole. From that act of generalization and abstraction I became better able to examine the structures, processes and the sociohistorical conditions that, according to my record, have shaped migrant workers' illnesses and have made them outlaw subjects, and unfree.

Those were the perspectives and the cognitive and material conditions upon which this sociological analysis was born. ${ }^{1}$ Having as a source of sociological inquiry my own experience as a worker, and my direct engagement with the stories of illness and pain that emerge from wounded subjectivities and injured bodies (the minds and bodies of the research participants I worked with), the sociological exploration written here is product of a dialectical exercise which, while seeking to explain the subject under investigation from a detached and objective point of view —carefully following the rules of the scientific method - kept always in mind that "the need to allow suffering

\footnotetext{
${ }^{1}$ It is important is to mention that I did not enter into the field as an innocent observer. As any other researcher, I arrived in the field equipped with theory, method and assumptions. Theory and method had to be adjusted at some moments through the research process. For example, my involvement as a worker in several industries allowed me to see that the health experiences of my migrant coworkers varied greatly according to the size of the company they were working in and the type of labour they performed in that job. As a consequence, I had to adapt my questions based on what type of work or what type of company they were working in. Theoretically, that meant that I had also had to consider a more historical perspective when talking about illnesses, as how the health was affected changed over time based on the types of jobs the workers were inserted into through their working experience in the country. Some of my existing assumptions changed while doing my fieldwork. For example, before entering into the field, as documented in my research project submitted before the Carleton's Ethics Committee, I used to think of the undocumented workers in Canada, and their experiences of illnesses, as a more or less monolithic one. However, differences in age, gender, length of time living in the country, types of jobs performed among other factors, made me realize the complexity and diversity of their health experiences. In order to capture that diversity, I had to divide the data collected by size of the company and incorporate race and gender in the analysis. In order to pass in the field, I had to underline my ethnicity and nationality as well. As I learned in the field, those markers facilitated the development of trust among the research participants and, therefore, my ability to pass.
} 
to speak is a condition of all truth" (Adorno, 2005: 28). For this reason, this doctoral dissertation is at the same time a rational attempt to understand how a migrant's illness and suffering are produced in this historical moment, and also an intellectual expression of a refusal against the morbid effects that social domination has on the lives of immigrants. In that sense, this sociological inquiry was born out of negativity in the Marcusean sense of the concept (Marcuse, 1960); that is, it was born as a form of dialectical reasoning carried out in refusal and as a critical response to the forms of domination that deny and neglect human freedom. That is the reason why the focus of this dissertation is on the understanding of the social mechanisms that produce illness, bondage, and human suffering.

The sociological objectification of undocumented migrants' health and mobility in a negative form (that is to say, to have as a goal the study of migrant workers' illnesses and unfreedom), as shaped by the socio-historical conditions under which they live, work and reproduce themselves as human beings, tacitly entails the recognition of four normative and sociological premises that I consider important to disclose here. First, it involves the recognition that illness and unfreedom are alien, harmful and undesirable conditions to human beings. Second, it involves the recognition that they are also not "normal" conditions of human beings, neither that they occur by "chance" nor by accident (except for some diseases); but, rather, that they are anomalies that have been shaped sometimes directly determined — by broader societal arrangements in particular geographical and historical coordinates. Third, it involves the recognition that socially-produced illness and injuries, as well as unfreedom, in so far as they impede the possibility of human self-realization and are linked to forms of social suffering, contribute to obstruct the development of a free and rational society, and therefore, must be scrutinized and challenged by critical sociology. Fourth, it also involves the recognition that the illnesses, suffering and unfreedom that migrant workers 
experience, insofar as they occur in one of the healthiest, freest and wealthiest countries of the world, represent expressions of late capitalism's morbid symptoms and also one of its most intolerable social pathologies.

Thus illness, "illegality," labour, and unfreedom in this dissertation will be analyzed in light of the social dynamics shaped by the historical social formation under which we live in this particular moment; a complex set of institutions and social relations identified by some as "Late Capitalism." I conceive of late capitalism as the hegemonic social formation that has become gradually consolidated since the last quarter of the 20th century in the core countries of the world system. This social formation is bound together by: 1) a regime of capital accumulation defined by its flexibility, dispossessing mechanisms, rapid international cross border mobility, and financialization (Arrighi, 2008; Harvey 1990; Sassen, 2012); 2) an ever expanding labour regime characterized by precarious employment and the global rise of human precarity (Shalla \& Clement 2007; Standing, 2013; Vosko, 2006); 3) a global regime for the administration of social life, including heavy administration of human mobility, increasingly characterized by a mixture of private and state-based surveillance and race/class-based control mechanisms targeting principally the mobility of the poor, the racialized, the criminalized, the beaten down, and other "racially undesirable" subjects (De Genova \& Peutz, 2010; Standing, 2013: 112-138; Walters, 2010: 85$86)$; 4) a state-based, controlled spatial regime where borders have been intensely produced — to the point of their proliferation even inside the nation states (Mezzandra, 2015) — and sustained through the threat of forced removal by a "global deportation regime" (De Genova, 2010: 58) with the aim of keeping the borders infrangible, while simultaneously using them as mechanisms to facilitate the circulation of commodities (including labour as commodity), and to selectively control the circulation of human beings. Finally, late capitalism is also underpinned by: 5) a regime 
of cultural forms and subjectivities that have been shaped by, and are functional to, such a contemporary social-political-spatial regime. This regime of cultural forms, which we could define also as late-capitalist structure of feelings, to use Raymond Williams' popular concept, includes aspects of what has been termed "neoliberal nativism"-a form of anti- immigrant rhetoric justified on economic grounds (Mize, 2008) - as well as the consolidation of "inverse cosmopolitanism" or "racism without races": a form of racism "that centers upon the immigration complex and that, at first sight, does not postulate the superiority of certain groups...in relation to others but 'only' the harmfulness of abolishing frontiers, and the incompatibility of lifestyles and traditions" (Balibar, 1997: 21; Balibar 2015). It includes also individualism, radicalization of political conservativism, anti-utopian thinking, rejection of anthropological universality, nostalgic sensitivity, and historical amnesia (Jameson, 1991). ${ }^{2}$ It is in relation to this historical formation, named here as Late Capitalism, that migration, precarious labour, illness and unfreedom will be thought through this doctoral thesis.

The analysis I offer here is based on empirical data that I collected while living and working side by side with undocumented immigrants. As such, it analyzes stories of trauma, dislocation and human suffering in contexts of forced migration, expulsion, cultural alienation, labour exploitation, and highly restricted (and policed) human mobility. This work intends to provide not only an

\footnotetext{
2 This definition of late capitalism is different from the eschatological definition provided by Ernest Mandel (1975), who coined the term, in the sense that it does not assume the imminent fatality of such sociohistorical formation. This definition also recognizes the importance of cultural forms that are produced under economic/political/historical formations. For that reason, as used here, "Late capitalism" is informed by the definition coined by Marxian cultural thinker Fredric Jameson (1991). I prefer the concept of "late capitalism" to define our current social, economic and political life instead of "neoliberalism" for two reasons. First, because, as Noam Chomsky (2016) has stated, the set of economic and political practices normally defined as neoliberal are, in fact, not new, nor liberal. The heavy implication of the State in the social life (and also in the economic sphere, though more as administrator of the capitalists' needs) is, firstly, the most anti-liberal practice, and, secondly, one of the oldest institutional practices human societies know. Second, because neoliberalism refers normally to an economic model or project, but normally ignores the cultural forms it produces. It also ignores the heavy implication of the administrative apparatus in the ordering of our social life and subjectivities.
} 
empirically founded analysis aimed at unveiling the social mechanisms producing illnesses and suffering, but also to lay out the basis for the development of a research program which can hopefully contribute, in the long run, to the accumulation of knowledge in the field of studies on health and human mobility. Inspired by the theoretical tradition of the Critical Theory of society, as outlined by Max Horkheimer (1976 [1937]; 1982), and the Frankfurt School, this work also aspires to stimulate the development of critical collective praxis aimed at the dismantling of the conditions that render undocumented migrant workers to subjugation, illness and suffering.

Grosso modo, those are the angles, axioms, and the rationale behind which the object of study was "framed" or sociologically objectified in this thesis. In what follows I will locate and justify the social problem under investigation in both its social and scientific dimensions. After framing the topic both qualitatively and quantitatively as linked to issues of inequality and social justice, I will carry out a brief literature review. In doing so, I hope to provide an idea of where this dissertation fits within the field of studies on migration and health in the Canadian context. Following that exercise, I will explain the methodological and the theoretical tools that were used to carry out the research that sustains this work.

\section{The Research Problem}

\section{The social context of the research problem.}

The undocumented or "illegal" population has been traditionally depicted by political elites and mainstream political commentators as consisting of people who abuse the generosity of the Canadian system and are also a burden, or who pose a threat to both the security of the local population and to the rule of law. Often imagined as opportunistic "queue jumpers," job stealers, potential carriers of diseases and/or latent criminals (Gogia \& Slade, 2011: 105; Park, 2013), 
people who live and work in the country without authorization — and therefore with no formal legal protection-are hardly thought of as vulnerable, and their important social and economic contribution to the Canadian society often goes unnoticed. This justifies a situation of social injustice, as the victimized and socially vulnerable yet often industrious member of society becomes seen, instead, as a threat to society or abuser of the system. But, as the numbers will reveal, this is far from being true.

Undocumented workers represent a great number of the total migrant labour force embedded in the Canadian labour market, and their contribution to the Canadian economy is quite significant. According to the Report of the Standing Committee on Citizenship and Immigration. Temporary Foreign Workers and Non-Status Workers, released by the Parliament of Canada in 2009, there were between 80,000 and 500,000 "non-status" immigrants in Canada (47). Most of them work and live in the three major Canadian urban centers: Toronto, Montreal and Vancouver (Elrick, 2007; Kandor et. al. 2004; Wright, 2003). If we estimate the mean value of those quantities, then we estimate that the number of immigrants who work and live in the country without authorization (around 330,000) is around the same than the total number of foreign workers who are legally employed in Canada through the variety of temporary foreign workers programs, which according to official numbers counted for 386,406 (Statistics Canada 2013; Elgersma, 2014). As temporary migrant workers, according to official numbers, represent $2 \%$ of the total labour force participating in the Canadian labour market, we can estimate that undocumented people represent about the same number of workers in local industries. This information is relevant because it gives us a real dimension about the nodal importance that the labour force of the undocumented workers represents for the Canadian economy. In order to be able to show the critical importance of the labour provided by the undocumented workers to the Canadian economy, let me describe first the 
contribution made by the temporary migrant workers to the national economy based on actual numbers.

Although temporary migrant workers represent $2 \%$ of the total Canadian labour force, their work is critical for certain sectors of the economy. For example, the horticultural sector, an important component of the Canadian agri-food system which has been contributing with around $7-8 \%$ to Canada's Gross Domestic Product (GDP) during the last decade (AAFC, 2017; Prebisch, 2007), heavily relies on migrant labour. In the provinces of British Columbia and Ontario, 50\% and 60\% of the total labour force sustaining that industry, respectively, is provided by temporary migrant workers (Otero \& Prebisch, 2015: 10; Agri-Food Economic Systems, 2015:7). Even more, according to The Economic Impact of the Seasonal Agricultural Worker Program in the Ontario Horticulture Sector (2015), a study released by Foreign Agricultural Resource Management Services (F.A.R.M.S.), the labour force provided by migrant workers legally employed through the Seasonal Agricultural Workers Program is the principal reason that the industry has been growing and leading the market at the international level during the last decade and, by extension, making enormous gains for the national and regional economy, contributing 5.4 billion dollars to the provincial economy each year. Temporary migrant workers also, according to such study, underpin the very existence of some of the horticultural farms, which "would not be able to continue to operate farming without the workers available under these programs" (19), mainly because changes in national demographics and labour composition (increasing educational levels, higher wages expectations, and population aging) have made the local population unwilling to take so-called "unskilled" positions in agriculture (22). The construction industry, food service, homecare and caregiving, and cleaning industries also rely on foreign workers in a significant way. 
The data provided below give a general idea of the important contribution that migrant labour has on the labour market and of its important contribution to the agricultural sector, particularly to horticulture. We can also estimate how much the undocumented labour force contributes to the agricultural sector. As documented by a variety of studies in the field, the press and my own empirical observation, undocumented workers in Canada tend to be employed in the same occupations as unskilled' temporary migrant workers; that is, they normally work in agriculture (principally horticulture), construction, cleaning, food services (as cooks, waitress, dishwashers), childcare, meatpacking factories and landscaping (Dharssi, 2016; Gastaldo, Carrasco \& Magalhães, 2012; Jimenez, 2017) ${ }^{3}$. So, because of the fact that undocumented workers are approximately the same in number as temporary workers, and because both populations tend to work in similar industries (counting here only those hired in low-skilled occupations), it can be inferred that the horticultural industry must be relying on more than the $50-60 \%$ that is registered in official statistics. That is, if we assume that in Canada—like in the United States where official estimates have been made- $72 \%$ of the undocumented population are of working age (PEWRC, $2016)^{4}$, and that they are found in the horticultural sector at a percentage of $30 \%$ (which is very likely, as, according to my registry, just like in the meatpacking companies, it is quite uncommon to see local, non-immigrant, non-racialized populations working in those branches of industry), my estimation is that approximately $85-90 \%$ of the labour force employed in that industry (horticulture) may be immigrant. Out of that population, 55\% are employed legally—-through the

\footnotetext{
${ }^{3}$ This happens mainly for two reasons. First, because some of them lose their legal status after being previously engaged in those industries, such as people who drop off the temporary program, and are more likely to find a job underground there, or 2) because in those areas of industry is easier to get dead-end jobs, as local people are unwilling to do those typically underpaid and physically demanding jobs.

${ }^{4}$ Making 5\% of the civilian labour force. Source: PEW Research Center (November 3, 2016) "Size of U.S. Unauthorized Immigrant Workforce Stable After the Great Recession." Retrieved from: www.pewhispanic.org/2016/11/03/size-of-u-s-unauthorized-immigrant-workforce-stable-after-the-great-recession/
} 
SAWP program, according to the official data already mentioned—and $30 \%$ are employed "under the table," according to my conservative estimate. Therefore, as the horticultural sector contributed 7.1 billions dollars to the Canadian economy in 2017 - equivalent to $8 \%$ of the 111.9 billion dollars produced by the agricultural industry according to official data (AAFC, 2017) —and relied on about $60 \%$ "legal" labour force and 30\% "illegal" labour force, it can be estimated that, in that sector, migrant labour in general ("legal" and "illegal") contributed 6.4 billion dollars to the Canadian economy $(7.1 \mathrm{~b} \times 90 / 100=6.4 \mathrm{~b})$ in 2017 . Similarly, according to the same formula $(7.1 \mathrm{~b}$ x 30/100), undocumented labour contributed approximately 2.1 billion dollars to the Canadian economy in 2017 (and 10.5 billion dollars over a period of 5 years). This wealth represents $88 \%$ of the total budget that the federal government allocated in 2016 to infrastructure around the whole country, 11.9 billion dollars over a period of 5 years, including infrastructure for early learning child-care; affordable housing; social infrastructure in First Nations; clean water; clean water infrastructure for First Nations; public transit; cultural and recreational buildings; climate change mitigation and adaptation infrastructure and municipal capacity-building (Stone, 2017). That is the size of their contribution to the Canadian economy ${ }^{5}$.

But their contribution cannot be measured only in terms of the monetary wealth they produce. If the numbers and estimates provided above make sense, then we can conclude that, just as in the case of the temporary foreign workers, for undocumented workers play an important role in the processes of production and reproduction of Canadian society. Their labour force makes possible

\footnotetext{
${ }^{5}$ Proportionally, this estimation is consistent with that that has been made in the United States. There are 8 million undocumented workers of working age in the US, which make up about 5 percent of the U.S. labor market. According to Edwards, Ryan \& Francesc Ortega (2016) their work produces a wealth of about 5 trillion dollars over a 10-year period ( 5 billion dollars per year). This represents $250 \%$ more than what we have calculated for the Canadian economy, which is understandable for the reason that the undocumented population in working age in Canada (about 237,600$72 \%$ in working age-, according to our calculation, is around one quarter million (about $800 \%$ less than in the US).
} 
the smooth functioning of key sectors of the economy (from horticulture to the service and construction industries), sectors that make Canada one of the world's wealthiest nations. As a labour force, they also participate in an important way in the set of social activities that are fundamental to guaranteeing the wellbeing and the social reproduction of vast sectors of Canadian society. They work, for example, in the construction or renovation of homes, schools, and hospitals that provide shelter, education and care to the local population; they, as we have seen, plant, harvest and process the healthy food which feeds an important segment of the local (and global) population; they also care for the elderly and children; they clean homes, streets, public and private buildings; they work in the assembly of all sort of useful gadgets in local factories and do a variety of harsh activities that almost nobody among the local population is willing to do, but which are all important for making people's lives easier, healthier, or better.

Their work contributes, in short, to making Canada one of the wealthiest and healthiest countries of the world. And yet, they are excluded from having access to some of the fundamental goods and social services that their labour force enables, including those which are essential to guarantee their well-being, and to guarantee their own social reproduction within and beyond national borders, such as healthy food, affordable housing, economic security, health, social care and education for themselves and their families, decent working conditions, and fair wages. What effects such conditions of deprivation and misrecognition have on undocumented migrant workers' health, and to what extent such effects transcend the Canadian national borders, are questions that this dissertation intends to answer.

The conditions that deprive immigrant workers of legal status, and from having access to the wealth and social goods they produce, have not always been present. Nor do those forms of 
exclusion and social deprivation occur only within Canadian borders. The selective exclusion of "undesirable" immigrants — most often underpinned by racial ideologies, and by economic and political rationalities in particular historical moments - has traditionally been used in Canada as a mechanism of nation making and state formation (Porter, 1970: 60-103; Thobani 2007: 75-96). New historical research has shown that the gradual "liberalization of immigration and citizenship legislation" (Thobani, 2007: 97-102), the "war on terror", and other changes brought about by capitalist globalization have intensified in the last decades the mechanisms of exclusion, “illegalization" and deportation of particular immigrants in Canada (Pratt, 2005). In the same way, it would be safe to assume that the exclusion and expulsion of those who now live in Canada without authorization have been underpinned by particular historical and social dynamics occurring in their home countries, just as has occurred with migration patterns historically around the world. Why, and how, have Latin American undocumented workers currently living in Canada become part of the surplus population in their home countries, and pariahs in Canadian society? To answer this question, the research process that I carried out examined the global forces that have made this possible, including the social forces underpinned by the forms of accumulation by dispossession that emerged since the last quarter of the 20th century. This exploration was carried out through the migration narratives of the undocumented workers themselves - narratives that helped me to understand, from my vantage point in the present, the historical reasons for their uprooting and their transformation into a labour force to be subsumed into the underground Canadian labour markets.

The scientific context of the research problem. Within the Canadian academic community, the study of "legal" immigrant health has been extensively explored, but the study of the health of those living in the country without status remains a lacuna. In effect, the sociological and 
anthropological studies which explore the relationship between immigration and health have produced a strong body of evidence that has been useful to understand the health issues immigrants living in Canada face, the social determinants of those health conditions, and the effects that those health conditions have on their overall wellbeing and life expectancy. Perhaps the most influential and widely known insight these studies have produced is the empirically-founded theorization known as "the healthy immigrant effect," a concept which describes a situation that, despite having been publicly discussed, has been scarcely addressed in public policy: the fact that, at the time of arrival, immigrants' health is generally better than that of the Canadian-born population, but tends to gradually deteriorate after the first decade of living in Canada, to the point of significantly affecting mortality rates and life expectancy (Ali, 2002; Ali, Mcdermott, and Gravel 2004; De Maio \& Kemp, 2008; Newbold \& Danforth, 2003; Ng, 2014; Perez, 2002). These studies have also found that this happens mainly as a consequence of the following social determinants of health: Poor living and working conditions, barriers to accessing health care, depressed income, lack of mobility in the labour market, language barriers, lack of social networks, and poor social support and integration. Other studies have made important contributions, by documenting how health status differentials vary across the immigrant population when social class, gender, ethnicity, age and race are considered. The poorest, the racialized, the eldest, and women are most affected by illnesses and lower life expectancy (Chen, Ng, and Wilkins 1996; Dunn and Dyck 2000; Pérez 2002; Ng, Pottie and Spitzer 2011; Stewart et.al. 2011; Spitzer 2011a, 2011b and 2012; Torres et.al. 2012).

Despite these important insights into the relationship between migration and health, the health of the undocumented immigrants remains insufficiently explored. Perhaps as a consequence of the difficulty involved in reaching out to people who live in the underground and remain invisible to 
the public eye — a difficulty which has been reinforced by the obstacles imposed on researchers by research boards ethics in Canadian universities, as long-time Canadian immigration researchers have pointed out (Bernhard, Goldring, Young, Berinstein \& Wilson, 2007: 102)-the undocumented population has remained under researched. For this reason, the evidence that has accumulated on migration and health mostly refers to the health of the immigrants who have arrived in Canada voluntarily, particularly those who live here with status of permanent residents, temporary workers, or new citizens. With some exceptions (see: Hennebry 2009 and 2010), it also mostly refers to the social determinants of health that operate within Canada, and to the effects they have on the immigrants who are legally living in the country. We know almost nothing, as will be discussed later, about the health conditions of those who are living in Canada without authorization — the so-called "illegal" population—and about the effects that such conditions have on them and their families within and beyond the national borders.

This doctoral dissertation seeks to fill this gap. Through extensive ethnographic work which consisted in working and living among undocumented workers in Montreal for 24 months, investigative labour which consisted also of empirical observation at the points of production in factories, points of attention/care in hospitals, and points of detention in immigration detention centers, as well as in-depth interviews with injured, incarcerated and deported undocumented workers, this dissertation evaluates the health consequences of living and working without authorization for immigrant workers and their families. In particular, it explores how and to what extent the paid and unpaid labour that the immigrant workers—and their families—-have to do to satisfy their fundamental human needs (shelter, food, care, education, etc.) under conditions of "illegality" "deportability," racialization, and exploitation, affects their physical and mental health in Canada and in their countries of origin. It also explores how the undocumented workers 
politically resist those processes and to what extent their collective resistance transforms the conditions of their vulnerable health both in Canadian society and in their countries of origin.

Unlike the dominant approaches in the field—as will be described later-my research looks at the current migratory status of immigrant workers (their condition of "illegality" and deportability) and its effects on health in light of the historical transformations of capitalism, and the forms of accumulation by dispossession it has globally buttressed since the 1970s. By proceeding in this way, this dissertation sheds light on the ways in which patterns of capital accumulation, production of migrant "illegality," and deportation practices work together in Late Capitalist societies.

\section{Literature review: What has been studied, and what is different about this doctoral dissertation?}

There are two reasons why the research process that sustains this dissertation is different from what has been produced within the field of undocumented workers studies, so far. The first relates to the questions I aim to answer, and the second has to do with the theoretical approach and the political economy rationale that lies behind it. In what follows I will describe what has been said in the field, with an emphasis on the Canadian literature, and will explain what is different about the questions and approach with which this dissertation is engaged.

What has been studied? Although still in their infancy, academic studies focusing on undocumented immigrants and the politics surrounding them have considerably grown over the last decade, particularly in late capitalist countries. Perhaps as a consequence, or response to the increasing restrictiveness of migratory laws, the securitization of the borders, and the proliferation of deportation practices - main trends in immigration and border control in the $21^{\text {st }}$ century (De Genova and Peutz 2010:23) — such studies have mostly focused on the following three aspects. First, an important number of studies have explored the politics of border control, as well as the 
practices of policing, expelling and deporting of undocumented people. Rather than focus on the study of undocumented migrants themselves, such approaches have scrutinized how the systems of power (imagined mainly in the form of states and institutions) deal with them. Such studies have explored, for example, the discursive and institutional mechanisms that are used by governments to cast the undocumented out, to police them, or to criminalize them. Heavily based on Foucauldian frameworks of analysis, such works see the deportation, surveillance and policing of undocumented immigrants as disciplinary technologies, or as instruments of population control, and they do it from a historical/genealogical perspective. Influential works on this area have been conducted by Walters (2002; 2004; 2006; and 2008); De Genova (2010); Ngai (2003); Pratt (2005); Andrijasevic and Walters (2010); Cornelisse (2010); Scherrer (2013); Karakayali (2010); Bloch and Schuster (2005); Gibney (2008) and Chan (2005). Although the state and its techniques of population control are most of the time their main object of study, sometimes scientific and academic discourses are also seen as major factors that underpin the mechanisms of policing and deportation of undocumented workers (See: De Genova and Ngai). Torpei (2000) and Bacon (2009) have dealt with the same questions and topics, but from a perspective which is more based on political economy perspectives, rather than on the traditional Foucauldian approaches.

There are other works that incur in what De Genova (2002) calls "anthropological pornography." They consist of academic works which focus on the detailed and ahistorical description of the everyday lives of the undocumented workers (the description of where they live, where they gather, where they work, etc.) and which have ended up serving the deportation machine, the state and the police, rather than contributing a serious academic discussion to the topic. I will not describe such works here. Enough is to say that such academic practice is the opposite of what this dissertation intends to do. 
The second most prominent area of research explores the ways by which migrant "illegality" is produced in the host countries. This area of research is much less developed, but more diverse with regards to the theoretical perspectives the researchers have adopted. Some researchers have used Foucauldian approaches to explain the mechanisms that illegalize immigrants. In their view, the State and the regulatory mechanisms that the state put into practice to regulate the local population, or the influx of external population, are the main agents that participate in the production of migrant illegality. At the risk of being simplistic, it can be said that such approaches share the idea that increasing border control and the proliferation of the regulatory frameworks that impede people's free entrance into the host countries are the main mechanisms that lie behind the "illegalization of immigrants." This perspective has also been historical in nature, and has normally pointed out that historical contingencies, narratives of national security, and important political events (such as the attacks to the World Trade Center in NY in September 11, 2001) have shaped the will of sovereign power to impede particular groups of migrants from entering the into their host countries; to strip some citizens out of their legal status; and to deport them. Important works in this area have been written by De Genova (2004 and 2005); De Genova and Peutz (2010); Ngai (2004); and Wright (2013). Other researchers, such as Dauvergne (2008), have pointed out that current trends toward the illegalization of particular immigrants can be explained better as the consequence of a tense relationship that occurs between the national states and the dynamics of globalization. From this perspective, the movement of people that globalization both promotes and reflects tends to force national states to strengthen control of their borders. This reassertion of sovereignty often results in the elaboration of restrictive laws that render some migrants illegal. 
In Canada, and using a different theoretical perspective, Goldring, Berinstein and Bernhard (2009) have also explored the social and institutional mechanisms by which immigrants become "illegals," or gradually descend into different degrees of precarity with regards to their legal status. They have explained such mechanisms by using an original perspective of political sociology, closer to a Weberian understanding of the state and the law, which has become highly influential among migration studies in this country. In their view, the legal and institutional mechanisms that the state puts into practice to incorporate immigrants into Canadian life are the main determinants of the gradual precarization of their legal status. The fact that Canadian law assigns newcomers different rights and privileges according to the legal conditions under which they were incorporated into Canadian society creates a sort of stratification which puts some of them outside of fundamental social rights. This, along with the fact that some of the legal and institutional channels available for them to remain legally in the country do not work properly, make some immigrants lose their legal status and remain in the country without legal authorization.

The last important area of research in the field is led by researchers who explore the forms of resistance to borders and deportation that are carried out by immigrants and native and local organizations. This area of research — mostly informed by what Anderson, Sharma \& Wright call the "No Borders Approach" (2009) - is composed of few but important pieces, and has been led in Canada by Nyers (2003, 2006, and 2010); Wright (2006); Burman (2006) and Fortier (2013). They have shed light on the ways in which such forms of political protest and contestation defy the mainstream notions of citizenship, borders, belonging, and sovereignty in Canadian society. The theorizations by William Walters in his piece "Acts of Demonstration: Mapping the Territory of (Non)Citizenship," (Walters, 1988), a paper in which "the power of autonomous movement," embodied in the struggles against deportation and other forms of control of movement, is defined 
as "the hidden secret of the history of class struggle," (188) constitute one of the main sources of inspiration for the development of this exciting field of inquiry. So far, however, none of the pieces produced within this field had shed light on issues around health; and specifically, on the potential ways in which migrant justice or "anti-border" political struggles contribute to shape the experiences of health (or illness) of those involved in such struggles: migrant workers, migrant justice organizations, and allies — an aspect I would like to touch on in this dissertation.

In addition to such works, which often explore the topics more with a theoretical interest, new ethnographic research has begun to explore, and empirically document, the challenges that the undocumented workers face in their everyday lives as a consequence of their limited access to essential public services (education, housing and health, principally), and also as a consequence of living in conditions of restricted mobility (See Holmes 2013; Basok, Belanger \& Rivas 2013; Talavera, Núñez-Mchiri \& Heyman 2010; Barthia 2010; Coutin 2010; Peutz 2010; Burman 2010; Fekete 2005). Within such a new direction, the study of the health status of those living without authorization has also become important. Outside of Canada, probably the most sophisticated and innovative work I found in this area is the ethnographic work carried out by Seth Holmes (2013). Holmes explores the conditions of political economy and the dense ideological mechanisms that converge in the production of the risks and injuries that undocumented immigrants from Oaxaca, Mexico experience while working in the farms and "labour camps," as he describes them, in California and Washington. Although sophisticated and relevant, his research does not shed light on how immigrants' resistance takes place, and to what extent such forms of resistance have an effect on the workers' own lives. It does not explore, either, how and to what extent what they experience in the United States affects their families down in Mexico. 
In Canada, on the other hand, the research on undocumented immigrant workers and health has been fundamentally focused on the description of the factors which affect the health of the undocumented, and on the barriers that prevent them from having access to the health care system. In a pioneer work on "irregular migrants" in Toronto, for example, Simich and colleagues (2007) describe some of the health problems the undocumented experience: trauma, depression, chronic stress, and stress-related physical illnesses, and point out that such health challenges are not overcome because the very condition of being sick, and the legal barriers they face in accessing the health care system make the "irregular migrants" unable even to seek help. In another work, Bernhard and colleagues (2007) draw a similar picture. They show that the health problems immigrants with precarious status experience (undocumented immigrants included), such as anxiety, sleeplessness, sadness and depression, and also the problems their children face (mainly diverse forms of trauma and problems with social integration), are determined by: 1) the anxieties immigrants live with due to fears of being deported, 2) the financial constraints they live in, and 3) the lack of "full status and/or documentation" (106) which prevent them from having access to care.

In the same vein, but with the goal of understanding in more detail the factors that lead people to lose their migratory status, the consequences that such conditions entail, and to understand the ways in which access to health services are negotiated, facilitated, or prevented in such a context, are the works by Landolt and Goldring (2013), who explore the intersection of precarious work and the production of "illegality' in Toronto; Saad (2013), who studies the psychological impact of losing immigration status among immigrants in Toronto; Villegas (2013), who explores the processes of negotiation carried out by undocumented immigrants for having access to the health services; and the work by Ruiz-Casares and colleagues (2010 and 2012), who have explored the 
role played by the values and attitudes among health providers and by the international legal conventions as applied in Canada, in preventing or facilitating health access for undocumented pregnant women and their children.

What are some of the limitations of such studies? What is new about this dissertation? The works mentioned have advanced our understanding of the mechanisms that render migrants illegal, and of many of the undocumented migrants' social determinants of health, but they show some limitations. The first limitation is that, with the exception of the pieces written by De Genova (2010), Bacon (2009), and Holmes (2013), such works tend to think of the state and the law as the main agents that participate in the production of migrant illegality, and the forms of precarityincluded health precarity - that such status produces. The consideration of the role that the dynamics of capital play on shaping such processes has been overlooked, if not frankly disregarded. This happens because such scholars think (more often assume) of state and regulatory frameworks as agents that operate in isolation, and study them with independence of the dynamics that organize contemporary global capitalism, and also with independence of the hierarchies among nation states that operate at the level of the world system. For this reason, important questions have been missed within this field of studies. It has not been asked, for example, how and to what extent the current dynamics of capital accumulation (which are arguably based on the radical dispossession of peoples' rights, labour stability, common and public property, and security (See Harvey, 2004; Sassen, 2010, 2011) occurring both in the countries of origin and destination, produce the conditions that undermine people's citizenship, or the conditions that uproot them from their countries and make them willing to move to countries where they will lack citizenship. It has not been asked, either, why and how particular industries from the receiving countries attract/mobilize dispossessed populations and illegally incorporate them into the labour force and 
its productive processes. Such questions of political economy, which are of course not new in the broader field of migration studies but which have been missed within the field of undocumented workers studies, this doctoral research will try to answer.

The second limitation of the studies described above, particularly in the case of research focused on health carried out in Canada, is that they have not asked how broader global forces that simultaneously exclude people from and incorporate them into particular industries and labour markets contribute to shape undocumented migrant workers' physical and mental health. What, in particular, are the characteristics of the industries that incorporate them, and which specific mechanisms particular to those industries make them experience health challenges? The existing research has not paid attention to the simultaneous ways by which deportation processes, and other institutional dynamics of misrecognition, along with labour processes, affect the physical and mental health of undocumented people.

Thirdly, the field has not paid close attention to the forms of resistance that the undocumented workers, and their local organizations, carry out to deal with the deportation processes, to overcome the barriers to access the health care system, or to deal with the health consequences that come from being excluded from health services. Nor has the literature examined the extent to which such forms of resistance have an impact on undocumented migrants' physical and mental health. This limitation occurs for three reasons. First, a great deal of the literature within the field tends to depict undocumented workers as passive, powerless subjects. This is an unintended consequence of the perspectives that have been adopted within the field, particularly with regards to immigrants' health. The social determinants of health perspective - despite the debates it hosts between "structuralist" and "individualist" perspectives-is fundamentally concerned with 
registering how social factors at the meso and macro structural level influence health outcomes. That is why the always tense, dialectical relation among social structures, social practices and subjects are not always sufficiently scrutinized, and the subjects tend to appear as receptacles of external forces that "determine" their health conditions on a top-down direction.

Second, the role that resistance plays on the configuration of migrant workers' health outcomes has been overlooked because of the way in which "resistance" or "agency" have been traditionally objectivated in most of those studies. And this is not unique to those studying migrant workers, but occurs in a broader scale in the area of social movements in the social sciences. As James C. Scott has argued, in social sciences, the concepts of "resistance" (we could add "agency" as well) have been traditionally used to describe the forms of public, open, and active contestations and actions aimed at defying the repressive mechanisms that exist in society. This limited perspective makes it difficult to see those forms of resistance and agency, which are put into work in a hidden form. Thus, by overlooking hidden forms of resistance and agency, including those aimed at compliance and submission, the health outcomes that are shaped within such context are also not properly registered.

Third, and finally, the link between political resistance and health have also not been comprehensively explored because when such a relationship is explored, it only registers the goal to overcome limitations to accessing health care or gaining access to it, as if physical and mental health could be modified or affected by having access to health institutions. By proceeding this way, it has been often ignored how and to what extent the very act of being engaged in one or diverse forms of resistance/agency/social struggles social struggles, contribute to shaping migrant 
workers' physical and mental health, as if defying, resisting, negotiating, submitting or contesting state power/capital power does not always involve strenuous physical and mental labour.

It is important to mention that my desire to bring questions of political economy (in conversation with questions raised from the standpoint of the theory of recognition) to the study of the health conditions of the undocumented workers has been motivated not exclusively by a scientific interest; neither has it been driven only by the desire for discovering new things as a professional and academic end in itself. Rather, my interest has been fundamentally stimulated by the conviction, rooted in the tradition of critical theory, that science is, or should be, an emancipatory tool whose ultimate "goal is [hu] man's emancipation from the conditions that slaves them" (Horkheimer 2002 [1972]: 246). It is my hope, then, that this dissertation can shed light on the historical processes and the global dynamics which have rendered people to forms of abject illegality and subjected them to social domination. I also hope that my work can contribute to stimulating critical collective action aimed at the transformation of the social conditions that submit the immigrant workers (and their children) to diverse forms of illness, domination, and suffering.

\section{Population of study}

The research that supports this dissertation was carried out among Latin American and Caribbean immigrant workers, men and women and their families, who live and work in Montreal, Quebec and surrounding communities. They were the focus of this study because of the fact that, according

to what has been documented in the field, and also according to Canadian organizations working with such populations, undocumented workers from that region (principally coming from Mexico, Jamaica, Honduras, Guatemala, and El Salvador) constitute one of the largest groups of 
undocumented immigrants living in that city (Immigrant Workers Centre, Dec. 04, 2014 personal communication; Khandor et.al. 2004; Wright, 2003). Montreal is also the second largest city in Canada, and where the struggles carried out by the sans papiers have become relevant at a national level (Fortier, 2013; Lowry \& Nyers, 2003). Since the undocumented workers in other Canadian urban centers have a similar distribution with regards to countries of origin and tend to be in similar industries - construction and home renovation, cleaning, slaughterhouses and meatpacking companies - the results of working with this population help me to extrapolate and make larger claims with regards to how the health of the undocumented migrant workers is shaped when they live and work in Canadian urban centers with similar characteristics to Montreal.

The research included not only the workers, but also a study of the factories that subsume the workers in their labour processes. Working in those factories, or asking about them when I was not able to work there, allowed me to observe at a very close distance the relations among workers, and the relationships between capital and labour that occur within the framework of the processes of formal subsumption of labour. In order to carry out the study as comprehensively as possible, I worked in and collected information from a variety of companies. These companies were separated, for heuristic reasons, into three types: 1) medium-sized local companies, 2) multinational companies, and 3) underground migrant workers' cooperatives. The recruitment mechanisms that make possible the integration of undocumented migrant workers into those companies (that is, the recruiters and their forms of operation) were also subjected to ethnographic scrutiny through participant observation.

\section{Theory}


The research process used a holistic approach to the study of the social determinants of health. This was achieved by assembling a hybrid theoretical framework that helped me to capture the array of objective and subjective social mechanisms that contribute to shaping undocumented immigrants' mental and physical health. The theoretical frameworks that guided this investigative labour are the Canadian Political Economy of Health, as advanced by Pat Armstrong, Hugh Armstrong and David Coburn (2001), and the theory of recognition elaborated by the thirdgeneration Frankfurt School thinker Axel Honneth (1995) and advanced further by Fraser \& Honneth (2003).

A) The Canadian Political Economy of Health and the Master Determinants. I took from the Canadian Political Economy of Health literature a set of materialist, historical and sensitive-toculture theoretical assumptions, as well as a critical position with regards to the methodological individualism in health studies. Within this theoretical approach, the conditions of health and disease experienced by individuals and communities are thought to be embedded in, and shaped by, large-scale economic, political, institutional, cultural dynamics, and power structures, rather than exclusively by personal lifestyles or individual choices. Canadian researchers who participate in this theoretical and empirical program have shown, for example, that beyond personal lifestyles, many of the health outcomes that individuals and social groups experience are in fact intrinsically linked to the ways in which the healthcare system has been historically structured (Armstrong and Armstrong, 2010); how social inequalities, poverty (Raphael, 2001, 2002 \& Raphael et. al. 2009) and class differences are lived (Coburn, 2004); how working conditions, labour skills and institutions are transformed (Armstrong and Armstrong, 2004; Armstrong, Choiniere and Day, 1993; Lewchuk, de Wolff, King and Polanyi, 2006); how public policies are put in practice 
(Coburn, 2000 and 2001: 45-65; Armstrong, et. al., 2001); and how asymmetric power relations between genders, whether inside and outside of institutional spheres, are organized (Doyal, 1995).

That set of factors that work as mediating mechanisms of people's health are known as "social determinants of health." They operate conjointly (though not always in coordinated way) and tend to reinforce each other. However, being product of particular historical formations, such healthmediating mechanisms are dynamic and affect individuals and collectivities in a form that is diverse and uneven. This is so because they operate within the framework of societies that are structured along lines of class, gender, ethnicity, age and other differentiation criteria that are dominant within the mode of production in a given historical context. People's social class, gender, ethnicity, age, and migratory status, among other factors, usually define the types of work that they will carry out, as well as their income, food, security, social support, health care and the type of social risks they are exposed to. A such, these criteria will define also how people get sick, become cured, or are medically treated in a given society (Marmot, 2015 and 2016).

That is not to say, however, that health and illness are simply determined by a list of factors that must be considered as "independent variables" by the social researcher, as is commonly pointed out by the dominant biomedical and epidemiological perspectives in the field of health studies. Unlike this point of view, the political economy of health perspective holds that the set of social conditions that shape health and illness of individuals and communities must be thought as "interrelated parts of the same whole. This whole is shaped, but not determined, by the dominant mode of production in a given historical time, that is by the means of producing and reproducing for socially determined needs" (Armstrong, Armstrong and Coburn 2001: vii). In fact, the work of David Coburn has been particularly focused on showing how the different social determinants of 
health that have been enumerated by academics in the area of health studies-including the determinants noted by those who are looking to understand the "causes of the causes" (See: Marmot, 2018 and 2005)— work, in the last instance, as intermediate mechanisms which are intimately shaped by the dynamics of the current phase of capitalism (See: Coburn 2000; 2004 and 2010). As such, they must be thought as embedded mechanisms of the four major structures that underpin the social totality that represents the capitalist social system: 1) the state (principal mechanism of social organization); 2) the labour process (principal mechanism of production and wealth creation); 3) the market (principal mechanism of exchange), and 4) ideologies and power relations. Following this rationale, I identify the social determinants most fundamentally linked to such major social structures as "Master Determinants of Health."

For the ends of this thesis, alienated labour, racial ideologies and State practices (including practices of surveillance, persecution and deportation) were the elements I most considered as linked to the Master Determinants of Health throughout the research process. I also situated those determinants as meso-level social entities that function as mediating mechanisms between the deeper dynamics organized by capitalism in the latest form we know (late capitalism) and what occurs among the bodies and minds of the undocumented workers living in Montreal.

B) Social Recognition. Although the political economy of health is useful for the understanding the broader, structural, and material mechanisms that shape the health of individuals and populations, it doesn't provide the theoretical tools to explore the subjective, non-material mechanisms which also participate in the production of physical and mental health outcomes. For this reason, I have added to my theoretical framework one aspect that has been scarcely used in the study of health from a political economy perspective: the role that forms of social 
misrecognition and disrespect — as theorized by the third-generation Frankfurt School thinker Axel Honneth (1995) - play on the processes of undermining the moral status of marginalized populations and, eventually, their mental and physical health.

For Axel Honneth, the institutional and interpersonal patterns of misrecognition that prevent certain populations from engaging in meaningful participation in society, as well as from having access to fundamental rights and social goods, result not only in their exclusion from material resources which are vital to the well-being of individuals and communities, but also prevent such populations from achieving the development of well-established human relationships-love and friendship included — and deprive them of "moral recognition," which is vital for individuals to attain their full realization as human beings. Deprived from moral recognition, individuals and communities who are subjected to misrecognition and disrespect gradually develop a deficit in the sentiments of self-respect and self-worth, a distorted conception of themselves, as well as a gradual denigration of their ways of life, all of which can bring them to a psychological collapse, or their "social death" (169). At the basis of Honneth's theorization are the suppositions that "human integrity owes its existence to the patterns of approval and mutual recognition" (131), and that common to all human beings is the longing for being respected, included, and recognized as equals by the others and by the set of institutions which have been established.

The notion of misrecognition in Axel Honneth, it has been said, is restricted to the interpersonal sphere. That is why it has been criticized as a perspective that tends to the "psychologization" of social relations of recognition; that focuses almost exclusively on "micro encounters" and face-toface interactions, and finally as a perspective that tends to ignore the role of the State in the production and reproduction of patterns of misrecognition (Garrett, 2010). This critique is 
misleading. Honneth don't ignores the role of the State in the production of forms of disrespect, nor does he aim to "psychologize" social relations, but rather to trace, in the moral economy of the intersubjective social relations-including the social relations facilitated by the State through the law - the origins and consequences of misrecognition/disrespect, as well as the possibilities of rebellion against it. To the ends of this thesis, however, a more critical limitation in Honneth's work can be pointed out. In his explicit pursuit of transcending the instrumentalist view that prevails in the study of social conflicts, social struggles and social movements (namely, the assumption that the oppressed both experience moral grievance and become motivated to engage in social struggles principally when material deprivation is present, and when they have economic interests to defend - residues of what the late Franz Fanon used to call "the white and bourgeois episteme")-, Honneth focuses substantially on the sphere of rights and morality. By doing that, he overlooks the fact that some forms of moral misrecognition and disrespect have their origin in the economic sphere and, therefore, are not likely to be transcended if the "struggles for recognition" keep that social sphere unaltered. For example: alienating or separating the workers from the products of their labour; reducing labour - the main source of wealth creation— to a status of disposable commodity; underpinning economic growth in rich countries at the expense of looting others; and alienating certain social groups from the satisfaction of their "radical human needs"- to borrow Agnes Heller's concept—such as freedom, including free time and freedom of movement, need for universality, food, shelter, clothing and warmth, constitute forms of misrecognition that have their origin in the economic sphere of capitalist society. Therefore, its transcendence, the full realization of "moral recognition" for the oppressed subjects, can only be possible if a transformation of the sphere of production occurs. 
Honneth's overemphasis on culture and on the moral foundations of misrecognition seems to be located on his declared goal of surpassing the "determinism" he thinks is present in his Frankfurt School predecessors, which he tries to overcome by building bridges between the Frankfurt School's critique of power (which, according to Honneth, locates oppression mainly in the sphere of capitalist production) and Foucault's critique of power (which, according to Honneth, locates oppression on the cultural sphere) (See: Honneth, 1997). It seems also to be located in Honneth's main intellectual sources: Mead's sociological pragmatism and the young Hegel. The problem with this is that, as Gunn and Wilding (2014) assert, by building upon Hegel's Jena papers and ignoring the more radical and comprehensive notion of recognition that appears "wild" and more complete in Hegel's The Phenomenology of Spirit, Honneth's theory of (mis)recognition ended up producing a version of misrecognition that fully addresses the moral and cultural logics that produce it, while ignoring its more material dimensions. Unlike what Gunn and Wilding suggest, however, I consider that to overcome Honneth's limitation while trying to elaborate a more comprehensive cultural-materialist conception of recognition/misrecognition, we should not avoid sociological pragmatism, but incorporate, as Gunn and Wilding suggest, Hegel's views on recognition, as expressed in the Master and Slave dialectic. It is through that metaphorical and ground-breaking meditation that Hegel invented a new idea in Western thought: the idea that identity and existence itself is a product of struggle. As expressed in The Phenomenology of Spirit: "self-consciousness", the moment in which "the self becomes fully aware of itself and of life," is thought to be a direct product of a struggle for recognition through which "the self exists only by being acknowledged or recognized" (Hegel, 1977 [1807]: 111). Most importantly, perhaps, is the fact that the counterpart of recognition, misrecognition, is defined by Hegel as produced not just by the forms of symbolic domination and bondage of the slave by the master, but also by the forms 
of exclusion and alienation that emerge from maldistributed material wealth. In the aphorisms 505 to 526 of the cited The Phenomenology of Spirit, for example, the pursuit, possession and accumulation of wealth appears as a condition which "gives self-conscious independence and freedom of choice $\ldots$ but at the expense of others" (560). This causes "arrogance of wealth," "enslavement of individual personality," reduction of "the essential to unessentiality," "alienation of the self being misrecognized," "mutual estrangement," in which "being-for-self is negated," "disintegration of the moral self," "unbonded resentment" and "rebellion of the self against rejection" (Hegel, 1977[1807]: 559-561).

Misrecognition, in both its subjective and objective, moral and material dimensions, can also be found in Karl Marx's Grundrisse (1993 [1939]), where the institutions and social relations that emerge under capitalism appear as the main source of alienation, structural violence, disrespect, and interpersonal misrecognition. In the Labour Theory of Value, central to the Marxian theoretical structure, for example, labour, despite being the fundamental instrument of value and wealth creation, appears estranged under the command of capital, and alienated from its creative qualities; and labourers appear misrecognized, disrespected, and stripped of the products of their labour (322-332). It is also in the work of Marx, the 1844 Economic and Philosophic Manuscripts (2010 [1843]), that recognition, that is, the positive transcendence of misrecognition, may be attained through communism, to which Marx refers as "the real appropriation of the human essence by and for [hu]man" and "the genuine resolution of the conflict between [hu]man and nature and between [hu]man and [hu]man.” (296). That is, the pacification of human existence can only arise through deep recognition between human beings as well as between human beings and all living creatures. 
The cultural materialist "recasting" of the theorization offered by Axel Honneth, with regards to the issue of "recognition" that I offer here, is not new. It follows a feminist idea developed by Nancy Fraser in a legendary conversation with Axel Honneth (2004). Through her reflections, Fraser suggests that, by looking at how misrecognition works within the limits of the continuum recognition/redistribution, we can better appreciate how and to what extent a wide range of forms of social oppressions are in fact shaped by both interpersonal and institutional forms of "misrecognition" and by the exploitation and maldistribution of material wealth. It follows that the demands for social justice aimed at overcoming social oppression ideally have two dimensions as well: one which stresses issues regarding misrecognition through demands for cultural, legal, and institutional recognition, and a second which emphasizes issues generated by economic exploitation, demanding redistribution as a way to overcome social exclusion, misrecognition and oppression. In the post-socialist era, demands for cultural recognition through identity politics predominate over the demands for redistribution, even though in reality the forms of cultural misrecognition (generated by the law, the State, and structure of representations) generate forms of distributive injustice (lack of access to essential social services and public goods) and, vice versa: the lack of access to redistributive justice generates forms of cultural misrecognition (Fraser, 1997:17-54). Even though the debate about to what extent the struggles led by the sans papiers in Canada participate in demands for redistribution or recognition are not the object of this study, it is worth recalling that the critical theorizations put forward by Nancy Fraser with regards to misrecognition are the contemporary antecedents of the materialist/cultural conception of recognition that I express here.

C) The concepts of "uprootedness," "abstract labour" and "migrant incorporation," which appear dispersed in several parts of this thesis, are also key components of my chosen theoretical 
framework. As will be seen, one of the arguments that runs throughout the chapters is that the problems of mental and physical health that the undocumented migrants experience are highly dependent on both the degree to which they are incorporated as workers by different industries into the underground labour market and the degree to which the labour they carry out within those industries is done under "abstract" and alienated forms. As such, this thesis is a critique of abstract labour and a critique of the liberal notion of integration in migration studies: It contends that the more time undocumented workers spend doing abstract labour-namely, integrated by capital as labour commodities producing exchange value - the more likely they are to experience uprootedness (and separation from Canadian society) and mental/physical illnesses.

The aforementioned argument differs from one of the core propositions developed by the highly popular liberal tradition in migration studies: the idea that labour is the main source of immigrant integration, an argument which has been developed in the light of the labour-market integration hypothesis coined after the work of Barry R. Chiswick (1978) and advanced further in Canada by Chiswick \& Miller (1990). Succinctly described, the labour market integration hypothesis argues that education, language proficiency and other elements of migrants' social capital are fundamental predictors of immigrant success in host countries (Ager \& Strang, 2008; Bloch 1999; Brenton \& Glennie, 2016; Brenton et.al., 2014; Calado, 2016; Caneva, 2014; Desiderio \& Schuster, 2013; Desiderio \& Weinar, 2014; Gebhardt, 2014; Gebhardt, 2016; Hersi, 2014; Liebig, 2017; Lemaître 2007; Martin, et.al. 2016; OECD, 2009; Reitz, 2007; Robinson, 1998; Sergeant et. al. 1999; Texeira, 2009; Tomlinson \& Egan 2002; Weiner, 1996). This is so, this approach suggests, because cultural capital facilitates integration into the labour market, and labour market works as the leading force of social integration. This understanding of immigrant integration as determined by their incorporation into the labour market dominates the academic debates in the core countries of 
the world system and, at the normative level, it structures the ways in which state institutions and international organizations deal with immigration policies. This has made popular the idea that labour incorporation is the main source of immigrants' social integration. But, as Peter S. Li (2003) in Canada has pointed out, this dominant concept of integration is problematic for two reasons. First, because it is reductionist, as it measures the success of cultural/social integration based principally on immigrants' earnings and position in the labour market and, second, because it is assimilationist, as it is based on the expectation that immigrants, in order to be recognized as successfully integrated, must conform and accept host societies' language, cultural traditions and prevailing norms. I would add that, in the light of the evidence that I present and discuss through this thesis, this notion of integration does not speak to the situation of the undocumented immigrants whose social, cultural and political participation in Canadian society is, in fact, highly constrained by their very participation in the labour market.

But the argument of this thesis does not only differ from the "labour market integration hypothesis." It departs also from the very notion of "integration" used in the liberal perspective in migration studies as this notion is exclusionary, even within the "social citizenship" version developed by T.H. Marshall (1950). In effect, as has been pointed out by other migration scholars from whom I have drawn inspiration, the liberal tradition in migration studies is often assimilationist (De Genova, 2010:416; Castles \& Miller, 2009: 247) and complicit with the nationstate political grammar — which builds upon a dichotomic exclusion/inclusion, us/them narrative (Balibar, 1991). It is based on the biopolitical will to exercise control over its subjects within juridically defined territorial boundaries (see Foucault, 2003 [1997]: 239-264), and it tends to define "integration" as the condition in which the individual "other" has become part of "us" through a one-sided process of adaptation for the grace of being granted a bundle of rights by the 
sovereign power. This constrained notion of integration ignores those who have been banned from, diminished in, or stripped from, citizenship by the sovereign power, such as guest workers, Native and other colonized populations, the disabled, stateless persons and undocumented immigrants (Castles \& Miller, 2009; De Genova, 2010; Rummery, 2002; Thobani, 2007). Since the illegalized immigrants have been barred from citizenship, their social being is reduced, de facto, to the status of subordinated (often racialized) labour commodity and, therefore, their "integration" reduced, to a greater extent, to labour integration.

Taking into consideration the reductionist and assimilationist content that the prevalent concept of integration in immigration studies conveys, Castles and Miller (2009) have suggested replacing this concept by that of "migrant incorporation" (247). Migrant incorporation can be defined as the processes by which immigrants become part of receiving societies (245). For the ends of this thesis, I will refer to the undocumented immigrants' incorporation in two ways: First, as the process by which capital incorporates or subsumes the undocumented workers into its labour processes as labour commodities, and second, as the process by which the undocumented workers become part of the Canadian society through cultural, political and social participation.

When the concept of "uprootedness" is discussed, this will invoke to the process by which structural forces displace populations from the locations in which they grow up. Uprootedness may be seen as a process that greatly alters the human condition, as it dislocates and alienates humans' fundamental need for relatedness, transcendence, sense of identity, and territorial, emotional and symbolic rootedness. Though the literature on the concept does not often mention it, this conception of uprootedness is based on the meditations on the subject that were developed by the Frankfurt School scholar Eric Fromm in his book The Sane Society (1955 [2002]: 21-61). It is also 
based on the ideas discussed in length by German psychiatrist Emil Kraepelin in his work $O n$ Uprootedness (1921), a state of being which, for him, was associated with symptoms such as an obsessive fixation on the past as a way of dealing with the pain of grief that uprootedness produces on human subjectivities. As commonly employed in migration studies, the concept helps explore and understand the experiences of alienation and dislocation, in their subjective and objective dimensions, of those who have been relocated or displaced by political, social, and cultural forces that cannot be resisted or controlled by individual will, such as refugees and forced migrants (Ferris, 1998; Becker \& Beyene, 1999; Malkki, 1992, 1995; Rystad, 1990; Silverstein, 2004); sex workers (Downe, 2006); Aboriginal and homeless peoples (Berman et al, 2009); and some sectors of the managerial class (Andreotti et al, 2013). Recent work on uprootedness has been also discussed in relation to migrant women workers in Canada (Edmunds, 2016).

As the experience of being uprooted does not involve consent or individual will, and, in fact, always involves the workings of structural violence as an "uprooting factor," this concept may be used to explore the forms of alienation and social suffering experienced by those who have been displaced or uprooted. It is useful also because it is a concept that includes the dialectical process by which displaced people are, at the same time, submitted to a process of rerootedness in the places they arrive (Apfelbaum, 2000; Edmunds, 2016; Sylverstein, 2004). This is the reason I explore, in Chapter Three, how feelings are structured among the undocumented workers I interviewed in relation to the social processes that uproot them and reroot them in Canadian society. As will be discussed, capital is a force that in Canada works as an uprooting force by subsuming these workers in alienating labour processes that prevent some of them from being socially incorporated into Canadian society. On the other side, Canadian migrant justice 
organizations work as a rerooting forces by successfully incorporating some undocumented workers into Canadian society.

Since the integration of undocumented migrant workers may be understood, in the definition I previously offered, as "incorporation" by capital, let me briefly theorize this concept, using a Marxian perspective, in relation to "formal" and "real" subsumption of labour by capital, and discuss how immigrant labour is subsumed at the international scale.

For Marx (1990 [1867]: 1019-1052), the concepts of real and formal subsumption of labour refer to the processes by which capital incorporates, subsumes or draws into itself forms of labour, production, distribution and consumption of socially produced goods which were previously carried out outside of the domain of capital; that is, outside of the processes by which labour and things become commodities to be bought and sold with the purpose of making money and expanding capital. The formal subsumption of labour is a fundamental part of the process of consolidation and expansion of capital. It is the very first stage in which labour becomes a commodity. It consists in transforming any kind of human creative activity that is used to transform raw material into objects to fulfill human needs (labour that creates use-value commodities) into a human activity that is bought for the purposes of producing commodities which have both usevalue and exchange-value properties, and also to put them in circulation and reproduce capital. At a deeper level, the real subsumption of labour implies the total incorporation or full immersion of labour into the capitalist system of production. Within the real subsumption, creative human labour, or what Marx called "living labour," becomes gradually unskilled and submitted to a process of degradation (Braverman, 1974: 169-183). This happens because labour is dispossessed from its creative qualities, subjected to disciplinary techniques, measured, valued and calculated 
in terms of time, transformed into a commodity to be bought and sold, dispossessed from its centrality within the process of production of commodities, subordinated to a larger chain of command, and reduced to just another piece within the larger system of production, circulation, and distribution of commodities.

Since the last quarter of the 20th century, with the consolidation of what Giovanni Arrighi (2009) refers to as the fourth systemic cycle of capital accumulation (a historical moment that implies the ascendancy of financial capital and the subordination of areas of industry that are focused on the real production of commodities), capital has started a global march of expansion through the engagement in money-making activities that are predominantly based on financial speculation (Arrighi \& Silver, 2001: 260-261; Lapavistsas, 2013:1-12), privatization, and the commodification of nature, common and public goods in the form of a new imperialism (Harvey, 2005). This real subsumption of the commons, via the privatization and "commodification of everything," as Marxian geographer David Harvey (2007) has shown, implies on one side, the dispossession of larger sectors of the population from labour rights and security, and the creation of latent and surplus populations in the countries of the global south, as people previously not engaged in the wage-system labour are incorporated and transformed into wage workers (women and children in las maquiladoras, for example) and other workers were discharged from industry or subjected to greater forms of insecurity, via the creation of labour regimes with less job security and more instability, and made surplus through the production of massive unemployment (Sassen, 2014; Harvey, 2005:137-182). On the other side, as some of the commodity-producing industries of the core countries face greater forms of subordination and challenges within this new (predominantly) financially-based capitalist world order—what political economist Hyman Minsky (1989; 1990) has called "money manager capitalism"- they become engaged in two types of activities in which 
the main goals are to save in costs associated with the production of commodities in order to navigate the new rules imposed by financial capitalism. First, they started to relocate their factories and businesses to the countries of the global south where the wages and raw material costs are lower (Sassen, 1988; Harvey, 1994). Second, some industries become engaged in the importation of labour force from abroad, principally from formerly colonized countries, via foreign worker programs set by governments, international organizations, and private hiring companies (Castles \& Miller, 2009: 221-222; Mize \& Swords, 2011; Prebisch, 2010; Roman \& Velasco Arregui, 2013).

Through the above-mentioned practices of hiring foreign labour, local industries in the core countries of the world-system have been heavily engaged in incorporating the latent and surplus population that the new labour order has created. As the labour that immigrants from the global south provide is cheap, disciplined and highly disposable, this has resulted in 1) the transformation of the immigrant labourer into a highly desired commodity for local industry in the core countries of the world-system, 2) the creation of circuits that link the local industry with the workers from the global south, 3) the transnational circulation of immigrant labourers, in their status as a labour commodity, through a global chain of labour commodities in the world-system, 4) the creation of dependency for the local industry —in the core countries of the world-system—on hiring a migrant or "foreign" labour force, and, finally, 5) the consolidation of a powerful local industry (composed mainly by brokers and employment agencies) whose main work consists in facilitating the importation and incorporation of migrant workers into local industries (Durand, 2015; Hansson, 2016; Jones \& Mielants et al, 2016; Piore, 1979; Prebisch, 2007, 2010 and 2015; Sassen, 1988 and 1999; Schwartzman, 2016; Valiani, 2016 and 2012; Verduzco, 2015; Wallerstein, 2016). 
In sum, the real subsumption of migrant labour at the international scale under the new rules of capital occurs mainly through that triple movement: a movement that, first, produces latent and surplus population in the global south via displacement, dispossession, and the creation of a new reserve army of labour. Second, it creates a dependency for certain branches of the industry in the global north upon a cheap and disciplined labour force. Finally, it incorporates the migrant labour force via a new local industry composed mainly by brokers and employment agencies that serve as a dominant system in which migrant labourers are incorporated into, and subsumed by, the local industry. Grosso modo, this is the structure and the way by which the migrant workers, in general, and the undocumented workers in particular, are integrated or incorporated into Canadian local industries.

\section{The Research Process: Methods and Techniques}

4.1 Ethnography in the World System. I used ethnography as a method of collecting data. Since ethnography is a data collection technique which has traditionally been used for the study of microscale, local phenomena, it may seem a mistake to consider it an appropriate method for a study seeking to capture the global, historical and economic processes shaping migrant workers' health. However, unlike the traditional understanding of ethnography, which often tends to fetishize the record of the present and to understand the specific meanings of local events as manifestations somehow disconnected from the global order, I share a different understanding of the ethnographic work. Following the theorizations of Michael Burawoy (2000: 1-40) and George Marcus (1995), I understand ethnographic practice as a set of tools which are useful for the detailed documentation of the specificities not only of current, local events, but also the factors that link those events with the historical/global social forces that have constituted them. From this perspective, and when those connections have been made explicit by the researcher, ethnographic practice is always an 
ethnography of the world system. As such, it is a research method which does not intend to describe exclusively what happens within tiny fractions of an apparently discontinuous and fragmented world, but to critically apprehend the totality of the world system through a detailed, "on the ground" description and analysis of its apparently disconnected fragments.

In trying to identify the links between "systemic" and "local" events, as well as between historical and current social forces shaping migrant workers' health, the ethnographic practice by which I collected data involved the use of three main techniques of gathering information: a) participant observation, b) in-depths interviews and c) oral history (collected through interviews). In what follows I will describe how I operated such data-gathering techniques as well as how I interacted with and recruited the research participants throughout the process of data collection.

4.2 Participant Observation Inside and Outside Factories. Although the field work, including exploratory visits, lasted 24 months, I worked for 12 months side by side with Latin American undocumented workers in the areas of industry where immigrant workers with precarious legal/social status (mainly refugee claimants, undocumented workers, and welfare recipients) tend to get jobs: in slaughterhouses and meat packing factories, construction and home renovation companies, employment agencies, and as industrial cleaners for multinational corporations. I collected data through participant observation and carried out direct empirical observation at those points of production. I also socialized with the workers outside of the factories. I conducted empirical observation in those spaces too, mainly while providing support and mealtime company to ill and incarcerated undocumented workers in hospitals and deportation centers. I paid particular attention to the characteristics of the paid and unpaid labour the workers carry out to satisfy their human needs in a context of legal, economic and social precarity, as well as the way in which such 
forms of labour affected their physical and mental health. Any information that I considered relevant for my research during those interactions was written down and recorded in a digital voice recorder in the form of "thick descriptions" as defined by Clifford Geertz (2018 [1973]). As the volume of the information that I collected was massive, I reviewed the recordings and my diaries and selected the information that I considered relevant and useful for conducting the analysis. Then, this information was coded, added to a database, and used when the analysis was carried out.

Before writing information about my participants in my diary, I always asked in a written form, plainly and directly, if they consented that such conversations be recorded and used in my research. Following the recommendation made by the Tri-Council Policy Statement for Conducting Research Involving Humans (3.12: 45 and 10.2:39), I documented the consent in my field notes by describing in detail the process by which I asked for consent, and the way in which consent was granted. In order to avoid affecting the anonymity and security of the workers and of the factories, I recorded my own experience and observations without alluding to people's names or about other characteristics that can make them identifiable.

4.3 Formal Interviews. As a way of complementing the data I collected through participant observation, I conducted interviews. Before I began the interviews, I socialized in depth with the workers in the places they gather: private homes, political protests, parks and cantinas. Once I gained the trust of each participant, I approached them individually and informed them about my research project and invited them to participate in the interview. The interviews took place in a safe, mutually agreed upon setting. I explicitly asked if they consented to be audio recorded during 
the interview. When the participants did not wish to be audiotaped, I asked for permission to take notes. Two interviews were registered through notes.

4.4 Oral History. Methodologically, the research project had an important historical component. This is because I wanted to be able to situate and understand the current migratory status of the immigrant workers, their condition of deportability, and their current health conditions, in relation to the broader transformations that have occurred throughout the last 40 years. I found this time framing relevant because, as has been shown by David Harvey (1989; 2003; 2005), Saskia Sassen $(2010 ; 2014)$ and Giovanni Arrighi (2009), among others, this is the period of time in which world capitalism manifested fundamental changes in its patterns of accumulation; changes that, among other things, have altered significantly the ways in which labour and capital are geographically mobilized, nation states behave, and human populations are mobilized. For such purposes, I relied on the use of oral history. Through the workers' narratives, and oral stories, I tried to find patterns that could help me to understand both the specific and broader dynamics that have shaped their current migratory status and their health status. Through their oral history narratives, I also was able to trace the social etiology of the illnesses they experience. In those conversations, when talking about the accidents, afflictions, or different forms of illnesses they were dealing with, we used to locate, in terms of time and space, where, in which time of the year, how, and why, an accident took place, an affliction started to manifest or a particular illness started to develop. By proceeding this way, the interviewees and I we often ended up with a "collection of stories of illnesses," as one of my participants said lightly.

\section{Taking Care of the Participants' Vital Security and Well-Being}


The people I interviewed were (and most still are) vulnerable in two fronts. First, they were living in the country with no legal recognition, and some of them were actually dealing with deportation orders. Second, since their migratory status made them less likely to get access to health services and to see their family members, and since I asked questions about health and family issues, they were also particularly vulnerable to experiencing discomfort or anxiety during the interview. Therefore, anonymity and psychological security were two fundamental requirements for the wellbeing of the participants. In order to guarantee confidentiality, and diminish the risk that the participants experience discomfort or anxiety during the interviews, the following mitigation strategy was carried out:

A) Before the interviews took place, I told the participants that, in order to guarantee confidentiality and consent, I wouldn't ask any questions that can make them identifiable, such as addresses, phone numbers, and real names, including those of their employers, friends, and family members. I told them, also, that they had the right to stop the interview at any time, or to refuse to answer any question they felt might compromise anonymity, confidentiality and secrecy. I told them also that, in coherence with the Tri-Council Policy Statement for Conducting Research Involving Humans, whose main purpose is to protect the welfare of the participants, the information they consented to share with me would not be shared with third parties, included government authorities or organizations (as stated in article 5.2:59), and that I would be the only person who had access to that information. I did not provide consent letters to the participants (to avoid putting them under risk of being identified), or ask them to sign a consent form, as they may see that as an excessive formality, or even "as a violation of trust," as it is recognized in the TriCouncil Policy Statement: Ethical Conduct for Research Involving Humans 2nd edition (Art. 10.2: 140). I also told them that the interview had a strict academic/scientific purpose, and that all the 
procedures we had to follow before the interview took place were aimed at ensuring voluntary participation, guaranteeing anonymity and confidentiality, and reducing the probabilities of harm.

B) I explained to them in detail, before the interview took place, what type of questions (and topics) the interview would explore. I told them that they had the right to: 1) refuse to answer the questions they did not feel comfortable with, 2) stop the interview at any time, or 3) to withdraw from the study at any moment. When, despite all my efforts to create a safe and secure environment for the participants, any of them experienced discomfort or distress during or after the interview, I stopped the interview, first, and asked the participant if he/she needed professional support to overcome distress or discomfort. In seven interviews, the participants expressed to me that they needed medical help (not as an outcome of the interview, of course). In all of those cases, I referred them to Médicins du Monde, an organization which provide free health services for immigrants with precarious migratory status. I also referred them to Solidarity Across Borders, a community-based organization which provides diverse forms of support to undocumented immigrants and refugee seekers in Montreal.

\section{Geographical Area of Study and Getting into the Field}

I carried out the research in Montreal, Quebec, a city which is, along with Toronto and Vancouver, one of the main hosts of undocumented workers in Canada. It also hosts the largest number of migrant justice grassroots organizations working directly with undocumented workers across the country. I conducted my field work for 12 months. This included working in the factories where the undocumented workers normally work, socializing with them in their free time and attending political protests, BBQ parties, and hanging out with them in a variety of other spaces of 
socialization organized by local organizers, or by groups led by the undocumented migrants themselves.

The process of getting into the field and reaching out to my research participants, a great number of whom I continued to see throughout the whole research process, was facilitated by the generous support I received from members of Solidarity Across Borders, Mexicanos Unidos por la Regularización and the Immigrants Workers Centre who, always respecting my academic autonomy, put me in contact with the undocumented migrant workers with whom I first established contact and from whom I received contacts for jobs, met other people, and was allowed to enter into the everyday lives of many people who live and work "in the shadows" of society and work in the local underground labour market. The guidance and contacts provided by one of the coworkers in my second job, a medium-sized meat company located in the offshores of Montreal, was helpful to the same ends. Through her generous support, I came in contact with a dispersed but numerous group of people, principally women, who have been working and living in the city without authorization for many years.

As I expected that the process of gaining trust among potential participants would take a long time, I started doing exploratory field work visits to the community 12 months before the official project was approved by the Carleton RBE's office. In that period of time, I was not working, but visiting public events and attending a variety of socializing events organized by local organizations. I also conducted visits to the Le Centre de prévention de l'immigration à Laval (Laval Holding Center) (CPI) with members of Solidarity Across Borders with the aim of providing moral support and meal-time company to incarcerated workers. In accordance to what is allowed by the Tri Council Policy Statement. Ethical Conduct for Research Involving Humans (Art 10.1), the exploratory 
visits I did prior to the approval of the RBE's office included note taking, diary writing, and observations. I used all this information while conducting the analysis. The time frame within which the whole research process took place included 24 months of field work.

\section{Interviews and Characteristics of the Interviewees.}

I originally planned to conduct a total of 30 semi-structured, in depth interviews with immigrant workers ( 15 women and 15 men) who live and work in Montreal without authorization. But I ended up interviewing 47 migrant workers (26 men and 21 women) whom I contacted through the use of the snowball technique. As mentioned, my access to those first participants was facilitated by social activists and a coworker who is an undocumented person herself. The interviewees and research participants were adult (over 18) immigrant workers from Latin America who, at the time of the interview, were working and living without legal recognition (non-status workers) in Montreal, Quebec, for at least 12 months. The interviews were conducted in Spanish. Due to my language limitations, potential participants who did not speak Spanish, English or French were excluded. People who were minors (under 18) at the time in which the interviews were conducted were also excluded from the study. As this research aimed to document immigrant workers' experiences and practices in particular historic and geographical coordinates, no quantitative criterion was used to justify the number of participants chosen to be interviewed. However, I stopped conducting interviews once data saturation was achieved and the stories collected started to get repetitive in terms of the information I was collecting. 
The interviews were designed according to the principles of the "active interview" (Holstein and Gubrium 1995), which assume that the best way to collect meaningful qualitative data from the participants is by carrying out the interview in the context of a "productive site" (3) in which interviewer and interviewee give birth to meanings and knowledge in the frame of a dialogical and active relationship. Using this as a guiding principle, I was always flexible in the selection of the participants; used open questions, provocations and interactional gestures to maintain a fluid conversation; and was permanently stimulated in making connections between cases, experiences, and anecdotes that seemed at first disconnected. I also tried, always, to cultivate rapport with the respondents, and, constantly provoked shifts in the roles of interviewer-interviewee to guarantee multivocality. The interviews were carried out in an in-depth and semi-structured format. They were between 2 and 4 hours in length and all of them were recorded using a digital recorder with the consent of the interviewee. The areas that were explored in each interview included: 1) General characteristics and profile of the participant, 2) His or her story of arrival in Canada, 3) His or her story of becoming an undocumented worker in Canada, 4) the characteristics of the paid and unpaid labour they carry out to satisfy their fundamental human needs (shelter, food, social networks, legal and social recognition, etc.), as well as the hazards that such forms of labour involves 5) His or her experiences in dealing with the possibility of deportation, 6) His or her stories of health and illness, 8) His or her experiences of dealing with access to health and other social services, 9) forms of coping with the lack of access to health care and other social services, 10) income, housing conditions, freedom of movement, and 11) the ways in which they deal with family issues, such as family relationships, remittances and parenting.

7.1 Short survey. Through the process of being in the field, I also collected information of approximately 100 undocumented workers through a short survey. This information was based on 
informal conversations and formal encounters I had with the participants through other participants via the snowball technique. In that first encounter, in which the participants and I learned if they were the type of person I was looking to interview, I spent about 15 minutes asking specifically about the period of time the potential participants had lived without authorization in Canada; the type of work they do for a living; the country of origin,; age, sex, income, and health challenges; and informed them about the full content of the interview. Often, following the wishes of the potential participants, and previous consent, the first encounter became a site of a first interview. But, in some case, that first encounter helped only to set the date for the long interview. As, for diverse reasons - mostly related with lack of time, work/life balance issues and stability - more than half of the participants could not make it for the second encounter, the information gathered in the first encounter, with their previous consent, was used during the data-analysis stage of this dissertation. It helped me to have gathered that information, as it provided me with a "general picture" of the situation in which the undocumented workers in Montreal live and the types of health challenges they face. This information has been used, for example, in the analysis when making calculations about their income, types of industries that hire undocumented labour force, and the types of health issues they face (such as sleep disorders and accidents in the workplace).

\section{Coding and Analysis of Data.}

As a way of ordering, classifying and analyzing the information collected in the interviews, I used the method proposed by Emerson, Frets and Shaw (1995) regarding coding and memoing, as well as the method provided by Norman Fairclough (2003) for analyzing qualitative interviews. By using these techniques, which seek to find patterns and regularities of thought and behaviour, I was able to identify key aspects of the complex set of institutional, economic and social processes 
shaping the way undocumented workers experience health in the context of precarious legal and social status.

The research project complied with all applicable policies and guidelines regarding research, including that of the Tri-council Policy Statement: Ethical Conduct for Research Involving Humans (TCPS) (CIHRNS, ERCC \& SSHRC, 2010), and was approved by the Carleton University's Research Ethics Board. In order to guarantee confidentiality and the anonymity of the research participants, I replaced participants' real names with pseudonyms. Also, in order to guarantee that the information I collected can be used strictly for academic purposes, I changed the names of the factories, and avoided any other information that could make them identifiable. I stored the data in a password encrypted file and I was the only person with access to the data.

\section{Standardizing and Classifying Illnesses}

The physical and mental health of the participants has been described and analyzed using a system of health symptoms classification, through which the diversity of health symptoms and the explanations the workers provided in the interviews (sometimes drawing from healthcare specialists diagnostics and others from non-western indigenous health knowledges) were subjected to a process of data standardization.

In terms of analyzing physical health, the data standardization process did not represent a major challenge. It consisted of listing the symptoms and classifications described by the participants in a chart using categories the research participants used, such as: "arthritis," "sore throat," "wounds and cuts," "back pain," "migraines," etcetera. Then, using the detailed information provided by the participants in the interviews regarding causes and symptoms, and also the classification system provided by the National Work Injury, Disease and Fatality Statistics elaborated by the 
Association of Workers' Compensation Boards of Canada (AWCBC) (2018), I grouped those symptoms under clusters that classified them in categories that were more specific and functional to a sociological analysis, such as: "repetitive strain injuries," "permanent back and shoulder pain" etcetera. Those clusters were also separated by 1) Type and occupation of industry (construction, industrial cleaning, landscaping), 2) Size of the industry (a.- Medium sized, b.- Multinational Corporation ${ }^{6}$ and c.- Underground Workers' Cooperative), 3) Nature of the labour process, and 4) Source of illness or injury ("Contact with temperature extremes," "exposure to noise," "Exposure to allergenic substances"). Although the method of interpretation was qualitative, grouping and classifying illnesses and injuries in this way helped me to notice regularities, signs of general tendencies and, when appropriate, helped me to extrapolate and express those tendencies in quantitative terms.

In terms of mental health, for the data standardization process I followed the same principle. It consisted in listing the symptoms and classifications described by the participants in a chart using the categories the research participants used, such as: "Depression," "Feelings of being nobody," "Anxiety," "Fear of Death," "Wishes of Vanishing," among others. Then, using the detailed information provided by the participants in the interviews regarding causes and symptoms, and also the classification system provided by The ICD-10 Classification of Mental and Behavioural Disorders Diagnostic Criteria for Research elaborated by the World Health Organization (1992), I grouped some of those symptoms under clusters that classified them in categories that were more functional for the purposes of my interpretative analysis. I also separated those clusters by 1) Type

\footnotetext{
${ }^{6}$ In this thesis, "Multinational Corporations" (MNC) are defined as enterprises that produce, own and deliver products and services in more than one country, and which are giant in size. MNCs are different from Transnational Corporations (TNCs), which the United Nations define as "enterprises which own or control production or service facilities outside the country in which they are based" (United Nations. Secretary-General, 1995).
} 
and occupation of industry (construction, industrial cleaning, landscaping), 2) Size of the industry (a.- Medium sized, b.- Multinational Corporation and c.- Underground Workers' Cooperative), 3) Nature of the labour process, and 4) Source of illness.

When generalized symptoms related to the "wear and tear of the body" (such as generalized stress, sleep problems, permanent anxiety, nervous tics, among others) were evident in some participants (sometimes expressed in that way by the workers themselves), I used the concept of "allostatic load" to refer to those cases. As I am not physician, I relied on the criteria that have been established by the specialized literature in the field. I also used the same criteria when locating "sleep disorders." For heuristic purposes, when dealing with the classification of sleep disorders, I made a qualitative distinction among the types of sleep disorders that the interviewed manifested. I used The International Classification of Sleep Disorders (ICSD) as a guide because it is the classification system that is used in the scientific field of studies on sleep disorders. The ICSD classify more than 81 sleep disorders, grouped in the following 8 categories: 1) The insomnias; 2) The sleep-related breathing disorders, 3) The hypersomnias of central origin, 4) The circadian rhythm sleep disorders, 5) The parasomnias, 6) The sleep-related movement disorders, 7) Isolated symptoms, apparently normal variants and unresolved issues, 7) Other sleep disorders. Following the ICSD criteria and using the narratives of the interviewees as a classifying guide as well, I divided sleep disorders in two main clusters. In the first cluster I included the sleep disorders that the workers experience occasionally. Within this cluster, I grouped: a) occasional insomnia (generally due to excess of fatigue and/or financial, family or work-related concerns or worries), b) sleepiness related to breathing disorders (when the person cannot sleep due to snoring or sleep apnea), c) hypersomnias of central origin (defined as "the inability to stay alert and awake during the major waking episodes of the day, resulting in unintended lapses into sleep"), d) circadian 
rhythm sleep disorders (when the person "cannot sleep when sleep is desired, needed, or expected"), and d) Parasomnias (which include certain type of nightmares that are experienced occasionally). In the second cluster I included sleep disorders that the research participants manifested on a persistent and repetitive basis over long periods of time and which are linked to highly traumatic events, or to anxiety or stress experienced over a long period of time (more than three years, according to WHO). Within this cluster, I included: 1) idiopathic nightmares and 2) post-traumatic nightmares - attributed by the scientific community as linked to Post-Traumatic Stress Disorder (Spoormarker, Schredt \& van den Bout, 2006: 22; Cervantes and Salgado de Snyder, 1989: Roth, Newman, Pelcovitz, Van der Kolk, \& Mandel, 1997; Spoormarker, Schredt and van den Bout, 2006; Van der Kolk, Perry \& Herman, 1991; Van der Kolk, Roth, Pelcovitz, Sunday \& Spinazzola, 2005;). Following the same criteria established by the scientific community, I linked post-traumatic nightmares to the concept of "historical trauma" which is defined by Lakota scholar Maria Yellow Horse Brave Heart (2003) as the "cumulative emotional and psychological wounding, over the lifespan and across generations, emanating from massive group trauma experiences" while "historical trauma response (HTR) is the constellation of features in reaction to this trauma. The HTR may include substance abuse, as a vehicle for attempting to numb the pain associated with trauma. The HTR often includes other types of self-destructive behavior, suicidal thoughts and gestures, depression, anxiety, low self-esteem, anger, and difficulty recognizing and expressing emotions. Associated with HTR is historical unresolved grief that accompanies the trauma; this grief may be considered impaired, delayed, fixated, and/or disenfranchised (2003: 7).

Although the method of interpretation was qualitative, grouping and classifying mental health problems in this way helped me to discover general tendencies and, when appropriate, helped me 
to extrapolate and express those tendencies in quantitative terms and locate them in terms of shortterm historical trends.

Following C. Wright Mills' advice on how to conduct sociological analysis as a "craftsman," (“craftsperson," I would say) by using creativity and imagination as sources of sociological inquiry rather than by "fetishizing the use of method or technique" (2000 [1959]:224), I used the aforementioned classifying criteria (categories, clusters, scientific classifications) as a general heuristic tool. It provided a guide to the understanding of the "general tendencies" and the "general picture," but the analysis and the ways in which particular forms of illness were related to, say, labour intensification, deportability, and other social processes, was carried out using the direct experiences described by the workers and my own forms of interpreting illness and social processes using frames of theoretical reference described in the theoretical part of this chapter.

\section{Content}

The dissertation is divided into eight subsequent chapters. The current chapter introduces and discuss the research problems as well as the theoretical framework and methodology. Chapter Two locates four social determinants of health which underpin the structural vulnerability to which the Latin American undocumented workers are subjected in this particular geographical and historical context. Based on reflections stemming from my fieldwork, in conversation with abstract concepts of political economy, this chapter shows that, for this particular population, the condition of being "subjects of administration," "subjects of deportability," "subjects of racialization" and "subjects of exploitation," work as primary sources of physical and mental illnesses. Because of their centrality in shaping the experience of health and illness for this population in particular, such determinants are thought of as the 'master determinants' of undocumented immigrants' health. 
Chapter Three examines the material conditions under which undocumented workers live, while working in Canada without authorization, and the way such conditions shape their material precariousness and mental suffering. By analyzing the labour dynamics and alienating social relations that emerge in three types of companies that employ undocumented workers (multinational corporations, medium-size local enterprises, and underground workers cooperatives) the chapter shows the different ways in which such conditions shape their social uprootedness and mental suffering. The chapter concludes with the proposition that the formal subsumption of labour, by which capital integrates undocumented workers into the wage-system and existing labour relations (fundamentally using forms of abstract labour), mediated mainly by recruiters and employment agencies, is the main factor that contributes to the uprootedness and mental suffering of the undocumented workers.

Chapters Four, Five and Six describe the mental and physical illnesses that undocumented workers experience in Canada, according to the type of industry they work in (medium-size local industries, multinational corporations, and underground workers' cooperatives) and the type of work they do. As a whole, these three chapters illustrate that those who work for medium-size local enterprises (discussed in Chapter Four) and multinational corporations (discussed in Chapter Five), as well as those who lost their legal status after being engaged in refugee claimant applications, principally women, are more likely to develop the most dramatic forms of physical and mental health diseases, such as suicidal thoughts, PTSD-related nightmares, incapacitating bodily injuries and several disorders arguably linked to allostatic load. In contrast, undocumented immigrants engaged in nonwage cooperative labour in underground workers' cooperatives are less likely to experience serious mental and physical diseases. This mainly happens because, as shown through Chapter 
Six, working in the workers' cooperatives, under conditions of "clandestine solidarity," expose the workers to forms of solidarity from Canadian grassroots which partially emancipate them from the harmful effects of state administration (surveillance, entrapment and deportation), racism, and exploitation.

Chapter Seven analyzes the way in which undocumented workers resist the social, institutional and labour mechanisms that undermine their physical and mental health. It also describes the ways in which Canadian migrant justice organizations engage with the undocumented workers in the strengthening and development of political resistance and contentious politics. This chapter argues that socio political solidarity, in the objective form of multi-ethnic collaboration during social struggles and protest, work as social determinants of better health. Unlike workers employed in medium-sized enterprises, who are more likely to engage in individual and passive resistance to exploitation, entrapment and deportation, undocumented workers employed in multinational corporations and in "illegal" pirate labour co-ops, are more likely to engage in more effective forms of collective resistance to exploitation, entrapment and deportation. For that reason, and also because in those labour spaces and sociopolitical struggles they tend to enrich their networks of friendships and loving relationships, they also tend to report better health outcomes, and experience more freedom and less mental suffering.

Finally, the Conclusion summarizes the main findings gathered through the research process. 


\section{Undocumented Immigrants and the Master Determinants of Health}

In the Political Economy of Health tradition, as discussed in the previous chapter, illnesses and health are considered to be shaped by the social, economic, political and historical context within which the subjects, and the social institutions to which they belong, live and reproduce as cultural and biological units. Acting upon the subjects through meso-level mediating mechanisms in a form that is related to the communities and the social position of individuals in society, the social determinants of health contribute to making people sick, cured, or living healthily in a form that is dynamic and uneven. This means that individuals and social groups are affected differently by the same social determinants. It also means that the social determinants of health vary across populations and historical moments. For that reason, this chapter attempts to identify the determinants that seem most fundamentally mediating the health of the Latin American undocumented population that I interviewed. As will be discussed, being subjected to precarious labour, subjected to the mechanisms used by the Canadian State to deal with undocumented population (principally to surveillance, detention and deportation), subjected to diverse forms of structural racism, and subjected to exploitation make the undocumented population living in Montreal vulnerable in their physical and mental health. For that reason, I have labelled those conditions as the master determinants for the health of the undocumented workers interviewed. As alienated labour is central to the lives of all of them, and central to the very existence of the social system in this historical time, this chapter will start by discussing this aspect. In particular, it will discuss the role that the degradation of labour in Canada's late capitalism plays as a social determinant of health as well as the role it plays as social determinant on the lives of the undocumented population. 


\section{The degradation of labour as master determinant of health}

During the second half of the twentieth century, particularly within the socio-political context in which the welfare state was crafted, a powerful social consensus depicted labour (in its alienated form, under the umbrella term of "full employment") as the main source of social wealth and the chief tool of economic growth, upward mobility, personal development and collective emancipation. ${ }^{7}$ That was the beginning of our current times; the time in which the "old mole" (to use Marx's famous metaphor) that is, the historical socialist dream seeking to emancipate labour from its entrapment in the wage system, and making it flourish in the form of a creative and joyful activity, was put to a standstill. But such an uncritical conception of labour promoted during the welfare state period is not new. In the Protestant Ethic and the Spirit of Capitalism, Max Weber (1930 [1992]) revealed how the moral and aesthetic principles informing such a conception of labour (hard work, discipline and puritan asceticism as source of social wealth) are at the core of the Calvinistic ethic which culturally reinforced the consolidation of capitalism in central and northern Europe and, later on, its expansion — via war, slavery and colonization — throughout the world. ${ }^{8}$ Although, according to Weber, such values were there the beginning of the consolidation

\footnotetext{
${ }^{7}$ In what has become an influential statement on full employment (“After the War-Full Employment”) prepared by Alvin H. Hansen, "the American Keynes," for the US Board of Governors of the Federal Reserve System in 1942, it is written: "The immediate aim of the American people is to preserve and safeguard political freedom. But a military victory for the democracies is not enough. If the victorious democracies muddle through another decade of economic frustration and mass unemployment, we may expect social disintegration and, sooner or later, another international conflagration. A positive program of post-war economic expansion and full employment, boldly conceived and vigorously pursued, is imperative. Democracies, if they are going to lead the world out of chaos and insecurity, must first and foremost offer their people opportunity, employment, and a rising standard of living."

The document was written in 1942 and by its own account had the approval, support and feedback of members of the Federal Reserve Banks and from a group of businessmen, economists and labour leaders. The plan suggested the implementation of the post-war economic policies based on the following points: 1) full employment, 2) expansion of the social infrastructure and social security system (including health care), 3) expansion of factory equipment, 4) invigoration of private enterprise, and 4) a high consumption economy.

${ }^{8}$ It is important to point out that religious ideas cannot be understood as the main historical determinants of capitalism. As has been pointed out by influential historical treatises on the topic, the social forces behind the emergence and
} 
of capitalism as social formation, greasing the wheels of commerce and capital accumulation by virtue of shaping individual and collective dispositions, subjectivities and social practices, later on, at the end of the 19th century, they were raised up to the rank of social and individual virtue by the German social democrats through the Gotha Programme (1875), a political program which, despite having as its ultimate goal the abolition of the wage-labour system, continued to imagine labour and factory labour, as the source of "all wealth and civilization."

Despite the colossal critique to which such a conception of labour was subjected under Karl Marx's Critique of the Gotha Programme (1891 [1938]), which was then re-elaborated by Walter Benjamin in his masterpiece Theses on the Philosophy of History (see Thesis XI and Thesis XIII, 1969 [1955]:258-261), the Calvinist conception of labour continued to spread in society in a secular form, although always somehow disputed by the socialist critique, particularly in the countries of the Global South where National Liberation movements, unions and socialist governments continued to exercise a significant influence on societies and democratizing movements. But the socialist critique slowly withered away during the post Second World War period in the countries of the Global North, a time in which a more anti socialist vision of labour

consolidation of capitalism cannot be reduced to moral factors. In the Grundrisse, for example, Karl Marx locates war, colonization, dispossession and real subsumption of labour and petty commodity producers as the main mechanisms by which capitalism was consolidated as dominant mode of production (Marx, 1973 [1939]: 459-471). I underline the Weberian explanation not as a "total" and comprehensive explanation of the origin of capitalism, but as a sociological explanation which helps to explore and recognize the ideological underpinnings of such economic formation. The Weberian understanding of religious morality and capitalism help us to interrogate the way in which a certain type of morality, or ethic, has been historically useful for certain economic and social models of society. In other words, the Weberian hypothesis is useful for the understanding of the ethos of capitalism. For a fine and rich analysis that explores the ethic of capitalism in North America using Marx and Weber, see: Kathleen Weeks: "Mapping the work ethic," chapter 1 of her book The Problem with Work: Feminism, Marxism, Antiwork Politics and Postwork Imaginaries (2011: 37-78).

9 "Labor is the source of all wealth and of all civilization" states the first point of the Gotha Programme. This is not to say, of course, that, consciously, social democrats resorted to Calvinism to inform their own notion of labour. It means, rather, as Kathi Weeks discusses in The Problem with Work (2011), that "the most irrational" aspects of the ethos of labour that were predominant in a particular period of time in Europe, become dominant, via processes of rationalization in the subsequent periods of time, even among people and movements holding critical positions. 
was exalted in a stronger, undisputed way by the new state formation (the welfare state) underpinned by a class compromise among industrial capitalists, political promoters of the new deal, and the working class. During this period, labour was reframed under a more conservative configuration, as, regardless in which form, "after war, full employment" become exalted as the main goal of economic policies not only among political elites but also among industrial unions, making possible both the integration of the working class into capitalist rationality and the abandonment of the critique of exploitation and alienated labour as a dominant relation of production (Gonzalez Casanova, 2017; Fraser, 1991).

Even though the notion of labour disseminated under the welfare state implied a strategic subordination of its harsher aspects, in favour of a more "humane" and collectivist version of it (consensus aimed at softening class tensions), the idea that wage labour (and that of factory labour and industrialization) is the main tool of social wellbeing remained unaltered. Whether in its individualistic version, of Calvinist origin according to Weber, or in its collectivist version, of Catholic origin according to Fernand Braudel (1992: 567-568), labour is exalted as an individual and collective virtue, as well as a source of social wealth and development. In both versions, waged/alienated labour is imagined as the only factor that makes social progress possible. It redeems people, both at the collective and at the individual level, and makes their lives easier and better. It makes it possible to improve societal development via the production of goods, the provision of services and the creation of infrastructure that sustains growth. It connects individuals to the community and enhances their social, physical and intellectual capacities. It also allows people to develop an identity, facilitates their access to the consumption of goods and services, and improves people's standard of living. It is thus the basis of development, economic growth and social modernization. Hence the idea that wage labour also emancipates society from social 
malaise, illness and death through the prolongation of life expectancy and the creation of security and social protection. That is, by giving people access to an income, material stability, social networks, and a sense of wellbeing, labour functions as a major source of health and a positive social determinant of health.

In the current historical context, however, this "corrupt conception of labour," as Walter Benjamin (1969 [1955]: 253-264) would put it, must be brought to account. Perhaps this the time to recall that wage labour, that is, labour in its abstract, alienated, non-creative form, was born out of - as Joseph Proudhon ${ }^{10}$ dissected and Karl Marx later on — a social mechanism by which wealth and value are made possible through objectification and exploitation of human beings. It is a form of social relation by which value and socially produced wealth is transferred to a few hands by virtue of their ownership of the means of production, as well as by virtue of their capacity to consume other peoples' labour, and to individually appropriate the surplus value that results from it. So, it seems to me that a critique of the current hegemonic conception of labour must start from the sociological objectification of that fundamental social fact, in the most Durkheimian sense of the term (Durkheim, 1998 [1895]: 59): under the command of capital, labour is both the primary mechanism of the inequality of wealth and wellbeing, and the primary mechanism of social domination. But furthermore, in a period in which unions and other workers' protection structures have been literally dismantled (even through violence itself), and the global crisis of capital has subjected a massive number of workers to unemployment or to employment in its most precarious form, both in the Global South and North, alienated labour has been gradually ceasing to be a source of income security, personal emancipation, social development and better health. This

\footnotetext{
${ }^{10}$ Pierre-Joseph Proudhon (1840 [2010]): What is property? "Property is the right to enjoy and dispose at will of another's goods, - the fruit of another's industry and labour" (208).
} 
happens not only because the current labour structures produce unhealthy forms of human precarity but also because the actually existing mechanisms of commodity production contribute to the destruction of the environment via its irrational organization at the exclusive service of endless accumulation, exchange value creation and industrialization (Foster, Clark \& York, 2010; Klein, 2014).

The precarity, uncertainty and instability produced by the global reorganization of labour and capital (reorganization which implies the radical subordination of the former to the latter) are increasingly becoming a norm in today's societies (Standing, 2011). Even in Scandinavian countries, or here in Canada, for example — countries traditionally depicted since the post WWII era as role models of rational and sound organization of labour and workers' protectioninsecurity and precarity linked to work have risen at an extraordinary rate during the last decades (Armstrong, Banerjee, Szebehely, Armstrong, Daly \& Lafrance, 2009; Calleman, 2011; Fudge \& Vosko; Golsch, 2005; Lewchuk, Clarke \& de Wolff, 2011; OECD, 2015; PEPSO, 2013 and 2017; Shalla, 2007; Shalla \& Clement et al, 2007; Thörnquist \& Engstrand, 2011; Vosko, Zukewich \& Cranford, 2003; Warskett, 2011), and workplaces have become, more and more, spaces of anxiety and unfairness (Armstrong, et. al 2009; Armstrong, Armstrong \& Scott-Dixon, 2008; Jackson \& Rao, 2016; Raphael et. al. 2016). Racialized workers are disproportionately overrepresented in the most dangerous, precarious, undervalued and underpaid jobs; women continue receiving lower wages compared to their male coworkers doing the same jobs; workers representation in the workplace continues to decline; part-time, contractual work has been increasing, and the morbidity rates associated to precarious employment have also been going up (Armstrong \& Armstrong, 2010; Armstrong, Armstrong \& Coburn et. al., 2001; Raphael et.al. 2011; Raphael et.al. 2017; Raphael, 2011; Vosko, 2003; Vosko, 2000; Warskett, 2011). 
Thus, under the new rules of capital, labour has been gradually transformed into a source of stress, anxiety, uncertainty and disease rather than a positive determinant of health, individual wellbeing and social improvement. In effect, subjected to the unpredictability and precarity stemming from the new labour markets and new labour processes, millions of human beings have been gradually forced to make a living by putting in more hours of work for lower wages, as the circumstances have been gradually pushing them to juggle in two or three jobs to comprise a decent income. In Canada, for example, as measured by Duxbury and Higgins (2013), 1 in 5 workers, principally people on the lower strata, those "who need every available hour to survive," are being forced to hold two or more jobs at the same time both to make ends meet and to submit to the demands of the employer. This situation has translated not only into greater job dissatisfaction, more workrelated stress and more frequent illnesses, but also into imbalances and tensions within families (crises of social reproduction), as the workers tend to outsource family responsibilities and spend less quality time with their families (Duxbury and Halinski, 2014; Duxbury \& Higgins, 2013; Higgins, Duxbury \& Julien 2014; Luke, 2014).

Those forms of precarity have intensified since 2008 with the global crisis of capital, aggravated by what Guy Standing calls "the politics of inferno," that is, a social dynamic in which the intensification of precarity, rampant social inequality, criminalization and incarceration of the poor, and the invasion and suppression of rights, freedoms and privacy are leading to the emergence of signs of fascism, despotism and social malaise (Standing, 2011: 132-154; see also: ILO, 2011; UN, 2011). But the precarization of human life, closely linked to the global degradation of labour in the twenty-first century, does not affect all the people in the same way. Highly educated and highly skilled professionals or leading figures in the high-tech or financial sectors (the famous "one percent"), mostly white men from the core countries of the world system, have 
been not only the least affected, but the main beneficiaries from the current labour regimes. This is not the case for Indigenous people, women of colour and racialized immigrants, the elderly, the disabled, and some queers and sexual minorities (particularly trans people) both in the core countries and in the periphery (Cranford, Vosko \& Zukewich 2003; Creese \& Wiebe, 2013; DasGupta, 1996; Fudge, Tucker \& Vosko, 2002; Fudge \& Vosko 2001; HRC, 2013; Hollibaugh, 2001; Pitcher, 2015; Fuller \& Vosko, 2008). These social groups have been most negatively affected in their health and overall wellbeing by precarious labour. Thus, under the current labour regimes, waged labour is becoming less and less a source of social wealth, health and wellbeing. On contrary, it has increasingly become a chief source of social and individual morbidity and a decline in life expectancy even in the core countries of the world system, as exemplifies the case of the United States, where in 2016, life expectancy declined one year for the first time since 1993 (New York Times, 2016).

The radical subordination of labour to capital, and the consequent relative and absolute precarization of the working class, seems to be the consequence of a general tendency occurring at the level of the global structure of capitalism. The General Law of Capitalist Accumulation developed by Karl Marx — Chapter 25 of Capital (1990 [1867]) and Notebook 4 "The Chapter on Capital" of the Grundrisse (1973: 374-479) —explains this historical tendency of labour and capital in the following way: In its endless march towards its valorization, capital always tends to produce surplus time, surplus labour and surplus population. Seeking to reproduce and to expand via increasing surplus value, capital perpetually needs to shorten the labour time, to intensify the labour processes, to introduce technological sophistication, and to reduce wages. This way of realization of surplus value creates a situation in which wealth is made possible upon the creation of growing levels of 1) exploitation of labour, and 2) its increasing disposability. This occurs 
mainly because, as the organic composition of capital grows faster than the mass of population engaged in production, capitalist production needs increasingly less labour power. Labour power increases capital while at the same time making it increasingly vulnerable to its own exploitation and own disposability. This means that accumulation of capital produces, by itself, the accumulation of misery, dispossession and exploitation. Under this pattern of self-realization, or autopoiesis, rationalization of production brings about the relative and absolute subordination, pauperization and precarization of labour.

But those processes do not occur without contradictions. Exploitation, pauperization, and disposability of labour create problems in both the relations of production (creating tension with capital) and in the sphere of circulation and production, as it generates a surplus of commodities and shortens labour's capacity to consume the products of its own labour. Although Marx tends to hope that the development of those crises will eventually bring the system of accumulation to a collapse, contemporary Marxian thinkers differ by pointing out the enormous capacity the system has to survive those contradictions. David Harvey, for example, sustains that the owners of capital tend to solve those crises, mainly, through: 1) overcoming geographical boundaries to open new markets, 2) transforming the structure of social needs and creating new commodities aimed at satisfying those needs, 3) expanding credit to incentivize consumption, and 4) disciplining labour and diminishing the workers' capacity to fight back through the dismantling of labour unions and the use of surplus labour as a reserve to incentivize worker competition and to keep wages low. The importation and incorporation of migrant labour under these contexts is key to capital in the core countries of the world system. This mechanism helps capital to keep managing its own crisis (which Wallenstein [2010] contends started in the 70's but has been aggravated since 2008), as it 
allows capital 1) to keep labour fragmented and divided, 2) maintain the local labouring class disciplined, and 3) to keep wages low.

What has been said so far with regards to the ways in which labour has been simultaneously subordinated to the command of capital, dispossessed from its creative capacities and transformed into an alienating activity, subjecting people's lives to new forms of unhealthy precarity and servitude, applies to the migrant workers living and working in Canada without authorization, but in a more radical form. It is not very difficult to understand why labour constitutes one of the primary causes of physical vulnerability for undocumented workers. If local workers in the core countries of the world system (traditionally more protected by labour protection frameworks) have been increasingly subjected to precarious and unhealthy labour structures through the dismantling of trade unions and the reorganization of work, the "surplus" of the world system — those who have been dispossessed from the rights traditionally associated with citizenship (such as labour protection and free circulation) - have been subsumed by capital in the most precarious and degrading labour processes.

Deprived of legal status and restricted in their capacity to circulate in the geographies of the new world order, those migrants are also deprived of social, legal and material security. This situation pushes them to experience a crisis of social reproduction: that is, a general difficulty to reproduce themselves and their families as social and biological beings due to radical shortage of resources needed to satisfy their social, cultural and biological needs as human beings (freedom of movement, food, shelter, health, warmth, clothing, education, family and social networks, etc.). This, in turn, often pushes them to engage in a struggle to solve that crisis of reproduction by actively searching for jobs which can provide an income "under any conditions." But, being 
classified by the State as illegal, expelled from the minimum benefits granted by membership in the social, cultural, and political community both the locally and in the society that has expelled them, racialized and subject to police surveillance and persecution, these workers end up (with surprising exceptions that will be described later) subsumed into labour processes which strip them from their condition of humanity (alienates them) and reduce them to being treated as disposable working machines.

In such a condition of alienation, the mass of undocumented workers, who constitute a significant proportion of the surplus population of 21 st century global capitalism, have become an "additional guard of the system," as Horkheimer and Adorno put it, "kept alive as an army of unemployed..." and "reduced to mere objects of administration," (2002 [1944]: 30): that is, a stock of cheap labour used and disposed at will in the processes of surplus value production, and expelled by the State and its policing and administrative apparatus when their profit-making utility ends.

\section{Subjects of administration}

According to my ethnographic records, the condition of illegality, and especially the forms of subjection to the administrative apparatus that this condition involves, constitutes a second social determinant of health. I am aware of the fact that the former statement might sound contradictory. Since illegality refers, by definition, to the condition of being outside of the legal system, then the question arises: How can it be stated that the condition of illegality subjects the undocumented workers to administration? Furthermore, how can it be said that being subjected to the administrative apparatus is linked to health?

I would like to start discussing this aspect by presenting you with the story of Claudia. Claudia is a young undocumented woman from El Salvador who lost her immigration status after being 
engaged in a legal battle trying to get refugee status. I met her when she was in the middle of a nervous breakdown. As she has been one of my research participants, she called me and asked me to put her in contact with organizations that could help her. She told me that she had been having those crises for a little while and that she and her partner were having problems because of that situation. Before she got medical treatment with the help of local organizations linked to Solidarity Across Borders, we had multiple conversations because I started visiting them to talk and distract ourselves going to the park for long walks on Sundays. In one of our conversations, we talked about the reasons for her continuous nervous crises. She told me: "I can't take it anymore (no aguanto más). I feel anguish and desperation all the time. My husband says I am getting crazy, that I am becoming too paranoiac and that I have a putrid mood. I am moody all the time, like I get angry very easily, or feel worry all the time." She told me also that, after the time in which the police entered into their building to solve a family dispute, she started to develop fears of being trapped by the police: "So, when I hear noises," -she said, "I feel like is the police and I run to lock myself into the closet, and I stay there for hours. I do not turn on the lights at night so that people think there is nobody at home. Even though people do not know, I feel persecuted." Claudia and her husband live in a small basement apartment with the basics in a 6-floor building and are often dealing with health and money issues.

I tried to give Claudia strength and told her that there are a lot of people living without papers in the city, just like herself, and that if she did not do anything wrong, it would be very unlikely that she would be discovered and put in detention. My attempt to make her feel better did not work and she told me that "they" know a lot of things about her: "I have given the government all my info, my address, pictures of me getting married to my husband, family names and all. The government knows all about me. I cannot believe this happens to me. I met my husband in an internet chat and 
we dated, and we got married in the US. We were both illegals there, but we never got the troubles we get here. There, in the US, nobody knows about you, only your friends know who you are. Nobody else knows anything about you. We had car there; we paid for the car insurance; we paid for our drivers' licences; we had jobs in a Chinese restaurant; we used to drive our car without trouble; we had a normal life. But here... no. I do not know why this is so difficult here for us."

The story of Claudia is very different from the opinions that I hear often from my fellow Canadian citizens with regards to the situation of the immigrants living in Canada without authorization. When talking informally about my work and research with undocumented workers in Montreal, local people often tend to predict how much more difficult life must be for the undocumented people who live in the United States. The idea that sustains this affirmation is that, if things here in Canada are difficult for them, in the US things must be worse because, after all, in Canada we are less cruel, and we have a more humane and caring society. Although this appreciation of Canada as more caring society may be true, it ignores the central aspect stressed by Claudia: the fact that she is in fear of the State, not of society. And that such fear stems from the fact that the government "knows everything" about her and that her precarious situations is linked to her radical exclusion - unlike her experience in the United States - from a variety of fundamental services and benefits that are linked to the exercise of freedom, including freedom of movement: health care, jobs, drivers' license, car ownership, less restriction of movement, lack of fear of the State $\ldots$ and anonymity.

The experience shared by Claudia, her fears and mental breakdown, will make more sense if we take a comparative look at how access to essential services and rights is guaranteed for undocumented immigrants in Canada and the United States. We will see this way that, despite the 
positive views of Canada as a more welcoming and caring society towards immigrants, the truth is that, compared to the United States, the Canadian State is extremely restrictive and exclusionary with regards to undocumented immigrants. In Canada, undocumented immigrants are excluded, by law, from health benefits, as the Canada's Interim Federal Health Plan (IFHP) excludes people without immigration status (Campbell, Klei, Hodges, Fisman \& Kitto, 2012; Glen, 2013). Additionally, they are not eligible for federal or provincial health plans (Villegas, 2013). Exclusion from health services was a product of the Federal Court of Appeal's 2011 decision in Toussaint $v$. Attorney General. In that decision, the court determined that a non-status person was "properly excluded" from a federal health insurance program and held that benefits under that program were only available to a "narrow class of resident aliens and a limited number of illegal aliens within the control and jurisdiction of the Canadian immigration authorities" (Glen, 2013). Undocumented people in Canada are also excluded from other essential public services and benefits such as language education programs, drivers' licenses, welfare, employment insurance and other social benefits, as accessing those benefits requires proof of residency or a Social Insurance Number. By extension, a variety of other private services are also unavailable to the undocumented population, such as gas, hydro and bank accounts, private insurances, and car and home ownership, among others. Access to these services requires official government issued ID, such as a health card, Canadian birth certificate or official proof of Canadian residency, such as Permanent Resident card or an Immigration, Refugees and Citizenship Canada (IRCC) form. Access to education, including education for children, is also denied in Canada to the undocumented population, with one exception: Under section 49.1 of Ontario's Education Act, parents who are "living unlawfully" in Canada can enroll their children (under the age of 18) in school, free of charge (Minister of Education, 2004; Magalhaes, Carrasco \& Gastaldo, 2010). 
In the United States, the situation of the undocumented populations in those regards is completely different. Although in the United States, undocumented immigrants are also, by law, "generally" excluded from public health care and other social benefits, the Emergency Medical Treatment and Active Labor Act (EMTALA) requires that all health clinics and hospitals that receive Medicaid funds provide free healthcare and emergency services, including surgery, to all residents regardless of immigration status. Similarly, by law, undocumented women and children have access to some health care services and also have surgery and other emergency procedures covered by Medicaid. Many state and local governments provide healthcare services to the undocumented population as well, especially women and those under 21 (Glen, 2013). Those legal venues have made possible that, in approximately $99 \%$ of the cases of health care that has been provided for free in some States, the undocumented population has been the main beneficiary of the EMTALA Act (Dubard \& Massing, 2007). Similarly, children and adults in the US are entitled to education in public schools, including state tuition in post-secondary institutions. Access to education has been guaranteed since 1982, after the Supreme Court ruled that students' access to a public education in the United States, including access to funding, cannot be denied based on their immigration status (Plyler v. Doe, 457 U.S. 202 [1982]). Even more, by law, parents or tutors of undocumented children are required to register their undocumented children under 17 in school. ${ }^{11}$ Likewise, in twelve states in the US non-status immigrants have legal access to driver's licenses, including California, Delaware, Illinois, Colorado, Hawaii, Connecticut, Maryland, Nevada, New Mexico, Utah, Washington and Vermont and Washington, for which a foreign birth certificate, foreign passport, or simply evidence of current residency in the state, such as a hydro bill, is

\footnotetext{
${ }^{11}$ Changes to the political landscape since the Trump administration have affected the attendance of children to school, as documented by several school boards and migrant rights activists. However, their right to education is still unmodified so far.
} 
required (National Conference of State Legislatures, 2016). Unlike in Canada, in the United States, opening a bank account, buying private insurance, owning a car or even buying a house require no more than basic bureaucratic steps, cash, and simple proof of residency, regardless of the legal status. That is probably why, according to official statistics, $63 \%$ of the undocumented population living in the US have access to health care, $31 \%$ are homeowners, and $92 \%$ of the undocumented children and youth (3 to 17 years old) have access to public education (Migration Policy Institute, 2017). In Canada, unlike the United States, to sum up, the undocumented population is banned from virtually all the entitlements and services they would have access to in the United States.

The comparative information above provides us with an idea that I would like to develop in this section: the idea that, as presented through the story of Claudia - a story that involves serious mental health problems - the relationship between migrant illegality and health in the Canadian context is fundamentally linked to the condition of deportability and radical social and legal exclusion that emerges as a result of being subjected to state administration and state surveillance and control. Why are people like Claudia more likely to be exposed to the mechanisms of state administration and possible deportation? The idea is that, as described by Claudia herself, unlike to what occurs in the United States - where three quarters of the undocumented immigrants enter by crossing the US-Mexican border clandestinely by land and without leaving any paper trail with the State (PWE, 2006), in Canada, as researchers Nupur Gogia and Bonnie Slade (2011) state, most of the undocumented immigrants arrived in the country legally as refugee seekers, temporary workers, tourists. or students who overstayed their visas (103). This is consistent with the data I gathered on the ground. Most of the Latin American undocumented immigrants living in Canada whom I interviewed originally crossed the Canadian border legally and lost their legal status, overwhelmingly, while already living in Canada and after having been engaged in refugee claims. 
Although 35 of them arrived as refugee seekers, four arrived as guest workers from the TFWP and five arrived as tourists. In the end they all lost their legal status after being engaged in refugee applications, submitted sometimes within the country and other times at a point of entry in a Canadian airport. Only three of the interviewees live in Canada in conditions of "Total Clandestinity" as they entered into Canada after crossing the US/Canadian border clandestinely and without claiming refugee status ${ }^{12}$.

This fact is at the root of the problem under investigation. Arriving to Canada under any of those categories (refugee seeker, guest worker or tourist) means that, before crossing Canadian borders, a substantial quantity of information about the visitor, guest worker, student or refugee seeker is gathered by the Canadian State. This is particularly relevant for the case of the ones who decided to claim refugee status. In effect, from the very beginning, the legal-based relationship that the undocumented workers that I interviewed established with the Canadian State and its administrative apparatuses entailed the disclosure and confession of detailed information about themselves as individuals, such as: language, country of origin, age, ethnic profile, health status, fingerprints, physical characteristics - including the image of their face, type and color of hair, skin and eyes-, as well as information about their relatives, friends, social networks, the reasons they came here as refugee seekers, and other important personal information. Confession and documentation made it possible for the Canadian State to maintain historical records, in very

\footnotetext{
12 Approximately three-quarters of the people interviewed arrived into Canada by plane and came from both urban and rural places, in a proportion of $60 \%$ and $40 \%$, respectively. One hundred percent of them have basic school education, and $10 \%$ even university education. An overwhelming majority among the refugee seekers told me also that they searched and found information in their country of origin about the paperwork that is required in the refugee process before embarking on the refugee application process in Canada. Those coming from low middle class or middle-class families, approximately 15 percent of my interviewees, were able to even pay to receive basic legal orientation services on migratory processes, and, as educated persons, were also better able to deal with the complexities that involve the formal refugee protection demand. In a refugee claimant process this fundamentally means that they were more diligent and efficient when it came to documenting, by providing material evidence, the reasons why they claimed they deserved to be granted asylum or refugee status.
} 
detailed form, about the workers' "existence" as refugee claimants or overstayers. Those records established the official "truth," representing the "actual" reasons the refugee claimants arrived and creating an official "certificate of existence" of my interviewees. Such official records documenting their presence in Canada are not only held by the Immigration and Refugee Board of Canada (IRB), the first institution with whom the refugee claimants establish and administrative relationship at the point of entry. That information is also handled by a variety of institutions that are mandated to facilitate the claimants' settlement while their refugee claim is considered, such as the institutions that provide language classes, legal aid, welfare, Emploi Québec, and schools (when they arrived with children), among others. The administrative apparatuses holding information about, and establishing a relationship with, the refugee claimants also include the independent court/hearing system hosted by IRB and the offices that decide first if a refugee is accepted or not, such as the Refugee Protection Division. Such a constellation of institutions forms the administrative apparatus that registers, builds, and manages the historical records documenting the presence and existence of the refugee claimants. They are also the ones that will keep regular contact with the claimants through the different moments or stages of the process, and simultaneously, govern the modalities under which settlement must take place while the refugee application is in process: housing, labour, education, geographical circulation, and so on.

After having undergone an always long, complicated and exhausting process before the immigration board and its hearing system, a process which ends when their application is ruled illegitimate, asylum seekers continue to be subjected to the control of the administrative apparatus. But now this subjection occurs in a cruder and more stressful way. From the moment their refugee application is rejected, the applicants receive a "removal order" that demands they "immediately" leave the country. My interviewees describe the moment in which they received the removal order 
as a very stressful event. Furthermore, they told me that stress intensified when they decided to stay and to live in the country without legal authorization. This fact transforms them, from the perspective of the administrative apparatus, into illegals, fugitives of the law, and subjects them to a process of investigation and arrest.

The specific conditions under which failed refugee claimants are classified illegals by the State have two immediate consequences on the lives and health of the undocumented people. The first is related to the fact that their lives become subjected to institutional intervention for the rest of the time they live within Canadian borders. Since the very moment in which the CBSA declares their stay in the country illegal, it issues an "active Canada-wide warrant for removal, following a determination that [a person] is inadmissible for failing to comply with the Immigration and Refugee Protection Act"13. Depending on how risky their stay in the country is considered, a determination held by CBSA under secrecy, some of them may be listed on the official CBSA website as "Wanted by the CBSA" section. Because their presence in the country is recorded by a variety of state institutions, the "Canada-wide warrant for removal" makes them targets of surveillance and denunciation by the very same institutions with which the former refugee applicants had established a relationship before being declared illegal. An assemblage of institutions, which includes not only the apparatus in charge of regulating the stay of non-citizens within national borders, but also the police and other federal and provincial institutions, receive information from the CBSA about the fugitive condition of their former clients, and they are asked

\footnotetext{
${ }^{13}$ As read literally from a removal letter that one of the participants shared with me.
} 
to collaborate in case they see the former clients again. Under such conditions, they suddenly become not only illegal, but also fugitives. ${ }^{14}$

The second consequence is equally important. Having been expelled into illegality, the now fugitives are stripped of the formal social protections and benefits they enjoyed while being considered refugee seekers. This situation has an important impact on their lives. By the time they received their removal order, many of them were already active in the legal labour markets, they had relatively satisfied their basic needs for housing, health, food, and formal education in one of the two official languages, access to social networks, freedom of movement within the national borders, and had developed knowledge about, and awareness of, the freedoms and prerogatives that people with permanent residence or citizenship are entitled to in the country. For about 90 percent of the people I interviewed, they also sent remittances on a regular basis to their families, which often include not only their children or spouses (when they were married) but also their mothers and fathers. Stripped of the freedoms and legal prerogatives they once enjoyed, and suddenly pushed to the margins of society, in conditions of illegality and "bare life" (Agamben, 1998), their processes of incorporation or re-rootedness in Canada, and relative social progress, as well as the project they were devoted to, to achieve a better life, were abruptly interrupted. Overnight, they turned, for the second time in their lives, into people dispossessed from material, legal and economic security, and prevented from social participation and social belonging, as well as from access to the satisfaction of the fundamental needs that humans have to live a life in dignity. The first moment of dispossession occurs in their countries of origin when their social,

\footnotetext{
${ }^{14}$ It is important to mention that changes in the political regime during the Donald Trump administration have been made undocumented immigrants fugitives, as by presidential mandate, since 2017 US Immigration and Customs Enforcement has been mandated to arrest and deport school children and any other undocumented immigrant they wish. This is uneven by place, as some States and cities through the US have been resisted those changes by legal means.
} 
personal and material security was interrupted due to displacement, marginalization, poverty, decline in quality of life or violence, and they were directly or indirectly forced to leave the country. The second experience of dispossession occurs here, when the administrative apparatus, declaring them illegal, expels them from legal recognition and subjects them to surveillance and the threat of deportation. Such an experience of twofold dispossession, as will be discussed in subsequent chapters, is felt as a long-lasting experience of defeat and exclusion. As such, it will leave its mark on the bodies and minds of the undocumented workers.

Being dispossessed from social participation in the community means, in the first place, that access to fundamental structures of social protection is withheld from them. For example, hospitals and language schools become accessible only if the fee is paid, although their fugitive-like status also prevents them in many cases from even thinking of the possibility of attending them, unless a life or death emergency arises, as I witnessed in the field. It means also that access to work permits is blocked, and consequently that the person is banned from the regular labour market. As illustrated by Claudia, access to a bank account, official identification, a driver's license, a social insurance number, an account for gas and electricity become almost impossible to attain or to preserve. Equally important, access to food banks or to any other institutional part of the social security system is withheld from them, which makes the situation more complicated, as access to food, shelter and clothing becomes central in a context of joblessness and exclusion from society. Exclusion from society in all of imaginable senses, and subjection to investigation and arrest, make the body and the mind of any human individual or community a natural target of mental and physical illnesses, all of which will be explained in the empirical part of this thesis.

\section{Subjects of deportation}


The experience of defeat, radical social exclusion and double dispossession are not the only factors shaping undocumented workers' structural vulnerability. The condition of being "subjects of administration," exposed to State intervention, transforms them also into persons subjected to investigation and persecution. And this fact in turn makes them permanently face the possibility of apprehension and deportation. Being "subjects of deportation," then, constitutes the third social determinant of health. This situation can be explained as follows. In the field of undocumented workers studies, as I have described in the previous chapter, illegality is depicted, per se, as the main social determinant of vulnerability. But according to my register, illegality per se does not explain with precision this situation. To achieve a better understanding of how vulnerability is shaped and experienced, I believe is necessary to make a distinction between illegality and deportability. The condition of "deportability" - to use the expression coined by Nicholas De Genova (2002), is an immediate consequence of the legal order that transformed the former refugee claimants into outlaws. Deportability is produced by illegalization. However, although intimately linked, illegalization and deportability have different effects on the lives of the undocumented immigrants. Illegalization, as described above, subjects the former refugee claimants to exclusion and to a double experience of dispossession. By depriving them of formal and institutional recognition, and by criminalizing their residence in the country, illegalization denies one of the fundamental elements that constitute the ontological condition of every human being: mobility and the freedom of movement (a condition which precedes the existence of the law, the nation-state and any geographical boundary). And, by doing that, the sovereign power disrespects, disrupts and mutilates the universal character of the immigrants as social beings. It also deprives them of the possibility of belonging to the political community, access to health, labour markets, workers' representation and other forms of social security. 
Deportability has a similarly corrosive impact on the illegalized immigrant. But such an impact is of a different order, and also has a more direct consequence on the bodies and minds of the illegalized subjects. Deportability, in so far as it is the result of a legal maneuver ordered by the State to expel the immigrant who has defied its sovereign power through the appropriation of her or his fundamental faculty of movement, involves the subjection of the "illegal" migrant to a variety of policing dispositifs and other disciplinary, law-enforcement technologies; that is, it subjects the illegalized immigrants to techniques of investigation, surveillance, persecution, apprehension, imprisonment and, eventually, deportation.

The condition of deportability, as the case of Claudia has shown us, has an impact on the illegalized immigrants at the level of their subjectivity and also at the level of their objective conditions of existence. At the objective/material level, the condition of being subjected to police investigation and to the possibility of entrapment and deportation has the effect (in the eyes of the persecuted subject) of extending the border or making it proliferate. Living under the threat of being trapped and deported means that, for undocumented immigrants, the border becomes more than a line that demarcates the limits of the region and the political community, real or imagined, from where the illegalized person has been banned. Due to the existence of an arrest warrant that is meant to be enforced by the police at any time, and also due to the potential possibility of being discovered, trapped and removed, the border appears everywhere. The border is there in the hospital, preventing them from access to health care; it is there at the school denying them access to education; is there at the factory, preventing them from access to a minimal living wage and representation; it is there at the corner every time they try to cross a traffic light (the point par excellence where they are trapped nowadays); it is there at the street, any street, where they are 
walking at night after visiting a friend or exploring a bar; it is there at any place where there is someone who may know their condition of "illegal" and may report that to the police; it is there in the morning, at lunch time, at night or during the day, at their department, or at the street, any of them, on the way to work. The border is there, here, everywhere, reminding them every day that, as outlaws subjected to investigation and persecution, they can be arrested, imprisoned and deported at any time. This situation transforms them into captive subjects, bare and vulnerable bodies that wander in the shadows with no formal presence and diminished social power.

At the level of the subjective conditions, on the other hand, the condition of deportability has the effect of crafting an anxious and fearful subjectivity. Insofar as the condition of deportability implies the possibility of being removed from the social space that the immigrant has chosen to live in, for whatever reason, as the best amongst the actually existing options, the fear of being trapped and deported produces a subjectivity that is fearful of the law, of the authority and the legal-administrative structure that is searching for their removal. There is so much to lose if deported, which breeds fear. It makes sense. Being caught and expelled would mean, above all, that the crisis of social reproduction and the need for human security that pushed them to emigrate will be re-established. It would also mean that the pursuit of a better life, or a life that is better than the one they had back home, will again be interrupted.

The fear that is produced by the recognition that, at any given time, they can be expelled from the place which they have chosen to live, reminds them that their entire family's living conditions can be affected in a negative and irreversible way. This produces great anxiety. But fear also affects the perception they have of themselves, because, in their mind, as I was told several times, persecution should only be used against people who have done damage to the community. 
Therefore, the recognition that they are being investigated, persecuted and subjected to the possibility of arrest and deportation reminds them of their status as criminals, outsiders, outlaws and therefore of their current social undesirability. This situation in turn pushes them to the recognition of their condition of social worthlessness. Finally, being "subjects of deportation" pushes them to hide and to live at distance from, or outside of, society, all of which confines them to social isolation, deprives them of social power, and subjects them to further social precariousness.

The intensity of how the condition of deportability is experienced, and therefore the effects that such condition has on the undocumented communities, at the subjective and at the objective level, changes over time. Unlike the condition of illegality, the condition of deportability can vary in intensity over time. Illegalization, insofar as it is caused by an expulsion of the subject from the legal structure, has a static and inflexible character (people can just live inside or outside the law, without exceptions) and that very fact has the effect of keeping the illegal subjects outside the political community in a permanent, stable way. The condition of deportability, on the contrary, insofar as it is dependent on the will of the sovereign power in order for the law to be enforced, intensifies or diminishes according to the time or the political and ideological conditions that are present in society. In other words, "illegal" people are not always submitted to the same conditions of deportability, as, if the political climate is favourable, they could even be being tolerated and respected in their existence within national borders, as the DACA program in the US exemplifies. Hence, time and context are relevant, and this was reported often by my interviewees. The people I interviewed, with few exceptions, lived the experience of being subjects of deportation at a particularly challenging time. Approximately three quarters of them received their removal or deportation order under the government of Stephen Harper. Under that government, some groups 
of immigrants, particularly Mexicans and Roma people, were transformed into objects of discourse and represented as "bogus refugees" and "cheaters of the system" (Molnar Diop, 2014; Park 2013; Silverman, Beaudoin \& Arbel, 2013). This element, along with all the changes that the immigration system has undergone under the last decades, acquiring an anti-immigrant tone most of the time (Beiser \& Bauder, 2014; Chase, 2014; Ibbitson, 2014), has made the undocumented workers experience deportability with greater intensity. They are living as outlaws in a historical moment in which a vast number of people are arriving as refugee seekers and a significant percentage of the local population have been developing anti-immigrant sentiments, as evidenced by the $253 \%$ increase in hate-related crimes against Muslims and other migrant populations over the last four years (Statistics Canada, 2017; Minsky, 2017), and as evidenced by the fact, as recent poll found, that almost 50\% of Canadian population want "illegal" cross border immigrants to be deported (CBC, 2017). They are also living as outlaws in a period of time in which immigration controls have become stricter, migrant detention centers have expanded dramatically, and in a time in which the scrutiny, surveillance, prosecution, detention and deportation of illegal immigrants have become an important priority to political elites and the Canadian State (Beiser \& Bauder; Canadian Association of Refugee Lawyers, 2014; Molnar \& Silverman, 2017; Silverman, 2014). All of those changes have made their experience of illegality particularly intense.

The importance of looking at the historical context when considering deportability as a social determinant of health was pointed out to me by an Algerian comrade, a veteran of the struggle for regularization in Canada. While I was helping to facilitate a workshop on "Solidarity as social determinant of health" organized by Solidarité sans frontiers in the summer of 2016, he shared in that event that during the struggle of the Algerians for their regularization, one of the factors that favoured their "getting together" was that the political climate was not so unfavourable for the 
immigrants at that time. Getting together for a struggle made them more able to socialize, practice solidarity and mutual aid, offer support, etc. That situation was "incredibly good" for them in terms of health, he remarked. "You could always get solutions to your problems of money, loneliness, food, housing, job... and all what we have discussed here" he stressed. He also mentioned that, unlike those times, it is clear now that the struggle itself is for making people get together, as the anti-immigrant social prejudices and fear of deportation prevent the undocumented from even attending social events, not to mention political rallies. This is because, he says, the State is now working harder to keep the undocumented out, and there are police and surveillance cameras "par touts les côtés" which keep many of them immersed in clandestinity, isolation, mistrust, fear and anxiety. It is for this reason that, I believe, being subjects of deportability in this particular historical time must be considered a third master determinant of health.

\section{Subjects of racialization.}

The fourth social determinant of health for the Latin American undocumented workers is linked to ethnicity, being subjects of racialization. The undocumented immigrants I met and interviewed during my fieldwork, through whom I met other several dozens of undocumented workers in the underground labour market, have a mestizo or Indigenous, non-European, ethnic profile. Most of them are brown skinned and have Indigenous phenotypes. That itself creates a challenge for them in terms of navigating through cultural and ethnic politics in the society they currently live in. By this I don't mean that the non-white, non-European ethnic identity is a problem in itself. What I mean is that the ethnicity, skin color and cultural traits of the Latin American became a "problem" due to the ethno-racial dominant criteria that exists in Canada, particularly in Quebec, their host society. By coming from non-white societies and inserting themselves into a society which, although ethnically diverse, is organized according to the hegemony of whiteness (hegemony that 
has been historically built upon domination, incorporation or even extermination of non-white populations), the Latin American immigrants, racially mixed and baroque in their cultural traits par excellence, face ethnic-based forms of structural subordination.

Such an ethnic subordination socially structures a form of repressive tolerance in the very form defined by Marcuse (1969); that is, a form of social tolerance which allows the presence of the Latin Americans, particularly of those more indigenous in their phenotypes and identities, as long as their express submission and alignment to the hegemonic moral and aesthetic values and behaviours imposed by the hegemony of whiteness. I use the term whiteness here, or blanquitud in Spanish, to refer to the historical social formation under which the subordination of "non-white" ethnic identities in Canada is structured. I use this category for an epistemological reason. From the standpoint of the theorizations elaborated by critical theories on race and ethnicity (ethnic and race studies), interpersonal or structural racism is often defined as a form of domination, exclusion or violence carried out against people based on the characteristics of their skin colour. In this view, racism constitutes a form of violence, whether structural or interpersonal, committed against nonwhite, "coloured" people. Unlike this colorist and dermopigmentist scholarly representation of racism, the concept of whiteness that I use here recognizes that, in addition to those forms of subordination and domination that are organized according to, and justified in the name of, an arbitrary hierarchization of human beings based on their skin color, it refers also, in a broader sense, to the ethical and aesthetic criteria that was moulded within a broader civilizing project, under which the current hierarchization of human beings was founded. Therefore, this concept of whiteness, which I borrow from Latin American critical theorist Bolivar Echeverría, refers not only to the ideological structure that organizes an overvaluation of people based solely on their white skin color, but also on the set of behaviours, values and ethical and aesthetic criteria that 
capitalist modernity demands from human beings as a necessary condition for being considered worth of respect, recognition and inclusion (Echeverría, 2010: 67). The hegemony of whiteness in its present form was born in the context of capitalist modernity. The moral values associated with the hegemonic notion of whiteness are: asceticism, sobriety, frugality and self-restraint in behaviour; devotion to productivity; moral purity; submission to instrumental rationality; selfinterested calculative behaviour, and a Puritan conception of order and hygiene. As these values correspond to the values and practices of the Puritan and Calvinist ethics that have moulded the "spirit of capitalism," they are all related to the civilizational project which was born out of capitalist modernity. And although such aesthetic and ethical values were historically created in a particular region of central and northern Europe, they became universal through the processes of capitalist expansion throughout the world via colonization, slavery, war, dispossession and genocide. Within our current civilizational order, which imposed the hegemony of whiteness, to be white (that is, to have a white skin) is not a sine qua non condition that a person must have in order to be recognized as a "full human being." Whiteness must be shown through behaviour also. This means that "coloured" people can also be granted with full recognition as human beings and treated as equals, respected, and not subordinated, provided they show before the eyes of the others that they have a white subjectivity and a white behavior. ${ }^{15}$ To sum up, capitalist modernity has been constituted by, and has also been constitutive of, the current form of racism underpinned by the ideology of whiteness, a form of racism that organizes privileges according to morals, aesthetics, behaviours, and also skin color (Allen, 2012; Echeverria, 2010; McIntosh, 2004; Roediger, 2007).

\footnotetext{
15 This is a not a rhetorical statement. The possibility of being granted with a certificate of whiteness for some "races," is as old as colonization. For example, in 17th-century Spanish America, the colonial authorities could recognize a person as "white" if the person had the means to purchase a "Gracias al sacar" certificate (Twinam, 2015).
} 
John Porter (1970) has elaborated the most sophisticated account of the specific mechanism by which the hegemony of whiteness has been historically instituted in Canada. In the third chapter of his masterpiece, The Vertical Mosaic. An Analysis of Social Class and Power in Canada, Porter explores the issue of class formation in Canada and the role that ethnicity has played on that process (68-98). He explains that, historically, the defeat of the First Nations led to the hegemonic consolidation of two "charter groups" whose historical origin is European: the English and the French. Those charter groups have since lead the process of class formation along lines of ethnicity. Ethnic identification with the charter groups is the mechanism by which this process has occurred. During periods of economic growth, these dominant charter groups have historically incorporated people from different ethnicities to carry out those economic projects as immigrant workers. They have also defined which kinds of labour the immigrant workers will carry out. Ethnic identification defines the entrance status and delineates the structure of classes in Canadian society along racial and ethnic lines. Ruling elites have historically provided Caucasian immigrants (immigrants of their own ethnicity) with better entrance positions. Unlike those coming from white European origins, immigrants from non-white ethnicities have been assigned the lower positions and received few or no opportunities to settle in the country and become better off. The waves of migration have only perpetuated race-based class formation in Canada, as every time new waves of immigrants arrive imported or attracted by periods of economic boom, they tend to be selected by the same elites, charter groups, who continue assigning status based on ethnicity and country of origin. Racial ideologies, Porter points out, have been used as master mechanisms to justify the inclusion or exclusion of non-white immigrants (61-67) into Canadian society.

As such, racism has an important effect on migrants coming from societies whose moral values, forms of behaviour and phenotypes are less compatible with the ethical and aesthetic criteria that 
capitalist modernity has universalized. The people who have a language, a skin color, a religion, a form of behaviour, a way of life and a generally "non-white" ethic and aesthetic image, are transformed into objects of discourse, a discourse that defines them as "other," as "different subjects" (Lawrence, 2004; Thobani, 2011). Based on such cultural representations, they are also subjected to an array of social and institutional practices and rituals (in the workplace, in society, in special state policies), as well as to processes of racialization, incorporation and subordination, all of which include forms of exploitation and misrecognition in the workplace, social disrespect, as well as exclusion from the juridical structure and the political community.

Racism in the form of fear, intolerance and sometimes even social hostility in everyday interactions is also another obstacle they face. This has been particularly evident during the last three years, in which racism has risen to an alarming rate. This is far from being an overstatement. The recent study carried out by Radio-Canada and CROP, "Les canadiens, le populisme et la xénophobie" (Radio-Canada, 2017; Radio-Canada and CROP, 2017) revealed that 37 percent of Canadians who were interviewed about migration and ethnicity expressed "strong fears" with regards to the arrival of recent immigrants from "non-white" countries. Such fears are shaped by the fact, the study reveals, that they believe that the new influx of immigrants jeopardize the "racial purity" of the country. Almost fifty percent of the people who were interviewed are "not white." The data revealed by CBC's survey on public perception on immigration is even more disturbing if we include also the percentage of people who feel "moderate" fears with regards to the arrival of immigrants to Canada and also those who, holding greater anti-immigrant positions, declared themselves to be "completely opposed" to immigration because they consider it a threat to the safety and purity of the country. Thus, if we include the first and the second group of people, we would realize that, in fact, the number of Canadians who are anxious about the supposedly 
damaging effects that the arrival of immigrants would have on the country's "racial purity," represents approximately $70 \%$ of the population. Among them, $23 \%$ would agree with a government ban on the arrival of Muslim immigrants to the country. Furthermore, in Quebec, the province where my ethnographic work was carried out, we have witnessed the aggressive emergence and repositioning of anti-immigrant movements aimed at the defense of white supremacy and racial purity. Such organizations (La Meute, Pégida and Atalante Quebec), which unapologetically defend white supremacy are quite popular among the white Quebecers and also among some "people of colour" (CBC, 2016 and 2017). Terrorist attacks against the Muslim populations, some of them resulting in assassinations, have been perpetuated by white supremacists (CBC, 2017). We have also witnessed the ascendancy of white supremacist ideologies dispersed and legitimized in society through discursive, political and juridical means. For example, since 2014, the government of Quebec has been promoting the defense of the "Quebec charter of values," a legal reform which was designed to safeguard what the cultural, economic and political elite understand as "Québec values," and which, despite being animated by racist prejudices, have proven to be very popular, even among the subaltern people whose mother tongue is not French (Birge, 2014; Leger et.al 2013: 10; Melançon, 2016; Stasiulis, 2013). The same has occurred with the recently adopted Bill 62. Under such a law, the province of Quebec bans cultural forms and practices that are considered "serious attacks" against the local culture and its moral values, such as the wearing of non-Western clothing and others non-Christian religious symbols, which especially target Muslim women to the point of creating health-related risks for them, as sociologist Gérard Bouchard and philosopher Charles Taylor have identified (CBC, 2017a and 2017b). 
The hegemonic social representation which portrays immigrants coming from "non-white," nonwestern societies as a threat to an imaginary racial purity and to an allegedly superior set of local values, not only creates fear, mistrust and even aversion toward the immigrants of colour. It also creates a set of subordinating practices at other levels of society, which have the final effect of assigning to the racialized immigrants the lowest positions within the social structure. Subordination and exclusion, in turn, have the effect of preventing the immigrants from having access to basic forms of social recognition, inclusion, integration and support, as well as to decent forms of life. Official statistics (Statistics Canada, 2017) that analyze the trends of immigrant arrival to Canada, as well as their incomes after the second year of arrival according to their country of origin, ethnicity and mother tongue, reveal how the Canadian State and certain sections of Canadian society position the immigrants within their socioeconomic structure, and how the stratification of society is organized along lines of race and ethnicity. Overall, the statistics reveal that since the 1980s, until 2017, the average income of the immigrants after the second year of their arrival has declined significantly during the last three decades. This decline in incomewhich is always a predictor of poverty, marginalization and lower status in society—was inversely proportional to the increase in income the immigrants who arrived in Canada from white, European societies. For example, in the early 1980s, a time in which the immigrants used to come in a larger percentage (almost 50\%) from countries of central, eastern and northern Europe, and from the United States, the average income after the second year of their arrival was the highest the immigrants have ever had during the last three decades. Conversely, the average income of the immigrants after the second year of their arrival has declined drastically as the ethnic profile of the migrant population diversified since the early 1990s. From that time on, immigrants have come predominantly from Africa, Asia, Latin America and the Caribbean, not from Central and Eastern 
Europe or the United States. For those reasons, being "subjects of racialization" is considered another master determinant of health when studying undocumented immigrants from Latin America.

\section{Subjects of exploitation}

Exploitation as a social determinant of health has been studied by the structural determinants approach. According to this perspective, the health of working people is mediated by the unequal access to the control of the means of production. The lack of control of the means of production determines, in the workplace, the subordination of the workers to the managerial class, thereby weakening the workers' ability to control their working conditions, and the peace under which work is carried out. As a consequence, workers become more exposed to hazards, overwork and work-related accidents (Muntaner et.al. 2015; Muntaner et.al. 2013; Muntaner \& Lynch,1999; Resnick \& Wolff 1982). As a social determinant of health, exploitation has also been studied through the category of inequality. Understood as the product of class domination relations, through policies that exacerbate social inequalities, exploitation translates into income inequality that deprives the working class of having access to the material resources that are indispensable to health: good quality food, decent living, housing and living conditions, quality Medicare, among other determinants of health (Raphael, 2009, Muntaner, 2012; Navarro, 2001; Navarro 2009). This perspective on exploitation and class-based domination is well expressed in the eloquent phrase by Vicente Navarro, a leading proponent of this perspective: "It is not inequalities that kill, but those who benefit from the inequalities that kill” (Navarro, 2009:16). 
Those two interconnected ways of framing exploitation as a social determinant of health are relevant to this study. In Canada, undocumented populations have no access to labour representation and, thus, have little or zero control on the labour processes, are paid low wages, and are excluded from the public health care system (Bernhard et. al 2007; Goldring \& Landolt, 2013; Magalhaes, Carrasco \& Gastaldo, 2010; Rousseau et.al. 2008; Saad, 2013; Simich, Wu \& Nerard, 2007; Villegas, 2013; Villegas). They become easy targets for exploitation in their workplace and are more prone to class-based marginalization, both predictors of poor mental and physical health.

For the ends of this study, this approach has some limitations. Seeing exploitation as exclusively mediated by the workplace, the labour market and by social inequality does not help to understand the conditions by which the workers, even doing the same type of jobs, are unevenly exposed to exploitation and therefore, to different health outcomes. How and to what extent do the workers' legal status and ethnicity, for example, determine both their incorporation under exploitative labour processes and their very responses to exploitation? I believe that, in order to understand the particular ways in which exploitation determines undocumented workers' health in Canada and in other late or advanced capitalist societies, it is necessary to consider the global context of political economy that make possible the existence, in the first place, of undocumented labour migration and, therefore, their incorporation into, and navigation within, exploitative labour processes. For this, I will use the category of "global exploitation," developed by sociologist Pablo Gonzalez Casanova (2017:171-194).

In the classic formula developed by Karl Marx, under which the social determinants of health approach succinctly described lines above was developed, exploitation was understood as a social 
relation of class domination which occurs at the point of production and is mediated by the labour market. Developed upon the value theory formula as theorized in "the concept of relative surplus value" (Marx, 1999 [1867]): 429-438), according to which value is the result of the socially necessary labour time invested in the creation of value exchange commodities, exploitation (that is, the appropriation of surplus value at the expense of labour) was achieved through: a) the lengthening of the working day (the creation of surplus labour) and b) labour intensificationwhat Marx called the "increasing production of surplus value through increasing productivity" (435). In this conception, intensification of labour and its precarization are socially necessary conditions for the accumulation of capital, and they lie at the very core of the conditions that determine the working conditions and the health of the working population.

But, as it was developed at the beginning of the development of historical capitalism, and as it ignores the colonial relation between the core countries of the world system and its periphery, this account of exploitation is limited. As theorized by Gonzalez Casanova in La sociología de la explotación (2017: 176-179), the appropriation of surplus value in contemporary capitalism is no longer exclusively mediated by the labour market, nor is it achieved solely through labour intensification and increasing labour productivity. Exploitation nowadays is "global" because it occurs both in the workplace in relation to waged labour and outside of the workplace in the form of south-north appropriation of surplus value via "value transfers." Those are: 1) transfers of raw material from the periphery to the core countries, 2) south-north value transfer through the collection of debt payments, and 3) surplus labour transfer in the form of south-north migratory flows. It is global also because, facilitated by such an assembly of surplus value mediation mechanisms, exploitation has led to the global or holistic dispossession of the working and nonworking population, principally, but not only, in the periphery of the world system. 
Global or holistic exploitation has created a mass of dispossessed people who are submitted to a generalized crisis of social reproduction ${ }^{16}$; that is, to a critical situation in which those deprived of nutritious food, housing, clothing, education, health care, freedom, societal support, stability, love, respect and moral recognition find it challenging to care for each other, to sustain life and to reproduce themselves as a species, both socially and biologically. Subjected to a generalized crisis of social reproduction, the mass of dispossessed, disposable people who are transferred as labour commodity to the global north show a structurally induced disposition to be exploited through a continuous demand for jobs with little engagement in forms of class-based resistance.

It is important to think of exploitation in this way because it conforms to the material base upon which the working and non-working population in the periphery is transferred and incorporated into the core countries of the world system. It is important also because it helps us to see how the generalized crisis of social reproduction that "global exploitation" has made possible produces both the assembly of a labour force that has been uprooted and made mobile within the new geographies of capital, and a workers' subjectivity that makes them willing to work, eager to be exploited, wherever is possible, in conditions that are optimal for the employers.

The crisis of social reproduction that stems from global exploitation makes workers vulnerable and more willing to submit themselves to radical forms of labour exploitation. For this reason,

\footnotetext{
${ }^{16}$ As defined by feminist political economists, social reproduction includes "the social processes involving in maintaining and reproducing people, specifically the laboring population and their labour power on a daily and generational basis" (Luxton \& Bezanson, 2006:3). Following this rationale, I define the generalized crisis of social reproduction as the condition in which those excluded from the material and cultural resources needed to sustain and reproduce life, find challenges to reproduce themselves as social and biological beings on a daily and generational basis.
} 
being "subjects of global exploitation" constitutes the fourth master determinant of health for undocumented workers. How is this related to health?

First, by being deprived of legal recognition and the right to belong to the social and political community in which they are incorporated, and also by being subjected to deportability, their alienation from basic foundations of social security in Canada becomes extended and intensified. This situation prevents them from having access to institutionalized social solidarity programs to get by during times of unemployment (such as unemployment insurance or social assistance) and excludes them from society. It also forces them to live under conditions of often deep material precarity and insecurity. Second, in such conditions of restricted mobility and social exclusion, the crisis of social reproduction they are used to, under "global exploitation," becomes extended and intensified, which makes them subject to a structurally induced incapability to sustain and reproduce human life, both socially and biologically, on a daily basis.

The crisis of social reproduction subjects them to a daily struggle for material survival and to remain within national borders. This condition of being engaged in a daily struggle for material survival and geographical sovereignty is at the basis of their migratory experience and should not be overlooked. Under this permanent "state of emergency," to put it in a Benjaminian way (Benjamin, 1969 [1955]: 257), the undocumented immigrants find no stronger allies than wage labour. This fits perfectly with the needs that certain branches of local industry have for a cheap, docile, flexible and disposable labour force. Their incorporation into the labour market, therefore, is highly profitable for capital, as the work they do, if assigned to the local white population within the framework of its real historical value, would have to be for much higher wages. This structurally induced necessity of the immigrant workers to keep themselves inserted in the labour 
market, coupled with, on one side, a labour market with a surplus of undesirable and precarious jobs and, on the other side, a dominant representation in Canadian society which racializes the non-white immigrants arriving from the global south, produces the social conditions that keep the labour power of the undocumented worker in a condition of devalued commodity. In that condition, dispossessed of social power, racialized, and possessing nothing but their devalued labour power, the undocumented worker carries out all kinds of necessary but undervalued and risky jobs that the local population is not willing to do. The real consumption of the undocumented worker by capital, under such conditions, makes the worker develop an enormous dependence on wage labour in the most precarious and exploitative form. This is what makes the undocumented workers "subjects of exploitation." 


\section{Part II:}

The Wounds of Labour 


\section{Wounded Subjectivities: Abstract Labour, Uprootedness and Mental Suffering}

Conducting my fieldwork, from the very beginning, was not an easy task. Through the first six months of exploring the city, visiting organizations and searching for places where I could find people to interview, I heard difficult stories. They were all stories of pain and sorrow. In the Immigrant Workers Centre, for example, I saw a woman and her child in pain, crying for her partner and his father. He had been arrested. I saw a man searching for a place to rest. He had left everything behind after his friend got arrested as well. I also saw tiredness among those who were there just to see if they could get legal help, or a letter, to convince the judge that they were good people and deserved to stay in Canada. I saw three women talking to the press about their fragile lives while asking for status.

Though all tragic, they were stories of people sticking together, looking for help, meeting with others, talking to the press and doing something for change. That image changed when I met Mateo and got into his world.

I met Mateo in a supermarket in Côte des Neiges. Mateo was carrying two large black plastic bags with aluminum cans inside. He collected cans and recycled them in the supermarket's recycling machines. Mateo's bags fell, and the cans scattered on the ground. I helped him to pick them up and we started to get to know each other. Two months later, he invited me to his house, where we eventually lived together for a year. With Mateo I discovered a world that I had not seen before. It is a world far from the world of the social organizations where people go to seek support, mourn their sorrows, talk to others or demand change. 
In Mateo's world, there is no time to visit organizations. There is no time to complain. There is no time to make friends. In that world you cannot waste your time. "They do not let you." The world of Mateo is heavily governed by the clock. There are foremen; there is a lot of work. There is no time. There are not many friends, but only "conocidos" (acquaintances). You cannot trust people: they will betray you; they will want to abuse you; they will take advantage. "You have to be discreet. There's a lot of snitch. Latinos are the worst. Better to get to work: From home to work, from work to home. There is no other way."

Mateo has many "acquaintances," and a few friends whom I also met. In Mateo's world, they all look alike: They speak little, they do not complain much, they do not organize, and they do not believe in those who organize. On weekends, to distract themselves, they often stay at home to have a few beers, or to watch TV. The world of Mateo is a world full of people, but very lonely. It is an underground world. It's a world of work; a world of brokers, a world of agencies, of heavy work, of a lot of work. Heavy work all year. It is also a world of wounds; wounds on the body and wounds on the soul.

When I started doing my field work, I discovered a tension among three social forces. The first, represented by the State, works to remove undocumented people from Canadian society. The second, represented by social organizations, works to incorporate immigrants into society in conditions of dignity. The third, represented by capital and its foremen, works to incorporate immigrants into abstract, alienated labour. This chapter explores these opposing forces as well as the effects that they have on the structures of socialization, social integration/uprootedness and the structures of feelings. 
Uprootedness, understood here as the physical and mental state that displaced persons endure as a result of "the loss of what they have known as "home" (Berman et al, 2009:419), is a common self-identified experience among an important number of the undocumented workers living and working in Greater Montreal whom I interviewed. This state, which often manifests in selfestrangement and discontent, is often created as a consequence of a progressive deterioration of the ties and relationships that the undocumented immigrants had with their families, friends, social networks, cultural symbols, and experiences in their countries of origin, all of which used to provide meaning to their identities and narratives as human beings. It is also produced as a consequence of a set of legal, economic, political, cultural and affective barriers that the undocumented immigrants face on a daily basis, all of which keep them excluded, trapped in social isolation, and prevents them from substantial integration or re-rootedness in Canadian society.

But, although powerful, the condition of uprootedness and dis-integration from Canadian society among the undocumented immigrants describes only one part of the equation. When we look at their lives more closely, it is possible to realize that they live immersed in a whirlwind of social forces that, in a contradictory way, incorporate and uproot them, recognize and misrecognize them, include and expulse them, simultaneously, from Canadian society. This dialectical, tense and contradictory process is so present and has such a powerful influence on their life experiences that it tends to structure their health and illness trajectories, both in terms of their bodies and of their minds.

This chapter tries to shed light on that situation by examining the social mechanisms through which the undocumented workers are either incorporated into or separated from Canadian society and by analyzing the effects that such a situation has on the ordering of their subjectivities, social 
alienation and mental suffering. First, it describes the migrant workers' experience of social uprootedness, as well as the effects that such an experience has on the ordering of their subjectivity, forms of socialization and mental suffering. In doing so, it explores how the structure of feelings that is crafted in the context in which the undocumented workers live. Second, the chapter explains the material conditions shaping the experience of uprootedness and the structure of feelings is crafted in such context. After locating employment agencies as the dominant mechanism by which the undocumented workers are subsumed (or integrated) by capital and incorporated into the underground labour market, it argues that this dominant mechanism of labour incorporation significantly contributes to the uprootedness, and social exclusion/separation from the social and cultural life of Canadian society. By empirically describing and analyzing the labor dynamics in three types of companies that employ undocumented workers (A.--Multinational corporations, B.-Medium-size local enterprises and C.-Underground Workers Cooperatives), the chapter shows that the undocumented immigrants are more likely to socially and culturally re-root into Canadian society when they work for the underground self-subsistence workers cooperatives. In contrast, undocumented workers inserted in the medium-sized local enterprises or multinational corporations, tend to stay trapped in deeper forms of uprootedness and segregation from Canadian society. The chapter concludes with the proposition that the formal subsumption of labour by which capital integrates the undocumented workers into the wage system and existing labour processes (fundamentally using forms of abstract labor), mediated mainly by recruiters and employment agencies, is the main factor that contributes to the uprootedness, estrangement and mental suffering of the undocumented workers. Unlike them, undocumented immigrants who are incorporated into underground self-subsistence micro enterprises under concrete, creative, and non-waged forms of labour, find more objective possibilities of social incorporation or re- 
rootedness into Canadian society, as well as more possibilities to achieve some degree of respect, moral recognition, and emancipation from suffering.

\section{1. "Down and Out" in the Great White North ${ }^{17}$ : The experience of uprootedness}

In physics, disintegration refers to the process by which individual parts which originally belonged to a whole entity are separated and torn apart from it. It also refers to the process by which an individual unit suddenly or gradually falls apart or collapses into many other parts. This happens because the process of separation has a debilitating effect on the whole unity that was originally constitutive of, and constituted by, individual parts. In the first case, the process of separation weakens and disintegrates both the system to which the separated part belonged, and the part which was separated from the system, due to the absence of points that support them. In the second case, the total or partial separation of one individual part, which belonged to a whole, into several other pieces leads to its weakening or collapse.

For the undocumented workers, the experience of social dis-integration and uprootedness is expressed in a similar way, although this must be seen in a transnational context. As they are subjects who have ties to two social spaces (their country of origin and Canada), their social uprootedness is expressed as a twofold process of structurally-induced social separation. They are separated, first, from the most fundamental social units to which they originally belonged in their countries of origin: their domestic units, their social networks, and also the symbolic referents which shaped, in the past, their identities, and delineated their biographic individual narratives. They are also separated from the host society.

\footnotetext{
${ }^{17}$ I borrowed the expression "Down and Out" from the book Down and Out in Paris and London by George Orwell (1930 [2013]).
} 
This experience of having been uprooted or separated from their home society, as I learned though my interviews and observation, deepens over time, to the point of reaching deep levels of estrangement and separation also from both the former home and the host society. In fact, one of the things that I could see during my field work was that the undocumented workers who live and work in Montreal live in a state of such social isolation and estrangement as individuals (or in isolated small groups) that, it can be said, they live "down and out" both literally and figuratively. They live down, literally occupying the lowest positions in the economic and political structure of Canadian society, which forces them to live in conditions of extreme poverty (with a median income of no more than 1,350 dollars per month, according to my records ${ }^{18}$ ), and also with a diminished moral status, as they are deprived of minimal institutional recognition, face expulsion and persecution from the State, and are often mistreated and exploited in the workplace. They live also out. By this I mean that they live plainly as outcasts, legally expelled from society, facing deportation orders, isolated, and never fully rooted into the local society in material, political, cultural and legal terms.

Furthermore, although most of the undocumented workers I met during my fieldwork have been living in Canada for an average of nine years, all of them live underground and most lack meaningful relationships, beyond the friendships they precariously develop while living in the already segregated ghettos. Also, with the exception of seven cases (whose extraordinary lives will be described in the very last part of this chapter), a great majority of them face communication

\footnotetext{
${ }^{18}$ According to the data on income that I collected through the interviews, the lowest income that a worker earns is 700 dollars per month and the highest income is 2,000 dollars per month. The workers who reported the lowest income tend to be mostly women who work on a casual basis doing house cleaning or men doing industrial cleaning on a casual basis for multinational corporations, while the workers who reported the highest income tend to be women and men working on a full-time basis in assembly lines or in agriculture. Because the individual income tends to vary throughout the year, as in the underground labour market jobs tend to be temporary or seasonal (even when they are full time), I calculated the mean income per year per each individual worker.
} 
challenges; that is, not only do they speak in a limited way the two official languages spoken in the country, or the city in which they live, but they also lack knowledge of the dominant communicative styles in the host society. This is perhaps the most serious of the limitations they face, as it creates enormous challenges in the process of incorporation or becoming re-rooted. In the same line, a great number of them reported having no Canadian-born friends (by which they normally mean Caucasian friends) and feel alone, "invisible" and ignored by local society. Essential aspects of the local culture, such as the functioning of institutions, the cultural norms, etiquette and rules of social coexistence, the debates and political / cultural disputes that are held in the community, the history of the country, the local geography and their own neighborhood and its symbols are often strange to them. In addition, the understanding that their status as "illegal immigrants" makes them subject to persecution, detention, and deportation, often makes them to hide and to rationally decide to live a life in the underground, furthering their isolation and calculated separation from local society. Overall, they live, then, "down and out," broken, cast out and troubled. How does this happen and what are the effects that such a situation has on the subjectivity and wellbeing of the undocumented workers?

\subsection{Uprootedness, structures of feelings and mental suffering: Nostalgia, sadness, pride in oneself and rage}

According to the interviews conducted, the experience of poverty, estrangement and separation from society that is generated by living in the middle of this ongoing detachment from what once they were, the gradual collapse of their most vital affective and symbolic networks, and the unmet universal human needs for belonging to the society in which they currently live, leaves an important mark in their individual subjectivity and in their social practices. At the level of subjectivity, the experience of social dislocation or uprootedness organizes a particular mood or 
state of mind that is predominantly underpinned by four types of emotions: nostalgia, sadness, pride in oneself, and anger. These emotions are not, of course, the only ones that are present and alive in their inner lives. They coexist along the rest of human emotions in a complex, mutually reinforcing and dynamic way. But, as I registered during my field work-work which involved putting my own body and mind in the center of my field work experience-nostalgia, sadness, pride in oneself, and rage are the emotions which predominantly mark their mood. According to my records, nostalgia and sadness are the emotions that are most present in the lives of the Latin American undocumented immigrants.

Certainly, during the course of the interviews and throughout the moments I registered in my field diary about their life trajectories and the material and emotional environment we lived in, I could see that, with the exception of the newcomers, most of the people I interviewed, particularly those who have been living in Canada for more than five years, live their lives chronically longing for the past, though they never do it in an uncritical way. What is missing in their lives is not so much the labour dynamics or the material conditions in which they used to live in in their countries of origin, nor quite often even the family relationships they used to have back in their hometowns. In the end, almost all of them had had unpleasant experiences in those areas, especially in the time almost immediately before they decided to emigrate. What is often missed, in fact, is a set of life experiences, symbols and relationships that used to provide meaning and a sense of coherence to their individual identities.

Nostalgia, that bittersweet feeling that arises from the experience of longing for the past, is expressed through repetitive rituals that reify and actualize symbols, social practices and ways of feeling that are assumed to be typical of the society one comes from. Similar to what has happened 
among earlier waves of immigrants (Higgs, 1982; Teixeira \& Da Rosa, 2009; Sakamoto \& Zhou 2005; Agnew et. al., 2005), among the Latin American undocumented immigrants, nostalgia is ritualized through a compulsive consumption of movies and television series, music, recipes and meals that are considered typical from the "country we come from," as well as through ways of dressing or ways of expressing feelings and emotions that are thought to be substantial part of "who we are." It is also expressed through repetitive comparison and contrast between that which we once were (or what we once had) and that which we are (or have) today. As such, nostalgia has a major impact on the undocumented migrant's experience of uprootedness.

How does this happen? In Canadian society, as in most countries that are high recipients of immigrants, the nostalgia of the immigrant is mediated by a cultural industry that produces and offers in the market all sort of fetishized commodities that are useful for ritualizing nostalgia. This capitalist mediation of nostalgia, often supported by what in marketing and development literature is called "ethnic marketing," "nostalgic trade" (Newlan \& Taylor, 2010; Orozco, 2008; Debass, \& Orozco, 2008), or by the constellation of "ethnic stores" led by the Latino immigrants themselves, shapes the way by which the "illegal" people deal with the feeling of yearning for home while living in Canadian society. In effect, as the undocumented immigrants live under chronic economic limitations and suffer from very limited access to the commodities offered by "nostalgic trade," they tend to ritualize and cope with the feeling of nostalgia by making use of cultural resources at hand, which lack exchange value, and which did not have to be bought in the market. They then tend to resort, for example, to the repetitive revindication of ways of being and ways of feeling that are consistent with what forged them as human beings back in their places of origin. They use phrases, verbs and expressions that are (or were) common in the places they grew up; they prepare dishes in the way they are prepared in the places "where they come from"; they listen to music 
from their regions of origin. And always, in a compulsive way, they reclaim a "way of being," a sensibility and a particular way of expressing feelings and emotions. This assertion or revindication of a way of being that is one's own, insofar as it is unfolded in the context of an existential necessity for belonging and actualization of the narratives that constitute their own individual identity, always ends up being carried out in contrast to what is assumed is scarce or non-existent in the host society. As these rituals are carried out in a repetitive way, and in contrast to what is here, they end up making the undocumented aware that those symbols which were constitutive of their identity are no longer present. And although such rituals allow them to assert themselves and to keep themselves firm and alive in the face of the difficulties of the present moment, they also make them aware that in their life there is an absence; that they navigate in this society in conditions of cultural orphan-hood. Therefore, ritualized in this way, nostalgia serves as an emotional refuge of resistance to the present, and also as a cognitive mechanism of recognition of our own cultural marginality. As a feeling underlying such rituals of differentiation, nostalgia makes it difficult for the undocumented worker to open up to what the new society, here and now, has to offer. Nostalgia, in this context, functions as a feeling of resistance and cultural isolation.

Among the set of human emotions that make up the undocumented workers' structure of feelings in Montreal in this particular historical moment, nostalgia plays the most conservative role of all. The conservative withdrawal and lonely discomfort that nostalgic reaction to dislocation creates in this context has similar effects and, to some extent, similar roots to those conservative feelings of loss, regret and an uncritical admiration for a golden past that people experience when major transformations occur, as Raymond Williams has traced historically, for example, with regards to the transitions from the country to the city (1975). Of course, the rejection of the present to which nostalgia predisposes one does not always translate into a conservative longing for the past, nor 
does it always push the nostalgic subject into withdrawal and social isolation. In some cases, particularly among those who have a radical political background, nostalgia acquires a more revolutionary character. In the same way that Fredric Jameson finds the forms of nostalgia of "revolutionary stimulus" in revolutionary thinkers like Walter Benjamin or the like (Jameson, 1969), among some of the research participants, the longing for a free, utopist and rebellious past, or the nostalgic memories that invoke for them images of solidarity, unselfish companionship, and the rebel vitality they used to see in the places they left behind, have lead them to a revolutionary opposition to the present. Those nostalgic images have also motivated them to look for the cooperation of like-minded local people, to get involved with local social movements, and therefore to partially overcome isolation. Three people I met possessing this kind of revolutionary nostalgia, asylum seekers escaping persecution, were a woman with a Philosophy degree, an Indigenous friend who was active in the student movement in his hometown, and a Guatemalan interviewee who was a guerrilla fighter in his Central America in his teens. All three will be invoked when we talk about the social mobilization of the sans papiers, but for the moment, they all represent exceptional cases to the dominant mode in which nostalgia is ritualized and lived among the people I worked with, serving primarily as an isolating mechanism.

Sadness comes after nostalgia, almost always in that order. And it settles into their lives like a slow and silent rain. In temporal terms, the interviewees report having started to feel sadness, a deep sadness, after the fourth or fifth year of their arrival. It is around that time when they tend to realize that their efforts to settle themselves in, and belong to, the new society have not been fruitful, and that the loyalty of the people they left behind in their countries of origin is weakening little by little. Sorrow installs itself into their lives during those moments of calm when the undocumented worker looks at her/his past and reflects on the present. But it installs itself also during those 
moments of anguish or crisis when she/he needed help and did not find many people around ready or willing to offer a hand. Or when her/his children or partner back home no longer enjoy her/his conversations over the phone, or when she/he finds out that their friends no longer ask for him/her. It is through these moments of crisis that the undocumented worker becomes aware of her/his status as a pariah and learns that, despite the passage of time, he/she has not developed meaningful and long-lasting interpersonal relationships in Canada, and that her/his material and affective life is very precarious.

Sadness is a feeling which is very present in the life of the undocumented workers. Although it installs itself slowly and is almost invisible, it has a very corrosive effect on their lives. It expresses itself regularly through the body in the form of a feeling of permanent exhaustion (sentirse cansado todo el tiempo "feeling tired all the time"), or in the form of having a semi-crooked back while walking with clumsy reflexes (which makes one look como un fantasma "like a ghost," they say), as well as in the form of having glassy eyes with distracted appearance almost all the time. Sadness also has a negative effect on the character, expressed almost overwhelmingly through a lack of hope, no longer having the disposition to weave dreams in which one - and not just the others—is the protagonist of moments of joy or the recipient of good news. Sadness tends to make them pessimistic and distrustful. Often the joy and optimism of the peers are considered as acts of naivety or purely lies.

In spite of everything, particularly when they witness firsthand the spectacle of the deportation of people whom they have met on the way, or when they see that some have returned to their home countries because they could not endure the difficulties (la chinga) that comes with having a life in the way it is lived here, or when they realize that in spite of all the difficulties, they have 
managed to support their family, as well as managed to provide them with money for education and a home, they often experience feelings of pride in themselves. They often see themselves as warriors who have not surrendered in the face of adversity. Jose, one of my interviewees, with whom I used to work cleaning parking sites in banks and local plazas, expresses this with particular clarity:

You are dealing with warriors. Here you see us all wounded, grimy, like fucking ghosts, as my compadre sometimes tells me. But here we are. Neither the migra nor the chinga have defeated us. And here we will continue. What the hell! You just have to be very careful with every step you take. That's why I'm telling you that you're dealing with warriors. We are warriors, then.

Often the pride of being a warrior and a survivor is strengthened by the conviction that what they do is for the material wellbeing of the family, and that the sacrifice that is being carried out will provide education and material goods to the family, resources to which they would not have had access in their countries of origin. This is particularly evident among those who are parents and guardians. And that gives them the strength to resist or to subjugate sadness. One summer at 7 p.m., my compadre (as we used to call each other to express reverence and respect for our friendly relationship) and I were watching TV. There was no furniture around, just an old TV, and we had just paid 50 dollars for TV cable service for a month. We were watching a Peruvian TV show that is popular amongst Latinos in Montreal: "Laura in America," a poor-quality talk show where family problems are discussed in a rather alarmist tone. On the program a middle-aged man was sharing the sorrow he felt after learning that the remittances he was sending back home had been spent by his family on superfluous items while his father and mother were being left behind in poverty. He felt betrayed and had developed depression and alcoholism and had stopped sending money to his nuclear family. Now, on the talk show, the man's moral integrity was being questioned. Watching this, my compadre and I started to talk about the main reasons for which 
poor Latinos immigrate to the US and Canada. I asked my compadre for his point of view on the situation. He felt angry at the man, as he thought he was behaving irresponsibly towards the family, the main source of strength and the only reason why it is worth the sacrifice of being here- - he meant North America — no matter how difficult this may be. I replied that I thought the guy had stopped sending money not because he was angry or just irresponsible, but also because he got into alcohol addiction and precarity because of sadness. I said that judging him like this on television was not the most helpful way to intervene, although Laura en America markets itself a TV show trying to meet that goal. He replied forcefully that he did not agree, and that for him sadness would never be a justification for which men can to stop sending remittances.

Then, he said:

I see that some people are depressed, and they go here and there with a sad look. I do not understand. Of course, I feel sad once in a while, compadre. I am not made out of rock. But I can get over it. I do not bend myself down because I know that I am fulfilling my duties (as a father). My oldest son is already maintenance technician and speaks English. The one in the middle already speaks French and he is finishing high school. And the other one is doing well in the school. My wife, too. She is doing well. They do not lack food on the table and they have always clothes, and a little house. Why do I still live here, despite everything? Because I love my family, compadre. I love my children. And I love myself too. And I want to have the strength to move on, to move forward. And if I know that they are not well, where will I then draw the strength to get up in the morning, to endure so much labour maltreatment? Where do I get the strength? For the Mexican, the strength comes from the family. There's no more. Those who bend over and return home with nothing, or those who leave their family, are those who are most "vulnerable to mental health" as you say. When things get bad, they have nowhere to go because they burned out the relationships they had back home. And they realize that they left behind the children, the family. But in my case things are not like that ... I have a home where to go to when I get back to my country.

As we see in my compadre's account, the sense of pride that arises from the conviction that one's

life is being sacrificed to guarantee the well-being of the family is a powerful emotional resource that literally keeps the undocumented workers standing; keeps them steady, enduring abuse, exhaustion, and sadness, and prevent them from "falling apart," both physically and emotionally. 
But neither nostalgia nor sadness nor pride are permanent and stable feelings in the subjectivity of the undocumented immigrant. What in fact is permanent is that this particular mixture of feelings is lived with great intensity and incredible frequency. As American anthropologists have identified very well (see: Kristin Yerris, 2014), Central Americans and Mexicans use an idiomatic expression to refer to the anguish and mental suffering that arises from living in the midst of this whirlwind of feelings: pensar demasiado (thinking too much). When my fellow migrant workers said to me that they were having a day or a week thinking too much, they normally meant that anxiety and worries_-and being all over the place with so many ideas, speculations and thoughts—have undermined their natural need to sleep, to rest and to eat. They then tend to cope with this stressful experience by getting distracted doing something like drinking, chatting or watching TV. This is because, when they are not working, they normally tend to "think too much." That is why on weekends it is common to get together to eat, talk, watch Spanish-language television programs, and have a few beers with roommates, who are almost always the only significant relationships they have. That helps to prevent oneself from being trapped in the act of "thinking too much"; that is, from anxiety and distress. In the apartment where I lived, for example, getting together to prepare and eat pozole, tacos or menudo while drinking beer and listening to music of Chavela Vargas and Jose Alfredo Jiménez, among other musical bands which are famous because of their sad songs, was a routine on Saturday evening or Sunday afternoon. And the most common thing is that during these collective rituals practiced to avoid thinking too much we used to go through the three states of mind mentioned above (nostalgia, sadness and pride in oneself) in a matter of hours. It was also very common to end up such collective rituals by sharing a little crying, even despite ourselves, or by having a discussion among friends and fellow workers even over the smallest and most insignificant detail. Such moments of weakness, crying and quarreling occur 
because although the will to survive, the love for the family and the pride, help to subjugate the desire to escape, to surrender to pain, or to "bend over" in the face of difficulties, they do not have in the long run the effect of erasing those desires altogether. These rituals also work very well as temporary anesthetic and amnesic strategies: crying, arguing or fighting help to forget and to avoid "thinking too much"; that is, they help to paralyze anguish, suffering and the strong desire of surrendering, and to escape, at least for a moment.

The repression of the strong desire to escape, to surrender and to return "to one's country," coupled with the multiple forms of emotional and material precarity in which it is lived here, keep their bodies tense and exhausted (with permanent back and chest pains, insomnia sometimes, and often with migraines, as reported by the interviewees) as well as their minds stressed out and aware of the fact that things, as they are now, cannot be sustainable in the long run. Over time, the eldest ones start worrying, for example, that their bodies won't be able to keep going at that rhythm for many more years, and that, although many of their family ties are not completely broken yet, they will continue to gradually weaken over time. They also become aware of the fact that their monthly income is neither secure nor sufficient to carry out a life with more than the essential needs met, mainly because they contribute financially to support two households with a single income. They also tend to develop the idea that it won't be possible, even in the long run, to be fully recognized by, and integrated into, the Canadian society, despite all the hard efforts they make. While discussing in an interview about the experience of recognition and integration for the Latin American undocumented immigrants, Ana, a Mexican single mother of four, told me with an exasperated facial expression, “Come on! Let's not fool ourselves, Eloy. If that [recognition and integration] has not happened yet after many years of living here, why the hell do we think that such a thing will happen in the future? They do not want us. Haven't you realized that yet?" 
Thus, their ability to understand the difficult context in which they live, and also their ability to understand the objective obstacles they face to sustain, in the long run, their current rhythm of life, coupled with the mood swings that make them permanently navigate among rapidly changing feelings of nostalgia, sadness, and pride, often pushes them to live a life with certain degree of mood instability, irritability and even frustration. In such a context of precarity and rapid mood changes, disputes with friends, fellow workers, peers and close people, and almost never with authority figures (i.e., the bosses or landlords, for example), become a common and fairly regular experience. This reinforces their isolation and produces a sort of emotional disability which manifests itself in a permanent incapacity to maintain stable and long-lasting relationships with others. It also produces, at times, resentment, which predisposes them to develop a passive and explosive character at the same time. Rage, as a consequence, often arrives as a hurricane, although sometimes expressed in a passive form and others more actively. In this context, disputes among friends, peers or fellow workers are not uncommon. Nor is it difficult to predict the long-term effects this may have on the ability to maintain positive, stable and long-lasting relations with themselves and others.

The willingness to cultivate friendship, to get socially involved, to participate in social events, and to expand social networks is undermined in this context, and so is also the stability and tranquility that are needed to care of themselves, their well-being and security. In addition, because of the labour precarity that they experience, their insecure permanence in the host society and the turmoil of emotions that govern their distressed subjectivities, life becomes for them an intense and exhausting experience, an experience that is felt as a never-ending struggle for survival. The 
consequence of all of that is that stability gets affected, and agency becomes slowed, ${ }^{19}$ though slow not in the sense that the workers perform at work (in the sweatshops or in the fields) at a slow pace or in a slothful way. Indeed, as I witnessed first-hand, almost all of them work extremely hard (some of them even in two or three jobs), at an incredibly fast speed and with unbelievable attention to detail in order to please the bosses and guarantee permanence in the job. So, not slow in that way. Slow agency is manifested more through the pace at which activities are performed in private life; that is, it is expressed at the level of the non-wage social reproductive labour they do outside the factory. Because they are so overwhelmed with daily life in the middle of a whirlwind of emotions while at the same time filling out all sort of paperwork to regularize their status, toiling in physically demanding jobs, and carrying out all sorts of emotional work to guarantee the wellbeing and functioning of their families, the tasks they have to do to keep up their personal lives running are relegated to the list of things to do, if such a list even gets written down. That kind of work, the reproductive labour that must be done to make things less difficult, is performed at a very low speed, and with an incredible lack of attention to detail. Keeping in regular contact with friends near and far, dedicating time to ask or provide help when needed, paying bills on time, attending birthday celebrations and community events, making sure to eat on time and as well as they can, and, in general, doing all that everyday work that must be done to make life easier, to break isolation, to enrich social life, and to reproduce themselves in society in a more healthy and dignified way, all those sort of activities are not done in a proper, stable and regular way. Therefore, the slow agency that affects the way the undocumented workers reproduce themselves as human beings in Canada is not a by-product of laziness, deficient cultural/ethnic traits or individual lack of will, but a consequence of living in the middle of a whirlwind of rapidly

\footnotetext{
${ }^{19}$ The reflections on "slow agency" were stimulated by conversations with Professor Justin Paulson.
} 
changing emotions and unstable mood swings - all of which creates a "structure of feelings" as defined by Raymond Williams (1977) that has been in the last instance structured by the very material conditions of isolation and precarity in which the undocumented workers live in the host society.

One day, while talking with Arturo about the hardship that social isolation may create on immigrants in general, and undocumented immigrants in particular, I told him how important is for me and for others I know to get involved in community organizing. As he responded to my comment in a positive way ("What a great idea!" he said), I invited him to attend a political demonstration in favor of the undocumented. It was an event which would close with a picnic in the Parc Villeray, a working-class neighborhood located close to our place. To my invitation he replied:

No. I do not respond much to those kinds of invitations or to parties. I do not go either to audiences or political demonstrations, my compa. And I am not going to respond to this one. I like the fact that they do politics and other things like that, but I do not respond to that, and I think I won't do it. I also do not like to go to parties or to the parks. I do not have time for that. And look, it really makes me sad to see families in the park all of them having fun together. It reminds me that I do not have my family here, that I do not have it close by. And that is why I don't even go out to the parks.

Arturo's response to my invitation, which was intended to help him to get out of the house, to get involved with his social context, to meet people and to have fun breaking isolation, is not unique. It represents, in fact, a very typical and regular response that I often received from the Latin American undocumented workers I worked with in Montreal. This is how I started to realize that the lack of will to socialize or become involved in community organizing events was not underpinned by "apathy," lack of political awareness or indifference, as some organizers think, but because they have no time, as Arturo told me (who would have it after toiling in two or three 
jobs?), and also because some even fear experiencing sadness when, by witnessing the joy of others, they are reminded of their current condition of solitude and separation from their families back home. Reinforced by fear, lack of time, and material precarity, uprootedness and separation from the host society becomes stronger and becomes installed in their lives as a powerful, ungovernable force which cannot be controlled by individual will and optimism.

But the experience of uprootedness described above, as well as the effects it has on the structuring of the undocumented workers' emotional or subjective life and agency is only one part of the history. The description I offered portrays a "broad trend" that, although hegemonic, is not monolithic. Joy, friendship, positive incorporation into the cultural and political realms of the Canadian society, as well as a healthy relationship with the self and others can also be found, although in fragments. Working myself in different branches of industry, from cleaning parking spaces and malls, to working in slaughterhouses and construction, and socializing with my coworkers in those contexts, I learned that labour, particularly the socialization structures that emerge out of those working spaces, plays an important role in the ordering of the structures of feelings and on the structuring of the workers' capacities to integrate into Canadian society, all of which, as will be discussed later in this thesis, greatly influence their mental and physical health conditions.

During my field work, I realized that the undocumented immigrants from Latin America who live and work in Montreal, although they live in fact objectively estranged or separated from different spheres of Canadian social life, are also, at the same time, deeply embedded and integrated into the labor structures of Canadian society. In fact, this form of labor incorporation (one that uses the sans papiers as a disposable labour force), works as one of the chief social forces that contributes 
to their social estrangement or separation from the affective, cultural and political spheres of Canadian society. To describe the mechanisms by which this particular form of labour incorporation contributes, paradoxically, to the immigrant workers' separation from Canadian social life is the goal of the following section.

\section{The capitalist incorporation: Real subsumption of undocumented labour in three types of industry}

In the current context, in which borders in advanced capitalist societies have been partially closed or become increasingly controlled with the purpose of restricting the entrance and free circulation of the poorest migrants of the world, paradoxically produced in the context of the so-called "globalization," capital seems to be the agent that most successfully incorporates and integrates "illegal" migrants into Canadian society. But because capital carries out integration through mechanisms of real and formal subsumption of labour — consumed for abstract labour purposesin the absence of workers' representation, under the management and control of underground employment agencies and in the context of strenuous working days, the capitalist incorporation of the sans papiers works as a form of integration that, although it allows them to socially and biologically reproduce themselves as persons, it keeps them socially and culturally separated and excluded from the host society.

But the capitalist incorporation of the undocumented worker is uneven. As the undocumented workers are subsumed by capital into different industries and under different labor processes, their labour incorporation and subsequent social estrangement or separation from Canadian society varies significantly according to the type of industries they work in. While doing my field work, working myself in the companies that employ undocumented workers, I elaborated a general 
profile of the industries that illegally consume or incorporate the labour power of the Latin American immigrants that are living in Canada without authorization. This work served me as the basis for describing the effects that such different forms of labour integration have on the social incorporation and the physical/mental health of the undocumented workers. In the following section, I will describe how that works in the different industries that incorporate them, and which I grouped for heuristic purposes in the following categories: Medium-sized enterprises, Multinational Corporations and Underground Workers' Cooperatives.

\subsection{The Multinational Corporations}

The knowledge accumulated in the field in light of the segmented labour markets approach, as well as much of the discourse that circulates in the local press, tend to indicate that the companies employing "illegal" labour force are the smaller companies that occupy a marginal or subordinate position within the global structure of capitalist production. It is also noted they hire undocumented labour with the purpose of surviving the competitive disadvantages they face in the global market (Sassen, 1988; Holmes, 2013). Although accurate in most of the cases that have been studied, this portrait seems to oversimplify a more complex reality that I observed during my field work. In Montréal and surrounding areas, there are a significant number of multinational corporations, and national companies linked to multinational corporations which have a leadership position at the national level, that employ undocumented workers. As a worker employed in several of these companies on informal contracts, I personally witnessed how such giant companies that hire undocumented immigrants belong to the circuits of transnational corporations that operate in the services sector: telecommunications, banks, and shipping enterprises.

\subsubsection{Multinational corporations and the labour process}


The multinational corporations do not hire undocumented workers directly, but rather do so through subcontracting intermediary companies that work in the cleaning sector, although sometimes the work the workers are asked to do goes far beyond that of simply cleaning work. The technical reasons why the multinational companies subcontract intermediary agencies (companies that illegally employ undocumented labour) are varied. Some of them do it to deal with an emergency that arises during alterations in the production processes; others do so as a disciplinary strategy to generate fear of replacement among the staff workers and make them work harder and faster upon the arrival of the foreign workers; some other hire undocumented labour as a mechanism to complete, in a shorter period of time, work for which the staff workers are not enough. Most of the reasons mentioned, however, have in common the fact that buying temporary and informally undocumented labour is useful and functional to the rationally calculated plans to reduce expenses in variable capital, mainly wages, labour maintenance and expenses for contracting contingent services. Hiring undocumented workers through cleaning agencies, as mentioned, is part of a larger strategy that consists of purchasing labour that is functional to the needs of production, reproduction and expansion of capital at a particular historical moment. Let's provide an example:

In the summer of 2015, 6 undocumented immigrants (4 Mexicans, one Guatemalan man and one Peruvian woman) and I worked for the owner of a small company that provides cleaning services to mostly multinational companies in Montreal and metropolitan area. Mr. Matus, a middle-class Colombian man in his mid-50s who is in charge of the company, offered us a temporary job for a salary of 10 dollars (cash) per hour, including a half-hour lunch break daily at the restaurant for the company's staff workers. It was a great deal, my fellow workers told me. When we arrived at the company we were hired to work for, transported in the van of Mr. Matus, I was able to verify 
that it was a multinational company which is highly recognized in the international shipping mail business. I will call this company UST to guarantee privacy and confidentiality. According to public information, UST is one of the most powerful multinational companies in the world in the mailing and parcel delivery market to all corners of the globe.

We worked at UST for 7 full days in 11-hour shifts including the half an hour break for lunch. They were exhausting working days, as the work we were asked to do was physically demanding. We swept and cleaned the parking lot, approximately half a hectare in size; we cleaned and moved from one place to another about 350 large and heavy boxes of parcels which were stored in two warehouses of approximately 600 square meters each; we cleaned trailers, assisted in the repair of ceiling light fixtures, and cleaned and rearranged the furniture of approximately 40 offices. We also gave a deep cleaning to a giant machine which is used to separate and select shipping parcels and unload them into the trailers, a machine that is operated by approximately 50 manual workers. During the third day of work I was able to have a brief conversation with Mr. Regis, head of the industrial cleaning and maintenance department at UST. I learned that he is the person directly responsible for hiring the industrial cleaning agency that contracted us to do that one-week job. During the 10-minute conversation with Mr. Regis (in which he instructed me on the activities that we would do after the lunch break), I took an opportunity to casually ask him why he had hired us. He told me that two weeks before, the Québec government's Health and Safety Department, Commission des normes, de l'équité, de la santé et de la sécurité du travail (CNESST) had made an inspection visit to verify if the corporation was respecting the workplace health and safety standards at work. He told me also that during that inspection the agents found several points that were violating the existing legislation on occupational health and safety of the province of Québec. 
As a result, in addition to making them to pay a huge fine, they were asked to fix those aspects violating the health and safety legislation within a "tight deadline."

In order to continue the conversation, I said with a naive tone, “Ah. That's why we are hired. To make the reparations in that short period of time, I imagine." He said "Yes," and explained that during the last year the Department he coordinates had cut personnel in a significant way. He told me that while in the past he managed ten people working for that Department, nowadays there were only three workers under his command. So, UST fired seven workers in one year, just in that department, and now the team includes only four workers, he said. He explained to me that was the reason he had to call from time to time to Mr. Matus, the Colombian gentleman who hired us to work in UST industrial cleaning, as he helped him to overcome the challenges that he faced in emergencies like the one they were facing that week we were hired; that is, in moments in which the work that had to be done out of normal routine could not be carried out in a short period of time because of the short number of staff workers they now had. "It is not the same thing now," he said. At that very moment my companion Beto, a former journalist from a recognized Mexican newspaper (Excelsior), was cleaning the base of the huge machine used to select and unload shipping parcels, in the middle of a dense cloud of dust. As Beto's labour was generating a huge cloud of dust, and at work we were given no health and safety equipment such as gloves, anti-dust masks, or boots, he had rolled a pair of napkins and inserted them in his nostrils as an alternative to a dust mask. While we both were watching the scene, Mr Regis said, "I do not like hiring people for doing this job, which looks like slave labour." No me gusta, mi amigo, he said in almost perfect Spanish. He had that sweet facial expression of the middle-class Caucasian Canadian people that combines political sensitivity and compassion. And then he repeated, now with a pragmatic tone: 
"I do not like it, but someone has to do it. And we have to do it fast. Thank you very much for the help."

In UST, I learned that my coworkers' labour, illegally hired and carried out with no respect for occupational health and safety standards, was critical for: 1) overcoming the emergencies faced by the multinational company during alterations in the process of production which cannot be solved without bringing in extra workers, due to the shortage of personnel created as a consequence of labour cuts during the last year, 2) guaranteeing the labour security of plant workers (at the expense of undocumented workers' safety), and 3) ensuring that the company, although putting the workers' health and safety at risk, complies with the legal labour standards that exist in Canada. I also learned that the work of Mr. Matus, the Colombian contractor who hired us for doing this job, made it possible that this unhealthy, insecure and illegal work was carried out without creating any greater risk to the multinational company, the main beneficiary of the work.

The weekend after we completed our work at UST, I consulted newspapers and other companies' documents available to the public and found out information that confirmed what Mr. Regis told me. Since 2008, as a result of the rise in oil prices generated by the global crisis of capitalism that began that year, the costs associated with the transportation and delivery of parcels increased. Such changes significantly affected USTs profit margin. In 2010, as a strategy to overcome the stagnation in the realization of surplus value and the influx of liquid capital, the company developed a restructuring plan to reduce costs, through fleet renewal, voluntary buyouts (staff cuts), decreases in the express delivery network and restructuration of pension plans for employers in some countries (fixed and variable capital costs for freight companies). After implementation of the plan in 2011, as revealed at a meeting with investors that raised the company's stock by 
15\%, the company saved: 1) 700 million dollars annually by reducing the use of the air network, 2) 300 million dollars per year by replacing outdated aircraft with modern fleet, and 3) 400 million per year through staff cuts.

The cuts of more than $70 \%$ of the industrial cleaning staff at the UST company in Montreal to which Mr. Regis was referring in our conversation were part this world-wide restructuring plan the corporation designed in 2011 to increase the annual profit rate. This helps us to understand why multinational companies like UST resort to subcontracting, hiring the services of small cleaning companies to carry out specific jobs for which the company's staff is not sufficient. On their side, small companies that are hired for such purposes, working for licensed cleaning companies, illegally hire migrant workers (not only "illegal" workers) who, because of their conditions of unemployment or vital precariousness, are willing to carry out any kind of labour or "slave labour," as Mr. Regis told me. And this is because the companies who hire undocumented workers to carry out such last-minute or emergency jobs offer the multinational companies at least three advantages. First, they offer them the possibility of hiring the workers without the commitment of permanent employment. Second, it allows them to pay the workers on a piecemeal basis without having to continue the payment of a permanent staff in the company for the whole year. Third, this way of hiring workers allows them to complete strenuous jobs, which "someone has to do" without having to deal with a unionized workforce which would refuse to carry out such dangerous and physically demanding tasks. In the end, this not only allows the corporations to save on costs associated with the social reproduction of the labour force (such as paid holidays, vacations, health benefits, etc.) and avoid dealing with unionized workers. It also allows them to be congruent with a larger project of labour restructuring and the reorganization of the labour process, by which the service companies try to maintain their position of leadership in the world 
market, in the face of the obstacles imposed by the global crisis of capitalism and the stagnation of growth it creates. By subcontracting employment agencies, or "cleaning companies," they save on the expenses that would result from having permanent staff. In addition, it allows the companies to have an available workforce at any time of the year and at any time of day, without challenge, since employment agencies are always open to carrying out specific jobs for a given time and price.

It is often said that undocumented persons take advantage of the system. But, in fact, undocumented immigrants are the ones who earn less and, conversely, the companies are the ones which earn the most. For example, firing seven permanent workers and replacing them by undocumented workers saves the company approximately $\$ 110,000$ dollars annually in costs associated with salaries and labour benefits. Instead of paying seven workers on a permanent basis, which would cost the company $\$ 210000$ (7 workers at $\$ 30000$ per year), by making business with Mr. Matus, UST only pays $\$ 100000$, what Mr Matus' agency charges for that labour.

We can therefore calculate the profits of Mr. Matus. From those $\$ 100000$ charged to UTS, Mr. Matus will discount approximately $\$ 42000$ in salaries (6 salaries of $\$ 7000$ ) plus the costs linked to transportation (around $\$ 8000 /$ year). He will therefore end up earning around 50,000 dollars per year (just for the jobs he does for UTS, without considering what he earns with his other contracts in the region). Not bad for doing labour management and transportation. Each of us, doing those kinds of jobs for UTS, would have earned 7, 000 dollars annually, despite the fact we did all the work. Hence, there is no doubt that for such companies and subcontractors, the risk of hiring workers illegally is worth it and works to their benefit. 


\subsubsection{Multinational corporations and social integration (or social re-rootedness)}

By sharing this work experience in UTS, I gained a better understanding of the way my comrades live, working for Mr. Matus and for three other similar agencies. I also understood better the social dynamics and experiences that came from working in the circuit of the multinational corporations, as well as the possibilities of integration that those kinds of jobs open up for the undocumented workers. Beto, Nacho, Rosa de Lima and Natalio, comrades whom I know well, and with whom I worked in UTS, navigate in this society with chronic economic difficulties. They never lack basic food: beans, tortillas, eggs, milk, vegetables (tomato, onion, potatoes and chili pepper) and meat (chicken and pork), but they never have money to buy much more than that. With the money they earn working for Mr. Matus, which is about $\$ 700$ or $\$ 1,000$ a month, they rent a 2-bedroom apartment in a working-class neighborhood located north of the island of Montreal at the price of $\$ 700$ a month. Five people live in that apartment in order to be able to pay rent, hydro, gas and internet bills. Their material difficulty is such that after paying the rent and utilities, they never have enough left to send their families; no more than 100-200 dollars a month, or 500-700 dollars in a lump sum every 4 or 5 months. In that economic context, sitting down in a restaurant or pub to eat a hamburger or drink a beer is a luxury that they cannot afford more than once a month.

Another difficulty they face is mistreatment in the workplace. Misrecognition, scorn, disrespect and other forms of moral grievance against their ethnic identity and labour are often displayed by contractors against the undocumented workers. When contractors are Latinos, usually Colombianand Chilean-born, it is common to hear them allude to the class or the ethnic status of the Latin American undocumented workers in a derogatory way. The hierarchies of nationality, gender, social class and skin color play a very important role in shaping the forms of abuse that the undocumented workers experience in the workplace. Quite often the contractors, in addition to 
possessing dual nationality: Colombian-Canadian or Chilean-Canadian, etc., are white or mestizo men with predominantly European phenotypes and high educational background who were raised in families which belong to the ruling or dominant classes in their countries of origin. As in Latin America and the Caribbean the unequal class structure is organized according to the colonial legacy (Cuba being perhaps the only exception to this rule). White or mestizo men with predominantly European features are the ones who occupy the leadership positions in the structure of society, while mestizos with predominantly indigenous and indigenous traits usually occupy the lowest positions. In Latin American societies, such racially-based class hierarchies are maintained and reproduced by mistreatment, exclusion and various forms of symbolic violence, and reproduced in the host society. Latin American brokers in Canada, mostly white men of dual nationality and high educational background, often use the same forms of mistreatment towards the undocumented migrants, as they are non-white and evidently come from the lowest social classes in their societies of origin. Their poverty, their misfortune and status of pariah in Canadian society is often imagined or explained by the brokers and contractors as a product of their indigenous origin and by the "innate" ignorance that is associated with being Indian or half Indian, a condition evidenced by their phenotype or brown skin color.

One afternoon, after our work shift was done, Rosa de Lima started to argue with our patron, $M r$. Matus, over the fact that he was trying to steal one hour of our work from our paycheque that day. "I am tired of this happening over and over again," she repeated with an angry tone. After a minute of verbal dispute, Mr. Matus said with an arrogant tone: "You see? I'm often embarrassed to tell Canadians that these kinds of people, Latinos, are 'my people.' They are lazy, incapable of doing things properly (malhechos) and dissenters (protestones). And also, pigheaded (cabeza dura) like good Indians. Look at her, look at her," he said to Nacho, Natalio, Beto, and me while pointing his 
finger at Rosa de Lima, our only female coworker. He said, "Do not fuck around. Get to work, do things right, and then protest about your paycheck. Do not fuck around. Poor, lazy ... and picky,” he said, with the disdain of someone feeling ethnic and class superiority. He glowered at the rest of us, as if he were telling us that we would have the same fate if we dared to ask him to do the right thing: to pay us the 11 hours we worked that day, instead of the 10 hours he was arbitrarily trying to pay us, robbing us 10 dollars that was worth one hour of work.

Experiencing often such forms of mistreatment and disrespect in the workplace, it is not uncommon to find companions who live with the idea that they are "nobody," and with the idea, expressed in ways that not always are so direct, that for "being an Indian" they are worthless, less than human, and that they do not deserve a better life than the one they have.

But those kinds of mistreatments and moral insults are carried out not only by the brokers who are Latinos. Caucasian local people are also involved, either by act or omission. Employment agencies often have "people of colour" among their human resources personnel, people who are of the same ethnicity of the workers who are more often hired. Sometimes this is done strategically to ensure good communication with the workers, and other times because HR jobs at that level are also low wage working-class jobs. I saw that happening often, for example, in cleaning companies where I was hired with Pancho, mainly cleaning parking lots, plazas and banks. Those people, called capataces by the migrant workers, are the ones who carry out the direct mistreatment in the workplace. Caucasian men with English or French surnames do not appear in the foreground, but they are in fact the ones who construct the pyramid on which the abuses are carried out. The participation of "stock" Canadians (Canadienses de cepa as my fellow workers call the caucasian Canadians) in that circle of violence occurs when they know the consequences for the body and 
the health of the undocumented immigrant workers and are aware of the mistreatment and forms of moral disrespect that the workers experience, but they decide to turn a blind eye to this reality. They either do not do anything about it or tend to justify it with a pragmatic position, as Mr. Regis, our boss in UST, told me: "I do not like to make you work like a slave. But this is a job that someone has to do it, and it must be done quickly." In fact, because "stock" or Caucasian Canadians are the ones who occupy the most prominent leadership positions within the chain of command within the labor structures under which ruthless mistreatment and exploitation occur, and due to the fact that they participate in them, even by doing nothing, they participate in a form of privilege that reproduces ethnic-based violence and white ascendency. Their participation in the circle of abuse, insofar as it is not visible to the eyes of others, exempts them from their objective responsibility. And with that the circle of violence and domination gets close. At the top of the hierarchy, the true cause of the existence of the problem, Caucasians benefit more economically and appear as the ones who are the least involved. The 'browns,' who are really working in such labour structures as foremen and work to meet the needs of 'white' labour hierarchies, are those who appear responsible to the public, along with the undocumented workers who are seen as the problem, the cheaters of the system, the "illegal aliens." Violence comes from above and it has a social class, a gender and a colour. It is a class, gender and ethnically-based transnational violence of true material consequences, but a violence which remains invisible and unquestioned by the people around.

Despite the enormous economic limitations and despite the abuse and misrecognition that they suffer in the workplace, Beto, Nacho, Rosa de Lima, and Natalio have much more contact with Canadian society outside the workplace and receive much more moral recognition from the Latin American community and the Québec society than most of the undocumented workers that I met 
during my field work. This is largely due to the fact that they have more free time than most of the workers I met and interviewed. In their free time, they visit friends, go to parties where they can grab a beer for free without sacrificing their salary; they attend conferences where, in addition to "always learning something," they can also always eat something and take leftovers home; they explore the city and its beautiful parks by night or day, and they sometimes go out dancing on the weekends. Their French language skills are much more developed than the average undocumented worker I met. In fact, they often helped me to translate what I did not understand while attending events or parties organized by local people. All of them have also had loving partners and less precarious love lives and tend to be much more engaged in political activism in favor of migrants than the rest of the people I met. In fact, Beto, Nacho, Rosa de Lima and Natalio collaborate diligently in an organization that advocates for the regularization of migrants without status, and led an organization created by Mexicans and Central Americans called Mexicanos Unidos por la Regularización (MUR). Although their lower status at work deprives them of the minimal income and moral recognition that is necessary to live a decent life, satisfied in their minimal material and moral needs, their existence is extremely rich in experiences and their presence among the Latino community very strong. Some of the local activists, academics and community-based organizations that advocate for migrant justice recognize their work very much. Although their life is not entirely satisfied in the midst of such a shortage of income, and their integration into Canadian society is limited (no one has more than one "stock Canadian" friend, for example), I could see that compared with the rest of Latinos I met, they are much more integrated in the cultural and social spheres of Canadian society. They are also better able to navigate within the institutional structures than the average undocumented worker I met. They are partially integrated in society. 
The labour dynamics in which they are inserted play a very important role for this form of partial integration to occur. Since their work basically depends on the call of Mr. Matus or on a chamba bomberazo (a call for an emergency job) that was recommended to them by a friend, they work an average of 80 to 100 hours a month (sometimes 40 and sometimes 150). "Cleaning the bowels of the multinationals," Nacho told me, "does not give you much money, but it makes possible for one and for our families to eat. And we have free time to live. You do not live well without money, and the family does not live with all the needs meet either. The food is also always plain and scarce, and the clothes are also always gnawed. But you learn from what you see, from what this city has to offer. You know people, you learn the language, and you have a bit of certainty that at the end of the month your family will have some money for food, clothing and even for school expenses. Our life is different than the life of the other paisas (co-nationals). They devote their entire lives to work, like if they were donkeys."

\section{The Employment Agencies: Permanent exploitation, permanent uprootedness}

Only a small number of undocumented workers living in the shadows of Montreal are employed by agencies that work directly with multinationals, companies whose unstable labour processes generate, as already described, the paradoxical possibility of becoming partially integrated into Canadian society while still being fundamentally excluded. The vast majority of undocumented people are integrated into the world of work in a more ruthless way, therefore, and are much less likely to become part of the local society in a meaningful way, as the labour dynamics in which they become immersed under such conditions do not allow them to integrate into the social, cultural and political spheres of the host society. 
In Montreal and surrounding areas, there are an important number of brokers and employment agencies whose main job consists of hiring undocumented workers to integrate them into the labour structures of medium-sized manufacturing, construction, cleaning, meat processing, and fruit and vegetable companies. Such companies have chosen to hire undocumented workers on a temporary basis as a strategy to avoid dealing with unionized and permanent personnel. The employment agencies we are talking about operate as legally established employment agencies and present themselves to the public as enterprises specialized in the labour management of unskilled workers whose labour power is marketed as being capable of meeting the needs of the local companies who face labour shortages. However, in addition to carrying out recruitment and selection of workers who are allowed to work legally in Canada, they also place mobile units in various strategic points, such as in subway stations located in northern working-class neighborhoods where precarious migrants predominantly live. In those places, every morning, between 5 and 7 a.m., they recruit undocumented immigrants, welfare recipients or people who are unemployed for having a criminal record, who are willing to work for cash at almost any place and price. After picking up the workers, the employment agencies bring them up in busses and vans to the factories which employ them, normally located outside of town.

The goal of the employment agencies is not of course to consume undocumented labour as an end in itself. Rather, these companies are looking for a labour force that it is willing to withstand heavy workloads and carry out tasks that are often undesirable by the local population; that is willing to work for low wages, usually a bit lower than the minimum wage; that is highly flexible, disposable and always available to carry out all kinds of tasks at any time of the day or night; and that is docile and not represented in the workplace by unions. 
The recruiters who manage the temporary staff companies are tough people. They are also very skilled at managing workers in the underground labour market. They often use a combination of strategies that include psychological manipulation during recruitment, and also authoritarianism and abuse in the handling of personnel during the day-to-day work. By using those techniques, it is possible for them to keep the workers in a state of docility, flexibility and captivity, but also to get partial forms of loyalty, all of which helps them to keep the workers willing to work hard, fast and without many complaints.

For recruitment purposes, the brokers post, for example, ads on Facebook pages such as "cash jobs," "ofrezco y busco trabajo," among others, where subscribers get offers to work for cash. Through the ads they offer very vague, but positive descriptions of the jobs they offer. They also use an optimistic tone about the effort that the job requires from the workers, and about the salary the workers will get working there. Those advertisements use headlines such as: "Work in your free time or weekends and get extra cash!" or "Earn up to $\$ 2,000$ by doing casual jobs," among others. Once the workers get to know the recruiters and start working for them, they are often encouraged to invite friends and relatives. I heard and was told several times, in fact, phrases like "You are an amazing worker! Where are you from? There is work for people like you!"

Racial or nationalist-like discourses are also often used to justify those kinds of complements and invitations to co-participate in the recruitment process with phrases like: "Jamaicans are great at construction. Amazing!" "Mexicans and Guatemalans are good at working in the farms," "I do not like Peruvians or Haitians because they are lazy and complain too much," "You guys are good at this. I want more people like you. Bring them here. I have job for them," and so on. The workers get interpellated because of those discursive maneuvers and even feel appreciated in their work. 
Motivated by such comments and compliments, it is not uncommon to see many of them coparticipating of the ongoing recruitment processes. For such reason, friends and relatives often end up working for the same recruiters. In agriculture, for example, it is possible to see entire families, including children, working in the same plant because of such forms of recruitment.

The recruiters use those interpellation mechanisms to hook as many workers as possible and keep them under their control. It pays off. Recruiters and staffing companies get at least 3 dollars per hour per each worker in the lowest paid, non-skilled jobs (cleaning, packing, picking vegetables, demolition) while in some areas of construction, for example floor installation, they may take up to 15 dollars per hour from the worker salaries, according to my estimates. Therefore, investing in recruiting and keeping the workers hooked up to the job as much as possible, and keeping them docile, is nodal for the staffing companies. Their recruiters, therefore, are not only highly skilled at manipulating and recruiting the workers. They are also extraordinarily good at devaluating and disempowering the labour force. For example, the first time the worker meets the recruiter, often invited by a friend, a relative or after seeing and ad on Facebook, the brokers use psychological techniques to lower the morale of the workers. They normally do that by talking first about legal papers or by asking them for their work permit, even though they often know about the legal status of the workers before the meeting takes place. When asked about it, the workers usually get nervous about it and offer an often not very convincing excuse for not having work permits. Then they are informed, in different ways, how important it is to have the documents in order, because it is risky and difficult to find work "under the table." This technique has the effect of clarifying that under the table there is always work available, while also reminding the workers about their condition of deportability. The main goal of the recruiters when starting the conversation about papers in the first meeting, as described by Robert, the most critical of my interviewees, is to make 
the workers think that they are helping them out by allowing them to work "under the table," which guarantee some loyalty and thankfulness from the beginning, while disempowering their potential capacity to resist as they are reminded of their condition of illegality. Quite often the brokers also sell the idea that they will protect them if the workers keep working for them, as they know how difficult must be living under such conditions. They also let them know that they must show tolerance and stalwart endurance at all times because the work may be demanding. They mean not to scare people away, mainly because they want to have them working under their control, but to warn them that if they take the job, there won't be much space for complaining. People are expected to work hard without complaining or showing fragility.

Although the brokers do all that is imaginable to create the illusion among the workers that they will be protected and safe from joblessness and potential deportation, when the workers are already inserted in the underground labour market the brokers often do not pay salaries on time; they commit wage theft and remind the workers in a subtle way that they cannot complain, as they already agreed to work under such conditions and also because the work is being carried out "under the table." Quite often the salary that was announced on the Facebook ad or agreed during the first meeting is not paid in full. Gentle and subtle manipulation ends if the brokers learn that "their" worker arrived late to work, works at a slow speed, or has committed a serious mistake doing their job. In those cases, it is quite common to see that the brokers resort to verbal insults, threats of replacement to discipline the worker. Sometimes the brokers themselves in the plants play the role of supervisors and the insults are not directed only to the undocumented workers, but to workers of color in general, to women and to people who have no base. Sexual harassment is also experienced by some of the undocumented workers, especially women. 
Although the workers became critically aware of the conditions of abuse, misrecognition and exploitation that they experience in the workplace, to the extent that they at times have an intense desire to quit, such desire rarely gets materialized. They normally keep themselves hooked up as much as they can in the job, until they are the ones who are discharged. This happens mainly because of the extraordinary capacity that the brokers have to keep the workers under control. So, for example, in order to discourage the workers from dropping off the job, the recruiters use a technique of bondage, or "motivation" as they sometimes call it, that is known in the circuit as semana caída (roughly translated as "fallen week"). This technique of control consists of keeping for themselves the equivalent to one or two weeks of salary as a "deposit," money which will be supposedly paid once the worker completes the verbal contract. This salary remains as a "deposit" and the recruiter says that this money will be given to the worker, when s/he will no longer want to work for him (the recruiters are always men) or that can be used when the worker needs it for example during an emergency. In reality, la semana caida or "deposit" is often not paid back. Two Salvadorian people who have worked for recruiters told me in a BBQ we had in a mutual friend's house, that the practice of keeping the "fallen week" from the workers equivalent to one- or twoweeks salary, serves as a "trial period," during which the worker is evaluated to see if she or he is suitable for the work. If the worker is not useful, she/he is simply discharged with no wages paid back. They say that it is understood that la semana caida help the workers to gain "hands on experience" and serves them as a "motivation and to decrease turnover." The semana caída works very well as a bondage technique. As the worker needs the money, and as has already invested a lot of energy working for one or two weeks, s/he feel less motivated to quit the job, regardless of how difficult or dehumanizing may be. Through this technique the undocumented workers are kept "motivated"; that is, are kept bound to the employer. Often, when a worker wants to quit the job, 
either because the job is strenuous, or for any other reason, the recruiter deliberately enters into conflict with the worker and fires her/him without returning la semana caida. According to my records, corroborated with several of my fellow workers, $80 \%$ of the undocumented workers never receive their "deposit" back. On semana caida, sexual harassment, physical assault and other abuses that the workers experience in the workplace, Natalia says:

Semana caida [means that] you work one week, and you don't get paid, you work the next week and you get paid only for the week you did last week. In theory, if you quit the job, you must get your deposit back, but that never happens. I don't know why they do that, but they do that everywhere. I have been around for seven years here and that is what happens. And mistreatment a lot. There is nobody who protect you, and when people want to get into a union... they are not allowed. Unions can be helpful. I had a union in Mexico and I know for own experience. But here, nothing. Sometimes I ask myself: How can that happen here, in such a developed country? Sometimes you can see worst things here than in our countries. These days, for example, minimum wage was raised up, and, in Mexico when minimum wage gets up, they you get your new wages but here I have not gotten a raise in my country. I have talked to the boss and just told me that I must wait. ... How can that happen here? One day in the job [a printing company] a black guy was hired to work in the line of production... he was performing slow in the job and he was asked to quit because he was doing things too slow. And he said 'no.' And I saw how he was shoved off and nobody said a word about it. He was also punched twice. He was punched up! I never expected this to happen here... It was a printing company where also, we packed laundry parts. We also packed CDs in plastic boxes to a 100 per hour speed. We were asked to work very speedy. Sometimes I even got body touching. The supervisors were women. They used to rub their intimate body parts on my body. Truly disgusting. I have never lived those kinds of thing in my life. When I emigrated, I had very different expectations, but I realize now, here there are somethings worst that in our countries.

Sometimes the agencies don't pay to you. I used to call my boss [the recruiter] to ask when I would get paid, as he used to avoid paying me for up to 15 days. Yes, I will pay you, he used to say... You can find all sort of those things happening here. Sometimes people thing that happens only in our countries but here you can find the same. Sometimes even worst. Well, maybe I think that way because I never worked on those spaces in Mexico. I mean, sometimes we are treated as animals, but we are not.

What was shared by Natalia was consistent with what other researchers have found in different geographical areas and other areas of industry employing undocumented workers through recruiters, in the sense that sexual harassment, and physical and verbal assault are common 
experiences among undocumented workers, for example in agriculture and construction (See, for example: Basok, Bellanger \& Rivas, 2014; Magalhaes et al, 2010).

The employment agencies that incorporate the undocumented migrant workers into the underground labour market, the "independent" brokers who select them and transport them, and the local medium-sized companies who hire the undocumented labourers, constitute a sophisticated web of technologies of integration of the undocumented workers whose ultimate effect is not only the deep immersion of the workers into abstract labour networks of exploitation, but also their exclusion from Canadian society. This web represents the dominant mechanism of labour incorporation into the underground labour markets and labour structures. Such labour regimes, insofar as they regularly and permanently contribute to the integration of the undocumented worker into this unstable, precarious and exploitative underground world of work, prevent them from integration into the life world of the Canadian society. The pincers of abstract, alienated labour carried out within the small manufacturing enterprises with the help of the underground employment agencies trap the worker in an iron cage. How does this occur and how exactly are the undocumented workers prevented from integrating into Canadian society? The dynamics of the working day play an important role for this to happen.

Due to the fact that such enterprises are located almost always outside of Montreal, and the workers are employed there during all the days of the week, except for Sundays, the labor dynamics and their time-consuming schedules do not leave time and energy to the workers to socialize. The workers employed in this way get up at 5 in the morning to arrive to the meeting point where they will be transported at 6 in the morning. They work in the sweatshops between 8 in the morning until 5 or 6 in the afternoon. When the working day is complete, the workers are transported back 
to the subway, and after that they go back to their apartments. After arriving home, at 7 or 8 at night, exhausted, they eat and go to sleep to wake up the next day at 5 in the morning and go to work. The time to socialize or to carry out leisure activities beyond what is necessary to reproduce themselves as human beings is virtually non-existent. Unlike those who work in the multinational corporations and large companies described in the previous section, workers who are recruited by the employment agencies and employed in local mid-sized manufacturing companies do not have time to socialize.

Janitors and clean-up workers face a more severe fate. In the cleaning sector the jobs are equally strenuous, albeit with the additional hardship that these jobs must be carried out mostly at times when there are no workers or clients at the buildings they clean, mostly at night or late evening. Also, huge buildings or a huge number of offices must be cleaned up in a very limited time. In the cleaning companies, undocumented workers are employed at undesirable times for the local population and at extremely low wages. It was common during my fieldwork to find workers employed to clean up to two buildings located at very far points from one another and in periods of time of between 10-12 hours in the evening and night. For example, when I worked for 2 months with El Primo, a peaceful, book-loving Mexican refugee claimant who was rejected in 2010, time in which he decided to remain and live a life clandestinely, our job consisted in cleaning two different buildings during the afternoon and night. At 5 pm, every day except Sundays, we cleaned a building of the Québec government which provides health services (CLC) to the local population. We used to clean 42 offices in that building distributed in two floors, in addition to the corridors, waiting rooms and common toilets. We were given 6 hours every day to complete that task, from $5 \mathrm{pm}$ to $11 \mathrm{pm}$. Then, at 11:15 pm we used to take two different buses to get to another private building located close to downtown, on Boulevard Saint Laurent, where we started working at 
midnight. We used to work there all night long, until $7 \mathrm{am}$. In those 7 hours, we cleaned the corridors, bathrooms and common areas of a 12-story building where gyms, software companies, travel agencies and other service sector companies are located. That was a very demanding job. For that labour we earned 100 dollars each per shift—shift that included cleaning both the CLC and the fancy building on Saint Laurent —as the first 6 hours in CLC, rated at 10 dollars per hour, were divided among us ( $\$ 30$ each) because our patron used to say to El Primo that the government building was meant to be completed by only one person. Obviously, that was not possible, reason for which he used to hired me or his wife. Because the cleaning workers must sleep during the day to recover from the 12 hours of work, plus 3 for transportation approximately, after preparing food, eating at home and doing some cleaning, no free time is left to socialize. The consequence of working under such dynamics is a life in almost total isolation, due to the lack of time and lack of energy to socialize, visit friends, attend parties, events and visit public spaces.

In both types of jobs, always mediated by employment agencies that connect them to the local manufacturing plants and service buildings, life takes place in public transportation and inside the factory, where one assembles products or cleans buildings. The isolation is even more severe for people who work in the cleaning industry, since those jobs are always asked to be carried out when there are no people and coworkers around. They work in isolation. Isolation in this context has important class implications. I always asked myself why El Primo and a great number of undocumented workers have not developed class consciousness, and why they do not have feelings of connection, in terms of class, with the rest of the undocumented workers we met. One of the hypotheses that I developed while working and comparing the working conditions and the socialization structures that emerge from the labour processes in the multinational corporations and in the medium-size industries, is that isolation plays a very important role for this to happen. 
As we know from Marxian thinkers, there are two basic conditions that must be present so that class consciousness can develop amongst workers. The first is for the workers to learn that they share a condition with others. This form of recognition is learned by working at in close physical proximity to each other, and by recognizing, through daily praxis and socialization, that they have a common experience, that they share the same grievances and that they belong to a same class. The second condition is that the workers must become engaged with each other in the daily struggle, active or passive, against the command of capital objectivized in the figure of the boss or the recruiter. Therefore, to be subsumed into the labour processes and to socialize and work with others is an important condition for class consciousness to arise.

In the case of the undocumented workers I worked with, neither the first condition nor the second are fully present. This situation is more pronounced in the local medium-size enterprises. In those places, as described here, workers tend to be inserted in labour days that 1) are highly securitized and surveilled, which prevents them from socializing and responding in a coordinated way towards abuses and exploitation, 2) are highly isolating, such as when the workers toil as industrial cleaners in slaughterhouses, or when cleaning offices at night, and 3) are highly demanding, physically and mentally, which leaves the workers few hours of spare time and no energy left to work with others and to engage in collective resistance against abuses, nor to engage in collective reasoning about the cause of their misfortune. In addition to that, being immigrants subjected to deportability, and having arrived here, or having decided to remain undocumented here, with the clear goal of increasing their living standards, as individuals and by themselves through hard work, creates in them a distorted idea about the true causes of poverty and about the true means by which wealth is produced, distributed and attained in society. As a consequence of this, undocumented workers develop the distorted idea that individual will, being masters of themselves, working hard and 
saving money, is enough to get ahead, or to move up. Some of them, particularly when things are not going well and isolation hits hard, tend to develop the idea that human will won't change much, and that to wait and see how things develop, and to have some sort of faith, while working hard, is enough. Trapped between this "crude empiricism and abstract utopianism," as Lukacs would put it (1971 [1920]:77), working and living under such material and subjective conditions, the workers develop a distorted idea of how wealth and well-being are achieved, and incur in what Marx called self-denial; a condition in which the worker imagines that the only way to have access to the wealth is by two means: 1) by saving money, "cutting corners in his consumption so as to withdraw less from circulation than he puts goods into it," "sacrificing substantial satisfaction to obtain the form of wealth," and by 2) "denying himself more and more rest, and in general denying himself any existence than his existence as a worker, and being as far as possible a worker only... through industriousness" (Marx, 1973 [1939]: 234-235). This "false consciousness" that reifies abstract and alienated labour, erroneously imagined as being the main mechanism of wealth creation (Lukacs, 1971 [1920]), makes it difficult for the worker to find objective possibilities to become part of a class against capital or a class for itself.

The aforementioned in some part explains why I think class consciousness is weak in general, particularly amongst the workers subsumed in the middle size enterprises. And that is why the will to rebel against abusive labour practices and to engage in contentious politics tends to be more present, according to my records, among those who work in the multinational corporations. In such giant corporations, workers toil for fewer hours, and normally they do it with others.

Even more than those whose work (and life) schedule is subjected to the unstable sway of the demands imposed by multinational corporations and giant enterprises, the workers who are 
employed by local companies suffer isolation at such a deeper level that most of them are prevented from socializing and having a life that involves activities beyond those needed to guarantee their plain reproduction as workers and biological beings. They live for, mostly, hard work, eat poorly, and sleep badly. The alienation to which the body and the mind of the worker are subjected in such conditions fatigues their bodies and alienates them from themselves, their social class and from society.

It is this mass of workers, living mainly in the underground world and deeply integrated into the labour market of local companies, who contribute with their labour power to the wealth of the city. They keep clean and useful the private and public buildings that provide essential jobs for the functioning of the economy and the processes of social reproduction of the local population. They therefore partly sustain the processes of social reproduction, integration and cohesion of the society in which they live at the cost of their own segregation from society.

\section{Arriba los pobres del mundo! The Underground Workers' Cooperatives and the incorporation of the undocumented workers}

Although dominant, the enterprises and labour dynamics described in the previous sections, under which undocumented workers are simultaneously highly incorporated into precarious and exploitative conditions while being uprooted and separated from society, are not the only ones that

exist. A diversity of sociohistorical and economic processes in Canadian society have led to the emergence of a growing number of bottom-up microenterprises, informal cooperatives and groups of individuals that carry out an array of informal service transactions as a means of subsistence and social survival. Most of those bottom-up initiatives are distributed in the province of Québec, according to official statistics (Statistics Canada, 2016). As such forms of exchange involve not 
only the exchange of services, but sometimes the exchange of money for services, they are classified by the Canadian State as part of the underground or "shadow economy" and defined as illegal. Also, they are often imagined as economic activities which can have potential damaging effects on the social body, as they may involve the circulation and exchange of harmful commodities (hard drugs and forced sex work, for example) or may allow the existence of labour regimes that reproduce and perpetuate exploitation, abuse and forms of servitude and slavery. However, such kinds of businesses are not the ones I will be talking about in this section. Some of the harmful enterprises that operate in the underground labour market were already discussed in the previous sections, particularly in the part where the employment agencies and recruiters were described. What I will describe in pages that follow is a scattered yet existing array of underground bottom-up business that, although operating outside of the law, represent forms of exchanges for which the main goal is to overcome or survive economic hardship. As such, they represent, as defined by Professor Bill Reimer (2000: 3-4; 2006) alternative systems of social security which aim at providing forms of welfare and protection for individuals and communities facing social precarity.

These underground or "pirate" microenterprises, to put it one way, which work in the informal Canadian economy, can work sometimes as spaces of subsistence, solidarity and mutual aid where some undocumented workers are integrated in a non-exploitative way. According to my observations, the kind of services they provide and the labour regimes they structure make the undocumented workers inserted in such informal cooperatives better able to integrate themselves into the cultural, political and economic spheres of Canadian society. Wandering through those spaces of the informal economy, I registered forms of inclusion, recognition and respect that I had not yet seen in my field work. 
In Montreal and in surrounding communities, there exist a number of small enterprises which are almost always run by families or friends who work together recycling, selecting, repairing and reselling commodities and use-value objects which were previously collected in the garbage. There are also small enterprises functioning as cooperatives which provide landscaping, cleaning, maintenance or home reparation services to the households located in the neighborhood where these micro enterprises are located. Still others operate in the traditional migrant neighborhoods, such as Parc Extension or Côte des Neiges, where they offer painting services or where, after collecting and repairing discarded furniture or electronics from wealthy boroughs, offer them for resale at low prices on websites such as Kijiji or Craigslist. As these companies are very small, are not registered by the State, and receive informal and unstable contacts via networks of friends and family friends, they produce limited revenues and, therefore, cannot buy labour power or engage in wage labour relationships. Their functioning on the basis of cooperation and non-wage labour relations makes them able to operate as informal subsistence cooperatives.

It is important to note that such underground, subsistence cooperatives are most of the times administered by people who, for health reasons or because of a criminal record, cannot work full time or have been previously expelled from the regular labour markets. That is to say, they are subsistence enterprises run by those who belong to what Marx used to call the "surplus population" (1990 [1867]:794-797).

As their work and income are unstable and sporadic, and they cannot engage in purchasing labour power, the earnings are not invested in buying labour power to produce more commodities and reproduce capital via the generation of surplus value (as per the general law of capitalist accumulation). The earnings or profits collected are instead distributed in more or less equal or 
proportional parts among the people who invested time and energy in the labour processes. The social relations that emerge from horizontally structured, cooperative labour processes provides the basis upon which the social integration or rerooting of the undocumented migrant into Canadian society becomes possible. Here is an example of how this works:

At the beginning of the summer of 2015 I met Monsieur Arnaud, a 70-year-old Quebecois man who had retired almost 10 years before. He operates a small recycling business which operates illegally as he has no business license. Mr. Arnaud's work through this microenterprise consists essentially in collecting all kinds of items from the garbage cans located in wealthy neighborhoods and carrying them in a trailer to his property, a modest house located 80 kilometers southwest of Montreal. Once the collected material is deposited in his property, each piece is disassembled and separated into different containers containing iron, aluminum, copper, plastic and computer parts and electronic devices. The disassembled material is then sold in the scrap yards, where iron, copper and aluminum are bought and sold. Mr. Arnaud also repairs cars, provides moving services and home renovation works for his neighbours, friends and other social networks he has access to. He does all that work for cash. Through this company, he recycles, repairs and sells all sort of devices: tools, construction machines, trailers, stereos, televisions, computers, tires and all kinds of things that are still in good working order and have an exchange value in the second-hand market. He has two Mexican friends who are living in Canada without authorization: Pablo and Manuel. They used to tell me that they work with Monsieur Arnaud, "not for him."

In a long and honest conversation, Mr. Arnaud told me that he makes his living as a jack of all trades - mechanic, carpenter, constructor, recycler, etc.-because the pension he gets from his retirement is very little and he barely can get ahead with it for his everyday expenses. He also told 
me that a long time ago he had trouble with the law, and that he has a criminal record, which limits his life in many ways. His criminal background and subsequent unemployment pushed him to end up living in the streets and to alcoholism as a young man. Although he recovered from alcoholism through a rehabilitation program, and with time he could buy a boat in which he made his home and lived on the waters of the Saint Laurent River for more than 10 years, the chances for having decent and stable work were always extremely limited. Although having a floating boat as a house and having emancipated himself from alcohol dependency meant some life improvement, the lack of a stable and decent job kept him trapped in poverty for the rest of his adult life and prevented him from saving money. His criminal record also limited his travel possibilities. He still cannot travel, for example, to the United States. This is why he has to do all the work he does currently with his recycling company. It allows him to make an income that complements his lean pension, he told me.

His life on the margins of Canadian society, his condition of poverty, at times an outlaw and quasipariah, led him to live a life in the underground and to meet immigrants and others who were also living as outcasts, at the margins of mainstream society. In this context, he told me, Mr. Arnaud learned to trust in the migrants, and developed a sensibility that makes him feel empathy for them. With time, particularly after an experience of support and solidarity in Cuba while surviving without money for more than a month, beyond empathy, he recalls, he started to see them as equals to him and developed little by little a relationship with the immigrants in conditions of equality, comradeship and fraternity. If at the beginning he used to see them as "others" and in some ways, as people who deserve pity or empathy, over time he realized that they are just as all human beings. He also says that of all the people he met while living in the streets and wandering in the margins 
of society, the Latinos became his favorite people, as he thinks that they are hardworking, resilient, honest, supportive and cheerful people.

Because of his criminal record, Mr. Arnaud has lost some fundamental benefits and freedoms that come from having a Canadian citizenship. His substantive citizenship is very limited because, due to his criminal record, he has no access to decent and permanent employment or stable income, and his freedom of movement is limited. That is why he decided to open a small, unregistered company, he told me. It is his means for surviving economic hardship. As his body tires quickly because of age, he needs helpers to get the job done and help his company produce a decent income. Paulo and Manuel came to him through a mutual friend. After escaping from the temporary workers program in which they worked at a tomato farm located on the shores of Montreal, they got into the underground world where they lived as pariahs for several months. In order to put food on the table, they used to recycle aluminum cans and sell them in the depanneurs. In that context they met Monsieur Arnaud, who invited them to join forces to make his small underground company do more, collect more and make a better income for all of them while working together. The earnings they get from selling recycled material to the scrap yard, or from repairing a vehicle, or from doing home renovations, are distributed by Mr. Arnaud. $40 \%$ of the total earnings go to Pablo and Manuel. As they work hard together every day, Pablo, Manuel and Arnaud have developed a relationship based on loyalty, trust and comaraderie. Pablo and Manuel feel thankful to Monsieur Arnaud because of the fact that, with him, they have a more stable income, and a less precarious life. They have also met local friends through Mr. Arnaud. Almost all of their new friends are Quebecoises de cepa, as they say, from whom they learn to speak French and learn more about the local culture. Manuel actually met his current girlfriend, a kind 
and active Quebecoise woman, in that context, working with Mr. Arnaud and his clandestine business.

Arnaud also feels grateful to his undocumented friends. In gratitude for their support and complicity, he teaches them about local culture and about how to survive precarity and navigate the Canadian system. He has taught them, for example, how to pick up food from the trash cans in large supermarkets (a practice called dumpster diving among English speaking Canadians in Montreal, he says), how to ask for food from the food banks, how to seek help and support from community organizations, how to get lawyers from the Legal Aid office to help them with their refugee applications, how to recognize and collect valuable and useful items from the garbage, how to make small home reparations, and how to use special tools for car reparations. Throughout the two years that they have been collaborating with Mr. Arnaud, Pablo and Manuel have learned how to speak French fluently and have developed a deep knowledge of the Quebecois culture. As Monsieur Arnaud is a Quebec sovereigntist from the bottom of his heart, he spends a lot of time talking about Quebecois culture, listening to local music and exploring with them through the most beautiful places in the region that Pablo and Manuel have ever seen: National parks, rivers, and other beauties. Manuel says:

The truth is that Arnaud does not pay us. We share what we earn. Much more remains for him $(60 \%)$ because the work we do comes from his contacts. Also, we use his car to collect and sell the material we recycle, we use his tools to do home repairs, and we use his house as a warehouse and workshop. The money we make here working with him helps us to put food on the table. Sometimes we even sleep at his home. And also he does something that is very important for us: He teaches us how things works here. That is good because, you know, we are sometimes a bit foolish (mensos). I already feel at home here, as if I were in a new country that is mine. And although I know that at any moment I can be caught and sent back to Mexico, I do not worry about that much anymore. I know that there is already someone here who supports me, starting with him [referring to Arnaud]. This wildly bearded man does so much for us. 
People like Mr. Arnaud, who possesses a special sensibility shaped in the context of having lived a marginal and adventurous existence, along with the "pirate" subsistence micro enterprises like the one he manages, constitute some of the social forces which have opened the doors of this country to undocumented workers like Pablo and Manuel, and helped them to navigate in this society in conditions of dignity, respect and recognition. Through the social and labour relations that emerge in such contexts, which involve mutual recognition, intense life adventures, nonwage labour relations, exchange, mutual aid and solidarity, people who have been illegalized and expelled from society, like Paulo and Manuel, find the time, the cultural mechanisms and the infrastructure that is needed to become integrated into Canadian society in conditions of dignity and respect.

It is important to point out that the possibilities for integration that are opened up for some undocumented workers have an important class dimension. As in the example of Pablo and Manuel, after they escaped from a labour camp where they were highly exploited and abused, a fact that transforms them into jobless pariahs, they found refuge in the house of a marginalized white Quebecois man. That is, their possibilities of integration were made possible just after they began working with Mr. Arnaud, a Francophone and poor Canadian man with diminished citizenship rights who is engaged in a daily struggle for subsistence. It is through their collaboration with Arnaud that they established relationships of solidarity, respect, and mutual recognition, and with whom they have found a more dignified material existence, social networks and other mechanisms for their social integration in Canadian society. It is also through these "clandestine" enterprises where they are engaged in forms of nonwage labour relations, performing forms of concrete labour (as opposed to abstract, alienated and waged labour), that deeper forms of social integration occur. It seems, therefore, that the social integration processes that their 
collaboration with Mr. Arnaud have produced, have such beautiful scopes because they happen at the margins of the instrumental relationships that in mainstream society (highly stratified along lines of citizenship, class and ethnicity) occur between employer and employee in the context of mass production. Their experience in terms of social integration into Canadian society is very different from the experience of those who are engaged in wage labour, as in the case of the undocumented workers who "clean the bowels of the multinationals" or those who work for local manufacturing factories via brokers and employment agencies.

My observation is that the "pirate" subsistence microenterprises do not reproduce relations of exploitation or labour relationships that are based on the purchase of a labour force aimed at increasing the production of commodities to increase surplus value and expand capital. What emerges from the labor processes among the pirate microenterprises are social relations that open up possibilities for collaboration, mutual recognition, solidarity, mutual aid and reciprocal respect. It is possible to find, in such labour spaces, among other things, the creation of forms of labour collaboration that make possible the existence of deep comaraderie, mutual recognition and what Paulo Freire called "radical love." Mr. Arnaud used to laugh a bit at me by repeating a phrase quite often. Every time I was explaining how good I used to feel hanging out with them while we were laughing and talking while making car repairs, exploring the forest or making a beautiful artistic bed for my house with the savage wood we collected in the forest, he used to say in Spanish with Quebecoise accent: "What you will find here, Eloy, is a "mechanic for love"” [una mecánica para el amor, he used to say in Spanish]. He repeated the word "love" quite often almost in a sarcastic way, as that was a word that I used sometimes during my conversations while doing field work. Arnaud says that he does not want to have work contracts "just for having a job to make money" or collecting and repairing items just for the sake of selling things. "What I like to have by doing 
this is also people around [he was referring to Pablo and Manuel], friends from whom I can feel support and company," he told me. And he provides support back to them as a way to show thankfulness.

A similar dynamic occurred with another three undocumented workers that I interviewed. After their refugee claim was rejected by the Canadian State, tired of working for exploitative employment agencies, they decided to join forces, to build up a small cooperative, and started to make a living by offering gardening and landscaping services to the local population in their neighborhood: Longueuil. In those "pirate" bottom-up microenterprises and other small familyrun businesses the undocumented workers make a living cleaning houses, cutting grass and doing small landscaping jobs. The work is done by two or three persons, and the money is distributed in fairly equitable percentages among them. During my field work, I realized that it is in such small, unlicensed small businesses run by people struggling for basic survival where the undocumented immigrants are more likely to find forms of solidarity and social integration and inclusion which are different from what they normally face within the mainstream society. It is within such labour contexts led by people who have been marginalized by society where undocumented workers find, according to my register, better forms of social inclusion and integration, as well as respect and recognition for their work. It is literally in these companies, set up on the basis of solidarity among the dispossessed, where deeper forms of integration into society are more possible. Solidarity and inclusion, then, come from below. They have a class dimension, and they are multicolor. In such labour contexts, transnational solidarity, radical love and inclusion form a class-based, transnational and multi-ethnic form of recognition which has truly positive material consequences for the poorest of the world, but unfortunately as a social fact they remain in the shadows, invisible to the eyes of social researchers, and unpopular as social practice in the mainstream society. 


\section{Mental and Physical Health in the Local, Medium-Sized Enterprises}

We are not more than simple workers. We are worth nothing more than that ...We are just workers, only workers, I mean, we are like beasts of burden. Look at this paisa: as long as a beast of burden keeps being useful, all is good ... it is used freely. As long as the beast is giving, giving, giving, everyone is happy. But when the beast cannot longer work, when it cannot give as much anymore, the beast is sold ... it is given, or it is thrown away. Once, I was working in a chicken plant, I fell down and bent my ankle. That's how I worked all night. It swelled up. I told the boss [the recruiter] about it in the morning and do you know what he did? He dumped me at the metro station and I never saw him again. And that's what happens here to us. That's why I say that we are only workers, we are not more than that. We are useful for doing work. For nothing else.

[Those with documents] can go to a government office to look for a job or to ask for help. They can help you to solve a problem. And maybe they treat you for what you are, a normal person, a person ... But we do not have any of that here. If you do not fix things by yourself, you're damned. Tomorrow you're on the street, under a bridge, with no money to send to the family. That's why I tell you: we worth nothing. We are only valued as long as we are good to work, work and work, just like a work animal.

This is an extract of a conversation that I had with Miguel, my former roommate and coworker, with whom I worked in renovating buildings for short seasons in Fall 2015 and Spring 2016. At the beginning, I was struck by how Miguel talked about the relationships between the undocumented workers and the dominant Canadian culture: a social relation in which the undocumented immigrants are "used" or seen as "only workers," working instruments, or "work animals" and then discharged when their utility comes to an end. Even though at the beginning Miguel's words sounded exaggerated to me, with the time I noticed other undocumented workers alluding to similar situations, and actually using similar metaphors: They often refer to the idea that they are "used"" and treated as "animals," "beasts of burden," working tools, "nobodies," or "just workers." This idea is also similar to an extraordinary speech I heard one day in downtown Montreal. In a demonstration organized by the Immigrants Workers Centre, a self-identified sans papiers said in Spanish to dozens of people while his words were translated: Se nos tolera sólo 
porque para ellos somos como máquinas de trabajo, bestias de carga ("We are tolerated just because we are seen like machines, beasts of burden.")

What is expressed by Miguel and by the other undocumented people referred to above has some resonance with my own working experience. While toiling in factories and conducting field work in the Montreal's underground labour market, I found that the idea that one is being used, abused and treated as a disposable working tool, something less than human, is often not an exaggeration. Through that work experience, I also learned that, in fact, the individual and collective experience that is moulded working in those factories is also powerfully linked to some of the health maladies that will be discussed in this section, particularly to the problem of nightmares, anxiety, fear of dying, suicidal tendencies, accidents and other mental and physical forms of suffering, some of which can arguably be linked to what I will call "short-term historical trauma." I became aware of those links on the ground. In the early summer of 2015 , I joined, as a cleaning worker, a company that hires undocumented immigrants. I was assigned to a squad of nine Latin American workers, all undocumented. We worked hard every day under the orders of Ramón, a Honduran-Canadian man who used to speak little and who was prone to rough handling people. Ramón used to pick us up every day at eight o'clock in the morning in the northeast offices of Cleaning Super Star where we waited for him sitting down quietly in the offices' corridors. Our hyper quiet behaviour there was imposed, not chosen. In the offices' social atmosphere reigned a cold silence, and no one used to speak to us, except for a Salvadorian middle-aged woman who worked as secretary. Not even the main bosses, a Basque man and a Lebanese who spoke Spanish relatively well, bothered to greet us when passed through the corridors. When he arrived at the office, Ramón drove us in a van, along with cleaning tools, to the places where we worked: banks, parking lots and malls in 
Greater Montreal Area. There we swept the parking lots, and cleaned windows and small warehouses.

Ramón interacted with us only to give us orders and to assign us with tasks. He had a "favourite sport," as we used to say: In the middle of the shift or right before its end, he meticulously examined our daily tasks. When happy, he would say, “Good job, cipotes. Let's get out of here that the cadejo prieto is coming." But when he found a flaw in our work, he used to reprimand us sharply and order us to do the work again. Reluctantly, but with a submissive attitude, we used to do what he ordered. For that reason, the time when he was checking our work was the most stressful part of the day. He had always his "favourites" and it was terrible to be marked as a bad worker. Being myself new to his team and one whom he did not choose, I was not certainly one of his favourites. One day Ramón went after me in a large parking lot of a commercial plaza where I was sweeping and collecting garbage along with a coworker. As it was a very windy day, I did not realize that a rather small bunch of plastic bags and some plastic bottles had blown into a place I already had cleaned. I did not see them. I only realized what had happened when Ramón arrived to check out our work and upbraided me, dragging me harshly by my t-shirt to the spot where he found the garbage. There he told me: "Look at this shit, colocho. Come on! What a useless idiot, honestly. You both, what a waste of time. De todos no se hace uno [you are both equally pigheaded]. I want this to be clean right now!" "Right now, I said!" he repeated in a rather unbearable authoritarian tone when we tried to explain what had happened. That is only one example among the many unpleasant and stressful moments we endured under his "professional" way of handling personnel. I often felt very offended by the way in which he used to treat me and used to treat some of my coworkers, to the point that more than once I felt the strong desire to punch him in the face or, worse, to tell him that I was not the person he thought I was, yielding to 
the conservative fallacy that assumes respect is deserved based on individual's social privileges. But I always repressed the urge to do so. My work registering his labour practices and authoritarian behaviour was more important than a fight or than ethical capitulation.

Although working there was not too physically demanding, it was certainly mentally stressful. After several weeks, the working environment started to consume my mental energy. I started to feel uneasy about work and eventually developed mild anxiety in the workplace and problems sleeping. There was something very strong inside me about that situation, a strongly negative emotional reaction to being humiliated so often. Completing the shift and heading back home always felt good, but Ramón's mix of offensive and at times condescending treatment were often in my head. He loved to grab the workers from the back or shoulder while directing them to see what he wanted them to see. Nobody with a minimal sense of respect for the others would do that. Like some of my coworkers, I started to develop feelings of being humiliated mixed with frustration, rage and a sort of general uneasiness. My relationship with my fellow workers was not too bad. The only problem was Ramón, a really stressful boss and certainly not much different from the network of Latino recruiters that operate in the underground labour market.

I came to the subject of sleep problems and nightmares in that context. But, as a privileged graduate student in a Canadian university, my experience was certainly very light compared to what those who have "no documents in order" have to go through. One Sunday, I mentioned to Nestor and Rigoberto that I was having anxiety and sleep problems, and we started talking about that topic. They both are migrant justice organizers. One of them, Rigoberto, had been living in Canada undocumented for four years and Nestor had been happily granted with refugee status months before. As both have a long experience working in the underground labour market, one of them, 
Rigoberto, saw my uneasy situation with sleeping as a normal affair. He also revealed that himself had serious sleep problems while before while working in two jobs at the same time: at a slaughterhouse in Saint Eustache and as an occasional cleaner in a shipping company on a temporary basis on weekends. If that happened also to you, he said, imagine the people who have to deal with much more than you. Nestor also told us that he went through those same kinds of experiences, but in a more severe way, three years ago, after being engaged over a long time in a legal fight with Flavory Tomate, his former employer. He recalled that, as a reprimand for him siding with one of his Guatemalan coworkers in a labour dispute, Flavory Tomate had fired him and "thrown him out" on the streets with no money, no job, and, literally, no place to sleep, as not only his income depended on his temporary contract with Flavory Tomate, but also his right to temporary residency and housing in Canada (he was a temporary migrant worker at that time). After having lost his job, his work permit, his status, and after being "in the streets" for three weeks, he got help from the Immigrant Workers Centre in Montreal which reached out to him and supported him on a legal battle against Flavory Tomate over his wrongful termination. As his case evolved and became headlined in national news, he also demanded refugee status. All that situation was so stressful, he remarked, that as the legal battle wore on, despite the enormous help he was receiving from the IWC, he started to have problems with his brother (also a temporary migrant worker) and other members of his family over his decision to fight Flavory Tomate and the Guatemalan Consulate. The stress was so high at that time, he said with his sweet chapin accent, that he also started to have night sweats. "I used to wake up at nights, either because I suddenly started trembling and sweating in the middle of the night, or because I was having a very bad dream, or both," he said. Rigoberto told us how common was for him and others he knows to experience "regular" sleep problems, sometimes nightmares, and encouraged me to explore that 
in my research process. I gave him my word I would do it and I will discuss in this chapter what I found.

In this chapter I will discuss how the feeling of being "nobody" along with more severe forms of mental and physical health problems, including nightmares, suicidal thoughts, accidents and generalized wear and tear of the body, as described by my interviewees, are shaped in the context of working in middle-sized local factories under conditions of illegality. But, as mentioned, workrelated precarity and authoritarianism in the workplace are not, by far, the only problems shaping human suffering and underpinning the structural violence to which undocumented workers are exposed. By looking at several composite cases, I will show that the labour processes in the medium-sized sweatshops, the recruiters, the possibility of being deported or deportation itself, state-based violence, racialization, gender-related precarity and the particular forms of agency displayed by the workers within this context all play an important role in the production of damaged bodies and wounded subjectivities.

When discussing exploitation as a master determinant of health at the end of the second chapter, I intended to show how Latin American undocumented workers, usually in the face of a crisis of social reproduction, tend to develop a tremendous will to get inserted into the labour processes within the underground labour market. In a social context which presents obstacles to their need to reproduce themselves and the family as social and biological beings, facing permanent threat of arrest and deportation, social isolation, racism, and also attached to a self-denying conception that imagine industriousness as a primordial way of upward mobility, migrant workers find no other ally than waged labour, in its most precarious form, to survive that general crisis of social 
reproduction. Existing fractions of capital that are willing to incorporate cheap and docile labour in Canada find undocumented workers a good commodity to prey on. This situation generates a structurally co-dependent relationship between capital and undocumented labour.

The crudest version of such an unhealthy, structurally co-dependent relationship between those fractions of capital and undocumented labour occurs in the local, medium-sized enterprises: chicken, quail and pig slaughterhouses; recycling plants; construction companies; packing businesses; dairy businesses, and house cleaning firms. As described in Chapter Three, those companies tend to rely on brokers and employment agencies for recruiting and incorporating the undocumented and other precarious people (including welfare recipients) into their labour processes. Although such companies hire bajo el agua (roughly translated as "under the water") as Mexicans and Guatemalans say, the workers are incorporated by those companies on a regular, stable basis. For the workers this means that they have to put their bodies every day in the line of production and subsume themselves into a disciplinary labour-time regime that demands them to wake up at 4 or $5 \mathrm{am}$, toil for at least 8 hours often under surveillance and pressure from supervisors and return home after the shift ends. Also, except for the companies operating within the construction and home renovation fields, which hire the workers on a less stable basis because for those companies the demand decreases in fall and winter, in most of the local, medium-sized enterprises the undocumented immigrants are incorporated all year round on a more or less stable basis. There the workers toil, sometimes up to 11-12 hours per shift under labour processes that are physically and mentally demanding. The medium sized companies also demand full availability from the workers, including availability to change the schedule at any time of the year, as well as availability to be able to work at day, night, during weekends or on holidays. 
Having to be totally devoted and available for unpredictable, strenuous labour shifts, highly controlled by often authoritarian bosses and supervisors, has several consequences on the mind and body of the undocumented workers. Let's start by describing how the material dynamics under which the undocumented workers carry out their labour in the medium-sized enterprises shape their subjectivity, how they think society perceives them and the forms of agency they put in practice in such context. This will help us later to understand how a whole set of mental and physical health challenges are developed or strengthened in such context.

\section{On being less than human: The labour process and production of wounded subjectivities}

At the level of subjective conditions, I will start first by describing an aspect of the relationship between work and mental health that was not so obvious for me at the beginning of the field work, but whose working mechanisms I was able grasp during the second year. It is, specifically, the way in which the experience of being subsumed into the medium-sized local companies on a permanent and stable way through recruiters, under conditions of disrespect for labour, deportability, racial subordination and material need, produce in the worker a fearful subjectivity and a particular way in which agency, in the form of often submissive behaviour, takes place.

In the medium-sized local factories, undocumented workers tend to develop the idea that the local society have a negative perception of them. This is manifested through the belief that, as persons, they are considered inferior to others, particularly if those others are Caucasian people, also referred just as "Canadians." Those beliefs manifest through the recognition, made explicit through conversations, that they imagine themselves as being considered cero a la izquierda (nobodies), people who have not much value beyond their capacity to toil as beasts of burden. In effect, as mentioned in the beginning of this chapter, those working in the sweatshops and medium-sized 
factories quite often described in the interviews how certain they are that they are tolerated to a certain extent not because they are appreciated or recognized as people who deserve respect and to be well treated, but simply because of the fact, they think, that patrones (bosses), State authorities, and society are certain that they are always willing to do all type of jobs which most local people don't want to do.

Although they may use varying definitions of slavery or servitude, people working in such branches of industry tend to recognize that the way in which they are treated resembles forms of bondage and servitude Latin Americans associate with a distant past. The association between the old-style social servitude and the current working conditions that the undocumented workers face in the host society are well represented in the comments that an undocumented Chilean man shared with me while recovering from a stroke. Victor Jara, as we used to call him, came to Canada as a visitor to take care of his mother, a Chilean-Canadian woman with ALS who lost mobility in her legs right after turning 78 and had to rely $100 \%$ on wheelchair. As the government of Canada did not grant Victor Jara with permanent residency, despite the fact there was a clear humanitarian reason behind his request (his mother did not have anyone in Canada to look after her and had had severe falls while trying to go to the bathroom by herself, for example). In order for him to be close to his mother, they both decided he would overstay. He did it, but eventually received a deportation order, and had no other option but to hide and to subsume himself into the underground labour market. There he got several cash jobs, none of them less challenging and exploitative than the other. As Victor Jara, unlike most of the undocumented workers we know, had no experience on those kinds of jobs, he used to quit the jobs often in the hope of finding a less demanding one. He lost any hope after one year of wandering around the labour market and decided to keep the one he got in a corn farm. 
After two months of intense work, at the end of the summer of 2015 he experienced a stroke at night and ended up in the hospital. Later, while providing support to him and his mother separately, as he was now living in the hiding in a basement offered by members of Mexicanos Unidos por la Regularización, I asked him why he thought he got into that health crisis. We were trying to see if an accident or something may have explained his situation, as he said he had good health before. To that question he responded that he did not know why, because he did not have an accident, and the doctor did not tell him exactly why that happened to him. After complaining badly about his job, he also said that for him his situation was clearly related to all he and his mother had been going through and to the types of jobs he has had while underground.

In his words:

So, being sin papeles [underground], with so many worries, and all this [the nature of his labour and his mother's situation] para qué quieres más? [why more explanation is needed?]. All of these jobs work like when there were kings, masters, slaves and all that. [Like] when in our countries, our ancestors used to be treated by the Spanish emperors, long time ago, when the world was organized otherwise, and our people were treated worse than animals.

When describing their working conditions, undocumented workers usually do not mean "slavery" in a literal sense (although some of them really mean it), but rather a radical form of disrespect for their labour and to an at times extreme form of misrecognition they experience in the workplace. I witnessed it firsthand and arrived at the same conclusion during the second year of my fieldwork. In the medium-sized enterprises, underground labourers are in some ways treated as slaves used to be treated: as people whose only value lies in their capacity to work and to produce goods; racialized bodies reduced to the status of a machine; people who are, in fact, treated as being less than human. 
Feeling that their labour and contribution to the local society are misrecognized, and that instead of minimal recognition for it, they get mistreatment in exchange, has morally damaging effects. In effect, when I asked the workers how important they think their contribution to the local society is, they tended to recognize that their work was important, insofar as it makes the local population's life easier, better and more comfortable. For this reason, when I asked them how mistreatment or misrecognition in the workplace makes them feel, they often expressed frustration and even disappointment about it. Julio provides an example of this. When in the interview I asked him:

How important or valuable the work you do here is? He responded:

It is very, very important. We work for a company that is one of the most important and powerful here in Canada, or at least in Quebec. The company is important not because it's big, but simply because, you know, food is the most important thing there exists in society, in any society. We all have to eat, right? It is the most important area. It's like agriculture. It is like the farmers who produce tomatoes. Without food we cannot live. No one can live without it...

But I think nobody values the work I do; neither the bosses, nor the government, nor anyone. And I say that because I am paid only the minimum wage here. And I work like a beast! There is no benefit for someone who works illegally, like me. ... Actually, we do not exist in Canada, we have no place in this society. We are like a cero a la izquierda (nobody). We do not count for anything, like for ... whatever social benefit. We do not count for any of that. We are a cero a la izquierda (nobody). Seriously, we are actually like nobody, we do not count ... If someone from the government knows that we are here and that there is a deportation order (orden de salida) against us, he just come here to take us out. The system is like that and those who do that work are like that too. They can just take us out of here. We are nothing, we are just like a cero a la izquierda ... That is my experience.

But I understand. We are illegals here, and I would not expect much from the government or from the people. In fact, people in general are very nice, I think. Look, even immigrants... Mary and all the people from Solidarity Across Borders, they saved my life last time I was in the hospital. And what can I say about my wife? You know that entire story, and as I said, I hope you can say that in your writing. She is here alive because of what you guys did for her while she got into the hospital! So, no complains about the people really. But in the factory, we really are not treated well. I do not want to sound like a complaining guy but, really, they do not care about us. ... They just want more, and more and more. Work. No stop, no stop, no stop. I feel very disappointed about it, sometimes. 
The description shared by Julio, a person who has been supported by local activists, by neighbors and by his own landlord who quite often patiently waits for the delayed monthly rental payment because he does understand how difficult his financial situation is, represent what a lot of my coworkers working in the middle-sized factories mention about it. Every time we talked about these issues in depth, I could recognize that in fact they do not feel so disappointed about people in general, or by Canadians as they normally call the local people, but by the very bad experiences they have in the workplace. They normally tend to think that, while they feel thankful for having a job and a salary, the way they are paid and the way they are treated, does not represent a recognition or respect for their labour, work that they think, quite correctly, is very important for the functioning of the local society. Therefore, the negative perception they have about the position they are assigned in society seems to have its origin in the nature of the work that they carry out in the workplaces, and more concretely, on the salary and treatment they get in exchange for their labour. That is how some of them tend to develop negative ideas with regards to their experience in Canada. However, looking at it closely, when the workers talk about mistreatment or misrecognition from what they sometimes call "local society," they actually refer to misrecognition or mistreatment of their labour by their patrones; that is, by capital, not by society.

So, it is important to describe at this moment what kind of jobs they do, and what type of social relations emerge in those contexts; relations not among workers, as that aspect was already described in Chapter Three, but relations between capital and labour, between obreros and patrones. This will bring us to how agency (not so much class struggle, yet) is manifested in such contexts and how such forms of agency shape their health. Let's start by providing a brief description of the nature of the work they do in those places. 


\section{Jobs and the labour processes in the local, medium-sized sweatshops}

In many of those jobs, workers wash and clean, overnight, the machinery that is used in the slaughterhouses, places where chickens, pigs or quails are killed, cut into pieces and where the resulting meat is packed and stored in cold rooms or freezers. Workers commonly call these places mataderos or rastros. Slaughterhouses and meatpacking companies, or mataderos, are cold, humid and semi dark places. At the end of the shift, it is common to find blood mixed with water covering the floor. In certain areas, it is also not uncommon to find pieces of meat in the process of putrefaction, or pieces of fat, urine and excrement that slipped through the hands of a worker during the hectic labour process. The odours at night, when the day shift ends, are sometimes so repulsive that I will never forget the night in which, helping Veronica and Armando, we witnessed how Veronica, there just for the second time in her life (she cleans homes for a living), started vomiting after the second hour of working there. We had been cleaning a mix of meat, blood and fat which the night before had not been cleaned out well by Armando, a reason for which he was almost fired, and for which he had asked us to help him out that week.

In the mataderos, at least in those ones in which undocumented and welfare recipients are hired underground, there is also a clear disregard for the security of labour. The workers are often given broken boots, jackets which do not provide enough protection from cold weather, plastic gloves which regularly have holes on them, and no helmets. In those conditions, industrial cleaning workers are urged to run across slippery floors holding hoses that spray water with high pressure to clean (with water, soap and chemicals) the huge machines and floors where animals are killed, meat is packed, and scraps are discarded. It is not uncommon for workers to fall down while working on the slippery and watery floors. Some of them, the cleaners, work overnight, from 6 in the afternoon to 5 or 6 in the morning every day, including Friday night. Overall, the work is 
physically demanding, dirty and dangerous. As those factories produce and pack meat, the buildings are always cold. It is extremely stressful for the body to experience constant temperature changes, especially during breaks in summer. During my fieldwork, I never met anybody who has endured more than three months in those jobs. I myself worked for no more than a week in a matadero located in Saint Eustache. I spent 5 days in the factory line suctioning with a highpressure suction hose the intestines of quails that, I learned, are exported to expensive hotels in the US and I could not make it for a second week. My right finger could not make it for another day when Friday arrived. It was a cold, smelly, dangerous, hyper-surveilled and highly demanding job. With few exceptions, in the line of production, we were all "brown" and "black" people; mostly men in the killing and cutting sections and mostly women in the cleaning and packing section. The workers that I met during my fieldwork who told me that they had been in slaughterhouses for few weeks, a month or so, used to explain me that the reason why they stopped working there was because their body at some point protested against working under so much pressure. The body is described as something that just suddenly "burst," got broken, or revienta, as Salvadorian and Honduran workers say. They normally stopped working there after having suffered an injury, often a problem in the hands that is called by the workers dedo de gatillo (trigger finger).

The work that is done in the recycling companies is not much different from that in the mataderos. It consists in selecting, separating and sorting out all types of bottles, cans and bags that are made out of plastic, steel, aluminum, glass or paper. The material handled by the workers also includes a variety of items from the garbage that can be recycled and transformed into another useful item. This is an industry that often calls itself "green" and the owners usually show pride in themselves for that reason. No doubt, such companies play an important function in society. But the workers, who are the ones who make that important work possible, do not feel like they are doing a "green 
job." They just know that in every shift they must group together all sort of bottles and deposit them into different bands. Those bands carry the material through a recycling process that includes separation, cleaning, trituration, compression, and further separation. As the material is handled, cleaned, separated and deposited by several people working at a high speed, and at high volumes, the environment is particularly noisy. So, those workplaces are noisy, dirty and malodorous.

Perhaps the most hazardous part of that job is that also exposes the workers to fumes. After having been selected, the bottles or containers that are always loaded with residual liquids, are subjected to a cleaning process with chemicals. These cleaning chemicals produce fumes of a strong odour and make some workers experience allergic reactions on their skin and/or in their eyes. Overall, the working environment is noisy, speedy, smelly and dirty. That is probably the reason why, unlike the "green," proud patrones, the workers doing the job in those factories show no pride of their labour. They see it as a very noisy, smelly, strenuous and highly demanding job.

In the recycling companies, the workers who are hired "under the table" are mostly undocumented from Latin America and Africa, welfare recipients, and some young local males who are there to make some money during school vacations. They work mostly at night in shifts that go from 10 to 12 hours every night, except for Sundays. Summer is particularly busy in recycling companies. The workers perform at a fast speed under the pressure and surveillance of supervisors who are often rude. The workers are asked there to change shifts often. I never figured out clearly why sudden changes in schedule happen in those factories so often, although one of my interviewees told me that he thinks the patrones do that to avoid being caught hiring under the table. I also think that this has to do with the fact that, as happens in some of the multinationals described in Chapter Three, the undocumented there, who represent just a small fraction of the entire labour force, also 
play the role of being additional guards of the system. That is to say, they are there not necessarily to make the patrones to save money by paying them low wages, but also to meet the production demands meet when "regular" or legally hired workers are absent or when the production has risen, requiring more labour power. In any case, the fact that they are called to adapt to such changes in labour schedule does not allow the worker to have stability or routine in sleep, to get their meals routinely under regular schedule. The supervisors watch them closely and demand that they work hard and fast.

Another job consists in selecting and packing all kinds of vegetables and other merchandise, such as cement, at a high speed and under surveillance cameras. In food processing plants, such as the ones where vegetables are packed or canned, the workers are also subjected to disciplinary techniques, which include, for example, writing the names of those who have performed better on big billboards placed at the sight of everyone, to make the rest of the workers to perform faster and better. Such disciplinary techniques are common in the workplaces linked to agriculture. In a small town close to Montreal, I packed cucumbers for a month in one of those plants and witnessed how those disciplinary techniques are used, along with yelling and threats of replacement when a worker is not performing quickly or well enough from the point of view of the bosses. The supervisors in vegetable-packing plants are normally Latin-American people "with papers in order" who are extremely rude and hard on the workers or local people who speak good Spanish. The ethnicity or language skills in Spanish are elements which are important to have for the capataces (as they are called by the Mexican workers), because people working in those places are usually Latin-American, mainly Mexicans, Guatemalans, and some Asians. Workers are asked to perform quickly, under constant surveillance and threats of replacement. Wages are normally below the minimum wage and the labour processes are demanding. The workers never receive 
more than 9 dollars per hour from the agency, and work for up to 10 or 12 hours shift. For this reason, local people do not want to do these jobs and the turnover rate in those companies is high.

In the medium sized factories and plants that I briefly described, the undocumented workers suffer from pressure, physical exhaustion, disrespect and sometimes even physical violence in the workplace. The labour processes are dangerous and physically demanding; the working environment is dirty, smelly, sometimes noisy, and the work is performed, under pressure, at a high speed. There is often no adequate or sufficient safety equipment provided to workers. Additionally, as they are hired, managed and paid by outside recruiters, as described in Chapter Three, the workers often suffer abuse not only from the supervisors at work, but also from the brokers who quite often do not pay the wages on time, commit wage theft, fire people without explanation and even sometimes use intimidation tactics and physical violence.

The treatment that the undocumented workers receive in the workplace and the techniques of abuse, manipulation and bondage under which they live while working through recruiters under the semana caida, bonding technique described in Chapter Three, closely resemble to what some scholars identify as "contemporary forms of slavery," "unfreedom" or "social servitude" (Anderson, 2004; Androff, 2010; Bales, 2007 \& 2012; Basok, 1999; Brass, 1999; Fudge, 2016; Manokha, 2004; Martig \& Saillant, 2017; Martig, 2017; Miers, 2003; Nizan, 2004; Pantaleón \& Castracani, 2017; Quirk, 2008; Reid-Musson, 2017; van der Anker et.al. 2004). Those conditions confine the undocumented workers bodies and minds to "a form of being denied," (Gunn 1994); that is, alienated, existing as other than themselves (2). Such material conditions seem to be at the basis of how they imagine Canadian society thinks of them: as "working machines," "work beasts," or "nobodies." 


\section{Performative submissiveness and mental suffering}

In such contexts of alienation, work functions like a mirror through which the undocumented workers learn what they "really are," in their view, in the society that "receives" them. The empirically founded understanding that their social being is at once legally expelled from society and reduced to a status of a working machine, shapes a particular way in which they tend to establish relationships with others, especially with authority figures such as employers or potential employers, recruiters, and the local white population. This last aspect is not clearly described in the interviews, but I was able to perceive it in the points of production. This way of relating to others consists of an everyday deployment of performative acts of submission which aim at keeping themselves inserted in the job and, by extension, at keeping themselves living in the country. Such performative acts of submission consist of: a) sending out signs of gratitude to the employer, the recruiter and the supervisor on a daily basis, such as bending down the head and back and using short phrases of appreciation and thankfulness; b) bursting out laughing when being publicly humiliated, as a way of hiding indignation, c) engaging in non-transparent, nondemocratic communicative acts with authority figures through which deference is given to the employers in all of which they say or do, for example by nodding the head as a sign of recognition and agreement with what the authority figure says, or by frequently saying "yes" through speech, and d) repressing the desire to express their own opinions. Finally, e) another form consists of withdrawing from social relationships, especially at work, and to avoid as much as possible interactions with the boss or supervisor, especially in the moments in which coworkers-from whom submission must be hidden—are around.

There is a structural reason for which those rituals of submission (or evasion) are carried out. Living under conditions of a crisis of social reproduction, cast out by the State, unauthorized to 
live and work in the country, separated from society, and prevented from accessing the institutional structures of social solidarity, undocumented immigrants have no other mechanism but their labour power to make ends meet and to continue living in the country. Even more, as the workers quickly learn that their social worth heavily depends on their capacity to perform in society like "working machines," on their capacity to carry out socially undesirable work, and on their permanent availability to work for as many hours as possible, they tend to develop the idea that their job can be only kept through displaying an attitude of hard work, dedication and docility. Men who have children or who work in assembly lines, in farms and in restaurants are more likely to act that in submissive or evasive ways. This is because in those workplaces they have to deal everyday with figures of authority and are more often exposed to the eyes of the supervisor, the recruiter and the employer on a daily basis. Those men are also more likely to neglect taking care of themselves at work, to look after their own safety, health and wellbeing. The case of Miguel, a 45-year-old Mexican undocumented worker father of three, exemplifies this situation. I transcribe Miguel's case from my field notes:

Miguel has been working for a construction and renovation company for 5 years. Because he often works side by side with his employer, he is under supervision every day. His boss is an educated, middle aged, Chilean-Canadian white man who owns the company. He picks up Miguel and other workers every day at $5 \mathrm{AM}$ from a metro station in Cote des Neiges and brings them back to the same metro station when the shift ends. Miguel's job is to renovate apartments: repairing and painting walls; changing floors, doors and windows; cleaning, and making small repairs in the bathroom and kitchen. It is all hard work. He works there around 8-10 hours every day from Monday to Saturday with poor safety equipment, mainly a pair of safety boots that his boss made him to buy for 80 dollars. I worked with him a short season painting and renovating buildings.

Miguel came to Canada, like most of the people I interviewed, looking for work. In Mexico, he was unemployed, and, because of his age, he never had prospects for secure employment after losing his job as a salesman in a local newspaper in his hometown located in the north or Mexico. He has a family of six: three teenagers, his wife, his father and his mother. They all live in the same house and all of them financially depend on him. He needs to work all the time to be able to pay his expenses and those of his family back in Mexico. Family expenses are high, as his elderly parents live in the same house with his children and wife, and his children are all at school. One day, while we were painting the lower part of the 
walls of a building (we were painting 12 apartments that week), there was a problem with a fellow worker, a Quebecois white man who asked us three times not to work so fast. The worker also complained about the fact that we were not wearing knee pads while painting on our knees. ... Miguel said yes, nodded his head while saying: oui oui, je comprend. Then he went out to smoke a cigarette to diminish tension. When the boss came to take a look at the work we were doing, Miguel asked the boss to leave us (to him and I) to work alone, away from that Quebecois man. He explained the reason of his request. The boss paid attention to him and the next day he diplomatically transferred the other worker to another building that was also being remodeled in another part of the city. I told Miguel that I did not understand why he did not pay attention to the worker, who seemed to me being right. 'It is better for us and for everyone if we work at a normal pace and protect ourselves in our health' I said. I also told him that I did not understand why he was reporting that to the boss! that we would get less tired, that it would be less tension with the workers, and that we would not end up so sore from the knees. I reminded him that, every day at night, he arrived so bad at home that he had to take a hot bath with salt and take a Tylenol pill to take away the pain from his knees (pain coming not only from work-related tiredness. He has a light disability in his left knee since long ago) and being able to sleep. Arturo got annoyed by my observations and told that I was naïve. He reminded me what he has told me before: That not complaining and not demanding much is what keeps them inserted in the job.

Miguel has intimidating manners. He is a physically robust man. He has coarse features, frowning eyebrows, as if he were angry all the time, and a strong tone of voice. He can be a bit intimidating when interacting or having a conversation. Among the comrades who get to know him well, we know that having a different opinion, or discussing with him very passionately on any subject (Canadian life, work, Latin American politics, soccer-his favourite topics) can easily lead to a verbal confrontation, as he often displays intimidating gestures with hands, head and eyes. His intimidating aesthetic, however, gets often radically transformed when he interacts with the boss or with a local white person. When his boss takes a lot of time before paying wages, for example, he gets mad when telling me about it, but is docile when in a face-to-face interaction with him. He has to inquire about his salary and wait without reluctance to get paid, sometimes up to two weeks. In such cases, he tends to display a sort of docile, at times elusive, and submissive behaviour. It 
seems that the fear of being expelled from work, or from the country, or the fear of being denounced, are the cause of such change. "Those are the rules of the game," as he says.

Performative submissiveness has an important effect on the health of the workers beyond solely preventing them from taking care of themselves in the workplace and making them act with docility with authority figures. Since that form of agency relies upon repression and self-neglecting discipline, it has also an effect on the level of the mental wellbeing. The sociological and anthropological literature documenting the resistance of the weak has registered in detail how apparently insignificant micro acts, carried out by workers when interacting with their bosses or when doing work, can by themselves constitute acts of resistance, small acts that contain a seed of insubordination which allows them to deal with their bosses' yoke. To fart right after having greeted the boss with vehement submission, to work slowly or to drag one's feet when receiving orders, to appropriate goods from the factory at the pace of an ant, for example, can constitute "weapons of the weak" to protect their dignity and to resist oppression, exploitation and authoritarianism (Scott, 1986, $1990 \& 2008$ ). The acts of performative submissiveness that I registered in the field in the medium-sized companies, which are quite different from those occurring in the multinational corporations, as will be discussed later, have some of those same characteristics. They are individual ways of dealing with authority in the workplace and with the possibility of deportation. But, instead of romanticizing them, while I was registering in the field all those acts of passive resistance, I asked myself several times: How are such forms of agency experienced deep inside? How do they manifest themselves in the worker's body and mind? In other words, what is the price, in terms of health, that the workers have to pay for carrying out such acts of performative submissiveness on a daily basis? I will try to provide an answer to these questions in the paragraphs that follow. 


\section{Mental suffering and nightmares}

Carried out constantly and repeatedly through physical and mental effort in the context of the threat of deportation and constant humiliation, performative submissiveness ends up reminding the workers of the importance of having personal dignity respected. Dignity, a condition, even though is kept subjugated, beaten down and weakened in the context of exploitation and deportability, never goes away. The idea that there is a frontier demarcating the limit of what is intolerable is something consubstantial to human beings. The very notion of what it means to be a human being, in Western thought, conditions this (Camus, 1991 [1951]). For this reason, the recognition that human dignity is something that must be preserved and protected enters into contradiction with the experience of daily humiliation and also with the mechanism that is used to navigate in this context: performative submissiveness. Therefore, the struggle among calculated performative submissiveness, the pleasure principle essential to all human beings (Marcuse, 1974 [1955]), and the moral principle, also consubstantial to all human beings, that recognizes that human dignity must be kept protected and respected, has the effect of keeping their subjectivities stressed out, in a permanent state of tension. Being subsumed into this windmill of contradictory social forces submits the bodies and the minds to permanent strain; tension that manifests itself in a variety of physical and mental discomforts and illnesses: sleep disorders, depressions, feelings of humiliation, feelings of "being nobodies," less than human, or "beasts of burden," as described above.

It also manifests itself through nightmares. From my point of view, an important number of the mental disorders, principally sleep disorders and nightmares, as registered during my field work, should be recognized as a way in which mental suffering is manifested in these contexts in which 
capital power and state power act upon the mind and body of the undocumented immigrant over an extended period of time. It is not by coincidence that sleep disorders and nightmares appear as the most frequent mental health disorder reported by the undocumented workers toiling in the middle size local sweatshops whom I interviewed. In what follows, I will describe how this happens.

\section{II}

\section{Sleep disorders, post-traumatic nightmares and Short-Term Historical Trauma}

Sleep disorders are at the top of the list of mental health problems that the undocumented working in the medium-sized companies reported during the interviews. A significant number of the sleep disorders that they mention appeared in the form of recurring nightmares. For this reason, when talking about sleep disorders and nightmares I will refer to the diverse forms of stress that the workers experience while working under such labour regimes, as well as to the severe forms of trauma, or interlinked traumatic events, that the workers have experienced while working and living under conditions of illegality.

In order to understand the social and historical dimensions of stress and trauma experienced by my companions, the set of mental health disorders linked to those stresses, and the responses to such forms of trauma, I will use to the concept of "historical trauma" as defined by Lakota professor Maria Yellow Horse Brave Heart (2003). In the definition coined by Brave Heart (2003), Historical Trauma (HT) refers to:

the cumulative emotional and psychological wounding, over the lifespan and across generations, emanating from massive group trauma experiences' while 'historical trauma response (HTR) is the constellation of features in reaction to this trauma. The HTR may include substance abuse, as a vehicle for attempting to numb the pain associated with trauma. The HTR often includes other types of self-destructive behavior, suicidal thoughts and gestures, depression, anxiety, low self-esteem, anger, and difficulty recognizing and expressing emotions. Associated with HTR is historical unresolved grief that accompanies 
the trauma; this grief may be considered impaired, delayed, fixated, and/or disenfranchised. (2003: p 7)

I am conscious of the fact that the concept of historical trauma provided by Brave Heart, and so the collective and individual responses to it, refers fundamentally to the traumatic experiences that have been accumulated in a social group as a consequence of being exposed to multiple forms of suffering and structural violence —as defined by Paul Farmer (2005:29)—, over long historical periods of time, for example as a consequence of experiencing genocide, colonization and dispossession. I am also conscious of the fact that the studies that have applied such concepts to communities and nations (black people, First Nations people, Jewish people, and Latino communities) explore the cumulative effects of trauma which has been passed down, historically, across generations. This represents a methodological challenge for me. As the community of undocumented workers that I worked with represent the very first generation of undocumented people living in Canada (almost all of them, as mentioned in the previous chapter, arrived as refugee seekers and have lost their status at some point in time over the last 10 years), the traumatic effects to which they have been exposed have not been yet transferred over across generations. In order to solve this methodological problem, I will adapt the concepts so that they can be applied to the cumulative effects of trauma over the lifespan of just one generation. I will then refer to Historical Trauma, and to the Historic Trauma Responses linked to it, on a short-term time scalele courte durée, to use Fernand Braudel's time scale typology (Braudel, 1995) ${ }^{20}$. By this I mean

\footnotetext{
${ }^{20}$ Although focusing on the "longue durée" was for Fernand Braudel the great task of the social scientist, he suggested that shedding light on how events occur (expressions of "le courte durée") and develop over shorter periods of time can help also to illuminate aspects of what occurs at the broader scale:

"Events are the ephemera of history," he said. "They pass across its stage like fireflies, hardly glimpsed before they settle back into darkness and as often as not into oblivion. Every event, however brief, has to be sure, a contribution to make, lights up some dark corner or even some wide vista of history. Nor is it only political history which benefits most, for every historical landscape - political, economic social, even geographical - is illumined by the intermittent flare of the event.... I am by no means the sworn enemy of the event" (Braudel, 1995: 901)
} 
that I will register the events linked to stress, suffering and trauma that have accumulated over the lifespan of the people I interview since the time they embarked on a transnational migratory experience until the time I conducted the interview, a time-frame which includes the moment in which they lost their legal status in Canada. I will call this "Short-Term Historical Trauma" (STHT). By "Short-Term Historical Trauma" I will understand the emotional and psychological woundings that have accumulated over the lifespan of just one generation of individuals since the time they embarked in a transnational migratory journey and lost their legal status in Canada until the day in which the interview was conducted. Following the same rationale, by "Short-Term Historical Trauma Response" (SHTR) I will consider the constellation of responses and coping mechanisms that individuals living undocumented in Canada carry out in reaction to the shortterm scale historical trauma they have experienced over their lifespan as international migrants and undocumented workers. In order to be coherent with the historical perspective that lies behind this concept, in this section I will try to link the events (histoire événementielle) that have caused harm, suffering and emotional and psychological wounding to the undocumented workers to broader historical processes, when such links can be identified. Human pain and suffering, in this way, can be seen as the forms of grief and trauma produced by the foam of broader historical waves.

Having made this methodological adaptation, let me describe first the mental health problems that were reported by my coworkers and by the people I interviewed in the field, followed by an analysis of the particular types of mental health disorders that they reported experiencing while

I decided to focus on "le courte duré" because focusing on the "longue durée" may put us in risk of repeating what can be predictable and obvious; that is, that colonization and the ways in which that long-term historical process created the borders and also defined the economic-political situation lived in Latin America, has shaped the historical trauma that south-north border crossing people experience today. I am more interested in the specificities. For that reason, I prefer to focus on the short-term historical events. 
living as outlaws in Canadian society, or that I observed them experiencing, and the ways in which these problems are linked to diverse forms of historical trauma, particularly severe forms of sleep disorders and nightmares.

\section{a) Sleep disorders among the undocumented immigrants}

Sleep disorders (including nightmares) are the most commonly identified as the leading cause of mental health challenges for the interviewees, and they appeared to be more concentrated amongst those working in the: 1) Pig, chicken and quail slaughterhouses, 2) Cleaning (hotels and industrial cleaning), 3) Recycling, 4) Restaurants, and 5) Vegetable farms and food packing companies. Within such factories, the sleep problems reported by the workers seem to be significantly interconnected to other mental health disorders, such as: stress, depression, anxiety, mood disorders and "feelings of being nobody."

For heuristic purposes, it is important to make a qualitative distinction among the sleep disorders that the interviewees reported, in order to be able to identify which types of sleep disorders can be classified as linked to post-traumatic stress disorders and to diverse forms of historical trauma. For such purposes, I will rely on the classification that has been created in the scientific field of studies on sleep disorders ${ }^{21}$, and also on the accounts of those whom I interviewed. Following the criteria

21 The International Classification of Sleep Disorders (ICSD) enlist more than 81 sleep disorders, grouped in the following 8 categories (see: Thorpy, 2012):

1. The insomnias

2. The sleep-related breathing disorders

3. The hypersomnias of central origin

4. The circadian rhythm sleep disorders

5. The parasomnias

6. The sleep-related movement disorders

7. Isolated symptoms, apparently normal variants and unresolved issues

8. Other sleep disorders 
that has been established in this field of study — which enlists sleep disorders in 8 categories (Thorpy, 2012) — and using the narratives of the interviewees as a classifying guide as well, sleep disorder experienced by the undocumented workers can be divided in two main clusters:

1) In the first cluster I include all the sleep disorders that the workers experience occasionally. These types of sleep problems are grouped here because they show some evidence of being linked to particular stressful events, fatigue or anxiety that the workers experience in particular moments of time. Within this cluster, the following variety of sleep disorders can be enlisted: a) occasional insomnia (generally due to excess of fatigue and/or financial, family or work-related concerns or worries), b) sleepiness related to breathing disorders (when the person cannot sleep due to snoring or sleep apnea), c) hypersomnias of central origin (defined as "the inability to stay alert and awake during the major waking episodes of the day, resulting in unintended lapses into sleep"), d) circadian rhythm sleep disorders (when the person "cannot sleep when sleep is desired, needed, or expected"), and d) Parasomnias (which include certain type of nightmares that are experienced occasionally)

2) In the second cluster I include sleep disorders that are experienced on a persistent and chronic basis over long periods of time. The types of sleep disorders grouped here show some evidence of being linked to highly traumatic events, or to anxiety or stress that are experienced over a long period of time (more than one year). Within this cluster, following the International Classification of Sleep Disorders, I include the cases in which the worker has been experiencing nightmares for more than one year. Classified as being part of Parasomnias, nightmares are defined by the scientific community as: "undesirable physical or experiential events that accompany sleep [and that] consist of abnormal sleep-related 
movements, behaviors, emotions, perceptions, dreaming, and autonomic nervous system functioning [...] They are disorders of arousal [...] and are manifestations of central nervous system activation" (Ahmed \& Thorpy, 2010: 219). As such, they disrupt sleep and have been associated with chronic sleep insomnia and night terrors. Scientific evidence shows that nightmares — which are divided in two main types: 1) idiopathic nightmares and 2) post-traumatic nightmares - usually contribute to the development of other mental and physical disorders, such as incapacity to focus, permanent fatigue, suicidal thoughts, incapacity to stay alert, night terrors, among others (Spoormaker, Schredt \& van den Bout, 2006: 22). Linked to post-traumatic stress disorders, post traumatic nightmares are more prevalent among people who have been exposed to genocide, war, and sexual assault, such as indigenous peoples, refugees, war veterans, battered women, abused children, and sexually assaulted peoples (Cervantes and Salgado de Snyder, 1989: Roth, Newman, Pelcovitz, Van der Kolk, \& Mandel, 1997; Spoormaker, Schredt and van den Bout, 2006; Van der Kolk, Perry \& Herman, 1991; Van der Kolk, Roth, Pelcovitz, Sunday \& Spinazzola, 2005;). Therefore, post-traumatic nightmares can be linked also to historical trauma.

Following the classification provided above, let me now offer a general picture of how sleep disorders are distributed among my working companions and interviewees. This information will show us who among the undocumented workers interviewed, men and women, are most affected by post-traumatic nightmares and historical trauma. We will later see how this focus on nightmares and sleep disorders, a phenomenon that has been largely ignored or overlooked by the students of labour, migration and health, particularly among those studying the health of the undocumented workers, will help us to understand how these forms of illnesses are important symptoms or 
expressions of broader and more widespread forms of human suffering that have been set into place by the morbid effects of state administration, labour exploitation and racism under their latter form, a form shaped by the dynamics of late capitalism. Finally, this will help us to understand how post-traumatic nightmares, which in the context of international migration start always first in the form of broken dreams, develop over time through a set of traumatic events which, in their latter stage, converge in the production of damaged bodies and wounded subjectivities.

More than half of the research participants interviewed reported experiencing one or more of the sleep problems that were classified in the first cluster as "occasional sleep problems." Most of them were men working in the cleaning services industry, in the chicken, pork and quail slaughterhouses, and in construction companies. Those workers are mainly affected by a) occasional insomnia due to work, family or financial concerns, b) hypersomnia, due to the lack of regular bedtime and everyday routine, and c) circadian rhythm sleep disorder, due to tiredness and overstress, and d) sleepiness related to breathing disorders (snoring in excess, which most of them attribute to fatigue).

Women tended to report "occasional sleep problems" sporadically. Grouped by the branch of industry in which they work, the women who reported higher levels of sleep disorders are: a) Those working in restaurants and cleaning hotels and those working in pork, chicken and quail slaughterhouses. They are mainly affected by a) occasional insomnia due to fatigue, work, family and financial concerns and b) circadian rhythm sleep disorder, due to fatigue and overstress.

It is important to point out that, although I mostly interviewed men, women are more likely to experience post traumatic nightmares and other mental health illnesses that can be classified as linked to historical trauma. 
Only a few of my interviewees reported not experiencing sleep disorders, except for occasional sleeplessness, whether because those workers spent the night doing some immigration-related paperwork, because they attended a party until late, or because they had a strenuous working day. Occasional and light sleep disorders of this type were mostly concentrated among young adventurers who had recently entered into the country with legal permission but overstayed, expecting to get some language skills, make some money working under the table, and learn from Canadian culture. This group included people who mostly worked in restaurants or in construction on a casual basis, as well as those who have been undocumented for a short period of time but have found a Québec partner and are in the process of transitioning to a legal status with the help of their partner and her family. They normally reported experiencing anxiety and stress due to family and financial concerns, as well as feelings of disappointment and even anger, particularly when they have had bad experiences with their recruiters or their bosses at the work (mainly due to authoritarianism or wage theft), or when they feel like have been racialized or excluded because of their lack of language skills. They also reported to experience mild levels of homesickness, sadness or depression, mainly because of social isolation. This group of workers also reported having some physical health problems, mainly due to work-related accidents and/or fatigue.

\section{b) Post-traumatic nightmares among the undocumented workers}

Unlike the cases I described above, around a quarter of the undocumented workers interviewed reported having sleep problems in their more severe form; that is, in the form of nightmares. In most of the cases, nightmares were accompanied by night sweats, night terror, and frightening dreams, which included images of persecution. When discussing about the content of those nightmares, I was told a diversity of narratives. But despite such diversity, the stories share a fundamental narrative structure: the protagonist of the dream is trapped in the middle of a war or 
he/she is being persecuted by a person, by a group of persons, or by an animal. The physiological characteristics of the persons or animals that persecute the protagonist of the frightening dream are not easily identifiable, and they appear in bizarre moments. Almost none of my interviewees, with the exception of an adult woman, managed to identify with a certain degree of precision the physical characteristics of the animal or of the group of people that persecute them and try to trap them in their dreams: "It is a huge, dark animal," she told me, "that has many hands and looks like a spider."

Although the rest of my companions who reported having bad dreams and nightmares failed to identify the physical characteristics of their persecutors in their dreams, they agreed that although the physical characteristics are not clearly identifiable, they are figures that evoke fear, that have bad intentions, as they want to trap, to obstruct, to kill or to damage the physical integrity of the persecuted subject. The central characters in the dream are individuals who face harassment or persecution in solitude, with nobody around facing the same situation. It is never a group of individuals who suffer persecution. Also, nobody is ever present on their side, in the support or protection of the protagonist who appears persecuted in the bad dream. The protagonist who is being persecuted is usually the person who is having the nightmare: the undocumented person narrating the dream. That is why, when talking about the nightmare, they tended to say: I had a bad dream in which I am persecuted, or in which somebody has been tried to kill me, etcetera. During the persecution, the protagonist carries out strategies for escaping and salvation by trying to cross a space or a line. That line is a border. But such a border is never clearly identified by my interviewees who could not identify if that is a line dividing two countries, two neighborhoods or something else. The only thing that is clearly identified by the interviewees is that such border 
divides a space of terror from a space that represents salvation and a safe place that will eventually eliminate menace or terror.

The type of nightmares described above are considered serious forms of sleep disorders and I classify them as post-traumatic nightmares. In the scientific field of studies on sleep disorders, described pages above, it is understood that this type of nightmare, accompanied by night terror, persecution images and night sweats, are part of a post-traumatic stress reaction normally suffered by people who experience Post Traumatic Stress Disorder (PTSD), such as war veterans, people witnessing or experiencing genocide, battered children and sexually assaulted people. It is also often experienced by refugees. PTSD is manifested in three ways: First, people experience forms of intrusion, an event by which the person re-experience the traumatic event through nightmares or flashbacks. Second, the person, deliberately or subconsciously, avoids external stimulus that could remind them of the traumatic event. Third, the person also experiences hyperarousal (insomnia and increased tension during the day). Post Traumatic Nightmares (PTN) are part of the re-experiencing cluster. They are thought as reaction of the mind and of the body to post traumatic stress disorder (Spoormaker et al, 2006: 22). I grouped these people in this category because, as described in the scientific classification in the field of sleep disorders, the workers who told those experiences said that they had been experiencing these types of nightmares over long periods of time (two years or more), and that they are often linked to physical manifestations such as trembling and night sweats. As such, they can be classified as post traumatic nightmares.

Those experiencing post traumatic nightmares, or nightmares linked to PTSD, are mostly working in the following types of industries: 1) Pork, chicken and quail slaughterhouses; 2) Recycling companies, and 3) Medium-sized companies making, packing and freezing pizza. Unlike what 
occurs among the people experiencing occasional sleep disorders linked to work, family and financial worries, gender differences in this case are more significant. Undocumented women interviewees, despite being less represented in my sample, were more likely to report having nightmares and frightening dreams for a long period of time.

Although initially I grouped people only according to the type of work they do and to their gender, when I analyzed their narratives in more detail I could appreciate that the majority of the nightmares that are linked to PTSD are in fact, most of them, linked to a variety of traumatic events that the interviewees have experienced since the moment they started their transnational migratory movement, or some time before that, while in their country of origin. In different ways, those traumatic events are related to, or have been shaped by, the social determinants of health enlisted in the first part of this chapter: long-time exposition to labour exploitation, racialization and state administration (including institutional mechanisms of surveillance, illegalization and deportation). Those traumatic events are also interlinked to each other and operate as constellations of wounds that have been accumulating on the bodies and minds of the undocumented workers over long periods of time, having as a consequence the progressive undermining of their mental health and their entrapment in the diverse types of sleep disorders and post-traumatic nightmares that they experience in the present. In what follows, I will provide a more detailed description, based on the workers' own narratives, that shows how the post-traumatic nightmares (for the workers inserted in the medium-sized enterprises) are linked to specific forms of short-term historical trauma. I will then analyze the ways in which post-traumatic nightmares are shaped, in the last instance, by the four master determinants of health described in the second chapter of this thesis. The analysis of post-traumatic nightmares will help us to uncover the central role that racialization, exploitation and abuse in the workplace, state administration and the condition of deportability, play on the 
production of this form of mental disease. This will reveal also the ways in which such conditions are likewise linked, more generally, to a variety of physical illness and workplace accidents that the undocumented workers experience.

\section{c) Post-Traumatic Nightmares and Short-Term Historical Trauma: Three composite cases}

People who have been experiencing nightmares for more than two years are the ones whom I classify here as having been subjected to the cumulative effects of "short-term historical trauma." This means that the post-traumatic nightmares experienced by the workers I interviewed are related to the variety of interlinked traumatic events that have gradually accumulated over time. Such traumatic events quite often started a short time before they decided to leave their country of origin, whether because of political reasons, state violence, displacement and/or dispossession, and ended up being reinforced when, after having been heavily involved in refugee application processes, the former asylum seekers, now undocumented workers (the nouns are extremely important here), lost their legal status. Being persecuted or forced to emigrate; being unable to return to their country of origin; being forced by material need to work and live under conditions of illegality; being exposed to labour exploitation and violence in the workplace on a stable basis; being subjected to racialization, and subjected to state investigation, entrapment and to the possibility of (or actual) deportation; all of those conditions, coupled with a permanent shortage of the basics needed to meet their most fundamental human needs (such as healthy food, health care, love—including erotic love - housing and clothing), accumulated over time and formed a constellation of wounds, traumas and griefs, that left them in a condition of permanent distress, emotional and material precarity, illnesses, pain and suffering. Let's discuss all those aspects by looking at three emblematic cases. 


\section{Case 1): Marina}

Women are the most affected by the accumulation of short-term historical traumas. The story of Marina, a Mexican woman who arrived in Canada as a refugee seeker escaping political violence and persecution, but who lost her legal status after being rejected by a Refugee Board of Canada judge, expresses well this tragic situation. On a winter night, over a cup of coffee in a crowded Tim Hortons on Jean Talon street, Marina shared with me a long list of events that seem to be clearly related to her sleep problems and recurrent nightmares. Marina is a Mexican woman born in Durango. At the age of 29, she emigrated to Ciudad Juarez, the city of femicide in Mexico, to work as an assistant to a radio company. After a long time of hard work, she was promoted to a director of a radio program which was linked to a local news program. On the radio program, Marina interviewed community workers from the region, politicians and local artists. She and her guests discussed, in the program, myriad events and problems that afflicted Ciudad Juarez. She conducted interviews and presented reports and information capsules. Her radio program was elaborated from a feminist perspective. From that perspective, she and her guests discussed topics related to inequality, urban insecurity, sexuality, family relationships, and "not-so-formal news" on Monday, as she calls the capsules she made, relating information about lost people, and calls to local cultural events. After two years of conducting the program, Marina faced problems of political persecution and threats to her safety.

As honest journalists do in northern Mexico, on the radio program she used to speak about the problem of femicide, as well as about impunity, corruption, drug trafficking groups and sexist violence that is promoted or tolerated by the State and local politicians. Due to her work, at some point Marina started to receive phone calls with death threats. She was never informed of the reason why she was receiving such threats. But she attributes this to the fact that, when talking 
about femicide, she used to criticize the Ciudad Juarez government, particularly the municipal government, because, according to her point of view, the local government has always been implicated, by omission, in the systematic killings of women in that city. Due to fears of being tortured or assassinated, Marina decided to emigrate to Canada. "They never did anything to me, except for the threatening calls. But I did not want to become another victim," she told me several times. But her migration and refugee application in Canada did not take place immediately. The fears she faced of being killed or tortured, she told me, forced her to quit her job first. And this situation kept her in a situation of unemployment and precariousness that worsened after a year, because of the fact that, after she left the program, she was no longer be able to find employment in any other radio program. "It's not that I was a threat to the system," she says, but simply that in general, "In Mexico there is no work. And the support for journalists that exist in Mexico, which was helpful for me, unfortunately does not addresses the unemployment aspect that threats generate, as well as the poverty and precariousness in which one ends up trapped after, as journalist, one is forced to quit the job." As a result of the precariousness and fear of being killed, Marina decided to ask for refuge in Canada. But the judges did not believe her, and her application was rejected. In the following extract of the interview that I conducted with Marina, she explains how this situation of being denied refuge in Canada, her subsequent condition of illegality, and her status as an immigrant woman have affected her physical and mental health and accumulated forms of trauma that have made her feel victim of incapacitating physical and mental problems, including recurrent nightmares and frightening dreams. I transcribe, here, a long extract of the interview in order to avoid ignoring the complexity and the historical context that explain the ways in which her mental and physical health have deteriorated over time and transformed her from the brave, healthy, capable and educated woman she was into the human being that she feels she is today: an 
introverted woman who is constantly dealing with low self-esteem and enduring physical pains associated with her deteriorated body. When we were talking about the state of her physical and mental health, the subject of sleep disorders and nightmares came up as a significant issue. On this, Marina said:

Nightmares? Yes, a lot! I wake up in the middle of the night and then I cannot sleep anymore, for at least two hours or an hour. I have been living in this situation for 5 years or so. And I go through the same kind of thing for two or three times a week. But there are weeks in which I do not experience that, and there also are weeks when I have nightmares almost every day. It changes a lot, but that does not stop happening to me. I think that is related to everything that I have gone through. Being rejected [in the refugee application] is a very difficult thing to deal with. And then the work, and the fear, the distrust that I already have for men because of what happened to me [a rape she experienced years ago]. Every time that happens [nightmares], I wake up sweating, scared. There is an animal that persecutes me, I want to escape, and I achieve that for a little while, but the animal keeps chasing me. I cross a river, or a fence, or a line, and then the beast finally catches me.... Then, I realize that it is a bad dream. I wake up, drink water, and then I go back to sleep. That happens quite often, but much more since they rejected me [referring to their refugee board of Canada], and also with the rape attempt I told you about. ...Yes. I have a lot of nightmares. I also get very sick from my throat. And I have read that every disease and every symptom is due to an emotional problem that you have not solved. And my throat gives me a lot of trouble. And I read it was because I shut up, I keep everything to myself. I share hardly anything because I can't express myself. And there it is. Voilá, as they say here .... And so, you see me sick of my throat all the time, like I'm going to drown. And, oh, I almost forgot this about the nightmares! Every time that happens to me, I wake up with the sensation that I'm going to drown, with my throat dry. That's why I drink water, lots of water when I wake up.

Marina told me that night that she also suffers from her ankles due to the fact that in her job she carries heavy boxes "for a long time, without stopping." She also suffers from anxiety, which makes her to eat "lots of flour, bread, ice cream, and all that," all of which have made her to gain weight and loss self-confidence and self-esteem. This situation is also aggravated by the fact that she also lost her some of her teeth. On this she says:

You see my older photos and you say: wow! I look super bad now, very, very ugly. One of my teeth broke. One day that I was biting a bagel... that I had put in the toaster... and I felt something like cracking, and I checked out and saw that my tooth was broken. I cried so much when that happened to me. Everything bad happens to me for being in this situation. 
I look so ugly. That greatly influences my self-stem... I cannot smile with confidence anymore because I look ugly. I feel so sorry when I look at the mirror and I see myself so chimuela [with no teeth]. For the jobs as waitress in the restaurants that counts a lot. You have to smile to the clients there, you have to show your teeth all the time. I cannot smile anymore. What a pity that I cannot smile anymore. I arrived in Canada with my teeth very healthy, but they broke. I do not know if I gave a hard bite to the bagel or if maybe the food I eat daily is so bad that my tooth become weak from the lack of calcium or something. I do not know, but the point is that ... they broke... But how is it not going to be like that? ... It's logical. When you do not have a job, you cannot eat well. ... In the food banks, they give you cans. And well, I eat all sort of poor food when I do not have a job. And so, I eat a lot of bread to fill my belly out and to avoid feeling hungry. In Mexico, I ate lots of vegetables, broths, tuna, fish. A lot of vegetables, salad, and things like that. And here, uf! not even in my dreams [ni esperanzas]. I will show you the pictures of before and after. I do not look like me, I look super ugly now. It has affected me a lot... Look, as an immigrant you usually face abuse, discrimination, rejection. ... But that is what a normal immigrant face, but for an illegal immigrant, things are a lot worst. I think that as an illegal you suffer the double of all that. And you have to take all that and keep yourself up [...] but I want to have hope.

In Marina's narrative we find several traumatic events that affect her mental and physical health. Although some of them are more intense than others, and they have occurred in different moments of time and in different geographical locations, all of them are somehow interrelated. As such, they must be seen as a constellation of traumas that, as they interact each other and intersect with other forms of precarity that emerge in the context of racism, labour exploitation, solitude, and abuse from the Latino community (her "own people" as she says), they get reinforced and produce cumulative effects on Marina's mind and body over time.

The set of events and traumas described by Marina have made her body and mind subjected to the cumulative effects of those traumatic events over a period of more than 15 years. As briefly described, in 2005, Marina suffered death threats in Mexico. As a result, she lived in fear of being killed for the next two years. This situation resulted also in her living under constant stress, fear of being killed, unemployment, poverty, and eventually forced her to leave her country. Once she entered into Canada, she asked the Canadian State to intervene by submitting a claim for refugee 
protection. After a "long and exhausting" refugee application process, as she refers to it, Marina's demand was rejected, and her stay declared illegal. Therefore, she also become deprived of the social benefits she had had while she was living as "refugee claimant" (the legal status a person is assigned when demands are made from within national borders). Overnight, she was left mentally and physically exhausted after multiple court hearings, with no work permit, no health coverage, no unemployment insurance, no right to social housing, and no right to social assistance (welfare). With no job and no access to social rights, subjected to poverty, and now fearing arrest, her only option was to join the underground labour market.

Through recruiters and employment agencies, the only option to get a job for those who have no contacts in the country, Marina became subsumed by a variety of small and medium-sized companies, such as restaurants, home cleaning companies and the local meat packing industry. Working in those places, she became subjected to exploitative and abusive practices by recruiters and supervisors, and also by the owners of small companies. She recalled with resentment and rage, for example, how the owners of small restaurants (Mexicans and Guatemalan men, mainly) people who once had arrived as immigrants but were now full citizens and proprietors, and women who had arrived as children of Holocaust refugees, and who were now proprietors of their own small or medium sized businesses, abused her and made her feel humiliated in the workplace. Instead of offering her solidarity and respect or feeling minimal empathy for her situation of vulnerability, they tended to show a mean disposition to cut hours of work at their discretion, to reduce wages, even though a previous wage had been agreed, to demand that she work faster or overtime, and to make demeaning (and non-objective) comments about the quality of her work, particularly when they needed to justify, she said, the lowering of wages. All of those abuses, she recalls with particular lucidity, always started after they learned about her precarious legal and 
material status. "I have learned about the human soul while living in these circumstances... as you cannot even imagine. People are capable of doing the worst things when they see you on the floor, and also people are capable of acting in the most self-humiliating ways when the other has power," she reflected while staring at the horizon through the windows of the Tim Hortons, one her former employers, with an exhausted look.

While navigating in that context of legal and material precarity, with no secure home to live in, in solitude and lacking social networks, she became also the victim of sexual abuse, which resulted in long-lasting memories of pain, as well as mistrust and fear towards men. Also, as a result of her incorporation to physically demanding jobs during long periods of time, her spine, which had already gone through a major fracture in Mexico two decades ago, entered into a deterioration process, a situation that worsened when she had another accident after she slipped and fell while walking on an icy road in winter. That accident caused Marina to experience chronic back and hip pain. It also affected her knees and ankles.

Most of the traumatic events and forms of precarity Marina experiences and that I locate as social determinants affecting her mental and physical health, coupled with the permanent exposure to stress and work-related physical exhaustion, are related to her gender, legal and ethnic status. Being a woman journalist in Mexico and then an undocumented brown Latina woman in Canada have exposed her to a set of risk factors which have seriously damaged her mental and physical health.

If we chronologically group the traumatic events and the forms of precarity to which she has been historically exposed during her adulthood, since the time she received the death threats in Mexico (in 2004) to her experience as a refugee claimant in Canada (2006), and then to her life as an 
undocumented immigrant in Canada as well (from 2009 to the present), we find that the entire chain of events equals 12 years of experiencing traumas and living in precarity. Let's briefly describe this in periods of time. In the medium term (during the last decade), she has experienced the following traumatic event: she lost her legal status and was declared illegal right after her refugee claim was rejected (an event that she locates as highly traumatizing, stressful and one of the "greatest defeats" in her life). She has been exposed to racial and ethnic discrimination since her arrival in Canada; she has suffered abuse and robbery within the Latino community; she has lived in permanent poverty and has therefore lacked access to a healthy diet; and she has been working in physically demanding jobs. All of this has happened since her arrival in Canada. In the short term, she has experienced the following traumatic events: Rape, and a hip injury that left her injured for two weeks (in a context of not having access to health care). This has happened during the last five years while living in Canada and labouring in highly exploitative jobs.

Examining the set of events experienced by Marina, including those that occurred in Mexico and which forced her to seek refuge in Canada and the car accident she had in 1998 which left her hip damaged, we find that she has been experiencing highly traumatizing events and living under a very precarious life for more than 18 years. This chain of events and precarious living conditions have made Marina's body and mind subject to an accelerated wear and tear; including a broken tooth; permanent back and ankle pain; a fear of living; depression, lowered self-esteem and body image issues; occasional loss of memory and inability to concentrate on intellectual daily tasks or on tasks that require the use of memory; lack of trust in other people; and, presumably, a health condition that in the field of social medicine is called allostatic load — that is, a set of symptoms generated by the wear and tear of the body and the nervous system that is generated by the permanent exposure to stress and strenuous physical work (Barr, 2012: 75-77). Only in light of 
this set of events which have historically accumulated over Marina's mind and body for almost two decades can we understand the reason why she now faces nightmares and bad dreams which may be attributed to post-traumatic stress disorder and historical trauma.

III

\section{State violence and the patriarchal reproduction of the short-term historical trauma}

Although in Marina's account we can see a variety of social determinants of health intertwined and in mutual interaction shaping Marina's health condition (gender, lack of social networks, precarious work, among others), the role of the State must be enlisted as a master determinant of her current health. By this I mean that, almost all of the traumatic events enlisted above (except for her hip accident in Mexico) are directly or indirectly related to a highly precarious migratory experience that has been first ignited and mobilized by force (by a sort of primitive version of institutional violence) and then administered (under the principles of instrumental rationality) by the state apparatus. As the ignition and subsequent administration of Marina's migratory experience occurred in two countries, Mexico and Canada, and involve two different forms of governmental structures, we must say that such forms of state violences are transnational. Such

transnational forms of state violence have two forms: a) a patriarchal-military form and b) a bureaucratic-administrative-police form. I identify the institutional intervention in Mexico that subjected Marina to the violence of death threat, and subsequently to unemployment and to exile, as a state violence that has a patriarchal-military character because the object of violence, carried out by state-hired gunmen, was the body of a woman who protests against violence against women. I also identify the institutional mechanisms that in Canada denied Marina the status of refuge, declared her illegal, stripped her of basic social rights and submitted her to surveillance and deportation processes, as a state violence that has a bureaucratic-administrative-police character. 
In the first form of state violence (that which has a patriarchal-military form), the municipal government of Ciudad Juarez, México deprived Marina from security and, through hired assassins, subjected her to a form of direct violence (death threats) in order to prevent her from continuing her professional work of providing critical analysis about women's insecurity and femicide in Mexico. That is why I classify it as a patriarchal and military violence. In the second form of state intervention, the Canadian government subjected Marina to three forms of institutional violence: misrecognition, illegalization and surveillance. That is why I call it administrative-bureaucraticpolice violence. Both forms of state violence have had highly destructive effects. Although the Canadian State violence in this case can be classified as a form of "legitimate violence," in the Weberian sense of the term, that is, as a force that is exercised by the administrative apparatus under the legitimacy of the law and in the name of possessing the "legitimate monopoly" of force (Weber, 2013 [1922]: 212-227), by no means is it less destructive. It is in fact a form of structural violence underpinned by three types of violence: 1) The first is the violence of legal domination and of legal misrecognition. In effect, through the refugee acceptance criteria defined by the law and interpreted by the Refuge Board of Canada, Marina's refugee claim was rejected, and the protection of her human security denied (violence of the law and violence of misrecognition); 2) The second is the violence of the dispossession of human security and social rights. By this I mean that, through the criteria established by the CBSA, Marina's residence in Canada was declared illegal and, as a result, she was expelled from the formal-juridical space that recognizes and protects people's human security through the order of individual rights - freedom of movement and individual rights — and the order of social rights — health care, education, work - (violence of dispossession and legal domination), and 3) the violence of police surveillance. Through the work of surveillance, investigation and persecution led by the Integrated Border Enforcement Teams 
(IBET) - composed of members from the RCMP, CBSA, CIC, CSIS and police forces at the municipal and provincial levels (See: PSC, 2017 and US Department of Justice, 2003), Marina's physical and juridical existence was subjected to techniques of investigation, surveillance and police persecution (Violence of surveillance). Seen as a whole, it can be argued that the role of the Mexican State in igniting Marina's migratory experience, and the consequent administration of such migratory experience by the Canadian State, have a patriarchal-policebureaucratic/administrative-transnational character.

Such transnational forms of state violence and state administration are at the basis of Marina's transformation into an illegal person and her exposure to suffering and structural violence. The long-time exposure to different traumatic events has subjected her body and mind to an ongoing deterioration process and to forms of post-traumatic stress that have made her experience nightmares, have mutilated and affected fundamental parts of her body (her teeth and hips) and greatly undermined her self-esteem. Thus, the precarity she lives in are related to the way in which the State produces forced human mobility in third world countries, and administers those forms of precarious migration in rich, host countries. Seen in that way, such forms of human suffering have been conditioned by transnational-like forms of state administration; a form of institutional intervention that, in the late-capitalist context, is exercised through a mixture of primitive (pure/crude/military) and modern (rational) forms of administrative violence.

In the light of Marina's experience, Max Weber's theorizations about the rationality that supposedly underpins the functioning of the modern state sound misleading. The State often works as a mechanism of arbitrary negation of anthropological universality and as a mechanism of intervention, class-based exclusion, domination and (often violent) reproduction of the social 
order, as the greater classics have dissected (Bakunin, 1953 [1882]; Marx, 1970 [1846]; Proudhon, 1849).

\section{Race, State, Capital and Short-term historical trauma}

\section{Case 2): Rachel}

Marina's story is not very different from that of other women I interviewed who suffer nightmares accompanied by night terrors on a regular basis and whom, using the criteria that have been established in the field of studies on sleep disorder, I have grouped as people experiencing posttraumatic nightmares or sleep disorders linked to PTSD. I will now describe and analyze another case. It is the case of Rachel, an 18-year old woman who also faces the effects of short-term historical trauma, a condition that also manifests in post-traumatic nightmares. Rachel's case is also linked to other more serious mental health symptoms: long-time, permanent depression and suicidal thoughts.

I choose to present the case of Rachel because it is qualitatively representative among the group of people who suffer from nightmares and bad dreams. Rachel's case is highlighted for two other reasons. First, because the traumatic effects described involve several members of the same family - two minors and their mother. Second, because this case expresses well the way in which the act of coming out of the underground by two minors, and their subsequent exposure to the dominant culture through their incorporation into the school system, led the children, simultaneously, to be exposed to the violence of racism, the violence of state administration (in the form of surveillance, entrapment and actual deportation) and the violence of labour exploitation. This case will demonstrate how the exposure to those master determinants of health, all at the same time, produce traumatic effects that accumulate, and transfer inter- and intra- 
generationally, and whose consequences for the mental health of the undocumented are devastating. The story involves traumatic events experienced by minors, but the interview was conducted when Rachel was already 18-year-old.

Rachel is an undocumented young woman who lives in Montreal with her mother. At the time of the interview, she dedicated herself to household chores because, due to major depression and fear of being arrested, she had temporarily dropped out of high school and stayed at home. Rachel began to experience sleep problems when she was 14 , and they worsened over time, particularly when she joined high school and especially after the moment when her brother was arrested by the police in the courtyard of his school, jailed in a detention center in Laval, released, and then arrested and imprisoned for a second time, a year later, and deported to Mexico in 2015. Her story describes a set of wounds that began in Mexico, Rachel's native country, expanded with the mourning process for her sudden departure from Mexico and the separation from her father and friends, and aggravated after her mother's refuge application was rejected and her residency in Canada declared illegal. It worsened also after the sudden arrest and deportation of her brother, the "only true friend" she has in life.

Rachel has experienced all the traumatic events described above throughout her childhood and adolescence, over the past 12 years. Throughout that time, those high-impact traumatic events, which began when she was 8 years old, have been interlinked with various forms of precariousness that, living in company of her mother, a 58-year-old undocumented single woman, have accumulated throughout her biographical trajectory. I have witnessed closely the gradual deterioration of her mental health because, since 2014, I have participated in Ramenons Daniel! a committee composed of lawyers, researchers committed to emancipatory research, students, 
educators and local activists who work together so that Daniel, Rachel's brother, can be allowed to return to Montreal to reunite with his family. As in Marina's case, the case of Rachel and her brother Daniel, exposes, perhaps in a more dramatic way, the harmful effects that state administration, in conjunction with the racialization of the migrant body and precarious, exploitative labour carried out under conditions of illegality have on the health of the undocumented people who are subsumed as workers by the local, medium-sized local companies.

Rachel and her brother Daniel arrived in Canada with their mother, who entered Canada as a refugee claimant. Rachel recalls the process of separation from her father and her most significant friends in Mexico, as well as the sudden poverty in which her whole family was trapped for a couple of years before their departure to Canada, as painful experiences. The refugee application process was equally exhausting, both for her and for her entire family, although she thinks that her mother is undoubtedly the one who has suffered the most throughout the process. Her mother, Lau, is a single mother of five, three of whom, being young adults, decided to remain in Mexico. The process of seeking refuge in Canada was exhausting because Rachel's mother, who, in a desperate attempt to escape both the discrimination that her son experienced in Mexico (Daniel has problems of deafness), and unemployment, decided to come to Canada without any other plan than to receive help from a woman who charged her two thousand dollars to get her papers in Canada.

As the "friend" of Rachel's mother had promised she would help them to get papers to live in Canada, but disappeared when they arrived, Rachel's mother was unprepared to ask for asylum when they arrived in Canada. In fact, since she did not bring documents to prove her refugee request (her friend had not even informed her that the purpose of getting her papers would be to go to immigration to seek for refuge), she did not have elaborated arguments, material evidence, 
nor had she received legal advice to support her claim. As a consequence, her case was rejected in less than a year. From the moment in which her case was rejected in 2008, with the consequent loss of social benefits associated with the status of asylum seekers, the life of Rachel and her family was plunged into precariousness as soon as they were declared illegal. Because of this, Rachel and her brother were also forced to drop out school. They stayed at home for a long time without the full-time company of their mother (she was working all the time), in conditions of semi-isolation, and helping their mother sporadically in the multiple jobs (mostly packing, cleaning or farming) that she had to do in order to put food on the table for her children.

In a long interview that we had in the deteriorated and tiny studio apartment, $3 \times 5$ meters in size, where they live (basically a room with an unseparated kitchen and a bathroom), Rachel talks about the state of her mental health. Depression and anxiety are in the top list. When I asked her about sleep problems, she told me she had sleep-related troubles, including nightmares, although at the time of the interview the problem of nightmares was already a bit more under control. For Rachel, nightmares began to manifest periodically in 2011 , two years after all of her family lost legal status (they were rejected in 2008 but went through a two-appeal process that were not successful either). They worsened between 2013 and 2014, a period of time in which her brother was caught and imprisoned twice and, eventually, deported. Rachel expresses that her "crises," as she calls those seasons in which nightmares and sleep problems appear on a more regular basis (periods in which she either sleeps a lot or not at all), consist of nightmares, accompanied by night terrors, anxiety, "fear of dying" and, occasionally, "desire to die or desire to disappear."

The desire to die, or death drive, that Rachel sometimes experiences, are strongly linked to her exposure to a variety of social determinants of health, but most concretely to the condition of 
deportability. The intensity of the fears of deportation has varied over time, but the fundamental fear of being trapped is always there, particularly since her brother was deported. But in addition to that, in her life there are many other traumatic events that have accumulated over time and seriously affected her mental well-being. The traumatic episodes that she and her family suffered in 2013 and 2014 with the entrapment, imprisonment and deportation of her brother have made Rachel to deal, permanently, with the pain of family separation, and also with the fear of being herself trapped as well. That situation has left an indelible mark on her life, because on both occasions, her brother's police entrapment took place in front of her eyes, and, as a horrendous spectacle, in the middle of the schoolyard. That set of events has made Rachel haunted with fears of being caught. The fear is of such magnitude that every time she sees a police patrol, or hears a police siren, or every time she sees the warning colors of a siren (even if sometimes those are the warning signs of an ambulance), Rachel imagine that it is the police coming to arrest and deport her or her mother. Such fears, according to her story, are expressed in her body with such intensity that when she sees those lights and those colors in a car, or the sound of a siren, she experiences body tremors "out of nervousness" (de nervios), her hands start sweating and she starts seeking a place to hide.

Rachel's situation indicates that the more undocumented people are exposed to state administration, racism, labour exploitation and deportation, the more dramatic mental health outcomes they will experience. The entrapment and deportation of her brother, in particular, but also the fears of being deported, her nightmares, and fears or desire to die, were presented with greater intensity not when her family was living in the underground (clandestinely) after being rejected in their refugee application and staying in Canada undocumented - though living locked in the house all the time was not good for her mental health either. The events affecting her mental 
health were presented or strengthened to a great extent since the moment in which she and her brother got access to formal education. That is, their chances of being deported, and in fact the deportation of her brother Daniel, occurred as a result of their coming out from the underground and their incorporation into the public world through their enrollment in the school system. It was not the lack of access to hospitals or public schools that deteriorated their health. Quite the opposite. Their incorporation into the school after two years of not being enrolled in school (from 2009 to 2011); their access to a fundamental social right, is the factor that exposed them to the set of violence that emerges from three of the master determinants of the health that we have mentioned: racialization, labour exploitation and state administration (in the form of surveillance, persecution, and deportation). Let's see how this contradictory situation presents itself.

In the interview, Rachel describes her school as a mix of a great and agonizing space. One the one side, she learned "a lot of good things" from teachers and friends. For example, her mastery of the French language, her capacity to read and write, and her love for music comes from her teachers, people from whom she feels admiration and respect. She remembers also the great feeling of having made three good friends at school. However, in general the school environment was a difficult place for her and her brother. This is because of three things she experienced there which have affected her health and moral and physical integrity quite substantially. There in the school environment, she learned that to be a Mexican is to be a carrier of a spoiled identity. She feels that, as an "obvious" Mexican woman — she has indigenous features from the Central American, Mayan region - she always carries the stigma (at least in the school that she attended) of being considered as an undocumented person or a person who may be linked to drug trafficking. She learned about this, Rachel explained to me, mainly through jokes, though sometimes through open bullying on the part of some of her schoolmates. They were just joking, she says. "I do not think there is racism 
at school, or bad faith. It is normal that we throw jokes at each other, but I remember that those jokes touched me, made me feel a little something deep inside" (se siente alguito). She says that, quite often, especially during physical education class, time in which people used to laugh and joke around, her classmates use to throw jokes at her and her brother by saying things like: "ándale, ándale, the migra is looking for you. Run like Speedy Gonzales. Go ahead, go for it!" Jokes making them look like narco students were also common: "Beware of the Mexican. She can be a narco. Ándale, ándale, the police is coming!"

The second negative lesson she learned in school is that her life "has little value, or worth less than others." She learned this, she tells me, not through jokes, but through the fact that she often faces, unlike most of her school friends, a shortage of cash and, therefore, cannot attend events where there is a fee to pay, or attend trips or parties organized by the school which require students to pay a fee or to spent money. In her own words:

I simply can't. We never have money to pay for that, nor do I have papers to travel abroad, like to the United States where my school friends sometimes go [...] That makes me feel like I am worth less than the others [como que yo valgo menos]. It's not like that my friends make me feel like I am worthless. They are good friends with me and I think they respect me. But, simply... look at this: I cannot travel like them, nor buy the fancy clothes that all the girls in the school wear. Nor I can buy the same things that they buy or attend the same events they attend. And that makes me feel like I am less than the rest, like I am worth less than the others. Actually... if you think about it, yes, it is true. Or so, that is how I see it.

The third negative thing she learned at school is that she can't trust that school authorities will protect her integrity or to keep her undocumented status secret. She learned this because, according to her suspicions, which were corroborated by Solidarity Across Borders, the director of the school was the one who reported to the police the undocumented status of Daniel, Rachel's brother, the final time he was caught by the police, incarcerated and deported. 
The coming out of the underground, where Rachel and Daniel used to live in, and their subsequent incorporation into school, not only exposed Rachel and her brother to the effects of racism, expressed through the jokes and sometimes through the mockery of their peers, jokes that, even if they were not badly intentioned, made them to "feel something deep inside." Their incorporation into the school; that is, their capacity to access their fundamental right to education, also subjected Rachel and Daniel to the mechanisms of state surveillance and the harmful effects of entrapment, incarceration and deportation. Also, going to the school, under such particular circumstances of poverty and precarious legal status, made them realize, through the direct gaze, the good material conditions, as well as the legal and symbolic privileges that their schoolmates have, and which, unlike them, allow them to travel freely and to buy, and wear, what they want and need. That is, in Rachel's words, going to school made them realize that they were, in fact, "worth less than the others." 22

But there is more to say in this story with regards to the determinants of health that have subjected Rachel to the effects of historical trauma. Her coming out from the underground and her subsequent incorporation into the school also exposed Rachel and her brother to the effects of exploitation at work. Because of the financial challenges associated with the school-related

\footnotetext{
22 On this last point, it grabbed my attention to realize that, as with Rachel and like what happens with others working in the middle sized enterprises that I interviewed, the condition of poverty in which they live is experienced as something that makes them feel like worthless people, or discriminated instead of feeling rage for what the system offers them in exchange for their labour or instead of thinking about themselves in terms of class, as a particular class of people who has been at the same time produced and used by the system due to particular conditions set by society. As the people working in the middle-sized enterprises represents most of the undocumented working population in Montreal, the classless identity is quite representative of the undocumented people I interview. The absence of a class identity or a class-based common grammar to understand and explain themselves within the current social context is probably linked, according to my register, to four material conditions: 1) the absence of union or union representation in the workplace, 2) the absence of that very grammar - which In Canada is normally produced by the false idea that we live in a classless society, as John Porter discussed with particular profundity, 3) the relative isolation, distance with regards to coworkers, and lack of time the workers have to get along with others and to develop that common grammar, and finally 4) the social class the now undocumented workers come from in their countries of origin.
} 
expenses, Rachel and her brother found themselves needing to work to help their mother. In fact, as soon as Rachel and her brother enrolled in school, the entire family unit had to work harder. Working is normally a great opportunity for adolescents. It helps them to develop autonomy and helps them to learn about the importance of working together as a family to overcome challenges and to achieve goals. But for Rachel and his brother, as undocumented, this experience was more challenging. During the school year, they worked part-time on weekends, which was not too bad, as Rachel notes. But in summers they used to get into full time jobs, mostly in the agricultural sector. They were incorporated into the underground labour market through the network of recruiters that her mom knew. In the workplace, the shifts were long and, despite being minors, they were usually asked to do heavy tasks, as if they were adults. It was through those spaces that their bodies were subjected to exploitation. They had worked in several medium-sized agricultural companies since they were 14 years old and were enrolled in the school system.

Rachel remember that in the workplace they were also exposed to racialization, as well as to the possibility of deportation, as are most immigrant undocumented workers. Also, soon after her brother was deported, Rachel started to participate in the Ramenons Daniel! Committee, and her presence become common in the press, radio and TV. That made her even more exposed to the public gaze. She has also experienced the legal processes that have involved a lot of wear and tear, poverty, work in excess and the conditions already described. Those particular conditions have subjected her body and mind been submitted to the four horses of the apocalypses in a permanent way: racism, exploitation, and state administration (including surveillance and deportation itself).

Since 2011, and especially since 2014, when her brother was deported, Rachel suffers from nightmares accompanied by night terrors. Although she does not remember the content of her 
nightmares with precision, she says that she wakes up frightened at night. She sometimes feels a strong desire to die or to disappear, and not even psychologists have been able to help her to keep those feelings under control. In Rachel's own words:

I would like that [to be cured from nightmares and sleep problems], because sometimes I have so many things in my head. But psychologists are useless. I have already been in therapy. Four years ago, I went with a psychologist. Médicins du Monde helped me out with that, because I used to have crises of fear ... fear of dying. And sometimes I even wanted to die also. I did not want to do anything. I was always distracted on the internet and I did not want to go to school, or leave the house, or do anything. Sometimes I just wanted to disappear, erase myself from the map. And my mom got scared. And I went to the psychologist. And the psychologist gave me advice, told me not to be afraid. He told me: when you start feeling this or that, do this and that. And, honestly, that didn't help me. Those crises happened... around 2011.

I think it was because of lots of news that I saw on TV. And also, for all that what we were going through, worries of all kinds. My poor mom. I see her struggling a lot. She is always worried. And she works so much! She leaves home very early and returns late at night, very tired and stressed out. And so, I got a lot of bad things in my head, many negative ideas. And those crises were daily. I still get those crises now. I still struggle with all that. But they used to be very ugly. And I could not sleep. I was sleeping like that, and I would wake up suddenly with my muscles all spasmed, my back contracted, my eyes wide open. I could not sleep. Well, I still sometimes can't sleep. When that happens, I wake up my mom [when I feel this way]. She sleeps here in the lower part of this bunk bed, and I say to my mom: help me, mom, help me. And my mom hugs me, and says: "Don't think about it, mi amor" and so on. That helps me.

\section{Case 3: Daniel}

Rachel's exposure to the master determinants that wear down her mental health and expose her to the forms of post-traumatic stress nightmares that have been described are similar to those that her brother experiences as a consequence of having gone through similar situations, in addition to entrapment, incarceration two times and eventually deportation. On October 8, 2014, the day Daniel turned 17, he was arrested by the police while visiting his former school. I personally went to visit Daniel while he was in prison in Laval, several times, to provide moral support and mealtime company. In those visits, Daniel told me that his arrest and imprisonment were a very traumatic event for him, since the police arrested him in front of the entire school, including his 
sister and most of his friends: "I believe I was treated like a criminal. It was like a movie, like a horror movie," he said to me once while he was in the detention center. After the arrest, he was detained in the CBSA Laval Immigration Holding Centre for more than a week, a period of time in which he was interrogated, asked for information about his family, address, mother and sister, and psychologically harassed, until the day he was deported, on October 16, 2014.

All of those experiences together have seriously affected Daniel's mental health. The state of his mental health was diagnosed in 2015 , one year after his deportation, by a mental health specialist from UNAM in Mexico City. When I went to visit Daniel in Mexico City and interviewed him in the Monumento a la Revolución, Colonia Tabacalera, surrounded by dozens and dozens of homeless people who were at the same time being hounded by the police in unsuccessful attempts to get them out of the park, he handed in to me the document in which the psychologist offers the following assessment:

In the evaluation carried out in 2014 [previous evaluation] it is reported that since then the possibility of having to return to Mexico was a source of stress and anxiety for Daniel, due to the fear of returning to a country with a high degree of insecurity and social violence, a place also where he experienced traumatic experiences and was often victim of mockery and psychological violence due to his hearing disability. [...]

The results of the psychometric tests and the clinical interviews conducted with Daniel indicate that he is in a state of severe depression. Daniel meets the criteria indicated in the DSM-V for the diagnosis of major depression [bolded in the original], which are described below:

- Daniel is in a depressed mood most of the day, he feels sadness and cries every day, he isolates himself from people, prefers to be at home and cannot find the motivation to do any activity.

- He has no interest in doing any activity and has lost his appetite.

- He feels tired and without energy, even though he does not do any activity.

- He feels his legs numb and he has the perception that he moves more slowly.

- He has feelings of guilt, he feels guilty for causing worries to his mother and he feels a huge frustration because of his perception that he cannot do anything to improve his situation.

- He has recurring suicidal ideas, which include planning and carrying out some of the steps of that plan $[\ldots]$ 
In addition to depression, Daniel meets the criteria to be diagnosed with Post-Traumatic Stress Disorder [bolded in the original], according to the DSM-V, since after deportation:

- He presents recurrent, involuntary and intrusive and triggering harrowing memories related to the experience of detention, arrest and deportation, and when he manages to sleep he has recurrent anxious dreams [sueños angustiosos] related to the events.

- He has a persistent negative emotional state (fear, guilt, terror), his interest in participating in meaningful activities has diminished and he is unable to experience positive emotions.

- He has a major disturbance in sleep and problems concentrating.

It is extremely important to point out that Daniel is at risk of committing suicide [bolded in the original]. His situation has led him to have suicidal ideations that are becoming more frequent and include careful planning. There are several factors that increase the risk of a suicidal act: depression, loneliness, lack of school and work activities, lack of educational development plans and a lack of plans for the future, the loss of daily coexistence with his friends and his family, the lack of people who provide emotional support in Mexico and anxiety. [...]

III

\section{"Total underground," the State and mental health}

The three cases presented (Marina, Rachel and Daniel) are relevant to what has been discussed on illegality and the master determinants of health, especially with regards to the fundamental role of the administrative apparatus, and that of deportability, as master determinants of health. In effect, although Marina, Rachel and Daniel have been exposed to the same determinants of health as the rest of the interviewees, they are among those who have reported more severe mental health problems. What is it what makes Marina, Rachel and Daniel unique if compared to the rest of the interviewees? It seems to me that the intensity and the frequency with which them have been exposed to the state mechanisms is what makes the difference. For example, when comparing their cases against a typical case selected among the interviewees who experience only mild and occasional sleep problems due to financial or family concerns it is possible to notice that those who been exposed to the state administration on a milder level, with less intensity, are among those who do not experience post traumatic nightmares, nor suicidal tendencies or fears of dying. And 
that happens mainly because they have chosen not to engage in court and legal appeals after their refugee claimant application has been rejected and instead have opted to carry out their lives in the underground, hidden from the state apparatus. Choosing to live underground after losing their refugee claimant legal status helped them to experience freedom. The experience of Trino will helps us to provide a representative example on how this works.

Trino is an undocumented worker who arrived in Canada from Honduras 9 years ago. Because his refugee application was submitted while staying temporarily in Canada as a tourist, he told me, it was rejected almost immediately. He had everything to move forward and decided to start looking for lawyers who helped him to get through the process. But because the lawyer he got from Aide Juridique was not very helpful, he said, he started a long process of collecting documents to make his case strong by himself. As he was working full-time, and his family back in his country had no money and was not very diligent in collecting the documents he needed, the process become highly demanding, time consuming and stressful. Therefore, he decided to stop the application process, to find another place to live and to find another job. That was not a bad decision, he tacitly suggested when told me:

That [choosing to live in the underground after being rejected] freed me a lot; it took from me the weight and stress that courts and appeals create... and all that. The huge load I was carrying on my back was taken away from me the day I decide not to care about that anymore and keep living just like that. It was like a liberation.

Similar accounts have been reported by those who entered into the country without authorization, crossing the border illegally, and opted to carry their lives in Canada in conditions of "total underground.” By that I mean that their social existence in the country has not been recorded by the administrative apparatus, because they did not apply for refugee status, and they live in Canada under secrecy and in concealment. Under such conditions, despite the multiple forms of 
precariousness they face in daily life, total underground has allowed them to stay away from the mechanisms of surveillance, persecution and arrest, factors which, as we have learned from the narratives and direct experiences of Rachel, Daniel and Marina, lie behind some of the most serious mental health illnesses and traumas. This is the case of Fidel, an undocumented worker whom I met while working in construction in South East Montreal.

Fidel is a Salvadoran man who decided to emigrate to Canada from the State of New York, in the United States, where he used to work in construction, as well. Although he had a "good standard of living" in New York, as he had always work at decent wages, he decided to move from the small city he was lived, because he and his wife, who had been living together for more than 10 years, got into a family crisis and decided to separate. His ex-wife found another man from the Salvadoran community and who was close to the circle of family and friends they had, reason for which he started to face "bullying" from some of his friends and peers. In order to avoid "humiliating comments" he decided to move to another US city which is located closer to the Quebec Eastern Townships. There he met a group of coworkers who used to cross clandestinely the US/Canada border to work in the Eastern Townships' agricultural business and tourism. In one of the raids conducted by the CBSA three of his friends working in a restaurant were arrested and he, along another friend, decided to move to Montreal, where they found a place to live and a job. He works now in a small construction company on a temporary basis. Fidel uses a fake ID that he carries on the right side of his hips all the time as a way to show that he is working legally in the country, while walking on the streets as a way to avoid caught by the police.

It struck my attention that, while explaining to me his life here, Fidel seemed not to be very worried about being caught; nor did he show signs of much stress. Although his life in Montreal is not easy 
mainly because, as he explained to me, he has not many friends and the wages he gets are very low, he feels fine and does not experience much stress, if compared with those who are dealing with deportation procedures and legal appeals.

From what has been discussed so far, it can be concluded that opting for the underground and partial withdrawal from the state apparatus seem to partially free some undocumented workers from the threat of deportability and the mechanisms of state control, which also frees them from the strain and emotional labour and mental effort that dealing with state institutions implies, as we learned by looking at the cases of Marina, Rachel and Daniel. To be sure, living in the underground and distancing themselves from the State does not free them from racism, labour exploitation or isolation (which are also very harmful, as discussed in Chapter Three), but it does diminish the intensity of the threat of deportability and the effects that state surveillance has over the body and mind of the undocumented population. By opting for that route, they also become "liberated," at least partially, from the forms of social suffering that the violence of deportability produces on the illegalized subjects.

In the following section, I will discuss how physical health is shaped when working for the small and medium-sized companies.

IV

\section{Physical health}

Thus far, we have analyzed how the mental health of the workers is affected in the medium-sized companies and made some reference to what happens at the level of physical health. However, if we incorporate a holistic approach to the study of health, we will find that physical and mental 
health are dialectically interconnected, and that, mediated by the master determinants of health and the conditions of political economy under which labour is carried out, both tend to reinforce each other. In this section I will analyze the physical health problems that the undocumented immigrants interviewed experience while working in the local, medium-sized companies and will identify the links that seem to exist between physical health, mental health and the master determinants of health. As will be shown in this section, the health condition that seems to mediate the relationship between physical and mental health can be identified in what in the specialized literature on labour and health is called "allostatic load." By "allostatic load" is understood, as discussed in previous sections, as the wear and tear of the body and the nervous system that is generated by the permanent exposure to stress and strenuous physical work (Barr, 2012: 76-77). This condition seems to operate at a meso level and works as a mediating determinant of an important number of accidents that undocumented workers interviewed experience. As such, as we will see, through the workers' narratives, that allostatic load seems to be conditioning the production of injured bodies and mutilated body organs. In order to understand this link, let's start, first, by discussing the physical health issues that the migrant workers experience, from the general to the particular.

In general terms, the workers who are inserted in the local, medium-sized manufacturing companies reported the greatest number of health-related injuries and illnesses. The number of work-related injuries or illnesses I divided into "severe" or "non-severe," which workers reported having experienced during a 24-month period before the interview took place, ranges between 12 and 23, which represents an average of 17.5 accidents every two years. For "severe" illnesses or accidents I refer here to those cases in which the workers had an incapacitating injury which required more than one week of recovery, or cases in which full recovery was not possible; that is, when people developed a permanent disability because of the accident. 
The most common physical health problems that the workers reported within the sweatshops are:

- Back, shoulder, muscle and leg pain

- Sprains (in hands and knees)

- Back injuries

- Repetitive strain injuries

- Rheumatism

- Nosebleed and sore throat (linked to long-time exposure to cold weather)

- Eye disorders and skin irritation (linked to long-term exposure to chemicals)

- Cuts (hands and feet)

- Tachycardia and other heart-related problems

- Mutilated body parts and other serious body injuries

The companies in which the workers reported higher number of accidents and physical injuries are chicken, quail and pig slaughterhouses and meatpacking companies; recycling companies; construction companies, and cleaning companies. The most dramatic forms of physical illnesses and injuries occur in the chicken, quail and pig slaughterhouses. In those places workers predominantly experience: 1) Sprains (in hands and knees); 2) Permanent pain in shoulders, muscles and legs; 3) Back injuries; 4) Repetitive strain injuries and trigger finger; 5) Nosebleed and sore throat (linked to long-time exposure to a cold environment), 6) Serious cuts and mutilated limbs.

Recycling plants are also workplaces where undocumented workers experience an important number of work-related physical injuries and illnesses. Although very few of the interviewees work in those plants, most of them reported a large number of physical health problems, among 
which the most common are: 1) Eye disorders (irritation, dryness, itchiness); 2) Permanent back and shoulders pain; 3) Skin irritation; 4) Tachycardia; 5) Sleep disorders; and 6) Stress. In construction and home renovation companies, bread making and packing companies, the illnesses and injuries were more related to 1) Permanent back and shoulder pain, and 2) Bruises in ankles and 3) Hand cuts.

\section{Labour processes and physical health: Two emblematic cases}

The labour processes in the slaughterhouses/meatpacking and recycling companies play an important role in these health-related problems. Toiling without workers' representation, within the framework of strenuous working days that last up to 12 hours every day, from Monday to Friday, at a fast speed, and under strict surveillance, pressure and threat from the foremen, the undocumented migrants' bodies are at grave physical risk. In order to demonstrate how this situation comes about, I will describe how the labour process contribute to the incidence of injuries and accidents in those two types of industry: The slaughterhouses/meat packing companies and recycling companies.

\section{1) The slaughterhouses and meat packing companies}

In the mataderos, as they are called by the interviewees, the workers select, cut and package meat at a very fast speed. Those tasks are carried out on a repetitive way throughout the entire shift every day. Because the workers work with meat, the workplaces are cold, which demands the worker to do the job protected with jackets, insulated boots and good quality gloves. However, the companies do not usually provide that safety equipment to the worker. Furthermore, due to the nature of the labour (selection, cutting and packing of meat), the workers need to perform their daily tasks standing in front of a machine doing the same activities throughout the entire shift. 
Standing for long periods of time working at a fast speed, under cold conditions and strict surveillance, the workers repeat the same movement throughout the day, hundreds or thousands of times.

The lengthening of the working day, and the intensity of the labour process- both determined by the attempt to achieve the maximum surplus value from labour - make labour in such sweatshops a source of injuries, accidents and diseases. Surveillance and lack of safety equipment for the workers play an important role as well. How does this happen? The meat, pork and chicken meatpacking plants are not huge in size, and they are internally separated by sections. On one side of the plant there are three areas where workers load, sort and cut meat. On the opposite side, the workers do the cleaning and packing of the meat that has been previously cut, cleaned, and selected. In each one of those two major areas, there is a cabin almost the size of the entire a wall which is controlled by a supervisor, almost invariably a Caucasian male. Panoptically designed to provide the supervisor with the capacity to watch the workers' performance through the entire shifts, the cabin is also equipped with several screens that are connected to cameras located in the line of production, corridors and the dressing rooms. Through the use of surveillance cameras, workers are closely observed by the supervisors. When the supervisor detects a problem in the line of production, observes an accident or a worker working slowly, he sends an order to a line manager.

The line managers, who monitor the workers at a close distance by walking around the line of production, play the role of disciplining the labour force. They are often people of colour who, as I observed, have "no accent," which indicates that they are children of first or second generation of immigrants born in Canada. Sometimes the line managers are also Caucasian males. Although 
the newbies are told that the role of the line managers is to help the workers to solve a problem that may arise in the line of production ("If you have a problem, ask him for help," we are told), such as replacing a broken knife, or a broken glove, etcetera, in reality their energy is much more focused on disciplining the workers and on making sure that they produce as much as possible in the shortest period of time. Their disciplining techniques often consists in throwing insults or reprimands. This way of "helping out" through panoptic forms of workers' control normally stresses out the workers and makes the job not only physically but mentally exhausting too: Muscles get stressed out and back and body pain are manifested. Migraines are also experienced as a by-product of working under such forms of surveillance and control.

Also, as the body toils under cold environment, normally minus 10 degrees Celsius, the worker tends to develop dryness in nose and throat. This happens especially in summer, because that is the time of the year when the breaks are taken outside the factory and the workers' body is more exposed to sudden changes of temperature. Often, this generates nosebleeds or throat infections. I witnessed how nosebleeds have the effect of lowering the morale of the worker. This is because the excess of blood makes them feel like there is something deeper generated by overwork. $E l$ cuerpo revienta por tanto trabajo, some say, meaning that the body starts expelling blood from the deep inside due to exhaustion. But, as I could saw while working there, nasal hemorrhages seem not to be so much related to a "body burst" from working under so much pressure, but to the fact that the cold dries out the nasal membranes, causing nosebleeds that look quite dramatic. Working under low temperatures and without adequate protection generates muscle spasms. Some also report bone pain associated with rheumatism. 
Unloading and cutting meat is physically demanding and also generates health problems to the workers' bodies. Those who are assigned the tasks of unloading heavy pieces of meat, like the legs of the animal (pig or cow), or the whole body of the pig hundreds of times throughout the working day for long periods of time, tend to develop back pain and muscle aches. The same happens to those who cut the meat, a task which consists in grabbing different parts of the animal and guiding it into meat-cutting machines hundreds of times through the shift. As those two types of tasks are exhausting for the body, and as people do it normally under pressure, it is common for the workers to develop long-lasting back, knee, and arm pain.

\section{2) The recycling companies}

The labour processes in the recycling companies also illustrate with particular clarity the relationship between work and physical ailments. In such companies, the workers must do their jobs at a fast speed throughout long working days (up to 11 hours), depending on the season. In those companies, migrant workers are often asked to change shifts without previous notice due to the high level of turnover, and also, as my interviewees suspect, to reduce the risk to the supervisors of being caught hiring "under the table."

For the aforementioned reason it is not uncommon to see that workers subsumed in the recycling companies end up working both night and day shifts during the same week. This makes it difficult for them to have routine and to rest well after the labour shift, all of which often creates among the workers stress, physical exhaustion and sleepiness. For that reason, workers go to work without having slept properly, sometimes even for two or three consecutive days and, therefore, often find themselves working in drowsy conditions. It is common for some of the recycling workers to resort to energy drinks such as "Red Bull" and "Monster." Energy drinks help them to keep themselves 
working hard without interruptions, but, as can be predicted, tend to subject their bodies and minds to high level of stress. As a consequence, some workers report experiencing a mix of mental and physical problems that include tachycardia, headaches and migraines, sleep problems, tiredness, and "nervous problems," as they label symptoms that seems to me linked to tiredness and stress.

Fumarolas describes the situation the workers in the recycling companies face:

... I almost never can sleep for more than 4-5 hours. That affects me badly. .... To boost myself daily I used to drink Red Bull. I used to spend two or three days without sleep properly ...Two or three days without sleep! Sometimes I used to get 2 or 3 Red Bulls per day. At some point I felt like my heart got slowed down: tic, tic. I feel like a "tic," "tic" in my heart. In fact, I feel like my heart is not good enough anymore, because I get tachycardia regularly. I used not to feel that way in the past. Tac, tac, tac, my heart beats in fast or slow away, just suddenly, without reason. I understand that if I run or do exercise, it is normal that my heart bump up quickly. But if I am here just sitting down there is no reason why my heart gets accelerated. That happens often, like two or three times per week. I feel like my heart got damaged.

In recycling factories, another factor that affects the physical health of workers is related to their exposition to chemical and fumes that affect the skin and eyes. The workers who were interviewed indicated that working with chemicals irritates their eyes and skin on a permanent basis.

In recycling jobs, workers tend to experience also: Eye disorders (in the form of irritation, dryness, itchy and red eyes); sleep disorders; skin irritation; tachycardia; heart troubles; dehydration, and also what one interviewed called "abnormal behavior," which includes being often distracted and having trouble focusing, as well as irritability and being hyper aware of noises at night. Stress, sadness and sleep problems and nightmares were also reported by the workers inserted in the recycling plants.

However, the labour processes are not the sole determinant of health. Often, exhausting labour processes operate in a mutually reinforcing way with other problems that are generated as a result 
of living under conditions of illegality. For example, in the meatpacking companies, slaughterhouses and recycling companies, the tasks assigned require a high level of dexterity, mental concentration and motor coordination. For this reason, when workers are dealing with sadness or stress generated when they have been rejected in their refugee applications, or when they have family problems or homesickness, those jobs become particularly risky. The mental suffering that arises in those situations, as I will discuss in the following part, prevents workers from achieving the maximum degree of concentration and motor coordination that are needed to perform well in those kinds of jobs. Those moments in which the workers are dealing with sadness or stress make them more likely to suffer accidents at work. Those accidents are sometimes so dramatic that they involve serious cuts or mutilation of body parts. In the next section I describe the way in which physical health conditions and mental conditions reinforce each other. In order to empirically illustrate this aspect, I will analyze how symptoms associated with allostatic load generate work-related accidents.

\section{Allostatic load, mental suffering and accidents}

After socializing with the workers for a significant period of time it became easier to realize how the mental health-related challenges often translate into a variety of physical problems. This relationship between mental and physical health manifests through: 1) a variety of body signs associated with the wear and tear of the body, and 2) a variety of accidents in the workplace.

Exposure to work-related stress for long periods of time subjects the body to an accelerated process of wear and tear that manifests through long-lasting back pain, migraines and headaches, dark circles under the eyes, and unexplained weight gain or weight loss. The workers refer to this process as acabarse [to get worn out]. Working women refer to this process in more aesthetical 
terms: Ponerse fea [to get ugly]. For them, men or women, "looking acabado" or "getting fea," means essentially that the body shows signs of premature aging, accelerated weight gain or weight loss, dry skin, red eyes and dark circles. It also means that the body regularly experiences a variety of pains and discomforts that seem to have no explanation, as no one-time accidents or harmful events can be identified as a leading cause of the problem. Women and men also often talk about varicose veins on their legs or inexplicable chest pain once in a while when waking up, or also about blood pressure-related problems.

The unexplained "wearing out" or "ugliness" of the body that appears prematurely also manifests through the development of a body image that reflects signs of exhaustion. When one looks like "fea" or "acabado" means that the reflex system of the body, the motor coordination system becomes slow or slightly uncoordinated, which manifests itself through a particular way of walking that makes one look "like a ghost." It also manifests itself through issues that obstruct the capacity of the body and mind to perform with efficacy in everyday life, such as loss of memory, difficulties resting well, and difficulties focusing. Some of them lose teeth (they get rotten) and lose hair for "inexplicable" reasons.

The constellation of illnesses or physical health problems reported by workers, which cannot be explained by the occurrence of a particular event, or an accident, coincide with what experts in the field of labour and health call "allostatic load." That is, a set of physical and mental problems, such as loss of memory, the inability to focus on daily tasks, body aches, motor coordination deficits, and other symptoms that are generated by long-time exposure to stress, daily worries and heavy workload. This situation of generalized deterioration is more common among people over 35 , 
especially among those who have been working "illegally" in the medium-sized sweatshops for more than $4-5$ years.

Regularly, the health problems associated with the wear and tear of the body (expressed through the phrases verse desgastado (looking worn out) or verse fea (looking ugly) that we have briefly described as arguably linked to allostatic load have repercussions on the image that the workers have of themselves, and on the self-esteem, but, perhaps most importantly, they also have consequences on the physical health, as they are often linked to work-related accidents which affect their physical integrity. Let's see how the constellation of signs that I have identified as been arguably linked to allostatic load determine the accidents that some of the undocumented experience in and outside of the workplace.

Among the workers who are employed in medium-sized enterprises, the generalized wear and tear of the body and mind identified here as linked to "allostatic load" plays an important role on the occurrence of accidents that the undocumented workers experience both inside and outside of the workplace. The most common accidents they reported are: 1) cuts in hands, 2) wrist and ankle sprains, 3) minor injuries in the back or shoulders, 4) severe fractures that required medical intervention or long periods of recovery, and 5) disabling wounds and mutilations in body parts.

Accidents at work occurred particularly among workers who work in meatpacking factories, slaughterhouses, or among those who work picking vegetables in farms, particularly those places where the use of knife is required and, therefore, high levels of mental concentration, motor coordination and coordination between mind and body are necessary. 
More than half of the accidents that workers in the medium size sweatshops reported were due to slips, falls or other accidents that seem to be linked to the conditions of distress in which the undocumented workers live and carry out their labour. Most of those accidents, both in and out of work, could have been prevented or avoided if the workers were labouring in mentally and physically optimal conditions. But the lack of motor coordination, fatigue, and difficulties to focusing on daily tasks, generated by the symptoms associated with stress or allostatic load led the worker to get involved in accidents.

When the accidents took place at work, the factors that I could identify as the immediate cause of the accident are: stress, working under pressure and with no protection, daily worries, and working without having enough sleep and rest. When accidents occurred outside the workplace, stress, lack of focus, especially when doing work at home (washing, cleaning the house or cooking) were identified as the main cause of accidents. Knife cuts and burns while cooking; slips and falls when mopping; or falls on the stairs of the building were identified as the main accidents linked to the lack of concentration, stress, and sleeplessness (generated by sleep disorders linked to worries, and daily fatigue due to working long shifts).

Certainly, the accidents that workers experienced were not only generated by the existence of symptoms that I here, for heuristic reasons, associate with stress, fatigue and allostatic load. An important number of accidents had as an immediate cause working without safety equipment. Most of the accidents that I grouped in this cluster occurred in the workplace, although a few occurred at home. During the interviews through which I reconstructed the causes of accidents, I was able to identify that these types of accidents included: 1) slips while carrying out cleaning tasks at the workplace, and sometimes at home; 2) falls that left bruises or muscular trauma; 3) cut in the hands 
due to working without safety gloves; and 4) bruises on the head. In all of these cases, working without safety equipment either due to the fact that the workers-who live in absolute poverty, as mentioned in Chapter Three - could not buy the safety equipment out of pocket, or because the safety equipment that they were given by the company was in bad conditions.

\section{Deportability and accidents}

All of the above indicates that allostatic load - the set of symptoms of mental and physical wear and tear generated by living and working in conditions of illegality—generates, create risks and forms of stress and mental suffering that result in accidents. The situation gets worse when the level of deportability intensifies. In effect, when workers are going through moments of particular stress, mainly when they have just received a deportation order, or when a friend or relative has been arrested or deported, or when a family member has died, or when there are family problems related to long-time family separation, they tend to be more vulnerable to risks and accidents. The most dramatic and harmful accidents, such as disabling injuries and mutilations in the body, can happen to the workers in such moments.

Some of the interviewees experienced disabling problems, including mutilation of parts of the human body just after receiving a deportation order. Some of the serious accidents that were generated at times in which the person was going through deportation processes include: broken ankles, deep cuts in the hands, broken hips, and car accidents that left a person disabled on a permanent basis, among others. Hector's case is emblematic of how symptoms associated to allostatic load, precarious labour and deportability make dramatic accidents happen.

Hector is a 32-year-old man who came to Canada as a visitor in 2006 and overstayed. Like most of the workers interviewed who arrived before 2008, months before the Harper's government 
imposed visas on Mexicans as a condition to enter into Canada, Hector arrived with his wife and daughter with the only goal of working hard, saving some money and returning to his country to try to have a better life. The situation of poverty in which he and his family lived back in Mexico led them to emigrate to Canada. Like most of my research participants and some of my working companions, Hector and his wife came with the intention of working hard, in whatever job possible, save some money and return in 3-4 years to their hometown to build a house, open a changarrito (grocery store) and earn a decent living that way, which, in turn, would help them to provide education to their daughter. Everything worked well during the first two years. As Hector is a hard-working man, his employer - a warehouse company which provides services to the chain store "Sobeys"- - loved him and gave him many hours of work at not so bad wages (10 dollars per hour). They were saving money and building their house quickly. But one day in mid-2008, they both received a deportation order. As they decided to stay anyway, they searched for another apartment, and Hector got a new job in a meatpacking factory and began to live a life hiding in the underground. Months after they received the deportation order, his wife wanted to return to Mexico, but Hector insisted on continuing to live and work here, arguing that the house was already on the way of being built. He wanted to keep up working hard to complete the project before returning to their home country. Those differences created tensions in the family. Living in the underground, dealing with the deportation order, and now employed in a highly demanding meatpacking company generated tensions and the couple broke up. She returned to Mexico, taking their daughter with her.

The family break up affected Hector a great deal; he felt he had lost his daughter forever. As a result of grief, Hector developed insomnia and had trouble focusing on daily tasks. Excessive workload, the mourning for his family's dissolution, solitude, and the worries that came out of 
living with a deportation order made him to feel like he had "the weight of the world" on his shoulders and subjected his body and mind to stress and fast wear and tear, as he "had never experienced." One day at work, while he had to cut pork legs in a meat packer, he forgot to wear protective metal gloves, and sliced three fingers off his left hand. He says that he was not focused while doing his work and was working practically without sleep and without paying attention. The recruiter, who had received a call from the employer, took the severed fingers, put them in a bag, and gave Hector bandages to stop the bleeding, and then a group of people took him to a subway station close to a Montreal Hospital. The recruiter told him to go there and promised to come back after doing some paperwork related to his accident. (He asked him also not to mention that it was a work-related accident.) But the recruiter never came back. In spite of having no papers, Hector received medical attention that cost him more than $\$ 4000$, all his savings he had put aside for building his family's house. He underwent reconstructive surgery, but his body did not respond well. In the end, his fingers could not be saved. Now he has a hand with two fingers and deals permanently with hand mobility problems. He has also troubles finding a job, as his hands, the main tools the workers have in the so-called "unskilled" jobs, "do not work anymore." He sobs discreetly while telling me:

It was terrible having lost my fingers. Imagine! I can't work well. But maybe the worst thing was not having anyone on my side, somebody who could look after me. I did not want to tell anyone in my family so that they don't get worries. Neither I can go there, nor they can come here. The other very bad thing was to realize that the guy who said that he was my friend [the recruiter] when I needed him the most, he just went and threw me out in the subway station near the hospital. He lied to me. He told me he would come back but never answered my calls. Somebody told me I could denounce him, but for what? That was not going to help me get my hands back. ... So, I stay home recovering. I could not do any kind of job for 5 months. After all that, finding something has been fricking difficult, my friend. Imagine! I can't live without working. In fact, I ... I really do not know what will happen to me. 
This dramatic case illustrates the way in which the condition of illegality - being subjected to deportation processes - along with the precarious and physically demanding labour processes, put the workers under such levels of stress that not only their family relationships get disrupted, but it also generates accidents with often severe consequences.

\section{Deportation, mental suffering and work-related accidents}

Precarity linked to deportability, labour exploitation and the mental/physical health symptoms associated with allostatic load, do not explain by themselves the totality of accidents and physical health problems that I registered in the field. Deportation, having been expelled from the country is in itself an important factor leading to serious accidents and mental suffering. I interviewed two men who were deported. The first was already discussed when talking about historical trauma. That is the case of Daniel, the young man who was deported after being caught in his school when he was a minor. As a result of the deportation, he has suffered in Mexico an unusual number of small accidents, ranging from cuts in his hands to a broken finger in his left hand. Although he does not consider it serious, he acknowledges that everyone was in some way linked to the fact that he is experiencing of long-time depression and, as a consequence, having trouble focusing.

The second case is more dramatic. Juancho is a construction worker who came to Canada from Mexico to look for his partner, a woman who had been given refugee status because of the death threats that she received from her former husband, an active soldier of the Mexican Army who had been protected by his superiors. As she could not sponsor Juancho, and they wanted to reunify as a family, Juancho saved money and travelled to Canada to reunite with his beloved one. Having no work permit, to make a living he had no option but to work underground as a construction worker. He had bad experiences working there, most of them related to abuses and wage theft. 
That experience of daily frustration in the job, along with the stress that comes from living underground, permanent shortage of money and food insecurity, for years, he recalls, ended up creating a very nociva (unhealthy) dynamic within the family. So, the couple began having conflicts, experiencing difficulties working together, and eventually they broke apart. As they agreed he would leave the tiny apartment they had, he ended up spending a lot of time in the street, mostly sleeping in a shelter located in downtown Montreal. Wandering through the streets and shelters with sadness, incapable of detecting risks and dealing with feelings of being lost one day he crossed the street against the light while going to a depanneur to buy cigarettes. He had done that several times, but that day he got caught, imprisoned in a deportation center for few days, and deported.

As he had spent many years in Canada, the relationships he had with friends and family back in Mexico had withered away. Also, the house he inherited from his mother, who died while he was in Canada and unable to attend the funeral, was occupied by his sister, who would not allow him to settle in when he got back into the city (Mexico City) after being deported. In a small park located in Colonia Tepito, a marginal neighborhood where the core of the Mexican black market is located, he told me:

It was when I got deported and got back to Mexico that I realized everything that I had lost for having lived [in Canada] undocumented. I got old and me desgasté todo. I lost my wife and my family. And I lost my house. All my friends got away [did not look for me anymore]. Then, fifteen days after I arrived in Mexico, I was literally living on the street. My sister did not let me into the house. I went to the government offices, the places they have for deported people. They do not help you in anything. They give you food, and they help you to get an ID. But nothing more. Well, I got an impressive depression. Still, in fact, I do not recover from that. ... Cómo no? [Of course]. We went there because we did not have a good life here. But I didn't move up, got better. One lives badly as a migrant there. When I was deported, because of my age, because of the time I lost ... I realized that I had been left... with nothing. I was there in plain sight, with nothing. How do you think I felt? I felt like dying. I thought about committing suicide. But one day I looked for a friend, who gave me a job doing the electrical jobs in the houses he repaired. He was a maestro albañil 
[bricklayer]. I knew how to do that. Then, exactly two months after arriving in Mexico, and doing that kind of job, I fell off a ladder at work. I was not in a sharp condition. I was not doing things well. I was dealing with sadness and not paying attention, so I fell off the stairs. I broke my hip, was taken to the hospital and had surgery. I spent almost a year recovering at my friend's house. I couldn't move, got disabled. My friend helped me out, he used to prepare food for me and everything. And I started walking in fact just two months ago. And here I am, getting ahead little by little. But, you see? Here you have me out of work, doing what I can do: selling things on the street, and so on, without my family. That's what I have gotten ...

Becoming a pariah, a sick pariah, was the common experience of the deportees that I interviewed in Mexico City. Days before the interview with Juancho took place, Daniel had told me with excruciating detail his living conditions: He was sleeping in a car seat that his uncle had arranged for him in the patio of a tiny and dilapidated first floor apartment located in a Mexico City's rough neighborhood while at the same time enduring the pain he was dealing with due to his violent separation from family and friends. Juancho, although he had gotten back his house through a happily unusually short litigation process against his sister, was living also in the abyss. Unable to work in electricity and construction during recovery, he was barely making a living while selling in the streets cheap merchandise he buys in the black market and paying quotas for "use rights" (derecho de piso) to a network of moguls who control the black market in the zone.

The stories collected with Juancho and Daniel hit me especially hard. After completing the 3-hour interview with Juancho, I accompanied him to the street where he sells counterfeit shoes and socks and returned to a friend's house where I spent part of the night vomiting. While recovering the next day after going to a doctor, I began to wonder to what extent the stories I had collected there were related to my own temporary malaise. There were certainly tiny fractions of their stories in which I could see the story of my father. I also experienced pain regarding the suffering they were enduring. Their stories affected my head and heart, almost like the nightmares that were 
undermining the tranquility and mental integrity of the persons I interviewed and discussed at the beginning of this chapter.

In the following chapter, I will discuss how working for the Multinational Corporations under conditions of illegality affects the physical and mental integrity of the undocumented workers interviewed. The difference between those two labour regimes is formidable. 


\section{Mental and Physical Health in the Multinational Corporations}

For unexpected reasons, in February 2015 I got in contact with the underground labour market that is informally moulded to satisfy the labour demands of the multinational corporations. This accidental discovery and my subsequent incorporation as a worker in such companies changed in a radical way my ethnographic experience and my own process of sociological inquiry. In effect, facing unexpected changes in my parenting schedules and academic labour, which meant I needed to be in Ottawa from Friday evening to Monday night, I was no longer available to keep working in the medium-sized companies where I conducted participant observation during my first 6 months of field work on a full-time basis. It is in that context that I met Melo and Rosa de Lima, two generous and active undocumented workers who helped me out to find jobs a ratos [for short periods of time] and on a casual basis.

My experience working there was eye-opening. The labour market that "cleans the bowels" of the multinational corporations, to borrow the expression of one of my interviewees, is composed by a well-established network of brokers and local companies which provide mostly "temporary staffing solutions," as well as cleaning and maintenance services to the multinational corporations. For those purposes, they recruit urban outcasts in the city's poorest neighborhoods on a casual basis. The market is also composed of scattered networks of unemployed undocumented workers who work regularly for those recruiters.

Through Melo's help, I worked first cleaning the gym, parking lot, windows and storage rooms of a communications company once per week. I got to know Rosa de Lima while doing that work. Rosa de Lima is an undocumented migrant woman from Peru who has been living and working in 
Montreal for a decade. Despite living and working in such a wealthy city, she lives in chronic poverty. She owns "no more than few dresses and earrings to dress up and go out once in a while, a few family pictures, working clothes, winter gear, a cell phone of the stone age and the bible," most of which she gets for free in the basement of a church where she also eats once in a while free, healthy meals that that church offers to Montreal's homeless people and the poor. She came to work in the circuit of the multinationals through a Panama recruiter whom she met through a coworker while she was working cleaning rooms in downtown hotels. Cleaning hotel rooms on a more or less full-time basis was especially arduous and physically demanding for a woman like Rosa de Lima, who is especially inclined to spirituality and who likes to do handicraft. So, one day she decided to quit that job and to go to work on a more casual basis.

The consequences of working on a casual basis in the multinational companies are paradoxical. On one side, low income keeps her trapped in material precarity, lacking access to the basics. On the other side, she shows not many signs of physical and mental exhaustion. In fact, since the first time I met her I could perceive that she possesses a sense of "connection" to the city and a particularly vivacious behaviour that clearly contrasted with what I had seen before among my coworkers and research participants. Rosa de Lima is also assertive, with a strong proclivity to rebel against injustices, as described in the confrontation she had with Mr. Matus over wages, and has a special disposition to take care of herself. For example, although her knowledge on health is taken from non-scientific sources, she displays an impressive theoretical and practical knowledge on how to take care of herself. Except when she used to recommend urine therapy as a "magical" detox, I normally enjoyed and learned from listening to her practical advice on how to, for example, control headaches, body weight, back pain, dry skin, and how to prevent flus and fatigue. 
There is another factor that called my attention while I met Rosa de Lima. The apartment she lives in, which she shares with Melo and three sin estatus as she used to call herself, was a zone of refuge for the socially marginalized. It was a meeting place where good fiestas, music, diversity, inclusion, thrilling get-togethers, dance, free love, respect, and cultural-political tertulias could enchant even to the most Puritan soul.

For me, that was an eye-opening, worth-exploring accidental discovery. Working in the multinational corporations and hanging out closely with the workers in those social spaces I learned, little by little, that this network of people, in some way linked to the Montreal left, were almost all casual workers. Little by little I also learned that the socialization structures that are moulded in the context of the multinational corporations' labour processes are certainly linked to the existence of these social spaces, as well as linked to the configuration of workers subjectivities that are more rebellious and live less tormented lives.

Continuing with the formula of the previous chapter, in what follows I will make a descriptive tour that accounts for how the labour dynamics in the multinational corporations, in conjunction with particular forms of interaction with the master determinants of health, shape the mental and physical health of those who work under such labour structures.

The mental and physical health challenges that the undocumented workers face when working in the multinational corporations are significantly different from those who work everyday in the local sweatshops described in the former chapter. The health consequences for the workers within those environments are less dire when compared with the local medium-sized enterprises. Although the workers inserted in the multinationals face health challenges, some also quite serious, 
the research participants did not report mental or physical problems which can be arguably linked to post-traumatic stress disorders or accidents with disabling consequences. They did not report either having been dealing with suicidal thoughts, nor having experienced serious accidents leading to mutilations.

But not only were the workers less exposed to work-related illnesses and accidents in these working environments. For the sociological reasons that I will discuss in this chapter, working for the multinationals tend to generate a set of objective conditions that allows the development of a particular type of class consciousness and class-based politics among the undocumented workers which helps them somehow to resist the health challenges and structural constraints they face both in the workplace and in everyday life. Such forms of consciousness and workers' agency which evade alienated labour, resist the deportation regime, claim anthropological universality and demand moral recognition of freedom of movement represent unique forms of resistance and struggle upon which new narratives of emancipation are being written in the advanced capitalist societies. What are the objective conditions that make this possible? It seems to me that working less and having free time are key for this to happen.

\section{Labour processes: labour, exploitation and free time}

Similar to what happens in the local, medium-sized factories, in the multinational corporations, workers are also subjected to processes of exploitation and discipline, but not in a chronic or regular way. This labour situation conforms to the objective conditions making the undocumented workers less susceptible to illnesses and less likely to experience accidents both inside and outside the workplace. 
Due to the conditions of global political economy —all linked to the labour restructuring processes that big companies are carrying out globally in the face of increased competition among oligopolies, and also to reverse the relative loss of surplus value generated by the global crisis of capitalism that started in 2008-some of these companies are resorting to downsize full-time personnel and to hire workers on a casual basis through subcontracting. Labour restructuring and downsizing means that when unexpected alterations in the production processes arise, the multinational corporations need "extra hands" that help them overcome such crises. It also means that subcontracted companies are required to take care of activities that do not require full-time personnel. Under the principles of "Lean management," the industrial maintenance areas in the companies are one of the most commonly affected by restructuring. In terms of labour demand, this means that subcontracted work and activities aimed at supporting production processes in times of emergency require workers to be hired on a casual and paid-per-service basis. That is, the workers hired under this schema are asked to do a variety of tasks for which the companies have no full-time, permanent personnel, for short periods of time or for a one-time event.

The personnel management companies, which often operate on the basis of carrying out dishonest and illegal activities towards the workers, such as wage theft, harassment and no respect for safety standards at work, function as workforce administrators of the needs that have been created by capitalism at a global scale in times of restructuring. As such, they have been key to the smooth implementation of those labour restructuring models. They are in charge of recruiting the floating and surplus population to cover the specific needs of big industry. In larger cities of advanced capitalist countries, the floating or surplus population, what Löic Wacquant calls the "urban outcasts" in his comparative studies on advanced marginality (2013), is usually constituted by racialized migrants, undocumented immigrants, unemployed, welfare recipients, and Native 
People who are congregated in the poorer neighborhoods. But in Canada, many of them, such as welfare recipients and vagabonds, usually do not have much corporal discipline for hard work (as many of them are people with disabilities or unemployed single parents) nor are they subjected to a desperate need for work because, despite limitations, they have access to social security social structures and welfare. In this particular Canadian context, therefore, racialized (often undocumented but not only) workers become the prime target for recruiters. Without access to the social security structures, and subjected to a permanent crisis of social reproduction, they are easy targets. Their labour power is subsumed by the multinational companies or by the companies which offer services to multinational corporations, as said, to carry out specific tasks such as industrial cleaning and occasional maintenance.

The way in which the recruiting companies subsume the undocumented workers into the multinational corporations' labour processes produces a paradoxical effect on the undocumented workers. Although they are also subsumed under conditions of exploitation and abuse-wages below minimum wage, no labour representation, and wage theft—-those jobs provide them with partial forms of autonomy. This is because, doing those jobs, the workers do not have to subsume themselves into the labour processes every day, and because of the particular ways in which they are managed through those labour processes. So, recruiting mechanisms and labour mechanisms make the difference for making workers' autonomy to emerge. This is how that works:

The workers in these companies are hired in two ways. Either the big companies look for contractors or recruiters from whom they request workers capable of providing support to staff in specific tasks, or they directly hire an agency to carry out specific jobs, no matter what kind of personnel the agency employs. In both cases, the undocumented workers are subsumed by the 
recruiting companies as an external support to the ordinary processes of production in the multinational companies. Once the task for which the worker has been hired is completed, the worker is paid and removed from the production process.

The ways in which the workers are managed in the workplace produce an interesting relation between capital and labour. When the worker is hired directly by the big company, the immediate supervisor tends to be the same person who is in charge of the area where the worker is hired temporarily. When the worker is hired by a recruiting company, which is more common, the supervisor watching the workers tends to be a fleet manager working on a permanent basis for the recruiting firm. His job is to pick up the workers at a meeting point, drive them to the workplace, make a couple of visits to watch the workers, and drive them back to the original meeting point when the work is done. In both cases, either when the supervisor is a worker of the multinational company or when the supervisor is a fleet manager, the labour supervision to which the workers are subjected, though often rough and at times abusive, is rarely sustained.

In short, subsumed by short-time labour processes and submitted to systems of supervision that are not permanent, the workers in the multinational companies tend to develop a relationship with capital that is not too invasive. This situation creates the basis for relative autonomy.

But things are not that simple. Despite the relative autonomy that the workers receive within the context described, the labour processes in the multinational corporations are not less intensive if compared with medium-sized companies. Here the worker has to work hard and fast, as well. Labour intensification makes this possible. Because of this, the exploitation rate can even be higher than in the local, medium-sized companies. This is first achieved through the extension of the working day and through the existence of the piecework wage system. As the wage is paid in 
installments within the framework of a previously agreed time, when the workers complete the tasks assigned before the time limit, they are often asked to do extra things before they get paid. Thus, for the same salary the worker ends up doing more than what was agreed, and the recruiter achieves what Marx called the appropriation of absolute surplus value, obtained by increasing the amount of time worked per worker in an accounting period. This is what makes exploitation and intensification possible, despite the relative autonomy of the workers with regards to supervision in the multinationals' workplaces.

\section{Labour processes and physical health}

Labour intensification, in the context of working for multinational corporations, has a peculiar effect on the body and on the physical health of the workers. Overall, the workers toiling for the multinational corporations reported fewer accidents and fewer work-related illnesses, if compared with the workers inserted in the local medium-sized sweatshops. Only a few of the research participants reported having suffered work-related illnesses or accidents during the last two years, for example. A few others reported not having faced, at the time the interview was conducted, a single physical health problem that can be linked to labour.

Among the participants, only one work-related accident reported was considered "severe." By "severe" I mean an illness or accident that required for the worker to take a week or more off work to recover. The vast majority of accidents and illnesses that I was told about were considered by the workers as "not severe" either because they did not prevent the worker from continuing working or because the worker did not feel a need to seek medical care. The severe accident that was reported among the interviewees was due to an intense back pain that resulted from carrying heavy packages for 4 hours. After the worker reported the accident in the company, he received a reprimand from the recruiter, who drove him back home (to the meeting point) and asked him to 
call back when he felt better. The recruiter never called him again, but the worker, despite having a very negative experience, thanked him for that because the pain was so intense that he thought he had damaged his back. A visit to Médecins du Monde gave him access to a doctor, who told him he just needed to rest for a while.

The work-related physical injuries that I registered most frequently among those who work for multinationals are: 1) Body, waist, back and shoulder pain, 2) Ankle and wrist sprains and dislocations (in the workplace), 3) Cuts in hands (in the workplace), 4) Contusions in arms, legs and head (in the workplace), and 5) Weak wrists (for long periods of time).

Although body, waist, back and shoulder pain is the most frequent health issue they report while working in the multinational corporations, grouping all those cases according to "type of occurrence" reveals that most of the health issues that the undocumented workers face while doing auxiliary labour in those places are, in fact, generated by work-related accidents. However, unlike what happens in medium-sized corporations, almost none of the accidents involved bone fractures, serious wounds, mutilations, or other work-related accidents that required more than a week to recover.

Another relevant fact that I learned talking to the workers inserted in the multinational corporations is that only 2 workers mentioned presented health problems that can be arguably linked to the wear and tear of the body, a situation that will be discussed in the mental health section. Most of the work-related accidents reported were produced by one-event incidents, not as a consequence of the gradual deterioration of the body due to long-time exposure to heavy workload. 
Why are accidents and diseases are less frequent in multinationals and less severe? Similarly, why do workers experience fewer health problems linked to the wear and tear of the body?

\section{Workers' autonomy, free time and health}

The short response to the first question stated above is related with the workers' autonomy. In effect, although the working days are as intense as the working days in the medium-sized enterprises, and although the rate of exploitation through the extension of the working day is, in some cases, higher than in the medium-sized sweatshops, in the multinational companies undocumented workers' have a very particular condition that makes a big difference in their lives: they have free time. The worker in multinational corporations spends about 80 hours of work per month. Sometimes slightly more, sometimes slightly less. This is different with regards to the time that an undocumented worker spends subsumed in the labour processes of the medium-size companies, which is around 140 hours, on average, per month (sometimes up to 180-190 hours, for example in summer). This means that the time that an undocumented worker subsumed by the multinational corporations devotes to alienated labour is up to $50 \%$ less than the time an undocumented worker spends toiling in the medium-sized enterprises. By extension, this also means that the probability of being exposed to work-related accidents for those who work in multinational companies is significantly lower. That is what explains why they get less injured.

The workers in the big corporations also have fewer problems related to the wear and tear of the body. This fact is also related to their autonomy with regards to capital. Since they submit themselves to alienated labour for fewer hours, they are less exposed to fatigue and the wear of tear of the body that is created by the daily grind under precarious employment. This is important because, as I have discussed previously, fatigue and daily wear and tear to the body are associated 
with the symptoms associated to allostatic load, which, in turn, work as determinants of a variety of physical and mental illnesses and accidents inside and outside the workplace.

Working fewer hours per month explains to a large extent the fact that in these industries the occurrence of "serious" or "severe" work-related injuries and accidents is less frequent. And all of this is related, as discussed, with the fact that, although intense and exploitative, working in the multinationals under short periods of time provides the undocumented workers with a relative autonomy with regards to alienated labour and abuses in the workplace.

But there is another reason why the undocumented workers toiling in multinationals report fewer physical health problems. This is also related to the relative "free" choice they gain as a consequence of being relatively more autonomous. As the commitment to the recruiter ends every time a job is completed (generally after 3 or 4 days of intense work, 2-3 times per month) the worker often can choose how often s/he wants to work or what kind of jobs does $\mathrm{s} / \mathrm{he}$ prefers. Sometimes, they can even choose which recruiter works better for them. In effect, according to my observation, workers who go with recruiters for multinational companies tend to choose among the recruiters who are available in the labour market. For example, some of them prefer to be hired to do external cleaning in banks, including washing windows, or cleaning swimming pools in hotels, because these jobs are less heavy and involve fewer occupational hazards. In the face of this circumstance, and to avoid turnover, some recruiters, in fact, tend to offer "incentives" to the worker, such as "lunch" paid or a pizza for everyone when the task is completed. In other words, the small margin of autonomy that the workers get under the hiring mechanisms used by multinationals and their underground labour managers (the recruiters) gives, in fact, some power to the worker. Again, all of this within the constraints that exist to "free choice" for those who, 
expelled from any kind of labour protection, face the power of capital and their despotic labour managers in the underground labour market. Despite this, unlike what happens in medium-sized companies, where workers have to put their bodies on the production line every day, no matter what work is assigned to them, in the multinational corporations the workers have relative autonomy to choose the type of work they do, and to certain extent, the time they want to put their bodies in the factories. This also partially explains why undocumented workers under multinational corporations tend to experience fewer accidents and fewer serious health problems.

\section{Free time, deportability and mental health}

Mentally, this condition of doing work under punctual contracts for short periods of time, does not demand too much from the workers. Working between three and five days every two or three weeks doing industrial cleaning tasks, even if such tasks are physically demanding, and even if the worker is subjected to intense labour processes, exploitation and disciplinary surveillance, the work by itself does not demand too much concentration. It does not produce too much mental exhaustion either. This translates into the fact that the workers reported fewer mental health problems linked to work. This, however, does not mean that mental health is not a problem for the workers employed in multinationals. In fact, two of them manifested having symptoms that may be associated with allostatic load. On this, we will return later, but for now I will identify the mental health challenges that the workers experience while working in the multinationals, as well as the way that situation is linked to the types of jobs they do and the free time they have.

In the multinational corporations, the undocumented workers are less exposed to the daily stress in the workplace but are more exposed to poverty-related stress and to the stress produced by deportability. Those factors have an important effect on their mental health. Certainly, being a 
precarious employee for the multinationals does not generate much money. Mentally, this situation creates constant worries to the workers. Being in constant shortage of income stability for the workers means having no food security, no capacity to send money to the family, and generalized poverty, all of which, in turn, create constant stress, anxiety and sleep disturbances. In addition, the fact that the undocumented workers in the multinationals are partially emancipated from exploitation and alienated labour (as "cleaning the bowels of multinationals" requires fewer labour hours per month), submerges the undocumented workers to a life dynamic that exposes them to other challenges, all of them paradoxically linked to the fact that they have more hours of "free time" and relative autonomy from alienated labour. In effect, as they work fewer hours and do so only for a few days per month, they tend to spend more time outside the factory. While exploring the city and its public spaces, the undocumented workers are more exposed to the gaze of the police and, therefore, their objective possibilities of being trapped and deported increase.

For these reasons, the mental health challenges that the undocumented workers experience when they work for the multinational corporations are more related to the poverty in which they are trapped and to the relative intensification of their "deportability" which is shaped while, being outside of the factory, they explore the city, visit food banks, supermarkets, political events, parties and interact with neighbors. As a result, it is not surprising that most of those working in multinational corporations experience 1) Sleep disorders linked to family and financial worries (all of them), 2) Constant worries and fears, 3) Feelings of guilt for not being able to help their relatives financially, 4) Sadness due to lack of freedom, 5) Homesickness, as well as 6) Hopelessness and uncertainty about the future ${ }^{23}$.

\footnotetext{
${ }^{23}$ Although I am certain that grouping certain emotions and subjective experiences (such as hopelessness, anger, fear and guilt) as part of the list of mental health problems can be problematic, I decided to include them because they
} 
So, working for multinational corporations is demanding. But labour within this context is not much at the root of the problem of workers' mental health issues. The root of the problem is linked to the unfreedom of living as an outcast, an illegalized person, and also with the intensification of deportability that stems from having been emancipated at least partially from wage labour. Melo provides an example how this works:

Melo is a rejected refugee claimant who, as a consequence, is now living in Canada without authorization and working for a multinational corporation. He has been struggling with depression, anxiety and sleep problems for more than a year. When we discussed the roots of the problem, he told me that he has been working for a recruiter for whom he does all sort of jobs, mainly for Aiskuro, a multinational luxury cars company that has a branch in Montreal North. Although he has been working for him for a year (precisely since the time he decided to go underground after being rejected in his demand for political asylum), he does those jobs on a casual basis. Sometimes he is asked to clean trailers after repair or service; other times he is asked to take care of the plant at night, or to help with industrial cleaning when a new fleet of cars or parts arrive. Except when his job consists of taking care of the cars at night, when all is todo tranquilo [nice and quiet] the rest of the tasks that he is assigned to do, particularly when cleaning, must be done very fast. The tasks normally last 4 or 5 days twice per month. He does not have to be at the job every day. His

\footnotetext{
shape in some way or another mental health issues such as anxiety or sleep problems, among others. For example, in addition to "hopelessness" and "uncertainty about the future," some people expressed feelings of anger against the system because they were rejected in their refugee applications. Others also expressed "exaggerated fear" of being trapped and deported. Because these three experiences (hopelessness, angriness and fear) are more related to a "structure of feelings" that emerge from living a life in the midst of legal and economic precarity, I grouped them as part of the mental health challenges for being linked to anxiety. The same happens with the feeling of guilt. "Guilt," as expressed by some, emerges as a consequence of feeling like an "irresponsible" parent or bad son/daughter, because, due to their financial situation, they are constantly not able to help the children or parents financially, which greatly breaks the family and individual expectations they had when they decided to come to Canada. As such and in this context, guilt shapes anxiety and sometimes depression, according to what they expressed.
} 
boss is not especially kind and sometimes it can be stressful to work under him, "but not too much." Within this kind of labour dynamics, Melo's mental health issues, as identified by himself, are not much related to exploitation. They are rather directly linked to all the other challenges he has to face because of his condition of illegality, which limits and impedes his full realization as human being. In addition to the powerful feeling of sadness he experienced since the government rejected his application for political asylum (experience that people normally describe in terms of mourning), the impossibility for him to see his family in moments of crises, creates a state of deep pain and suffering. When trying to identify the roots of his current depression and mental distress, I said, "You are essentially telling me that your boss is kind of authoritarian and demanding and that you struggle with shortage of money. From 1 to 10, how much this labour and financial situation affect the situation of sadness you describe?" To which he responded:

Not much. The job does not affect me much. It actually helps me out to get by.

[The problem is that] My demand for refugee was rejected on June 21, in 2013. The judge did not accept my brother and my cousin as witnesses because he said that they are part of my family and cannot be accepted as a proof. ... So, they rejected my demand based on those grounds. [...] Also, since I got my Passport four months before coming to Canada, the judges thought that I had planned in advance my travel to Canada. I was rejected also on my appeal request ...

Uf! That has really affected me. Look. I left everything behind to integrate myself in this society. I left my son behind, my parents ... everything. Unfortunately, my mother died in 2010 and I could not attend her funerals... because... going there meant that I had to withdraw the demand I put before the Canadian government. And, finally, I got rejected. That has affected me in the mind [en la Cabeza]. That situation expresses through my sadness and sometimes anxiety. It is not easy to lose a beloved one... Your mother. Imagine! And well. After I decided to go through all this 'til the end, being rejected knocked me down very strongly. Emotionally, the feeling is very strong [es muy fuerte el sentimiento]. I do not sleep well. I have insomnia ... Sometimes I think and ask myself: 'After five years of being here, what is what I have accomplished?' I have not seen my kid for five years. I have not followed his development. I cannot see him. I do not know how he is growing. I could not see how my mother left this soil behind [cómo partió de esta tierra]. I could not do anything. And now I am rejected. Imagine! How would you feel about it? It is very painful. There is a lot of sorrow. Lots, lots of sadness there is inside me...

But I will go through the end. I will do this for my son. If I cannot make it here, I will go to another country. But I won't give up. 
There are two cases of generalized wear and tear, affecting both physical and mental health of those who work for the underground labour managers of the multinationals. Those two cases are worth highlighting because they warn about the need to see how, despite the fact that we group the workers according to the type of work they have done at the time of the interview, in many cases the realities intersect and give results that "do not fit" the categories I used. For different circumstances and because not everyone rationally chooses to work in "medium-sized" local companies, in "multinationals" or in "workers' cooperatives," often the workers' bodies are inserted into a variety of labour processes and, in fact, sometimes tends to circulate, above all, in multinational companies or local companies, according to the specific needs of their particular life trajectory. For this reason, some of the workers whom I interviewed being inserted in the "local medium-sized companies" had already worked for multinationals, or vice versa. And that gave me unexpected or very different results. Therefore, when recording the causes of diseases, I could find that some of them were dealing with physical and mental health issues which were actually conditioned by a situation linked to a broader biographical trajectory. This is the case of a 35 -yearold Guatemalan man with whom I developed a cool friendship spending time together talking about Latin American culture and politics. Salvador came from El Salvador in early 2000 requesting that his status as Canadian citizen be recognized. He was born in Canada in the eighties, but at a very young age his uncle took him to live in El Salvador. His mother lives in Montreal and has Canadian citizenship status, but as my friend's citizenship documents were not in order and were confusing, and as his mother did not help much through the process, his demand was declared incomplete. As the process was long, exhausting and expensive, he decided to remain without permit with the aim of working hard and saving money to return one day to El Salvador where he would build a house and open a Mexican-type taco store to get by and to "live in peace." Eager to 
reach that dream, he worked for many hours at a local company cleaning a big building at night. After some years of working there, his desgaste (wear and tear) was such that one day he decided to try cleaning the parking lots and warehouses of banks in the city. At the time of interview, he worked few hours, but his body had already been subjected to much wear and tear circulating in a variety of companies. This is the reason why his body showed signs of premature aging (described as envejecimiento prematuro by himself), anxiety, frightening dreams and lack of appetite for life. Circulation through several companies, including the transnationals, and all the worries that came along with "not having papers in order" were shaping the mental health problems he was facing at the time of the interview.

The second case is that of a Mexican who had decided to work in the same company as Salvador to "rest a bit," (para descansar un poco to use his own expression). He was literally escaping from a long-time exposure to stress, having worked in a packing business and a local yogurt company for several years.

\section{Free time, class consciousness and autonomy of movement}

Working for the multinational companies produces a particular kind of class consciousness. Working less and having more free time makes the workers more autonomous, as well as more rebellious (politically active) and more universalist. In effect, one aspect that seemed very salient among those working for multinational companies or in other part-time jobs is that, unlike other undocumented workers interviewed, they tend to develop a less negative perception of themselves, and a more universalist class identity. They also tend to develop more determination to get engaged 
in a variety forms of resistance against exploitation in the workplace. I will describe how this happens in the following paragraphs.

Unlike the those working in the middle-sized companies who tend to consider themselves as "nobodies" because that is how they are treated in the shop floor, the compañeros working fewer hours in multinational corporations tend to call themselves or to call their compañeros according to their country of origin, or as "migrants," or as "non-status" or even as rechazados (meaning rejected on their refuge application claim). Referring to themselves according to their country of origin or the legal status they are assigned by the State has a strong anthropological meaning and an important political impact on themselves, their identities and on the community to which they belong. The phrases "I am Mexican," "I am an immigrant," or, moreover, "I am a non-status migrant" or "I am a rejected one," in the current sociopolitical context have a radical political meaning. Calling themselves in such ways seems to work as an act of self-assertion- even if not intentional — or an assertive vindication of a national, ethnic identity or as a recognition of a social status that, although is recognized as having a subordinated position in society, refuses to hide and dares to say its name. To be an "immigrant," in a descriptive way, from the natives' point of view, refers to somebody who has arrived from another place. But being "Mexican," "Honduran" or "Guatemalan," in the dominant narrative, refers to an immigrant who comes from a place that is almost always associated with backwardness, poverty and marginality. Even worse, increasingly, in the dominant grammar of the receiving States in late capitalist societies, it also refers to a human being who is potentially "bogus," a potentially corrupt human being who is likely to become a burden for the State. Despite this, they do not hide that and self-describe themselves as "immigrants" as "Guatemalans" or as "Mexicans." In the same way, being a person "with no status" or a "rejected one" tacitly implies the recognition that, at least in the society where one 
lives, there is a social and legal "status" that has not been achieved, or tacitly means that belonging to the local society requires an acceptance from the receiving state which, deliberatively, was not granted. But such forms of self-nomination in a "negative" way do not arise from a passive acceptance of one's current legal and social marginality, nor from a self-denigrating perception of oneself. Rather, such forms of self-nomination seem to arise from a desire for self-assertion. As such, they work as forms of discursive, cultural and political resistance against misrecognition.

By asserting the possession of stigmatized ethnic/cultural identities and by calling themselves as being part of that fraction of the population who have been denied legal status, they implicitly seem to claim three aspects which seem to be important for the development of class consciousness. Such aspects are: 1) That they are coming from a humble sociocultural background (one of which they are not ashamed), 2) that they have been deliberately rejected by the system, and 3) that perhaps the situation of being a "rejected one" has occurred as a consequence of coming from a humble class background.

If we look at the context in which such forms of public presentation of the self are disclosed or raised up, we could appreciate that such forms of self-presentation seem to aim at denouncing the notion that one's life, one's status and one's identity are being subjected to a misrecognition. That is why I think of those forms of public self-presentation as acts of denunciation against the violence of misrecognition. They are based on the vindication of a class and cultural identity that it is assumed as being unjustly subordinated.

The ideas expressed above, which may sound like overgeneralizations and speculations, were taken from the notes I wrote after attending and socializing in the gatherings that used to take place in the department where Rosa de Lima lives, described at the beginning of this chapter. They were 
developed also in light of conversations that I had on the topic with undocumented workers who gather there, a group of 8-10 persons. For example, one Friday night, I had a short and nice conversation with Jorge. We were talking in the balcony while enjoying the beautiful starry night. Jorge has been undocumented since 2010, works often in Rosa de Lima's team and is politically active in the organization Mexicanos Unidos por la Regularización. When the topic arose of why some of them call themselves sin estatus, he mentioned:

Every time the issue comes out, let's say with the people I know, I say it [that I have no status]. I feel no shame about it. Of course, if it is safe to do so. Two neighbours already know. Everybody in my group knows it, some local people... know it as well. That's how people know that I am not a delinquent, that I am a normal person; a poor one, a humble one, but a normal person, a normal worker. I want to show that what their government is doing with us is wrong. They are the ones who rejected me. Not my fault. Look. They have tons of mining companies out there in our countries, robbing all our resources, but we are the bad people of the movie! [los malos de la película]. The same about being Mexican. I see some people hiding it, why? Maybe they want to be considered European? I am paisa [paisano, conational] and not ashamed of it. Look at this: I speak Spanish, French and a bit of English. I can do almost anything you can ask me to. I have lived here, there, out there. I know a lot of things [Me las se de todas todas]. I feel myself more complete than a lot of people. Why feeling shame? Have you talked to Quebecers? Those people feel pride of their origins, even if they are from poor, remote places, far from civilization. I like that, and I think we should be like that.

So, being a "Mexican migrant," or a person "without status" or "a rejected one" is not, for many of my compañeros, something we should be ashamed of. In fact, it is something we should feel proud of, as, in fact, being an immigrant makes a person, to borrow Jorge's expression, "more universal," "more experienced," and "more complete" human being. Of course, not all of those working for the multinationals mean the same when using those forms of self-identification, nor all of them assert positively their identities when using them. To be sure, there are several competing meanings attached to those ways of presentation of the self, as happens to any other social representations. But, in the end, and this is, I believe, the substantial part of it, such forms of self-identification mean, fundamentally, that one, as a migrant, is in fact a person-unjustly 
misrecognized or subordinated, but a person anyway, not a "beast of burden" nor a "zero to the left," nor a "nobody."

As such, those forms of self-identification, reclaiming humanity for the migrant subject, and conveying pride in themselves, have a class character, but in a particular way, and definitely not in the traditional way class consciousness is understood in the Marxian tradition. Through my fieldwork I was able to identify that those who tend to develop class consciousness or class-based identity are not the ones who work the most. As we saw, the compañeros who spend more time in the factory do not often tend to consider themselves "migrant workers" but, perhaps as a consequence of the treatment they receive and the conditions of isolation the live in, they often define themselves as being treated like "beasts of burden," "zero to the left" or "nobodies." Unlike them, those who work less, especially those who clean the "bowels of the multinationals" are the ones who are more likely to develop class consciousness and to assert ethnic and class-based identities. But, as we saw, such forms of ethnic and class-based self-identification do not come from the act of considering themselves only as "migrant workers," but from considering themselves, often through acts calculated public disclosure, as "non-status migrants," that is to say, migrants of humble origin, or the undocumented poor, who have been unfairly "rejected."

Those forms of self-identification that have an impact on the ways they relate to others. Perhaps as a consequence of considering themselves "non-status immigrants," people who have been "rejected" because of their humble origin, they are more likely to practice a variety of forms of solidarity with those who are "migrants," with those who are "workers" and also with those who are neither of those, such as: unemployed, local vagabonds, sex workers, marginalized queers and other social outcasts. That is to say, their empathy and cultural/political connection with others not 
only targets "the working class," but, more comprehensively, it targets the oppressed of the world; those who suffer whether because they are exploited in the workplace or because they are rejected, exileés, expelled from, or made pariahs in, different spaces of society. I witnessed this happening in different spaces while exploring the city with some of them, although what happens in the apartment of Rosa de Lima, Roberto and Melo better describes this situation. Let me describe what I saw happening there:

Roberto, Rosa de Lima and Melo's place is a humble but ample abode where we used to meet in our free times (close to the end of my field work) with other compañeros with whom I worked in UTS. That apartment was a meeting place, not only for those of us working for Mr. Matus and another Panama man, but also for an extended network of friends with whom we used to meet on weekends, including anti-capitalist pro-migrant justice activists who used to make short visits once in a while, and other "local personages"- as Robert used to say—who often spent weeks living there as "refugees." All of the refugee local people did not have working-class backgrounds. They were often social exilées: Two unemployed elderly women from Latin America; a trans man from Pakistan who has been exiled from friends and family; a Bolivian man unable to keep up in the jobs because of his age and back problems; a mature evangelical man from Eastern Europe who had been made a social outcast and who seemed not to be well from his mental health, among others. All together, meeting there, we always talked about local politics, music, Latin American culture, Zapatismo, socialism, sexual politics, religion and a variety of topics we came across. There were always a variety of people with different class and cultural backgrounds, a variety of languages, many intelligent and sensitive people, deep friendship, free love, and also food, music, and a party once in a while. One night, one of the visitors got upset because our trans compañera came home dressed up in high heels, miniskirts, hair extensions and made flirting jokes with him. 
He complained with Melo about it and asked him not to invite her, neither had her living home. Melo responded with a serious tone: "This house is for the fucked up, like me, like you, like her, and like all of us. Here we all fit, all are welcome here. We are all rejected, we do not have a homeland. This place is our little homeland." ("Wow! Everything's for everyone! No, Melo?" said a Quebecoise compañera in Spanish and with a French accent.) "So, let's get used to it, shake hands and not discriminate," Melo concluded. Melo is a Mexican Indigenous man whose second language is Spanish and who was ethically and politically educated in the Zapatista movement and in the student movement in his hometown. Since his dream is to study a career in college, he decided to work for Mr. Matus' agency and another one led by a Salvadoran man, because that is the only way he can earn a little money while studying French. He is involved in pro-migrant politics, without which he would feel "incomplete."

The situation I described is not an isolated event. To be on the side of the oppressed because they feel part of them, is not a marginal attitude. Although phrased in different forms, it is something present among literally all the people who have had access and contact with the local migrant justice organizations. Of course, not everyone who works in these companies thinks and acts alike. Melo was already a man heavily trained in leftist politics before arriving in Canada and has studied law. But those who have achieved a certain degree of autonomy from capital and exploitation in the workplace are more likely to show this more comprehensive form of identification with those who suffer and solidarity with the dispossessed, regardless if they are from the working class or not. Also, because of that autonomy and free time, they tend to mix with local organizations, to develop a form of class consciousness with similar characteristics. 
Having free time has played an important role in the development of this form of universalist class consciousness. How does this happen? As discussed, autonomy gives the workers free time for themselves, time which is often devoted to recreating their lives, building social relationships, strengthening social bonds, and exploring the geographies and navigating the social relationships in the local society. The free time that is owned by the worker after doing an "emergency job" (chamba bomberazo), is also devoted to visiting friends, to communicating by phone, WhatsApp or Messenger with the family, and sometimes even to engaging in community work. Isolation is less severe under such conditions, which facilitates the emergence of the feeling that one's dignity is not severely affected. Free time and autonomy with regards to the command of capital also gives them the opportunity to meet people from the local society, to develop language skills and to expose themselves more often to the resources for immigrants that exist in the local society. In addition, because they are poor — as a consequence of putting fewer hours of work monthly—-they are often in need of visiting food banks and looking for organizations which provide help to the immigrant populations. They also attend events and visit spaces that the Canadian civil society has opened for migrants. The contact with the "external world" via local grassroots organizations has exposed many of them to critical discourses and to the structures that migrant justice grassroots organizations have built for mobilizing the immigrants and the sans papiers in particular. This latter point has worked as a powerful resource for the emergence of rebel subjectivities among migrants of this category, and has been so important for building up the type of the universalist class consciousness and identification with the oppressed, that is worth reviewing how this has happened.

In Montreal, a large number of community groups and grassroots organizations work with, and provide support to, precarious immigrants. Some of these organizations are funded by the federal 
government to provide services to them. In such spaces, immigrants are helped to solve their most immediate needs, such as housing, healthcare, legal aid, jobs, and food security. According to what I was told by my undocumented companions themselves, such places have an important impact on the "non-status immigrants" subjectivities, as people who become regulars to those spaces are more likely to think of themselves as persons with dignity, as persons who are treated fairly and as persons who are not alone. This is because in those spaces they realize that an important part of the local society treats them as allies and makes them feel welcome and as persons with rights, regardless of their legal status, ethnic background, gender or skin color. Although such organizations are of an "assistentialist" nature, they are often led and managed by people with progressive and pro-immigrant politics, so the treatment they receive on those spaces, according to my observations, is kind, respectful and inclusive.

But in addition to these groups, there are grassroots organizations of a clear anti-systemic, promigrant justice orientation, both in anarchist and socialist versions. Those more autonomous grassroots organizations specifically target the undocumented migrants, and other migrants of precarious status with whom they create spaces where undocumented workers and local activists practice solidarity and mutual aid, create community and develop critical theorizations against borders, exploitation and discrimination. Even in their diversity, those groups tend to articulate a variety of anti-capitalist, anti-colonialist, anti-borders and anti-oppression politics. Linked to feminists, first nations, queer, anti-capitalist and anti-borders struggles, those organizations have become a sort of pedagogical vehicle through which undocumented workers learn and incorporate a form of radical imagination and radical political praxis aim fundamentally to the appropriation of the autonomy of the migrants to move and to circulate following their own needs and desires (just like the citizens of the core countries of the world system do), and doing it with the help of 
people, where the state approves it or not, whether capital needs them or not as labourers. This form of radical appropriation of the people's fundamental prerogative to circulate the geographies beyond the logic imposed by Capital and the State-logic which selectively allows people to circulate based on corporate needs or political agendas designed from above-is expressed through the formula often heard in demonstrations: "Freedom to move, freedom to stay and freedom to return," and represents the fundamental goal of those spaces and organizations.

Those spaces, practices and discourses, made possible by the work of local migrant-justice grassroots organizations, have had a powerful influence on the development of undocumented workers' rebel subjectivity and class consciousness. According to my interviewees, their involvement with those grassroots migrant justice organizations and structures have made them feel and learn, first of all, that they are valuable people and that there are sectors of the local society that do not reject them. In fact, they have learned in those spaces that those sectors of the society are allies; "good people" from whom they receive not only daily support throughout their migratory adventure, but also ideas that let them know that what they do, navigating society without documents, is not wrong. The radical resignification of their status as undocumented workers, resignification which provides a positive meaning to the condition of being an undocumented, is born in these spaces. Emancipated de facto from the command of capital, such spaces can be defined as "spatial form utopias" to borrow the expression from David Harvey (2000: 107); that is, spaces in which a life lived otherwise can lead to the emergence of new radical possibilities.

But learning through praxis in this context goes beyond learning about kindness and providing positive meaning to be undocumented. Working alongside the local activists and other local allies, 
the undocumented workers who had, already, a background in anti-capitalist politics, have found in those spaces individuals who are similar to them. In the process of working together, they have enriched their visions and their political practices. Many of my companions involved with those grassroots organizations mention that they have incorporated new ideas in their political imagination. For example, some have learned that the migrant struggles must be based on antipatriarchal, anti-homophobic, anti-racist, anti-colonialist and anti-capitalist visions, as much of the hardship experienced by racialized immigrants, and undocumented migrants in particular, may be linked to forms of domination stemming from those systems of power. As they have incorporated new forms of envisioning changes and political alliances with other social struggles, through those spaces, they have also nurtured their social networks, all of which have made them "more complete" as human beings.

Being in contact through political praxis with immigrants from a variety of countries, people from different social classes and political backgrounds, local French and English speakers, First Nations Peoples and people of different ages, sexual identities and ethnic backgrounds has enriched their social life and made them feel less lonely. As a consequence, the structures of feelings, heavily underpinned by sadness and nostalgia - conditioned by isolation and labour exploitation as described in Chapter Three-are subjected to an important transformation under the new circumstances. Many say, for example, that they have changed in a positive way while getting involved in those organizations and social struggles. They have developed a more positive representation of themselves; they have learned how to overcome isolation, developed language skills, made friends, practice of solidarity and mutual aid and, in general, become better persons, less moody, less sad. The isolating fence to which the deportation machine, "illegality" and the pincers of abstract labour subject the undocumented workers, crumble when the undocumented 
migrants submerge themselves into the local networks of anti-systemic migrant justice grassroots organizations.

But not only that. The holistic anti-systemic gaze they have been exposed to, and because of their own experience with exploitation and racism, has made some of them intolerant to exploitation, racism, sexism and domination in all forms. Therefore, their sense of political connection, as we have mentioned, is with all those who are oppressed and mistreated within those systems of oppression: working class women, racialized immigrants, sexual dissidents, Indigenous people, and social outcasts. Critics of capitalism and defenders, via praxis itself, of the autonomy of migration and freedom of movement, many of them have developed a critique of alienated labour, to which some of them see as the master determinant of illness and of social/individual migrant alienation. Based on this critique of alienated labour, some have decided on their own to practice labour abstentionism and to live from the help of others in exchange for performing little tasks or support in the everyday life; some others have created "illegal" coops through which they provide services to friends in exchange for money, and, finally, others have decided engage in wage labour on a short-term basis, like working for recruiters who offer services for multinationals and require from the workers few hours per month. The critique of alienated labour through praxis has been nourished by the existence of local anti-capitalist discourses, in conjunction with the very undocumented migrant desire for freedom and autonomy with regards to labour, as experience itself has taught them how slavering and literally "insane" are the jobs available for the in the underground Canadian labour market.

\section{Free time, autonomy of migration and class struggle}


Free time and access to the spaces and infrastructures created by the local anti-systemic organizations play an important role in the development of class consciousness and class struggle among the undocumented workers who are inserted in the multinational corporations. Being relatively free from the pincers of abstract labour has led some of them to emancipate themselves from the yoke of the boss, from the yoke of capital, and to explore, albeit in a limited way, the geographies of the city. Having access to spaces where solidarity and mutual aid are practiced and to social networks that make their participation in local struggles possible has made the undocumented workers partially appropriate for themselves their freedom of movement. In fact, through the process of social participation in local politics, access to public services and their capacity to move and explore the city according to their own needs and desires, their social citizenship has been, de facto, reclaimed and recovered. The existence of the spaces and social networks mixing together undocumented immigrants with the local populations has made this possible. It has also enabled a defiance of the multiplicity of borders that flourish under the state and police surveillance. It creates cracks in the borders through which the fundamental human need for movement and free circulation gets materialized through the act of human solidarity and mutual aid. The appropriation, de facto, of freedom of movement has made possible among the undocumented migrant workers the crystallization of their autonomy of movement, the autonomy of migration.

The appropriation of substantive citizenship de facto that occurs in such a context and the fight against deportations in which the workers are involved have a class character. As a whole, they are "extensions of class struggle," as defined by Walters (2002) which have a universalist character. It is universalist in the sense that not only capital power-the main site of class-based oppression - is challenged, but since alliances with a variety of oppressed populations are 
established (not only with those who have been exposed to the violence of capital, but to other types of violence too) the consciousness and political connection with others get also diversified, amplified and multiplied. That's why they are friends of the oppressed of the world, not only friends of the oppressed working class. So, the struggle of the sans papiers who have relative autonomy and participate in local struggles is a more universalistic class struggle; a struggle against borders, against the restrictions on mobility and against the alienating subsumption of migrant labour by capital. It is also a struggle that challenges the epistemological borders that limit the imagination of the traditional labour movement, which often ignores the demands of those who have been expelled by capital and therefore do not belong to the working class. It is also a wellrounded struggle and vision, as it includes a critique of capitalism, colonialism, patriarchy and racism. As such, they are "integrative liberation politics" as defined by Alan Sears (2014). This in turn has created the possibility of creating groups and working with others who are different from oneself. As they work with others and have access to radical knowledge and free time, the workers are more likely to develop class consciousness if compared with those who work for the local medium-sized companies. Through working with others, "multinational" undocumented workers involved in the local spaces listen to others and recognize the set of grievances that are collectively experienced. The reasons of their displacement and exploitation are recognized as a collective, not an individual experience, and class struggle acquires another character. When workers have more free time and get involved with others through the local anti-systemic networks, class struggle becomes transformed from rituals of performative submission to rituals of rebellion and resistance, whether in its passive or its active form. Therefore, such forms of resistance have an emancipatory character, either in a passive version or an active version. 
But not only free time and access to local networks enable the workers' involvement in struggles against exploitation and borders. The conditions in which contact is established with the recruiter, the conditions under which they are recruited, and the type of surveillance they are exposed to in the workplace, play an important role. As the employer does not work directly with the undocumented workers in the multinational corporations, the surveillance in the workplace tends to be less severe. In addition, as the recruiter tends to hook the workers in groups, people who are regularly friends, it is easier for them to establish solidarity among workers, who often become friends over time. In fact, almost everyone who works for multinationals is recruited through friends. Working with friends and not having the employer surveilling them all the time, that is, not being subject to their monitoring and disciplining processes constantly and having fellow undocumented workers on their side at work all the time, provides some autonomy to the worker and gives more space for collective and individual resistance to happen. In this context, some of the workers I interviewed told me they tend to take advantage of this situation to resort to what in Latin American labour politics is popularly called tortuguismo [labour slowdown] and to work at a slower pace. This way they manage to resist the exploitation that occurs in the workplace via the intensification and the extension of the working day. Roberto, a Mexican who has been living and working "without papers" in Montreal for more than 9 years, says this with particular clarity:

What do I do to resist? Well, nothing! Well, look, when the patrón is not seeing me, I play dumb [me hago el pendejo]. Then, when I see them coming, I pretend that I work hard, but that's feint. They want to see you in a hurry all fucked up [enchinga]. No! I work hard when they look at me, but then, when they leave, I play dumb [me hago pendejo]. I work slow, just doing the feint. Of course, in the end you have to complete the job. But you do not have to be like a slave there working at $100 \%$ your speed the whole day. There is a saying in my town that people repeat: "They pretend to pay you, you pretend to work, too!" That's how I deal with this, and I give the same advice to my compas. That's why I told you the other day the same to you: Do not be fool. Don't try to get in good with the Pope. In the end, they won't even thank you. They will give you a kick in the ass as soon as they can, and that's it! Better do it like that; do 
the feint like you work. Because when the payday arrives, they will make the feint they pay you.

To be less exposed to labour exploitation by means of working less and to resort to tortuguismo whenever possible, subject the body and mind to less stress and exploitation. That guarantees more autonomy and freedom of movement to migrant workers and make them more able to participate in political struggles. As a whole, that explains why the workers incorporated in the multinational corporations tend to get less sick and expose themselves to fewer serious accidents inside and outside the workplace. 


\title{
Mental and Physical Health in the Underground Workers' Cooperatives
}

\begin{abstract}
According to Fourier, as a result of efficient cooperative labour, four moons would illuminate the earthly night, the ice would recede from the poles, sea water would no longer taste salty, and beasts of prey would do man's bidding. All this illustrates a kind of labour which, far from exploiting nature, is capable of delivering her of the creations which lie dormant in her womb as potentials. Nature, which, as Dietzgen puts it, 'exists gratis,' is a complement to the corrupted conception of labour.
\end{abstract}

-Walter Benjamin, Theses on the Philosophy of History (Thesis XI). 1955

[1969]

"Paisa!" it was a common word I used to hear while walking through the streets of Wonderland, the magnificent immigrant, working-class neighborhood where I lived when started doing exploratory visits to the field in 2014. Paisa! which could be roughly translated as "conational" is a friendly way Mexicans living in the United States or Canada use to greet a fellow national. It is also used by Colombians and other Latinos when they see you are Mexican. That is how I come to know about the existence of underground labour cooperatives in Montreal.

Since the first day in which I settled in the neighborhood, I noticed how many paisas I had encountered and greeted on the street. Most of them were normally busy doing all sort of jobs: making small repairs in front yards, carrying and loading stoves or refrigerators into trucks, painting, or doing small repairs outside or inside homes. As I was staying in the apartment of a couple who has been living in the borough for a decade, I asked them for how long they thought Latin Americans and Mexicans in particular have been arriving in the neighborhood. They told me that most of them in fact do not live there but visit the neighborhood to do small jobs for the local residents, most of them first or second-generation immigrants who arrived from South Asian countries, as well as Greek people and local Quebecers and Anglophone Canadians who are heavily involved in community activism. Later on, a well-known migrant justice organizer who 
used to live close to my place, Gladiator, told me that most of them are undocumented immigrants who provide services at a very low cost to the local residents in order to make a living. $\mathrm{He}$ introduced me to one of them and that is how I had access to those networks.

My attention was called to the variety of arrangements the Mexican paisas and other Latin Americans made with the local residents. They collect domestic electronics for free; offer moving services in exchange for money; make small repairs to the local "ethnic" stores in exchange for food; buy all sort of gadgets, tools, bikes at a low price for repair and re-sale; offer painting services at low prices, among other small jobs. Most of those services and exchanges are offered on an individual basis, although, later I learned, some of them, particularly painting, moving and home repairing services are offered by groups that work on a cooperative basis with no brokers or intermediaries.

Hanging around with the immigrant workers in those informal cooperatives brought me to explore all sort of neighborhoods of Montreal, Longueil and to spend time in a beautiful small town located $150 \mathrm{~km}$ outside Montreal, where I learned about the stories, the lives, the challenges, the health conditions, and the joys (finally!) of those working in such informal cooperatives. In this chapter, I will talk about the later aspect: how health is shaped under conditions of underground cooperative labour.

\section{I}

The number of undocumented migrants working in "pirate" cooperatives is much lower than the number of those working for multinational corporations and local medium-sized enterprises. Throughout my fieldwork, I collaborated with three informal coops. In two of them, the ones coordinated by local Canadian people, there were undocumented workers and Canadian citizens 
working together. One of them was composed by undocumented workers only. This latest coop is supported by a Latin American man who recruits clients and who has a registered company. However, the work is done collectively, and the profits are distributed equally among those involved in the labour processes. The workers' cooperatives are grouped here as "pirate cooperatives" for two reasons. First, they are cooperatives for the reason that the labour processes and division of labour are structured on the basis of horizontality and on the basis of equal cooperation among their members. Second, they are called "pirate or "underground" because they operate outside of the formal economy, as they are not registered with the State. For the only case in which the cooperative is formally registered, it is done as an enterprise which belongs to one person only, but, in reality, the work is done cooperatively by the variety of members of the cooperative.

In all of the undocumented workers' cooperatives, the work is assigned to their members on the basis of individual skills, and the profits made are distributed in relatively equal parts among all of the workers. In fact, in two of the underground coops, the profits are distributed on an egalitarian basis, while in one of them the distribution of profits was given on a $60 / 40$ basis, with the Caucasian person obtaining the highest percentage. This non-egalitarian redistribution of profits is based on the rationale that the local person provides all the tools and labour instruments of work. In the three coops I met a total of 16 workers. Although all of them were Mexicans, Guatemalans and Salvadorans - I met them through common Latin American contacts-I learned from them that these types of cooperatives, which are put together as a survival mechanism by undocumented workers as a way to deal with precarity, are not uncommon among other groups of migrants, particularly among Jamaicans and Asians. They are created exclusively by undocumented migrants. As mentioned in Chapter Three, the local population in Québec, Canadian citizens 
especially from, and in, the rural areas, have been historically resorting to this type of small and informal labour structures as a way to navigate the financial challenges they face due to unemployment and precariousness. They provide supplementary or sometimes the only source of income to precarious families, unemployed people, particularly in tough times, when crisis or unemployment affect larger sectors of the population. Through these types of "illegal" and "pirate" labour structures, poor families, unemployed individuals, friends and relatives offer goods and/or services in exchange for money to the local population who can pay or barter goods and/or services to friends or neighbors in exchange for other services without money being the mediating mechanism, but rather the "use value" itself.

Although not exclusively, the goods/services that are offered through "pirate" companies or cooperatives are mainly in the area of construction and home renovation, electrical repairs, carpentry, mechanics and vehicle repairs. Some others work in the area of recycling (collecting household waxes that can be repaired, reused and resold), or in the area of home cleaning (collecting junk, cleaning jobs), or simply collecting metals for resale in the recycling companies. In the same way, as I could see in the field, some migrants, especially those who already have local contacts from their own country or ethnicity, put together such informal labour structures to deal with unemployment and economic precarity. As these cooperatives are not registered, which allow saving in taxes, and a large number of local people require small services in their home on a daily basis, the informal companies offer solutions to the immediate needs of the local population—or of the same "ethnic populations" - at a low cost. That is why they tend to flourish in times of economic crises and hardship. The "pirate cooperatives" that I met in the border of the city or in the countryside are not exclusively put together by the undocumented migrants, but, as said, have a long period of existence among the local population, including migrant populations. 
Considering that the three undocumented cooperatives that I met in the field are not isolated cases, by means of an extrapolation I can calculate that around 4 or 5 percent of the undocumented population who live in Montreal work in such labour structures. From the total of 16 workers that I met in the "pirate" cooperatives, I was able to interview 5. However, since my reflections on pirate coops here are based also on participant observation, they are sufficient to provide an account about the dimension of the phenomenon in qualitative terms.

\section{Cooperative labour and physical health}

Despite the fact that the number of undocumented workers who participate in the informal coops is small compared to the number of workers in the multinational corporations or in the local medium-sized enterprises, the data on labour and health that I was able to collect through the interviews are revealing.

By observing the labour processes and conversing with the workers, I learned that those who work in the pirate cooperatives face relatively few problems with mental and physical health. In fact, when they do report health issues, they refer mostly to physical health problems, mostly associated with work or with previous health conditions. None of the interviewees, including those who were interviewed informally, with consent, reported having experienced more than one "serious" illness or accident during a whole year; that is, no one has ever experienced more than one illness or accident that required more than two weeks in recovery. Only one worker reported a health problem, sprained ankle, which required 4 days in recovery. So, in terms of physical health, the results are radically different if we compare these cases with those who work for multinationals or with those who work for local medium-sized companies. 
The main physical health problems I could register in the underground workers coops are: 1) Back and knees pain; 2) Shoulder and arm pain; 3) Contusions in arms and feet; 4) Light cuts to the hands and arms, and 5) Gastric problems. Those challenges that tend to differ according to the type of work they do. For example, in the recycling pirate company led by Mr. Arnaud, the workers mainly experience light body aches, such as back pain and bumps and bruises on the arms and feet. One of the workers suffered gastric problems quite often, as well, which transforms into light diarrhea although, as I will discuss in the mental health section, that seems to be a manifestation of worries and anxieties associated with long-time family separation.

In these labour spaces, one of the workers had "serious" health problems. This is the case of Manuel, a mature man who came to know Arnaud while wandering around Montreal after having escaped from a tomato farm. The year before we had the interview, Manuel had a problem with his knee, a deep pain that lasted for more than 4 weeks. He first felt it while loading an industrial refrigerator that had been given to Monsieur Arnaud, which they were planning to repair and sell. Like Manuel, the injuries of the other workers in this category are related strictly with the nature of the work they do.

There were no accidents or other illnesses reported outside the workplace. As described in Chapter Three, in the small pirate coop-like business led by Mr. Arnaud the main activity is to recycle household items, electronics, work tools, and to sort for resale material that contains copper, aluminum and other metals. The intensity of the labour processes is low and does not represent a problem for the workers, nor the number of hours that the workers have to put every day. Recycling requires collecting, loading and reviewing material that is often heavy and bulky, such as refrigerators, stoves, home furniture, and wood. This creates risks, as it involves lots of walking 
while carrying heavy and bulky items. In addition, recycling involves not only collecting often bulky and heavy items from the garbage, or from homes which have donated the material, but also the repair of items that may still be useful, and the separation of parts that will be sold in the recycling companies. Separating the material is a meticulous job and requires a certain degree of concentration. During all this process, physical strength is needed to handle and move the devices around, and also to spend a significant amount of time crouching. As in this coop-like pirate business the workers make rustic wooden furniture on request, make car reparations and provide home maintenance, there are days of the week in which, due to heavy demand from clients, they have to work more than 8 hours.

The physical exhaustion in that context can be hard sometimes, almost similar to that of the workers toiling in the multinational corporations. In summer, this is particularly true. During the months of July and August, for example, they spend many days collecting aluminum cans at regional festivals. At least three days per week, they spend the mornings collecting the cans left by the attendees in such events and bringing them to the recycling companies. In terms of labour, those two months are particularly intense and back pains appear more often. This is the reason why the health problems they experience, including Monsieur Arnaud himself who puts the same work effort as the three migrants who labour with him, are related to back pain and contusions in the arms and legs. But none of them are so severe that they require going to the doctor or being hospitalized. There are zero cases in which workers have suffered severe fractures, broken bones, or mutilations.

In all of the physical health problems reported by the workers, including accidents, neither impudent conduct at work nor the lack of use of health and safety equipment worked as health 
determinants in any of the cases mentioned. This makes sense. Even in the most demanding months of the year, they set the pace in the workplace, they have no boss or supervisor demanding they work faster, and they regularly, though not all the time as I saw, wear protective boots and gloves.

There is a second reason why the workers in the underground cooperatives are much healthier than the rest of the workers I interviewed. In the cooperatives the workers have almost complete autonomy in the labour process, as they do not have bosses or supervisors measuring or disciplining the time they take performing a task. In effect, despite the fact that they work a lot and they do it with a certain degree of intensity, they do not do it that way because there is a boss who demands it, but because the clients' demand — which is high in summer, lower down in autumn and spring, and decreases greatly in winter-requires them to do it. Throughout the labour process, workers tend to give themselves pauses that are mutually agreed. They also decide the length of the pause. I never saw them be less than 30 minutes, although sometimes they can be an hour or so, particularly in September and October when labour demand gets slower. In the same way, when something happens to a person, such as a wrist or hand sprain, and they cannot work, the worker takes the pauses that are needed for the recovery. Each one does their assigned individual task according to their abilities and can take breaks when they decide for lunch, for dinner, or to smoke a cigarette.

Free time and autonomy make the working days particularly delightful in fall, as the labour demand reduces significantly and walks around at night with friends and visitors while seeing the stars and joking around make their life and work quite a good experience.

This same labour situation that allows the workers to have free time and enjoy autonomy is present in the cooperative that offer gardening services in the suburbs of Montreal. The workers doing 
mostly landscaping jobs through this informal cooperative mostly face back and knees pain. This is due to the fact that they spend a lot of time on their knees providing maintenance to gardens and sometimes repairing fences. Back and knee pain are more pronounced in summer and part of autumn, as the rest of the year the demand for labour is lower and people tend to devote more time to house painting.

It is important to highlight that some of the health problems identified by the workers in cooperatives, especially those linked to body aches, were identified as linked to previous illnesses they developed in their countries of origin. What is remarkable about this fact is that, unlike undocumented workers in the multinational corporations and in the medium-size companies, the undocumented workers in the cooperatives were more able to track the genealogy and development of their health conditions, which greatly speaks to the sense of awareness of their own wellbeing and connection with themselves. Every time I asked them about health, they used to think carefully about it and to identify by themselves their illness trajectories in historical terms and to link causes, symptoms, historical development and consequences in their everyday life. For example, Oscar, a Guatemalan man who does painting and gardening maintenance, says that he cannot work much on painting because his left shoulder hurts. As a child he broke his shoulder playing baseball. As a result, his shoulder become "crooked," and now he cannot keep his arms extended upwards for a long time. In the same way, another worker pointed out that his gastric problems, which do not allow him to eat spices or grease, and that sometimes causes him serious problems in his esophagus, were probably linked to his tendency when he lived in Mexico to eat lots of spicy food and chiles jalapeños. 
The details about their health provided by the undocumented workers in the underground labour cooperatives greatly contrast with the more plain answers I received from those who work in the medium-size companies, who provided me with a list of their current health problems with not much attention to the details, nor with clear identification of the causes of the illnesses. It seems to me that working at their own pace, autonomy, free time and cooperative labour accounts for not only the absence of serious physical health problems but also behind the sense of reflexivity and awareness about health that the workers experience in these companies.

\section{Cooperative labour and mental health}

Although working under a cooperative labour dynamic is clearly much better for the physical health of the workers, when we look at the mental health of the interviewees in their everyday life, we can see a more nuanced picture. This is for two reasons. In the first place, all the workers with whom I spoke deal with sadness on a regular basis. Sadness occurs much more among them than any other challenge and it has a more profound impact on their well-being. With the exception of a single young man who said he did not experience sadness, for example when thinking about his place of origin or family, the rest of the interviewees mentioned that sadness is something that haunts them regularly. Every so often, especially after there is an important family commemoration or when they learn that a family member is sick, they tend to get the blues. Sadness, as described by some of them, and as I could observe in fact, often manifests itself through periodic loss of appetite, a feeling of tiredness and a lack of interest in everyday activities. There was one of them, a young kind man in his late twenties from Veracruz, Mexico, who discretely cried a couple of 
times when talking with me about his very young daughter. This is so, because, when he talks with her over the phone, her daughter says: Papi, ya vente, ya te quiero ver. Ya te quiero ver. Te quiero mucho papi. Quiero que vayas conmigo a la escuela [Come back, daddy, I want to see you. I like you a lot, daddy. I want you to bring me to the school].

Although working in the cooperatives allows the workers to have more time and freedom to explore the local geography, the condition of illegality restricts that freedom and impedes them from periodic visits to their relatives and friends. This situation of restricted mobility and lack of freedom to circulate and cross international borders-issues not solved by the otherwise emancipatory experience of working in the informal cooperatives - is linked to the issues they face with sadness.

Scarcity of money also plays an important role in the negative experience of sadness. The workers in cooperatives often mention that it is hard for them to be unable to send the amount of money home to their families that they had expected to send when they decided to emigrate to Canada. Although working in cooperatives gives them access to a fair and sometimes to an equalitarian share of the revenues the cooperative makes, those revenues are often meagre and unpredictable. All of this makes them feel guilty about not being able to keep playing the role of provider at home. Doubts about their masculinity and leadership capacity at home, important expectations associated to manhood in Latin American patriarchal culture, add to those feelings of sadness. They are sometimes identified as guilt or "shame."

Financial restrictions, rather than lack of access to health care, were also identified as mediators of the worsening of health and wellbeing of some of them. Two of the interviewees stated that they have problems with tooth decay and pain associated with it, but this was related to the fact that in 
Mexico they already had problems with bad teeth. They said that those problems worsened here because they had never gone to the dentist due to the lack of money, as the service is expensive. One day I personally brought one of them to a dentist who is well known among Latin American people in Montreal for providing services to a very low cost. He is a kind Chinese-Canadian dentist. There my research participant got teeth cleaning and cavity filling services for 150 dollars, which he found very costly given his very low income.

Long-time family separation, also imposed by the conditions of restricted mobility in which they live due to their legal status in Canada, is a problem which greatly imposes mental health challenges on them. This situation intensifies when family crises arise. One of them, Ronaldo, for example, has gone through a very painful separation process with his wife, with whom he has a 6year-old son. Although he and his ex-partner have already found a life by themselves (his expartner has a partner now and he also found a partner here) Ronaldo faces mental health issues due to this circumstance. Although he feels well with his new partner and has managed to somehow integrate in the local society, he mentions that he is often trapped by feelings of guilt for imagining that perhaps he is responsible for the separation. He refers to his son as the one who is suffering and paying the consequences of his decision, although he also says that he had no option: "I came here because there we could not live well. We lived so poor and with so many family problems that it was better to go [irse, emigrar]. But it hurts a lot to think of my son without a father." When talking about those issues at night, after the shift work ended, he told me several times that that mix of sadness and guiltiness, often makes him to experience stomach cramps [retorcijones de panza] from time to time. 
Unlike those who work for medium-sized companies or multinationals, the workers in the informal cooperatives did not report having experienced work-related accidents or accidents in their daily life as a result of being sad or depressed from time to time. Even though they all said they had sleep problems - just like the rest of undocumented workers I interviewed-linked to family or financial worries, those problems are never so severe and seem not to create serious obstacles in their life. In fact, there were no cases of sleep deprivation, insomnia, night terrors or nightmares reported among the workers in cooperatives. None of them either had had an accident linked to sleep deprivation. Working in company of others, within the framework of worker autonomy and cooperation, have played an important role in this. In fact, the forms of solidarity that can be found in those cooperative work spaces and the absence of surveillance and pressures from bosses and supervisors seem to be working as positive determinants of mental and physical health.

Ernesto is a young Salvadoran man who entered Canada clandestinely. He decided to enter to Canada that way because it was the way he entered in the United States. In the United States, where he lived for three years, he had problems with the law for driving with a false license and without documents. Because his job was not a good place to be, and because he was not getting along very well with his family (brothers and sisters in law) in the US, he decided to try Canada. He mentions that it was the best decision. Upon arriving in Canada, a mechanic who is originally from his country put him in contact with his fellow migrant workers of the landscaping cooperative where he works now. He mentions that he is doing very well because working "with my paisanos, I feel in company, and I have no problems with anyone." Now he speaks French and says that whenever he feels lonely, he simply goes to sleep at night in the apartment of one of his coworkers who has a local girlfriend. That is how he socializes and has his mind taken off his problems. Arnaud has also mentioned to me that when he sees some of them "struggling with melancholy," by which he 
meant sadness, depression or experiencing homesickness, he tries to give them encouragement by going for a walk on the river or do things to laugh a little. I have seen some others providing comments of encouragement or providing each other tender gestures of generosity when somebody is not feeling good. Staying up until late at night listening to music and telling stories of any kind after dinner also works as a mechanism for building solidarity, solidifying cohesion and defeating isolation. Also, according to what I saw while collaborating with them, encouragements to work, even when the other don't feel like it, work among them as a sort of therapeutic against sadness or other mental health disturbances. For that reason, it seems to me that cooperative labour, autonomy, solidarity and kindness in the workplace, and relatively more freedom to explore the local geography, make any mental health issues among those working for informal cooperatives have a radically different dimension, compared with the experience of those working in the medium size companies. These elements have a have a positive impact on workers' mental health.

Although working within a cooperative labour context, and within the framework of workers' autonomy and solidarity do not emancipate the workers from anxiety, the consequences of it were also less severe when compared with the rest of the workers interviewed. In effect, as it happens in the local, medium-size companies and in the multinational corporations, the workers inserted in the informal cooperatives often experience anxiety linked to fears of deportation. But here the difference is that, although anxiety and sadness were also linked to the lack of freedom and the impossibility of crossing the border to visit friends and relatives in their countries of origin, that experience was never so high as to create serious problems beyond mild sleep problems.

Among the workers interviewed I did not find a case of "generalized wear and tear" linked to longtime exposure to stress and other symptoms linked to what in the specialized literature is called 
allostatic load. Anxiety seemed to be a little more present among those who work in the countryside, with Monsieur Arnaud. This is because they are more exposed to the gaze of the police, whether when they have to travel to the city or when they are picking up recyclable items in the suburbs and rural areas. This makes them more likely to experience anxiety linked to deportability. Although the workers who work with Mr. Arnaud told me they felt protected and feel like they have someone to watch over them if they are facing a problem, they also told me how their nervousness arises when a new person, somebody they do not know, arrives at the house requesting for a service. I, in fact, witnessed how they prefer to remain low profile or even to disappear a little from the context of the interaction to avoid being subjected to the gaze of the potential new client or visitor. The geographic space matters here for the development of anxiety. Working in the countryside exposes them more to the public gaze. Since the countryside in Quebec is overwhelmingly inhabited by the local white population, the migrants are more easily distinguishable in such contexts because of their skin color, accent, and ways of dressing. Latin American men, particularly newcomers, love to tuck their shirts in and to wear caps all the time, which makes them very visible.

\section{Recognition, solidarity and class consciousness}

For the workers in the cooperatives, the anxiety for belonging or for claiming an identity based on legal status or ethnic origin is practically non-existent. This is very different from what the workers inserted in the multinationals express. This seems to be related to the fact that, as exploitation and class-based oppression is neutralized in the context of cooperative labour, and as their contact with the local society is more positive, the self-identifying labels such as "migrants," "Mexicans," "Guatemalans," "without status," or "illegals" are not so indispensable. At least, they are not used to claim pride, difference, or as a political act of denunciation, as happens in the case of the workers 
in multinationals. In fact, one thing that seemed obvious to me is that they tend to avoid such forms of racial, legal or ethnic forms self-identification.

It was never clear to me if this is done due to security reasons or to avoid hindering the process of identification and recognition in which they are engaged with the local society. Whatever the reason may be, this situation has two direct effects on the relationship they have with their fellow undocumented migrants and with the local society. In the first place, the practice of solidarity with the other undocumented is not present among them, nor are they very interested in participating in local struggles aim at supporting the demands of the sans papiers. Although they need and use the local services offered by organizations, and although they receive invitations to participate in marches for the regularization of the sans papiers, their response is elusive or frankly negative. This is very similar to what I saw happen among people who work in medium-sized companies, but very different from those who work for multinationals, who are the most involved with local social struggles, more politicized and more prone to claiming their cultural and ethnic identity and their legal status for political reasons. The undocumented workers inserted in the local informal coops tend to see themselves, in a more individualistic way, as agents that navigate the system in a relatively successful process towards recognition from the local society.

In the second place, the process of recognition within the local society, which is understood as key for successful social integration, has generated among them the idea that such process can be negatively affected by their involvement in social struggles or the revindication of migrant identities. So, in order to avoid interrupting such process of recognition and integration, the workers tend to avoid ethnic-based tensions by keeping a passive and, at times, docile attitude when interacting with the local population. For example, I often heard Mr. Arnaud or other local 
people refer to Latin American countries in folkloric terms. I also heard others blame the countries where the workers come from for massive migration and describe those countries, and the migrants' cultures, as failed or backward. Although such observations are often false or rampant generalizations based on cultural prejudices, it was common for me to see the workers keeping a passive attitude towards them and engaging in forms of communication that were not entirely democratic. By keeping themselves docile when hearing those comments or generalizations about their culture, it is tacitly accepted that their countries or cultures are backward and, by extension, that their cultural or ethnic identities may also have a defect or deficiency. For example, during the labour processes in the informal cooperative led by Monsieur Arnaud, he is the person who tends to impose the way in which things must be done by saying things like: this is not the way in which we do things here. Things must be done this way. This is not well done, you have to do it this way, etcetera. It was not uncommon for me to see that in the face of those remarks, the workers normally accept such forms of misrecognition even when, for example, sometimes they have incredible skills developed in their countries of origin. But instead of claiming that with confidence, they tend to accept such forms of subordination. Even more, when we used to talk just amongst ourselves, in the absence of local people, such as Monsieur Arnaud, it was common to hear phrases like: in my homeland it is done like that, but I think they are right, it is not well done. The truth is that here, they do things right.

Such forms of ethnic subordination I saw more often happening in the local medium enterprises and cooperative enterprises. In the process of mutual recognition between the immigrants and the local population, it is quite clear who is the one who holds the power to recognize whom, and who is the one who must seek to be recognized by whom; who is the master and who is the slave, to express it in terms of the Hegelian metaphor. So, although class struggle and exploitation are 
neutralized in the context of cooperative labour, and health is much better in those contexts than in the context of the medium-sized companies and multinationals, ethnic subordination, though in a much milder form, remains somehow intact. Sometimes I was left doubtful if the good relationship they seemed to have with the local community and Monsieur Arnaud was due to the fact that, within the framework of inter-ethnic relations, the workers navigated through it by accepting the conditions for recognition set by the local society.

Those factors seem for me to lie behind the absence of solidarity and identification that the workers inserted in the underground labour cooperatives seem to express towards their fellow undocumented immigrants and their reluctance to claim a more militant immigrant identity. It seems that they do not want to stir things up because they do not want to stop being accepted and recognized by the local society.

In spite of the contradictory and partial forms in which mild or partial ethnic subordination happens within the context of inter-ethnic relations in the cooperative labour context, it was possible to observe that in such workplaces, undocumented workers tend to report the best conditions of mental and physical health. Perhaps this is due to the fact that, even though partial forms of ethnic subordination may be hard to deal with, working under cooperative conditions with relative autonomy, freedom, free time and solidarity make better mental and physical health more possible. 


\section{Part III:}

The Seeds of a New Society 


\section{Social Solidarity, Social Struggles and Health}

On March 5, 2015, around 2 a.m., I received an emergency phone call from Carlos, one of my research participants. In a very frantic voice, Carlos told me that his wife, Mirna, was very sick and needed to be taken to emergency. Carlos does not speak French, nor does he speak English. He did not know anybody with a car who could help him in that situation either. I immediately put my clothes on and drove to his home, a tiny basement apartment located in a working-class neighborhood in the northern industrial part of the city. When I arrived, I saw Mirna lying on the couch sweating and moaning in pain. Her belly, she said, hurt in an unbearable way. We immediately took her to a nearby "French hospital." On my way to the hospital, I sent a message to Mary, a prominent local activist associated with Solidarity Across Borders, a Montreal-based organization which supports precarious status immigrants. After 15 minutes waiting, Mirna was seen by an administrative assistant who asked her for la carte d'assurance maladie. She got nervous, because she does not have any, and said she left it at home. There was no trouble. With a professional tone, the assistant asked her for basic personal information and assigned her to a doctor. After an inspection, the doctor told Mary, Carlos and me that Mirna suffered from an unattended gallbladder rupture and that her gallbladder had to be removed immediately. I learned there that Mirna had been dealing with pain for days, taking painkillers, because she feared going to the hospital. Fortunately, the operation lasted about one hour and at 7 a.m. Mirna was transferred to a recovery bed, sana y salva (safe and healthy). She was there for two days.

The doctor was kind all the time. At the moment he was giving the medical prescription and an "exit sheet," Mary told him that we had not brought with us her health card. En avez-vous vraiment 
besoin? Mary asked. We were expecting a high bill to be paid for lacking a health card. Mirna and Carlos looked quite nervous, not much about the bill but about the possibility of being "discovered" as not being carriers of health insurance. The doctor turned his head towards Mirna and Carlos who presented clearly as precarious status immigrants: Their worn-out body appearance, their skin color, their shabby clothing and their very limited linguistic skills could make anyone to guess that. The doctor then answered Mary with a kind tone: "I don't need it." He did not ask for any signature either. He then asked us to recall she had to come back for a checkup in a week and urged us to take care well of her. We got some more papers from a nurse and we returned to Mirna's home.

After Mirna got back home to recover, members of Solidarity Across Borders made several visits to provide Mirna with mealtime company, to help prepare food for her and do household chores. They also provided her with money collected through private donations called "mutual aid fund." It is a one-time donation given to precarious status migrants going through financial hardship. With that money Mirna and Carlos managed to pay the monthly rent. While in recovery and unemployment, Mirna was provided also with weekly full meal boxes which included cereals, vegetables, rice, beans, cookies, juice, soya milk, cheese, bread and other essentials. Mirna often recalls that day when SAB's solidarity work saved her life.

Mirna and Carlos, who arrived here from Honduras and Mexico via the United States, have been living undocumented in Montreal since 2011. To make a living, they work full time in a chicken slaughterhouse at very low wages and sell meals on Saturdays in the workshops which abound around their neighborhood. That helps to complement their meagre income. Fully immersed in that agitated work-life dynamic, they live severely estranged from society. Although they know 
some people from the local church, they rarely get to socialize with them. Full-time immersion in precarious labour and fears of being "discovered" as non-status immigrants prevent them from socializing. That is the reason why they did not call any neighbors when Mirna's emergency health situation occurred. For that reason, Carlos and Mirna often say that the support they got from SAB saved Mirna's life. I believe that is correct. The health professionals in the hospital also saved Mirna's life and did not send her any bill, I believe because of compassion.

While doing my field work, I saw many examples in which local activists, migrant justice organizations and health professionals, quite often closely interconnected, make it possible for people like Mirna and Carlos to receive access to professional services in moment of health crises. Their rationale is that any human being deserves access to health. Health is a fundamental human right. Some others state, in a more pragmatic tone, that this society owes much to the undocumented workers for their contribution, and that they believe that health, housing and education are the minimal things they deserve in appreciation. Regardless of the rationale, organizations like $\mathrm{SAB}$, committed health professionals and other Canadian organizations mobilize people, resources, ideas, memories and everyday support work to make possible that one of the most vulnerable groups in our society, the undocumented and the migrant poor, can be deeply included in society in conditions of tender recognition and respect. The implications of the collective work carried out by undocumented activists and local pro-migrant justice organizations are formidable for the health and well-being of the undocumented immigrant, as I will discuss in this chapter. Providing empirical examples gathered on the ground, I will also discuss how the emergence of new forms of collective labour and political praxis that, due to their ample implications, seem to be planting the seeds of the freer, healthier and more egalitarian society that it might flourish in the future. 
In the previous chapters, I have described the ways in which capital subsumes undocumented immigrants, mainly through abstract and alienating forms labour, in different types of industries. I have also discussed how the dynamics that emerge from those different labour processes, in dynamic interaction with the master determinants of health identified in Chapter Two (racialization, exploitation and administration, mainly), shape the mental health of the undocumented workers. But the exposure of the undocumented migrants to the master determinants of health does not occur unilaterally, from the top to the bottom, nor are the undocumented migrants only exposed to diverse types of violence that negatively affects their health. Just as the bodies and minds of the illegalized subjects are exposed to the violence of exploitation, racism and deportability/deportation, they are also exposed to other social forces which operate in an opposite way and which contribute to protect their life and health. In Canada, and particularly in the Canadian metropolises (Montreal being an extraordinary example of this) such social forces are represented in a formidable constellation of social struggles and migrant justice organizations that operate in a coordinated way at the margins — and often against— the State and capital. By incorporating the undocumented workers into their political labour processes in conditions of equality and mutual recognition, those organizations contribute to the production of structures of solidarity and forms of social struggle that have positive repercussions for the physical and mental integrity of the undocumented workers. In the following pages I will describe the characteristics of those constellations of struggle and the way in which their work contributes to protecting the physical health of the workers "from the top to the bottom." But I will also describe the way in which, from the "bottom-up," undocumented migrants have found such organizations, and the way in which cooperative political labour between immigrants and local 
organizations generates forms of social relations and modes of moral recognition that have important repercussions on the mental health of the workers, and also on their freedom of movement.

\section{The "infrastructure of dissent" and the protection of health and life}

In Montreal, a large number of groups, NGOs and grassroots organizations work with migrants of precarious status. Some of those NGOs and organizations are directly funded by governments as part of the state restructuring processes that have involved levels of "privatization" of social rights and public services that used to be responsibility of the State to offer and protect. Although such organizations are often run by people with a strong social commitment and cover a wide range of the immigrant population living with precarious status, such as refugees, refugee claimants, new residents, newcomers, among others, they rarely manage to offer support services to the undocumented immigrants.

In addition to such groups, there are grassroots organizations of normally anti-capitalist orientation, in anarchist or socialist versions, which work independently of the State and target undocumented migrants and other groups of migrants of precarious status. For more than 15 years, organizations such as Solidarity Across Borders, No One Is Illegal, and the Immigrants Workers Centre, among others, have been carrying out political work in the form of advocacy, outreach, rallies and day-to-day support work that specifically targets racialized immigrants and undocumented workers. Those grassroots organizations carry out campaigns and rallies "against the borders" or in favor of people without status; offer free legal support services; design specific campaigns for migrant workers' rights; hold public events on topics linked to migrant justice issues; launch campaigns against deportations and carry out support work for undocumented 
migrants in indefinite detention, among other actions. Through that work they have consolidated networks of solidarity for and among undocumented immigrants. Lawyers, health professionals, social workers, sociologists, students, teachers, researchers, labour movement organizers, First Nations people, anti-poverty activists, artists, queer activists, and communicators, among others, actively participate and consolidate those dense networks of solidarity with the undocumented workers.

Through those networks and structures of solidarity, a significant number of undocumented people have had access to education, medical services, emergency financial help, affordable housing, furniture, clothing, food, and medicine. As a whole, these organizations make up a constellation of anti-systemic movements whose common project is to create a society without classes, without borders and without exploitation based on race, ethnicity, gender or sexual orientation. These organizations produce discourses and carry out an array of comprehensive political practices which do not establish rigid priorities of emancipation nor establish taxonomic hierarchies among struggles. They also tend to erase antagonistic distinctions between reformist and revolutionary tactics and strategies; between class-based and identity-based politics; and between redistribution and recognition, among others. Or, when they do demarcate hierarchies, define priorities and underline differences among forms of struggle, they tend to do so based on the contextual circumstances and often following flexible principles that seem to be open to change.

As a consequence of this open and heterodox approach, it is common to see in their meetings and spaces a mix of groups and individuals who adhere to a variety of emancipatory politics, such as: feminist organizations that fight against patriarchy and the forms of domination by the hegemonic sex/gender system; groups of queers and trans people who work for sexual liberation; associations 
of health care professionals working for social justice and to guarantee access to health for all; disabled persons' organizations that work for accessibility and against ableism; First Nations peoples who work for self-determination and against the effects of colonialism; anarchist and socialist-oriented unions that want to build a classless society; anti-racist organizations; lawyers working for social justice; networks of social researchers committed to emancipatory research, among many others who, for different reasons, feel committed to support undocumented workers.

Since their work in these networks is guided by migrant justice principles, all agree with the fact that they contain a diverse and at times scattered, but well connected, constellation of struggles that work for the creation of a world in which no human being is considered illegal. Based on this idea that claims anthropological universality and radical egalitarianism, their work focuses on the opening of spaces, practices and possibilities for the undocumented immigrants so that they can have access to essential social goods and social services regardless of their legal status. And also, so that they can appropriate, via praxis and solidarity, their autonomy of movement.

Those networks not only produce discourses, circulate representations and carry out political practices aimed at building a world without borders and without social domination. They also mobilize financial resources, open up spaces for the organization of struggles and offer migrants material and ideological support to create groups of migrant solidarity and migrant militancy, such as meeting spaces, computer equipment, books and documents, political training, workshops for the development of skills and practices based on mutual support, as well as political discussion forums and political training workshops. Through that work, which also includes mobilization of resources, those organizations have contributed to build what Alan Sears (2006) calls "infrastructure for dissent," that is, a set of structures, spaces and practices that contribute to build 
debate, sustain collective memory and collective vision, as well as subjectivities amicable to social change. Public universities, workers' action centers such as the IWC, union spaces (to a lesser extent) and student associations fundamentally from the English-speaking public universities (such QPIRG Concordia and QPIRG McGill) have been fundamental in building this "infrastructure for migrant dissent."

The infrastructures created by such groups have managed to integrate undocumented immigrants and other racialized immigrants of precarious status to Canadian society. That is, they have managed to incorporate those who have been placed on the margins of Canadian society by the processes of illegalization, and expulsion from the formal recognition of rights, into society de facto and without permission. Although the subsumption of the illegalized subject into the migrant justice Canadian civil society occurs from top to bottom; that is, from the point of view of "the natives," and without having been driven by the undocumented immigrant themselves, insofar as it occurs within the framework of an established structure for dissent and framed within a discourse of radical recognition of "the other," it has functioned as a catalyst for the emergence of migrant insurgencies. In turn, those forms of migrant insurgencies, through practice and discourse, have been making it possible for the immigrants who have been expelled from the order of rights to inhabit the social order "otherwise," giving them access to social rights of which they have been deprived, and a means of claiming their autonomy and freedom of movement. Since the main consequence of the State and its surveillance/expulsion mechanisms, and of capital and its labour subsumption mechanisms, is to control the autonomy and freedom to circulate of the illegalized migrant body (whether through labour exploitation and discipline or through law enforcement mechanisms), the work advanced by the Canadian organizations that I have succinctly described runs against the grain and contests the very core of the ways in which capital and the State, in 
advanced capitalist societies, undermine the social security, the health and the freedom of the immigrant poor. For that reason, pro migrant justice Canadian organizations have been rewriting the grammar of the new political struggles in the 21 st century.

Upon the basis of the solid structure for dissent and the solidarity networks that Canadian migrant justice grassroots organizations have built and expanded through the city, undocumented migrants have been incorporated into a set of practices and social processes which make possible not only their partial but radical appropriation of freedom of movement, and their involvement with the Canadian society, but also their access to practices of care which have a positive and direct impact on their physical and mental health. Such practices that Canadian grassroots organizations carry out with the purpose of protecting the health and human integrity of the undocumented workers will be called here "integrative life-protecting politics."

The integrative life-protecting politics are "integrative" in a triple sense. First, they are integrative because they incorporate a holistic approach to human health and care which goes beyond at least three core assumptions that underpin the partial and restricting dominant medical model which Pat and Hugh Armstrong (2010) have dissected in detail, namely: a) the assumption that uses an "engineering model of the body" (39) and "reads" human bodies as machines composed of separated pieces, rather than composed of a complex relation of material and non-material elements that are intrinsically linked to each other; b) the assumption that "health care is primarily about curing illnesses and disability" and which, based on that partial understanding of care, labels psychological support, meal-time company, feeding, bathing and talking to the ill person as tasks not linked to medical care, and c) the assumption that sees doctors, mostly represented in a male body, as authority and expert and therefore the only figures with social legitimacy to identify and 
treat illnesses (39-41). Against such dominant assumptions, identified by the Armstrongs as key for the historical undermining of the health care system in Canada, the integrative life-protective politics carried out by the Canadian grassroots organizations identify health as shaped by a complex set of material and non-material elements occurring in society and seek a cure by putting into practice a variety of interventions which include the involvement of medical experts but also include moral support, psychological help, meal-time company, recovery therapy at home, recreational activities, financial help, food, meal preparation, and house cleaning on a daily basis throughout the whole process of crisis and recovery.

Second, the "integrative life-protecting politics" are named here as integrative because they incorporate a holistic approach to human health and care which includes a set of material and moral resources that have proven to be related to the holistic wellbeing of human beings, such as: access to health care services, decent housing, nutritious food, education, decent working conditions, social support and social networks, freedom of movement, moral recognition, inclusion, respect, and emancipation from oppression.

Third, the "integrative life-protecting politics" are also considered "integrative" because they intend to guarantee the universal access to health care, and to all the social resources that are linked to health and well-being, to all people, principally to the marginalized poor, regardless of their legal status.

I call them "politics" - and not just "practices"- because, insofar as they aim at protecting the health, human integrity and freedom of undocumented migrants, they adhere to the principle and "ultimate content of all politics," which, in the words of Enrique Dussel, seeks, in the last instance: 
"the protection and qualitative prolongation of human life," as well as "the advancement of the life of the community, of the people, and of humanity" (See Dussel, 2015: 61).

For the aforementioned reasons, the "integrative life-protecting politics" which aim at the protection and qualitative care and prolongation of the life of the sans papiers are producers of, and in turn are produced by, an infrastructure of solidarity and a dense constellation of social struggles that makes possible their access to the social, common and public goods that are linked to health, life and human freedom. In the pages that follow I will describe what such goods consist of, how and through which mechanisms undocumented immigrants have accessed them, and how all of that has positively impacted their physical and mental health, based on two paradigmatic cases: the work of Solidarity Across Borders and the work of Médicins du Monde.

\section{Solidarity Across Borders and the Protection of Life and Freedom}

Solidarity Across Borders is a Montreal-based organization born 19 years ago. Composed primarily of a group of Anglophone anarchists - some of whom arrived in Montreal from other Canadian provinces escaping from police repression after the G20 riots held in Toronto in 2010-this organization is primarily engaged, as its name implies, in extending the practice of human solidarity across the globe regardless of the limitations that the borders impose. Although the group was founded mainly by anarchists, now it is composed of more than 300 people who have different political trajectories but feel committed to migrant justice and the working principles of the organization.

At the beginning, Solidarity Across Borders was mostly dedicated to the political mobilization against the deportations of various groups of migrants, such as Algerians and Haitians, among others. But, over time, its political praxis has extended and now includes putting in practice 
principles of mutual aid and solidarity with the sans papiers in everyday life, work that is carried out through a series of activities coordinated by the Support Committee. The Support Committee is dedicated to providing accompaniment to undocumented migrants on a daily basis, and to encouraging the creation of spaces for mutual support, and solidarity networks through which the undocumented workers can find, and can also help others to find, solutions to the problems and obstacles they face on a day-to-day basis as a result of their legal status, such as access to healthcare and legal representation, among others.

In addition to the continuous work organizing and mobilizing people to contest deportations and deportability in the public space, $\mathrm{SAB}$ is currently composed of various committees seeking to guarantee full access to common, public and private goods and services for undocumented workers. Through such committees, SAB helps several families to have access to food through a food delivery system that works on a monthly basis; free legal advice for those who are facing deportation; individual accompaniment to hospitals and clinics where the undocumented access health care and medicines normally free of charge or at low cost. SAB also creates spaces and organizes events where people without status can express their most immediate needs and receive/offer support, solidarity and mutual aid. It advocates and opens spaces in public schools for the kids living without status; manages an accommodation program through which those struggling with affordable housing, suffering persecution, or escaping deportation orders, can live free of charge or at a low charge in volunteers' homes on a temporary basis; and manages a "mutual aid fund" for people facing financial problems.

Based on the undocumented people's needs, as assessed by the committees in their daily work, $\mathrm{SAB}$ offers information and contacts who can provide help to solve various problems: access to 
legal representation, medical and dental services, and support in order to contract public services that require identification, such as electricity, gas, telephone, among others.

As a whole, the work of Solidarity Across Borders has contributed to open cracks in the contemporary border and deportation regime. Through such cracks, migrants have been de facto accessing the public, common and private goods which are fundamental to their health: support networks, health services, medicines, legal defense, clothing, nutritious food, economic resources to get ahead in times of financial hardship, decent housing and education.

Although $\mathrm{SAB}$ is run on a day-to-day basis by a core group of local organizers, it brings together dozens of organizations, activists, health professionals, academics, students and health professionals who work with the undocumented population in a variety of projects, events and activities. Organizations such as AGIR : Action LGBTQ avec les immigrants et réfugiés; Au delà de l'arc-en-ciel : aide aux immigrants LGBT; Centre des travailleurs et travailleuses immigrants; Collectiféducation sans frontières; Mexicanos Unidos por la Regularización; Dignidad Migrante; Forum contre la violence policière et l'impunité; Justice for Deepan; Justice for Mohammad Mahjoub; Justice pour Adil Charkaoui; Justice pour les Victimes de bavures policières; La Coalition contre la répression et les abus policiers; Montréal-Nord Républik; No One is Illegal; People's Commission Network - Réseau de la Commission Populaire, QPIRG - Concordia and QPIRG - McGill, among many others, comprise such a dense network.

Connected in the form of a network by means of listservs, and through frequent face-to-face communication, those individuals and organizations guarantee the access of undocumented migrants to health services. In many different ways, such networks create, administer, find and offer health services to ill and injured migrants, make home visits or simply connect migrants with 
health professionals who find ways and moments of time during which migrants of precarious status can go to the doctor or have access to public hospitals where they are not asked for legal documents as a condition to be recipients of medical attention. Over the past 15 years, undocumented migrants living and working in and around Montreal, including those who live in other small Quebec cities, have had access to health and hospital services because of the work of Solidarity Across Borders.

The qualitative and quantitative impact that SAB's work has on the lives and health of the nonstatus immigrants in the province of Quebec is not insignificant. I witnessed this on a daily basis. Through an empirical register that I carried out during my field work, which consisted in simply recording the number of people who had access to health services because of SAB advocacy over certain periods of time, as well as describing and grouping those cases according to the type of health problem the undocumented migrants faced and type of service they received, I was able to count that the average number of people receiving medical services as a result of the $\mathrm{SAB}$ intervention is 22 people per month. The main health problems that were given proper treatment and care during those cases corresponded to diseases that are considered serious, namely:

- Severely disabling chronic pains in different parts of the body (mainly back, knees and hands)

- Blood pressure problems

- Health problems linked to diabetes

- Heart problems

- Kidney problems

- Gallbladder problems 
Because undocumented people tend to seek medical intervention only in times of serious health crises - which normally happens when the body cannot longer function as a tool for labour on a daily basis - an important number of the monthly cases in which the people got access to medicare through SAB's work required hospitalization or surgery. On average, three people per month received from SAB not only the contacts to get medical attention, but also help to negotiate the entrance in hospitals and the payment of the bills that come after going through surgery. Those sick also received from SAB meal-time company in the hospitals and at home after surgery; financial help to navigate the hardship of unemployment; as well as moral and psychological support, food delivery and preparation, and metro tickets.

Three of the persons I interviewed received medical attention through SAB's intervention. According to the medical diagnosis that was given to them, in two of those three cases, medical attention was given immediately because both were matters of life and death. This was the case of Mirna, an undocumented woman from Honduras who went through surgery due to a serious gallbladder problem, and the case of Mario, who was hospitalized due to a kidney infection. The other case did not need hospitalization, but was also very serious, since he received medication to treat a high blood pressure problem that was creating headaches, dizziness and vomiting which impeded his work.

The itinerant SAB's food bank delivers food free of charge to more than 40 families on a monthly basis, although through SAB's support, more than 150 undocumented people and their families have access to the food banks of Montreal and surrounding cities on a regular basis. The same goes for accessing to clothing, household items and education for the children of the undocumented.

\section{Médecins du monde: Caring for the Poor}


Médecins du monde is an international and internationalist organization that offers health services for vulnerable populations. It is composed of health professionals who are committed to the protection of human life, particularly with respect to people who have been prevented from accessing health care because of their marginalized status in society, including the sans papiers.

In Montreal, this organization provides health services through mobile units that are placed at various points in the city on a regular basis. Through outreach work carried out in key points of the city, undocumented workers who normally do not have access to migrant justice networks because of their work schedules or because of fear of exploring the city, have had access to these health services and medicines for free. MdM's work is based on a holistic understanding of health care in which mind and body are not seen as separated, but as part of a same whole. Therefore, the services they provide include preventive medicine and, even though they do not offer mental health care directly, they refer the patients to health professionals in their networks who provide it to them for free.

At least twice a week, dozens of medical students from local universities make "flash mob visits" to neighborhood centers where the precarious migrants tend to gather, including clinics where they themselves send the undocumented immigrants to get free health services. Through those flash mob visits, the students of medicine offer disease prevention techniques, proper teeth cleaning and ideas on how to prevent diseases. During those quick demonstration visits, they also distribute printed information about where the migrants with precarious status can get free medical services without having to bring in official identification.

According to the outreach coordinator with whom I used to talk often, a devoted social worker who is responsible for the MdM's outreach work, the organization also offers information on food 
banks and free mental health services to the people use their services, particularly to pregnant women, as they consider that "health is the result of many social conditions that go beyond the mere attention to diseases."

MdM provides services to an average of 200 undocumented people a month, including children, the elderly and pregnant women. They form a network of researchers, doctors, social workers and nurses who, in addition to offering medical support services, integrate migrants themselves into the development of their advocacy programs through which they seek to influence public policies to make it possible that the federal government can one day offer universal health services to migrants without status. Their work is then a work of attention, prevention and advocacy in favour of the vulnerable poor.

\section{Constellations of struggle, moral recognition and mental health}

But the integrative life-protecting politics carried out by SAB and MdM not only provide access to medical services, medicines, shelter, food and other resources that are vital for the undocumented population to deal with the health crises and the crisis of social reproduction they often experience. Through the workshops and spaces that such organizations have opened for precarious status migrants, networks and organizations led by undocumented migrants have also emerged. The creation of such networks and spaces set up exclusively for the undocumented have an impact on their mental health. Organizations such as Dignidad Migrante (Migrant Dignity), MUR (Mexicans United for Regularization) or the advocacy group of MdM for universal access

to healthcare for migrants without status have themselves generated spaces where the undocumented feel heard, recognized and accepted. 
The participation of many of them in such organizations, struggles, solidarities, and mutual support practices, as mentioned by some of the interviewees, has raised their morale and strengthened their hope. Through such networks they have had access to organizations and people who show them "the other side of Canadian society," the face of a society that is able to welcome and treat people with tenderness, respect and esteem regardless of skin color, migratory status, sexual orientation, gender ascription, social class and other identity markers. Some mentioned to me that participating or getting involved in such organizations and movements has made them to feel something important in their lives. Sometimes this was because, for the first time, they have been able to participate in press conferences or give a speech at a rally, or have their voice heard by journalists. Others mentioned that knowing local güeros activists have made them to see "the other side of the Canadian reality" and made them to feel love for this country, a place that they now consider their "second homeland" (la segunda patria). Others told me that they were simply happy to know that there were places where they could be heard and treated with kindness. Others mentioned to me that participating in the processes of struggle with local organizations has made them better human beings. The latter because, according to what they say, getting involved in SAB's work has taught them to see the world "in a different way," as it has taught them to think that all human should be treated equally, with respect and dignity, regardless of any kind of difference.

In different ways, the narratives of my interviewees show a particular way in which solidarity is understood and experienced among those who have had access to the solidarity structures created by the constellation of struggles have been described. In effect, through the descriptions about how the involvement in SAB made them feel, there is a tacit recognition that solidarity is not only a practice that "helps" one another in a material way to overcome obstacles, but also a gesture of moral recognition that practically and symbolically help the oppressed subjects to break down the 
feelings of humiliation, isolation, disenfranchisement, self-disrespect and other alienating experiences that are produced by subordination, exploitation and social exclusion.

The narratives of the undocumented workers involved in organizations led by undocumented workers created in the light of $\mathrm{SAB}$ and $\mathrm{MdM}$ also show that, through such processes, the subjectivity of the undocumented finds symbolic and subjective spaces of comfort that are translated into an experience of joy. Feeling recognized through the good treatment of others made them feel, in their words, "happy," "well," "important," "boosted in morale," "grateful," "love for the second homeland," and "hopeful." It is not necessary to explain the impact that such positive feelings can have on the mental health of people.

Through the work carried out between local organizations and precarious status immigrants, some of the people I interviewed have found forms of moral recognition whose consequences are worth mentioning. The first form of recognition has a material character. It occurs in the form of accessing common, public and private goods and services that make more likely for the undocumented workers to increase their wellbeing via accessing to food, health services and other material resources that help them to partially overcome the crisis of social reproduction. This makes it possible for them to partially overcome the legal barrier which sets apart citizens and people without status, and which translates into unequal access to social and individual prerogatives. Insofar as the border and its concomitant blockade of prerogatives for non-status immigrants gets cracked, the migrants' autonomy of movement becomes fortified.

The fortification of the undocumented migrants' autonomy of movement created in the light of this cooperation between migrant justice organizations and undocumented immigrants has a concrete material positive impact on the participants. But it also has an impact on a moral and 
subjective dimension. Having access to the socially produced goods, and also to the set of prerogatives which have been blocked to them, has contributed to the repossession of their human dignity and has brought them back into social existence as human beings. That is to say, the social death that the processes of state exclusion, illegalization, racism and labour exploitation produces among the undocumented migrants is partially defeated through the forms of recognition they attain while working along Canadian grassroots organizations. Migrant justice struggles for inclusion and recognition defeat social death, and represent forms of collective action that reclaim, assert, sustain and reproduce life. Through the access to essential goods and liberties, the condition of humanity of the undocumented workers, their social being, and their lives are placed at the center of political and social life. The discourses that represent them as human beings who should not be considered "illegal" have also the effect of placing them, as political subjects, at the center of the public debate. This discursive transference, which has the effect of bringing them back them from the margins to the center, constitutes one of the most radical effects that those struggles have on the undocumented workers at the subjective level. It makes them freer people and sometimes, literally, saves their lives and humanizes them.

\section{Tensions of recognition and their impact on mental health}

The protection of life and freedom of movement occurs not only from the top to the bottom, the top being the structures that the humanist left in Canadian society has built, and the bottom being the passive and precarious migrants who are integrated into such structures of protection. The workers' autonomy that is generated as a result of working fewer hours, especially in the multinational corporations, and the desire for emancipation of the migrants themselvesconsubstantial to every oppressed subject—has made it possible for many migrants, particularly among those who carry with them stories of struggle and political knowledge from their countries 
of origin, to take initiative to search by themselves for Canadian migrant justice organizations or for people who share their political and class interests. Those encounters have given rise to a collaborative work between much more autonomous, politicized and active undocumented migrants and local organizers. Out of such collaboration, as I have already mentioned, have emerged life-protecting politics and substantial forms of moral recognition which save lives, cure diseases and reclaim the dignity of illegalized and marginalized people.

However, such processes of mutual recognition that occur within the framework of the collaborative political work between migrants and local Canadian militants do not occur without tensions or contradictions. The expectations and objective/subjective experiences of the sans papiers often find points of friction, contradiction and conflict with the experiences, expectations and forms of operation of the local organizers and organizations. Let's see how this happens from the top to the bottom and from the bottom to the top, and how that has a non-positive impact on the experience of the undocumented activists in the context of the broader struggles for their moral and legal recognition in the host society.

As has been pointed out by many of the interviewees who participate in such struggles, almost all of them workers for the multinational corporations, the local activism of the güeros has five characteristics that they identify as problematic: 1) The first of those characteristics is that such a form of activism is based on a very accelerated productivity system which tends to measure political worthiness in quantitative terms. By this they mean that the social justice work that is carried out is based on the development of many tasks that often overlap and require great dedication. In addition, that work needs to be done at a very fast speed and high intensity. 
2) The second characteristic of such a form of migrant justice activism is based on a heteronomic and ethnocentric view of the social struggle. All of my interviewees involved in social struggles with local activists mentioned that quite often the strategies and tactics are often planned by local activists and that, although this is not often clearly stated, the tacit expectation is that migrants will bend to these models that have been previously prepared and planned "from the top to the bottom," and act accordingly. This model is identified by undocumented activists as the main reason many of the migrants who are integrated into activism end up detaching from the movements- "not feeling heard." In the meetings where this is discussed openly, migrant activists do not feel listened to or taken seriously in their observations.

3) The third characteristic of the migrant justice activism led by the local organizers that the workers interviewed find problematic has to do with what they see as an unequal and politically incoherent division of labour within the activist structures. By this they mean that the local organizations with whom they work directly, despite ascribing themselves to anarchist politics and communist notions of cooperative work, and despite aspiring to radical equality among human beings, quite often participate in the production and reproduction of a hidden system of hierarchies which is organized on the basis of an unequal sexual division of labour that is remnant of the patriarchal culture. Within this sexist and patriarchal division of labour, certain tasks that are carried out primarily by women, such as everyday tasks of solidarity with the oppressed, those tasks which require the investment of an important amount of emotional labour, as well as the practice of kind, warm and loving behaviour to the dispossessed, such as the tasks aiming at providing health, food and shelter or emotional/moral support to a person going through the hardships of illness, domestic violence or depression. A good part of the work which requires the use of rational and instrumental skills for the planning and execution of political militancy and 
insurgent action in the public world is dominated by men. Latina women and men expressed frustration through the interviews for feeling that they are, in fact, less required in the tasks of political organizing and militancy.

4) The fourth characteristic of this model of migrant justice local activism, and over which my interviewees expressed frustration, is that it sustains a dominant model of "being an activist" that is always represented in the figure of a man who has "vain characteristics." I was able to confirm that this model of activist exists. In fact, this model of the activist, which from my point of view has been molded by sediments or residues of narcissism, voluntarism and individualism which are emblematic of the bourgeois subjectivity, a late-capitalist structure of feelings, is often identified by the women and immigrants participating in these movements. In fact, they identify this figure with the nickname of Manarchist. The "manarchist," as the name denotes, is a man of anarchist ideas who professes to be an anarchist, but who uses everyday machismo tactics of patriarchal domination to manipulate the will of the group and to impose his individual views above the views and interests of the group.

5) The fifth characteristic of this model of local pro-migrant justice activism identified by the undocumented militants as problematic is related to the existence of a symbolic system of distribution of prestige that grants moral recognition and "respect" to activists according to their "high capacity to work," and productivity, often measured in quantitative terms, willingness to take risks and heroism. As in this system of distribution of recognition the "doing of things," "dedication," "risk" and heroism are measured on quantitative, narcissistic, individualistic terms and evaluated from the natives' point of view, that is, from the point of view of those who have full legal citizenship and do not have "precarious status," the ones who end up accumulating the 
symbolic capital ("respect" and recognition from the group) are the local men of full citizenship who have the privilege of free time, the networks and the cultural capital that allows them to "produce," fast and in volumes, to be visible, to take risks, to show full dedication to the cause and willingness to sacrifice themselves with heroism. Because of the ways in which symbolic capital can be accumulated within the activist circles, it is often the "Manarchists" who tend to monopolize moral recognition within the framework of this symbolic system of distribution of prestige, moral recognition and privileges.

All the characteristics that were pointed out by undocumented activists were discussed as ethical and political contradictions which provoke frustration. But they have a more profound impact on the migrants' subjectivity, on their structure of feelings and on the effectiveness of the struggles for recognition in which they are involved. In the first place, those contradictions allow the existence of a series of practices that contribute to reproduce the subordination and misrecognition of the undocumented migrants. As such characteristics prevent local activists from sincerely listening to undocumented immigrants, they impede the development of a humble will to learn from the profound experiences of struggle, resistance and forms of survival in the face of oppression that undocumented migrants have developed over the years and make that the sans papiers face new forms of misrecognition. Second, those forms of misrecognition have the effect of making the undocumented activists feel that they are being reified as persons and used for political purposes which they themselves have not defined. They often state that their role within such struggles is sometimes limited to providing testimonies of the tragedies that they experience as migrants, testimonies that have a powerful impact in the local press, but that prevent them from participating substantially in the groups because they are not recognized in their capacities for analysis and planning, in the elaboration of the explanations, the analyzes and the design of 
strategies of the group as a whole. That is, the existence of the activist models described produce in the undocumented activists not only the feeling that they are misrecognized but also manipulated, used and reified.

This set of tensions, misrecognitions and reifications has a particular impact on the subjectivities of the undocumented migrants. As such, they do not help much to cure the emotional wounds that the undocumented have accumulated as a result of a long exposure to injury, grievances and exploitation. Living exiled from the order of formal recognition of rights, at the margins of society, under conditions of labour exploitation and, above all, subjected to the possibility of deportation, generate in the illegalized subject, as we have described throughout the previous chapters, a constellation of emotional and physical wounds. But not only that. The will to live and the tendency towards survival carried out in the context of long-term emotional hardship and social death, often has the effect of making the undocumented migrants eager and needy for recognition. Long-time exposure to subordination, as Franz Fanon (2008 [1952]: 24-44) has theorized, turns subjects exposed to the violence of domination into persons in vital need of being recognized. This is so because, within the dynamics of the struggle for recognition between the slave and the master, the slave learns that his/her being can only be fully recognized via his/her identification with the master, when he or she resembles the master, and by the act of being evaluated through the eyes of the master or entering into the culture of the master.

Following the insights of Franz Fanon, it can be said that in the process of working together with local organizations, as it occurs within the framework of an imbalance of symbolic power, the illegalized subject, lacking the prestige and symbolic capital to achieve recognition of the symbolic master - the "white" local culture-, is "pushed" into a perpetual fight for recognition from their 
allies. But, as this battle to be recognized is carried out by using the criteria for moral recognition established by the local society and the local allies, their symbolic master, in a kind of ethnocentric way, this battle to be recognized and appreciated leads the undocumented to ritualize, in a repetitive way, the activities and attitudes that in this particular relationship are established as worthy of being valued. As their demands, claims and observations have failed to change the rules of the game, and as the undocumented have internalized that they can only access moral recognition by working a lot, "like a machine," as well as by exhibiting heroic will, taking risks and acting like a "Manarchist," some of them engage in a fierce battle to achieve and to show that they possess such qualities. All of this is encouraged by the idea that perhaps this could be the way in which, in the local society, they can finally be recognized and accepted legally and culturally. But they do not have the conditions possessed by the symbolic Master, from whom they desire acceptance and recognition. Because the undocumented have precarious material conditions, do not have access to welfare or social security systems, and have to work in the exploiting underground labour market to be able to reproduce as biological and social beings, they encounter objective difficulties that prevent them from accessing these forms of prestige and recognition that are granted within the framework of the unwritten rules of the game.

As a result of the enormous emotional and physical effort that activism demands in this context of high productivity expectations that the symbolic master possesses, the social struggle ends up producing among the undocumented workers physical and mental discomfort; it exhausts their bodies and creates certain levels of frustration. On many occasions, it also produces disenchantment with politics. It was common during my fieldwork to find physical and psychological manifestations associated with what in the studies on health and work is called "burnout," such as: generalized exhaustion of the body and mind, depressive symptoms, lack of 
appetite for social activities, low disposition to erotic and sexual life, social withdrawal, isolation and slight degrees of inability to concentrate on daily tasks. I also found that "burnout" is one of the main determinants of health among undocumented activists and the second cause of desertion from the social struggle for intermittent periods of time. The first cause of desertion is the return to abstract labour and labour exploitation.

That being said, I do not intend to paint a gray and negative panorama. What I have described points to a contradiction in the struggle for recognition, but does not represent the general trend. The "big picture" points out that the struggles carried out by the local social organizations, together with undocumented people, are producing forms of activism and politics that are effectively contributing to contest the unhealthy and destructive effects that deportability, labour exploitation, racism and misrecognition have on the bodies and minds of undocumented workers, the new pariahs of the 21 st century capitalism. Through this struggle, the destructive effects of deportability are not the only ones which are contested. Forms of solidarity and collective work are being launched which, literally, are saving lives and contributing to the improvement of the mental and physical health of many people who live and work without legal status in Canada. By doing this, they are also rewriting the new routes and the new emancipation projects which define the type of society which may potentially flourish in the future. The aforementioned contradictions have the goal of pointing out that in the dialectic struggle that is established between inner and outer recognition, understood as the radical acknowledgment of human beings in conditions of equality, the oppressed subjects find obstacles. And such obstacles can only be overcome through constant work aimed at identifying and overcoming such contradictions. This is the only condition for achieving, as Marx said, "the real appropriation of the human essence by and for [hu]man," (Marx, 2010 [1843]: 96), a goal that is achieved within the framework of a society without classes, without 
borders and without social domination that envisages the contemporary struggles of the undocumented immigrants and their allies.

Some of the answers that can help local activists to achieve forms of recognition on the road to emancipation must be found among the undocumented workers themselves. On a sunny Sunday day, as we walked together in a Montreal march for the regularization of the undocumented living in Canada, the "Status for All! March for justice and dignity for all migrants and refugees," I asked Melo how he thought the relationships between the undocumented immigrants and their local allies could be better integrated in their struggle. He answered with certainty: "By asking. That is how I learned from them that our struggle seeks something beyond mere legal regularization, that our struggle is for building a world without borders and without exploitation, exploitation against anyone. I think they also can ask us more and learn from us as well.”

By asking we walk. 


\section{Conclusions}

The goal of this thesis was threefold. First, it was to understand how the undocumented migrant workers' physical and mental health are shaped while living and working under conditions of illegality in Canada's late capitalism. Its second goal was to understand how undocumented workers' respond to the conditions that shape their health. Finally, its third goal was to identify and discuss how and to what extent those forms of response, agency or struggle, were shaping their own health.

The method consisted in carrying out an ethnography following the principles of "global ethnography," which suggest that the work of the researcher is to register and to make visible the links that exist between the local events and the global social forces. With this in mind, I worked in the underground labour market in Montreal for 24 months where I interviewed undocumented immigrant workers from Latin America about their migration trajectories, and their experiences making a living in the underground labour market, as well as about their health challenges while navigating in Canadian society. I collected those stories and conducted participant observation in factories and houses, at parties, in informal conversations and at political demonstrations. I also collected stories and carried out participant observation in detention centers and hospitals while providing support and company to those who were in detention and to those who were going through health crises. Providing support was not made with the purpose of just "extracting data," but was my humble way of giving back all of what I received from them: trust, encouragement, housing, meal-time company, contacts to carry out interviews and even research ideas. Many insights and research questions that are relevant to their own lives and that enriched my own academic inquiries presented in this thesis were born in the light of our conversations and often 
with their encouragement. As this research collected the data in transnational contexts and reflects the health experiences of people engaged in transnational forms of mobility, it constitutes an ethnography that sheds light on some of the transformations occurring in the core countries of the world system, particularly with regards to how human mobility is mobilized, governed and subsumed by State and capital in late capitalist societies.

This thesis identified three aspects that I consider important to underline as a form of conclusion.

1) The first is that the undocumented immigrants who work for medium-size local enterprises, as well as those who were more exposed to the effects of deportability or deportation itself were more likely to develop the most dramatic forms of physical and mental health diseases. How can this situation be explained?

The long-time exposure to precarious labour, in conditions of exploitation, as well as in conditions of control by recruiters, and the social isolation that this situation generates, plays an important role. This is so because the workers who spend the most time of their lives at work are more exposed to the master determinants of health that were discussed in Chapter Two: deportabilitygenerated by the State or the administrative apparatus-racism and labor exploitation. In this conclusion I will explain how these factors reinforce each other in the context of working for the medium-sized factories. But I will first describe the health problems that the undocumented workers faced while working in this labour context.

a) Mental and physical health in the middle-sized companies.

As I have pointed out, in the middle-sized companies, the undocumented workers experience the most dramatic forms of mental suffering and physical injuries. With regards to mental health, these 
workers are more likely to experience problems that can arguably be linked to what I call "short-term historical traumas" such as: persistent nightmares or night terrors that have lasted for more than two years; suicidal tendencies, as well as fear or desire of dying.

With regards to physical health, the workers subsumed in the middle-sized companies are also more likely to experience more and more severe physical health problems, when compared with those working in multinationals and underground labour cooperatives. They are usually more affected by back and leg pain, sprains, back injuries, rheumatism, nose bleeds, cuts and eye disorders. In the meatpacking companies and slaughterhouses as well as in the recycling factories the workers are more exposed to work-related stress and they are the ones more affected by injuries and by the physical health problems described. The most dramatic forms of physical injuries are also experienced in the middle-sized companies. Some of the workers have lost their fingers and others developed incapacitating injuries in different parts of their bodies.

Workers inserted in the middle-sized companies also show signs associated with the wear and tear of the body and mind which in the scientific literature in labour and health are classified as linked to allostatic load: loss of memory, difficulties to focus on daily activities, lack of dexterity, dark circles, permanent fatigue and weight loss. Some accidents that the workers experienced in and outside of the workplace were linked to this condition. Inability to focus while working, for example, led one of my interviewees to sever three fingers from his hand while working in a meatpacking company.

The aforementioned problems are heavily shaped by two main factors: the length and intensity of the labour process in the middle-sized companies, and the recruiting mechanisms by which the workers are integrated into the labour processes. In effect, as they work for long hours, every day 
under intense labour processes, their body gets more exposed to wear and tear and accidents in the workplace. Also, the length and intensity of the labour process prevents them from socializing with the local population and with people from their own communities. This keeps them uprooted and separated from society. In such conditions, they are less likely to seek health care services. The recruiting mechanisms by which the workers are subsumed into such labour processes (through recruiters) and the forms of bondage and control that the recruiters use to keep the workers disciplined and attached to those kinds of jobs, such as threats of deportation and salary retention, prevents the workers from the development of autonomy and from the will to become engaged in collective forms of resistance. In fact, as a way of keeping themselves inserted in the job, they resort to self-exploiting forms of agency, such as acts of "performative submissiveness" and partial withdrawal from social relations. They also just work harder and harder, as if they were "work machines."

The aforementioned objective conditions the workers face in the workplace create a system of structural violence that explain the physical and mental health challenges that the undocumented workers face while living and working under conditions of illegality.

b) Deportability, labour and health

Those who have been more exposed to the possibilities of being deported (deportability), those who have witnessed deportations, and those who have been themselves deported also are the undocumented workers who have been most severely affected by mental health problems arguably linked to short-term historical traumas. In effect, undocumented immigrants who work in the medium-sized companies are more severely affected in their mental and physical health not only as a result of their exposure to labor exploitation. Often, the highly demanding labour processes 
that exist in these companies overlap with other determinants of health and they reinforce each other. In Chapter Four we have seen how those undocumented who have been affected by deportations and who work in medium-sized companies suffer the most dramatic consequences to their health. This is so because, under conditions of deportability, the permanent fear of being detained as well as the need to go to work on a daily basis, keep the workers in conditions of constant fear and anxiety. Every day, when leaving home to go to work, they face the possibility of being deported in the street or at work. This also occurs because the condition of deportability submits the undocumented persons to stress and worries.

Therefore, when dealing with these two determinants on a daily basis, undocumented workers who are subsumed in medium-sized companies and who face greater possibilities of being deported, are more prone to developing severe problems, such as: post-traumatic nightmares and workrelated accidents. In the same way, undocumented persons who are affected by higher levels of deportability are more likely to present symptoms arguably related to allostatic load.

Those who have been arrested and deported have experienced particularly severe mental and physical health problems. As we saw in the composited cases in Chapter Four, arrest and deportation have produced on them enormous pain and suffering. That situation has in turn undermined their capacity to focus on daily tasks. As a consequence, they have suffered accidents in the workplace.

Likewise, people who have lost their status after having been involved in refugee application processes and who work in medium-sized companies have also gone through rather dramatic deterioration processes and into deeper levels of precarity. The reason is that the refugee application processes are long, time-consuming, exhausting and often expensive. Therefore, when 
the workers are exposed for a long time to highly demanding labor processes, and at the same time they are dealing with refugee application processes, including court appeals, they tend to suffer physical and mental wear. Several workers began to experience nightmares and other serious mental health problems due to the stress experienced through legal appeals. In some cases, the situation gets worse when they are "rejected" and their presence in the country classified as illegal. The generalized wear and tear that occurs in these application processes also works as determinant of problems arguably linked to allostatic load.

All of the above explains why undocumented workers in the medium-sized companies while involved in refugee application or deportation processes are more vulnerable in their health.

2) The second aspect that has been shown in this thesis is that the undocumented immigrants who live "in the total underground" that is, those who work for underground workers' cooperatives, are more likely to report better physical and mental health outcomes.

In radical contrast to the severe mental and health challenges that the undocumented workers face while working in the medium-sized factories, undocumented immigrants who work under labour structures based in solidarity and cooperation, that is, those who work for underground workers cooperatives, have shown better health outcomes. In the cooperatives, the workers do not experience severe injuries or accidents, nor severe problems linked to mental health. As described in Chapter Six, the physical health problems that the workers experience within this labour context are linked to light body pain, as well as light cuts to the hands, and sprains. In none of those cases were the accidents and injuries considered severe. None of those accidents involved body organ mutilations, nor problems that needed more than two or three weeks of recovery. Their mental 
health challenges are also mild, if compared with the rest of the workers, as in those spaces the workers do not experience more than mild levels of anxiety, sadness over long-time family separation, and financial worries.

As discussed through the thesis, this situation happens for two reasons:

The first reason is that in the cooperatives the labour process is controlled by the workers themselves. As the work is carried out on a collaborative basis, and as they do not work under supervision of bosses and recruiters, they have control over the pace in which the work has to be done. Being emancipated from capital and exploitation in the workplace creates a safer workplace environment.

The second reason is related to the fact that their relationship with the local society is predominantly based on the practice of solidarity and mutual aid, forms of social relations which are carried out in the underground. By this I mean that, as those economic exchanges of money for services between the local society and the undocumented workers inserted in underground cooperatives are done "under the water," they constitute forms of "clandestine solidarity." However, because those exchanges exist, the undocumented workers can have access to means of survival and to forms of social relations that are not based on exploitation. Also, as there is no exploitation at the basis of those exchanges and as workers normally receive others forms of support than just simply jobs and money from the local society, their social life is richer. Under conditions of cooperative labour and "clandestine solidarity," their possibilities of integration to the local society are richer as well. Therefore, even though they face material precarity, fears of being deported and other challenges stemming out of their condition of illegality, having positive and solidarity-based social relations with Canadian people have made them live freer and healthier. 
Relationships based on "clandestine solidarity" constitute an important factor helping them to navigate in this society in conditions of dignity, respect and recognition. This aspect also positively affects their mental and physical health. Through the social and labour relations that emerge in such contexts, which involve mutual recognition, cooperative labour, non-exploitative labour relations, mutual aid and solidarity, people who have been illegalized and expelled from society, find the time, the spaces, the cultural mechanisms and the social infrastructure that are needed to become partially integrated into Canadian society in conditions of dignity and respect. This, in turn, has been helping them to access the social goods, health services, nutritious food and other material and non-material resources that are positive determinants of health.

3) The third aspect that has been shown in this thesis is that Canadian pro migrant justice organizations play an important role in the configuration of forms of social inclusion and access to social and material goods that have a positive effect on the lives of the undocumented workers.

The undocumented workers inserted in the multinational corporations have been the most positively affected by the mechanisms of incorporation into Canadian society carried out by the grassroots organizations. The mechanism that allows the undocumented workers in the multinational corporations to become integrated by Canadian organizations and experience better health outcomes is related to the relative autonomy that the workers develop while inserted in the multinational corporations' labour processes. The reasons that explain this situation are complex but can be summarized as follows: 
As in the middle-sized companies, in the multinational corporations the workers also work hard and are assigned the most dangerous and physically demanding tasks. Likewise, the recruiters who hire the workers also use despotic disciplinary mechanisms to pressure the workers to work hard and fast through the labour process. However, unlike what occurs in the middle-sized enterprises, the workers in the multinational corporations are hired under one-time verbal agreements and for short periods of time. This situation provides them with more autonomy with regard to capital.

Workers' autonomy has an important effect at the level of their structures of socialization. Being less exposed to the command of capital allows the undocumented workers to have more free time. Having free time, in turn, allows the workers to develop and enrich their social networks. It allows them also to explore the local culture, to meet people and to develop language skills, all of which helps them to overcome isolation and to be exposed to Canadian culture. Perhaps most importantly, it exposes them to the Canadian migrant justice organizations and to the structures of care that they have built to help the precarious status immigrants to have better lives.

Those grassroots organizations which specifically target the undocumented migrants, create spaces where undocumented workers and local activists know each other and mix. Those spaces, practices and discourses have a powerful influence on the undocumented workers for three reasons:

First, by being in contact with people from a variety of countries, from different social classes and from political backgrounds, such as immigrants, local French and English Canadians, First Nations Peoples and people of different ages, sexual identities and ethnic backgrounds, they have been more able to enrich their social life. This has made them feel less lonely and "more complete" as human beings, as some say. As a consequence, the structures of feelings, heavily underpinned by 
sadness, nostalgia and rage - conditioned by isolation and labour exploitation as described in Chapter Three-is subjected to an important transformation under the new circumstances.

Second, by having access to spaces where solidarity and mutual aid are practiced and to social networks that make their participation in local struggles possible, the undocumented workers have become better able to participate in social struggles and to partially appropriate for themselves their freedom of movement. In fact, through the process of social participation in local politics, their access to public services and their capacity to move and explore the city according to their own needs and desires, the prerogatives they had lost as a consequence of being deprived of citizenship, have been, de facto, reclaimed and recovered.

Third, through their involvement with Canadian society, they have gained access to practices of care and forms of moral recognition (as legal recognition is absent) which have a positive and direct impact on their physical and mental health. The first form of moral recognition has a material character. It occurs in the form of access to common, public and private goods and services that make more likely for the undocumented workers to increase their well-being via accessing to food, health services and other material resources that help them to partially overcome the crisis of social reproduction. Having access to those material goods and social services from which they had been banned helps them to get access to hospitals. As discussed in Chapter Seven, having access to hospitals in moments of serious health crisis has saved the lives of dozens of people, as I could witness and describe in this thesis.

The second form of moral recognition has an impact on a moral and subjective dimension. Having access to the socially produced goods, and also to the set of prerogatives which have been blocked to them, has contributed to the repossession of their human dignity and has brought them back into 
social existence as human beings. That is to say, the social death that the processes of state exclusion, illegalization, racism and labour exploitation produce among the undocumented migrants is partially defeated through those forms of recognition. It can be said, therefore, that the set of pro-migrant justice politics carried out by Canadian organizations has the effect of defeating social death. For this reason, they represent forms of collective action that reclaim, assert, sustain and reproduce life.

This study shows that the way in which capital operates plays an important role on the production of migrants' "illegality." Studies on the production of illegality in Canada and other advanced capitalist societies have shown in detail the way in which the State, through surveillance, deportation, legal changes, restrictive migration policies and the strengthening of border controls, significantly contributes to the illegalization of the immigrants. The scholars using this mostly Foucauldian perspective, and those who study the health of the migrants from a legal Weberian perspective, have made important progress in our understanding of the ways by which this phenomenon occurs. Though important, such perspectives show only parts of the story, as they have overlooked the role that capital plays — through global exploitation- on both the production of migrant illegality and the production of the suffering of the illegalized migrant.

Capital is also an important determinant in the production of the illegalization of migrants. This is the thesis sustained throughout this dissertation. As the research results of this study have shown, the role played by "global exploitation" in the immigrants' countries of origin and the incorporation of the uprooted immigrant as a labour commodity in the local industries through exploitative labour processes, the main mechanism of incorporation of illegal immigrants into Canadian society heavily participates in the illegalization of the immigrants. This complex process happens fundamentally through a double movement. First, the "global exploitation" to which 
increasing sectors of the population in the global south are subjected produces subjects exposed to dispossession. As has been discussed in the section "Subjects of Exploitation" of this dissertation, the generalized dispossession to which third-world populations are being subjected, via labour exploitation, and the holistic undermining of the social security systems, including protection of people from male-dominated, patriarchal, homophobic, and racial-based violence in their countries of origin, is the point of origin where a deep erosion of the substantive rights associated with citizenship occurs. As a consequence, although people in those countries are citizens by law, "global exploitation" contributes to the erosion of the substantive content of their rights as citizens. Despite being "full citizens," they cannot fully exercise their citizen rights in real life (there are hospitals, but no good healthcare provided; human rights commissions but no substantial work carried out due to lack of budget, personnel and infrastructure, and there are may be jobs but with no protections). This situation transforms them into "denizens" in their own countries.

Then, in a second movement, the new pariahs of the 21 st century capitalism are transferred as cheap labour commodities to the core countries of the world system in conditions of generalized crisis of social reproduction, armed with a tremendous will to be exploited as the latest mechanism they have for material survival. Once installed in Canadian society, denied political asylum (as discussed, more than $90 \%$ of my interviewees arrived in Canada seeking refuge) and without more material options for survival, they decide to overstay or to remain in the country sans papiers, sans patrie, sans ami(e)s. In such conditions of crisis of social reproduction and without rights, they are incorporated into a second phase of exploitation and dispossession. This is the phase in which the reproduction and perpetuation of illegality through the mechanism of labour exploitation in the receiving countries occurs. In effect, incorporated by capital, or by certain fractions of capital, as labour commodities, in slave-like labour conditions, subsumed as workers through extensive and 
intensive working hours, banned from accessing to the most essential private, common and public goods, prerogatives and social benefits and services, "illegal" migrants find themselves subsumed in forms of radical isolation that prevents them from reclaiming their substantive rights back. Drained of mental and physical energy by precarious labour, isolated, lacking contacts and dispossessed from free time they often avoid seeking help. Under such material conditions, undocumented migrant workers find material, legal and mental limits that prevent them from looking at alternative routes to solve their precarious migratory situation through collective political labour. In those conditions they also often resort to working in isolation in the hope change will come one day or, in the worst cases, they tend to isolate themselves from society even more and to subsume themselves into self-destructive behaviours. The permanent subsumption of some of the illegal workers interviewed in this studio who work for such exploitative companies, mainly local, medium-sized sweatshops, as shown in Chapter Four, makes them sick and takes away their time and natural human will to resist exploitation, to resist the crisis of social reproduction, to resist deportation, and to develop the will to engage in collective struggles aimed at obtaining legal recognition, regularization and permanent residence. The capitalist incorporation of the pariahs of 21st century capitalism, that is, their incorporation into the world of abstract labour as labour commodities, keeps them trapped in webs of labour exploitation. This also keeps them trapped in a perpetual condition of illegality through global exploitation, an exploitation that occurs under clear neocolonial modalities. Many of the narratives collected through extensive ethnographic labour, narratives that were described at length throughout Chapters Three and Chapter Four of this dissertation portray this fundamental fact. Living under the yoke of abstract labour, a social relation primarily shaped by the way in which capital operates both in the South and Global North, contributes to the perpetual production and reproduction of migrants "illegality." 
But the incorporation of the undocumented migrant workers by capital is uneven. And their incorporation into Canadian society does not occur only through the real subsumption of labour by capital. The incorporation of the undocumented immigrant into Canadian society occurs also through society via forms of care, support, collective labour, collective political struggle, radical love and solidarity. And "that is how the light gets in," as the great Montreal poet put it so well. The existence of labour processes that are different to the ones above described—labour processes that offer the workers the possibility of material survival in the framework of labour dynamics that are less exploitative and provide more free time, such as those jobs performed in multinationals under short-term contracts or in the underground cooperatives under non-exploitative social relations, as we have seen in Chapter Six and Chapter Seven—allow the undocumented workers to have time for themselves, neither time for capital nor time for the reproduction of surplus labour. Emancipated, or partially emancipated from the chains of abstract labour, workers in such contexts tend to cultivate and to develop human agency and tend to participate in new forms of class struggle that have a holistic, universalist and integrative liberatory character. Free time, emancipated from wage, and abstract labour, allows the undocumented workers also to get out there and to mix with the most tender sectors of Canadian society; it allows them to learn the two official languages; it allows them to explore the beauties this society has to offer for free; it allows them to experience love in a variety of manifestations; it allows them to recreate eroticism and free love. It allows them also to meet local migrant justice organizations. Their contact and their work with the Canadian local organizations allow them to reassert the substantive prerogatives traditionally associated with citizenship, such as freedom of movement (even in a restricted way). This situation further allows them access to public and common goods to which they have been previously denied in their countries of origin and in Canadian society through labour exploitation 
and deportability. As it was illustrated in Chapter Five, the existence of these cases in which workers are not extremely exploited and in which, as a consequence, they show more disposition to political struggles, shows that the autonomy of the migrant with respect to capitalist exploitation (developed in the light of spending less time in the factory line), to a greater extent, allows them to recover and to reassert prerogatives and freedoms prescribed to them. Having recorded the existence of underground cooperatives - places where "illegal" migrants work and engage under non-exploitative social relations-shows furthermore that emancipation with respect to exploitation experienced through wage labour gives them freedoms and prerogatives that are obtained through solidarity and in collaboration with Canadian civil society often at the margins, under more fortunate states of exception and often without the permission of the State. It is for these empirical reasons that capital must be recognized as one of the master determinants of the production and reproduction of migrants' illegality, migrants' illness and migrants' suffering in late capitalist societies.

Finally, as has been demonstrated in Chapter Seven, the collaborative work with elements of the Canadian civil society, the incorporation of the "illegal" migrants into processes of collective political work at the margins of all kinds of capitalist exploitation, has helped some of the undocumented migrants escape the substantial effects of the master determinants of health mentioned in the second chapter of this thesis: racism, state administration (including surveillance, entrapment and deportation) and exploitation. If what has been said so far is true, then we can conclude that social recognition, collective work through cooperation and mutual recognition among human beings, the incorporation of the undocumented migrant in society as a universal human being, and not as a labour commodity, as well as the tender, radical and universalist love that Canadian organizations show through the practice of solidarity, work as positive social 
determinants of health. As such, they contribute to sow the seeds of a new, freer, healthier and more loving society that places the protection of life as its goal, as its means, and as a priority that cannot be postergated.

It follows, also, that it may not be through the defense of "freedom to move, freedom to stay and freedom to return" that the new struggles for life and human freedom must be based upon. Neoclassical political economists have already defended that idea. This is a demand put forward by capital with regards to the circulation of money and labour as commodities through the geographies of the world-system since time immemorial. It seems, instead, that it may be through the slow dismantling of the very social conditions that make people illegal, such as global exploitation, and in the simultaneous recasting of cooperative labour, that non-exploitative social relations and planetary human freedom may flourish. That way, four moons may one day illuminate the earthly night, and the tears of the wretched of the earth may no longer taste salty. But this idea, of course, can be better formulated in the form of a question. 


\section{Bibliography}

Adorno, Theodor. 2005. Dialéctica Negativa. La jerga de la autenticidad. Madrid, ES: AKAL

Agamben, Giorgio. 1998. Homo Sacer. Sovereign Power and Bare Life. Stanford, CA: Stanford University Press.

Ager, Alastair \& Alison Strang. 2008. 'Understanding Integration: A Conceptual Framework.' Journal of Refugee Studies, 21 (2): 166-191.

Agnew, Vijay (ed.). 2005. Diaspora, Memory and Identity: A Search for Home. Toronto, ON: Toronto University Press.

Agri-Food Economic Systems. 2015. The Economic Impact of the Seasonal Agricultural Worker Program in the Ontario Horticulture Sector. Prepared for Foreign Agricultural Resource Management Services (F.A.R.M.S.). Retrieved from: https://cahrcccrha.ca/sites/default/files/2015-04-EconomicImpactSAWPHorticulture-Apr-15.pdf

Agriculture and Agri-Food Canada. 2017. An Overview of the Canadian Agriculture and AgriFood System 2017. Retrieved from:

www.agr.gc.ca/eng/about-us/publications/economic-publications/an-overview-of-the-canadianagriculture-and-agri-food-system-2017/?id=1510326669269

Ahmed, Imran \& Michael Thorpy. 2010. 'Clinical Evaluations of parasomnias.' In: M.J. Thorpy \& G. Plazzi (eds.) The Parasomnias and other Sleep-related Movement Disorders (Pp:19-33). Cambridge, MA: Cambridge University Press.

Ali, Jennifer, Sarah Mcdermott, and Ronald Gravel. 2004. "Recent research on immigrant health from Statistics Canada's population surveys" Canadian Journal of Public Health, 95(3): 1-13.

Ali, Jennifer. 2002. 'Mental health of Canada's immigrants.' Supplement to Health Reports, 13. Retrieved from: www.statcan.gc.ca/pub/82-003-s/2002001/pdf/82-003-s2002006-eng.pdf

Allen, Theodore W. 2012. The Invention of the White Race. The origin of racial oppression in Anglo-America. New York, NY: Verso Books.

Anderson, Bridget, Nandita Sharma \& Cynthia Wright. 2009. 'Editorial: Why no Borders?' Refuge, 26 (2): 5-18

Anderson, Bridget, Nandita Sharma \& Cynthia Wright. 2013. 'No Borders: Struggling for a Global Commons.' Tikkun. Retrieved from: www.tikkun.org/nextgen/no-borders

Anderson, Bridget. 2004. 'Migrant Domestic Workers and Slavery.' In: C. van der Anker (Ed.) The Political Economy of the New Slavery (Pp: 107-17). New York, NY: Palgrave Macmillan

Andreotti, Alberta, Le Gales, Patrick \& Francisco Fuentes. 2013. Transnational mobility and rootedness: The upper middle classes in European cities. Global Networks, 13 (1), 41-59. 
Andrijasevic, Rutvisica. 2010, 'From Exception to Excess: Detention and Deportations in Contemporary Europe.' In: Nicholas de Genova \& Nathalie Peutz (Eds.) The deportation regime: sovereignty, space, and the freedom of movement (Pp: 147-165). Durham, NC: Duke University Press.

Andrijasevic, Rutvisika \& William Walters. 2010. 'The International Organization for Migration and the international government of borders.' Environment and Planning D: Society and Space, 28(6) 977-999

Androff, David K. 2010. The problem of contemporary slavery: An international human rights challenge for social work. International Social Work, 54 (2): 209-222

Apfelbaum, Erika R. 2000. And now what, after such tribulations? Memory and dislocation in the era of uprooting. American Psychologist, 55, 1008-1013.

Armstrong, Pat (et.al.). 2001. Exposing Privatization: Women and Health Care Reform in Canada, Toronto: University of Toronto Press.

Armstrong, Pat \& Hugh Armstrong. 2010. The Double Ghetto: Canadian Women and Their Segregated Work. Toronto, ON: Oxford University Press.

Armstrong, Pat \& Hugh Armstrong. 2010a. Wasting Away: The Undermining of Canadian Health Care. Toronto, ON: Oxford University Press.

Armstrong, Pat \& Hugh Armstrong. 2004. 'Planning for Care: Approaches to Health Human Resource Policy and Planning.' In Gregory P. Marchildon, Pierre-Gerlier Forest, Thomas Allan McIntosh (eds.) The Romanow Papers: Changing health care in Canada. Toronto, ON: University of Toronto Press.

Armstrong, Pat, Albert, Banerjee, Marta, Szebehely, Hugh, Armstrong, Tamara Daly \& Stirling Lafrance. 2009. They Deserve Better: The Long-term Care Experience in Canada and Scandinavia. Ottawa, ON: Canadian Center for Policy Alternatives.

Armstrong, Pat, Hugh Armstrong \& Krista Scott-Dixon. 2008. Critical to Care: The Invisible Women in Health Services. Toronto, ON: University of Toronto Press.

Armstrong, Pat, Hugh Armstrong \& David Coburn (eds.). 2001. Unhealthy Times: Political Economy Perspectives on Health and Care in Canada. Toronto, ON: Oxford University Press.

Armstrong, Pat, Jacqueline Choiniere \& Elaine Day. 1993. Vital Signs: Nursing Work in Transition, Toronto, ON: Garamond Press.

Arrighi, Giovanni \& Beverly J. Silver. 2001. Capitalism and world (dis)order. Review of Review of International Studies, 27, 257-279

Arrighi, Giovanni. 2009. The Long Twentieth Century. Money, Power and the Origins of Our Times. New York, NY: Verso Books 
Bacon, David. 2009. How Globalization Creates Migration and Criminalizes Immigrants. New York: Beacon Press.

Bakunin, Mikhail Alexandrovich. 1953 [1882]. The Immorality of the State. New York, NY: The Free Press

Bales, Kevin. 2007. Ending Slavery: How We Free Today's Slaves. Berkeley, CA: University of California Press.

Bales, Kevin. 2012. Disposable People: New Slavery in the Global Economy. Los Angeles, CA: University of California Press.

Balibar, Étienne. 1991. 'Is there a Neo-Racism?' In Etienne Balibar and ImManuel Wallerstein (ed.) Race, Nation, Class: Ambiguous Identities (pp. 17-28). New York, NY: Verso.

Balibar, Étienne. 1991a. 'Racism and Nationalism.' In: Etienne Balibar and ImManuel Wallerstein (eds.) Race, Nation, Class: Ambiguous Identities (pp. 37-67). New York, NY: Verso.

Balibar, Étienne. 2015. War, racism and nationalism. Verso Books. Retrieved from: www.versobooks.com/blogs/1559-etienne-balibar-war-racism-and-nationalism

Barr, Donald A. 2014. Health disparities in the US: Social Class, Race, Ethnicity and Health. Baltimore, MD: John Hopkins University Press.

Basok, Tanya, Daniele Belanger \& Eloy Rivas. 2013. 'Reproducing Deportability: Migrant Agricultural Workers in South-western Ontario.' Journal of Ethnic and Migration Studies, 40 (9): 1394-1413.

Basok, Tanya. 1999. 'Free to Be Unfree: Mexican Guest Workers in Canada.' Labour, Capital and Society, 32 (2): 192-221.

Becker, Gay, Beyene, Yewoubdar \& Pauline Ken. 2000. Health, welfare reform, and narratives of uncertainty among Cambodian refugees. Culture, Medicine and Psychiatry, 24, 139-163

Beiser, Morton \& Harald Bauder. May 2014. "Canada's Immigration System Undergoing Quiet, Ugly Revolution.” Toronto Star. Retrieved from:

www.thestar.com/opinion/commentary/2014/05/12/canadas_immigration_system_undergoing_q uiet_ugly_revolution.html

Benjamin, Walter. 1955 [1969]. 'Theses on the Philosophy of History.' In: Walter Benjamin Illuminations (pp: 253-264). New York, NY: Schoken Books

Benton, Meghan \& Alex Glennie. 2016. Digital Humanitarianism: How Tech Entrepreneurs are Supporting Refugee Integration. Washington, DC: Migration Policy Institute. Retrieved from : www.migrationpolicy.org/research/digital-humanitar-ianism-how-tech-entrepreneurs-aresupporting-refugee-integration. 
Benton, Meghan, Madeleine Sumption, Kristine Alsvik, Susan Fratzke, Christiane Kuptsch \& Demetrios G. Papademetriou. 2014. Aiming Higher: Policies to Get Immigrants into MiddleSkilled Work in Europe. Washington, DC: Migration Policy Institute. Retrieved from: www.migrationpolicy.org/research/aiming-higher-policies-get-immigrants - middle-skilledwork-europe.

Berman, Helene, Alvernaz Mulcahy, Gloria, Forchuk, Cheryl, Edmunds, Kathlyn, Haldenby, Amy \& Raquel Lopez. 2009. Uprooted and displaced: A critical narrative study of homeless, aboriginal, and newcomer girls in Canada. Issues in Mental Health Nursing, 30(7), 418-430.

Berman, Helene, Ford-Gilboe, Marylin, Moutrey, Beth \& Saira Cekic. 2001. Portraits of pain and promise: A photographic study of Bosnian youth. Canadian Journal of Nursing Research, 32(4), 21-41.

Bernhard, J. K., Goldring, L. Young, Julie, Berinstein, C. \& B. Wilson. 2007. 'Living with Precarious Legal Status in Canada: Implications for the Well-Being of Children and Families.' Refuge 24(2):101-114.

Bloch, Alice. 1999. 'Refugees in the job market: a case of unused skills in the British economy.' In: Bloch A., Levy C. (eds) Refugees, Citizenship and Social Policy in Europe. London, UK: Palgrave Macmillan

Birge, Silma. 2014. 'Reading the Racial Subtext of the Québécois Accommodation Controversy: An Analytics of Racialized Governmentality.' In: Amanda Gows \& Daiva Stasiulis (eds.) Gender and Multiculturalism: North-South Perspectives (pp: 157-182). New York, NY: Routdledge:

Bloch, Alice \& Liza Schuzter. 2005. 'At the extremes of exclusion: Deportation, detention and dispersal.' Ethnic and Racial Studies, 28(3): 491-512

Brass, Tom. 1999. Towards a comparative political economy of unfree labour: Case studies and debates. London, UK: Frank Cass.

Braudel, Fernand. 1995. The Mediterranean and the Mediterranean World in the Age of Philip II (Vol II). Berkeley and Los Angeles, CA: University of California Press.

Braudel, Fernand. 1992. Civilization and Capitalism 15Th-18th Century. The Wheels of Commerce (Volume II). Berkeley and Los Angeles: CA: The University of California Press

Brave Heart, Maria Yellow Horse. 2003. 'The Historical Trauma Response Among Natives and Its Relationship with Substance Abuse: A Lakota Illustration.' Journal of Psychoactive Drugs, 35 (1): 7-13.

Braverman, Harry.1974. Labor and Monopoly Capital: The Degradation of Work in the Twentieth Century. New York, NY: Monthly Review Press.

Burawoy, Michael. 1998. 'The Extended Case Method.' Sociological Theory, 16 (1):5-33. 
Burawoy, Michael, et.al. 2010. Global Ethnography. Forces, Connections, and Imaginations in a Postmodern World. Berkeley and Los Angeles, CA: The University of California Press.

Burman, Jenny. 2006. "Absence, "Removal," and Everyday Life in the Diasporic City. Antidetention/Antideportation Activism in Montréal.' Space and Culture, 9 (3): 279-293.

Calado, Pedro. 2016. Migration and Integration from a Holistic Perspective: Experiences from Portugal. Migration Policy Practice 6 (2): 7-10.

Calleman, Catharina. 2011. 'Domestic Services in a Land of Equality: The Case of Sweden.' Canadian Journal of Women and the Law, 23(1): 121-139.

Campbell, Ruth, Klei, A. G., Hodges, Brian D., Fisman, David \& Simon Kitto. 2012. A Comparison of Health Access between Permanent Residents, Undocumented Immigrants and Refugee Claimants in Toronto, Canada. Journal of Immigrant Minority Health, 16 (1), 165-176

Camus, Albert. 1991 [1951]. L'Homme révolté. Paris, FR: Les Éditions Gallimard.

Caneva, Elena. 2014. The Integration of Migrants in Italy: An Overview of Policy Instruments and Actors. San Domenico di Fiesole, IT: INTERACT Project, European University Institute. Retrieved from : cadmus.eui.eu/bitstream/ handle/1814/32019/INTERACT-RR2014_05.pdf? sequence=1.

Canadian Association of Refugee Lawyers. December 2014. 'Designated Country of Origin Scheme is Arbitrary, Unfair, and Unconstitutional." CARL Press Release. Retrieved from: http://www.carl-acaadr.ca/articles/32

Castles, Stephen \& Mark Miller. 2009. The Age of Migration. International Population Movements in the Modern World (Fourth Edition). New York, NY: Guildford Press

CBC. Aug 2017. 'How Quebec's largest far-right group tries to win friends, influence people.' CBCNews. Retrieved from:

www.cbc.ca/news/canada/montreal/quebec-la-meute-far-right-1.4255193

CBC. Dec 2016. 'Inside Quebec's far right: A secretive online group steps into the real world' CBCNews. Retrieved from:

www.cbc.ca/news/canada/montreal/quebec-far-right-la-meute-1.3876225

CBC. Feb 2017. '10 minutes of terror: What happened in the Quebec City mosque Sunday night.' CBCNews. Retrieved from:

www.cbc.ca/news/canada/montreal/10-minutes-of-terror-what-happened-in-the-quebec-citymosque-sunday-night-1.3962281

CBC. Mar 2017. 'Almost half of Canadians want illegal border crossers deported, poll suggests.' CBCNews. Retrieved from:

www.cbc.ca/news/canada/manitoba/asylum-seekers-poll-ipsos-reuters-1.4032521 
CBC. Oct. 2017a. 'Breaking down Bill 62: What you can and can't do while wearing a niqab in Quebec' CBCNews. Retrieved from:

www.cbc.ca/news/canada/montreal/bill-62-examples-ministry-release-1.4369347

CBC. Oct. 2017b. "Problematic and a "dog's breakfast": Quebec face-covering ban panned by authors of landmark report.' CBCNews. Retrieved from:

http://www.cbc.ca/news/canada/montreal/quebec-bill-62-bouchard-taylor-1.4362278

Cervantes, R.C. Salgado de Snyder, VN \& A.M. Padilla. 1989. 'Posttraumatic stress in immigrants from Central America and Mexico.' Hospital Community Psychiatry, 40(6):615-619.

Chan, Wendy. 2005. 'Crime, deportation and the regulation of immigrants in Canada.' Crime, Law and Social Change, Vol. 44 (2): 153-180.

Chase, Steven. 2014. “Ottawa to Cherry Pick Most Desirable Economic Immigrants for Fast Track Access to Canada." The Globe and Mail. Retrieved from:

www.macleans.ca/opinion/migrants-are-dying-in-canadian-detention-centres-the-governmentneeds-to-act/

Chen, Jiajian, Edward Ng \& Russell Wilkins. 1996. 'The health of Canada's immigrants in 199495,' Health Reports, 7:33-45.

Chiswick, Barry R. 1978. 'The Effect of Americanization on the Earnings of Foreign-born Men.' Journal of Political Economy. 86 (5): 897-921

Chiswick, Barry R. \& Paul W. Miller. 1990. Language in the labour market: The immigrant experience in Canada and the United States. Discussion paper No784. Retrieved from: http://qed.econ.queensu.ca/working papers/papers/qed_wp 784.pdf

Chomsky, Noam. 2016. "Conversation with Yanis Varoufaki." New York Public Library. Retrieved from:

www.yanisvaroufakis.eu/2016/06/28/full-transcript-of-the-yanis-varoufakis-noam-chomskynypl-discussion/

Choudry, Aziz, Jill Hanley, Steve Jordan, Eric Shragge \& Martha Stiegman. 2009. Fight Back. Workplace Justice for Immigrants. Black Point, NS: Ferenwood Punlishing.

CIHRNS, ERCC \& SSHRC. 2010. Tri-Council Policy Statement: Ethical Conduct for Research Involving Humans (TCPS). from: www.pre.ethics.gc.ca/pdf/eng/tcps2/TCPS_2_FINAL_Web.pdf

Coburn, David. 2000. "Income inequality, social cohesion and the health status of populations: the role of neo-liberalism". Social Science and Medicine, 51 (1), 2000: 35-46.

Coburn, David. 2001. 'Health, Health Care, and Neoliberalism.' In Armstrong, Pat, Hugh Armstrong and David Coburn (eds.) (pp: 45-65) Unhealthy Times: Political Economy Perspectives on Health and Care in Canada. Toronto, ON: Oxford University Press. 
Coburn, David. 2004. "Beyond the income inequality hypothesis: globalization, neo-liberalism and health inequalities." Social Science and Medicine. 58 (1): 41-56.

Coburn, David. 2010. "Global Health: a political economy of historical trends and contemporary inequalities." In: G. Teeple and S. McBride (eds.), Relations of Global Power: Neoliberal Order and Disorder. Toronto, ON: University of Toronto Press.

Coburn, David. 2010. "Inequality and Health “. In C. Leys and L. Panitch (eds.) Morbid Symptoms: Health under Capitalism. Black Point, NS: Fernwood Publishers

Cranford, Cynthia J., Leah F. Vosko \& Nancy Zukewich. 2003. 'The Gender of Precarious Employment in Canada,' Relations industrielles / Industrial Relations, 58(3): 454-482

Creese, Gillian \& Brandy Wiebe. 'Survival Employment”: Gender and Deskilling among African Immigrants in Canada.' International Migration, 50 (5): 56-76

Das Gupta, Tanya. 1996. Racism and Paid Work. Toronto, ON: Garamond Press.

Dauvergne, Catherine. 2008. Making People Illegal: What Globalization Means for Migration and Law. Cambridge, MA: Cambridge University Press.

De Genova, Nicholas. 2002. 'Migrant “Illegality” and Deportability in Everyday Life', Annual Review of Anthropology, 31: 419-447

De Genova, Nicholas. 2004. 'The Legal Production of Mexican/Migrant "Illegality",' Latino Studies 2 (2): 160-185.

De Genova, Nicolas \& Nathalie Peutz. 2010. The Deportation Regime: Sovereignty, Space, and the Freedom of Movement. Durham, NC: Duke University Press.

De Genova, Nicholas. 2010. "Migration and Race in Europe: The Trans-Atlantic Metastases of a Post-Colonial Cancer.” European Journal of Social Theory 13(3): 405-419.

De Maio, Fernando \& Eagan Kemp. 2008. 'The deterioration of health status among immigrants to Canada.' Global Public Health, 5(5): 462-478.

Debass, Thomas \& Manuel Orozco. 2008. Digesting Nostalgic Trade: A Prequel to a Value Chain Approach. Washington, DC: USAID Breakfast Seminar Series Presentation. Retrieved from: www.microlinks.org/ev_en.php?ID=29168_201\&ID2=DO_TOP

Denzin, Norman. 1997. Interpretive ethnography: Ethnographic practices for the $21^{\text {st }}$ century. London, UK: Sage Publications

Desiderio, Maria Vincenza and Anke Schuster, eds. 2013. Improving Access to Labour Market Information for Migrants and Employers. Brussels, BE: International Organisation for Migration. 
Desiderio, Maria Vincenza \& Agnieszka Weinar. 2014. Supporting Immigrant Integration in Europe? Developing the Governance for Diaspora Engagement. Brussels, BE: Migration Policy Institute Europe

Dharssi, Alia. September 14, 2016. 'Canadian cities help undocumented migrants as Ottawa deports them.' Calgary Herald. Retrieved from:

http://calgaryherald.com/news/national/canadian-cities-help-undocumented-workers-as-ottawadeports-them

Downe, Pamela J. 2006. Two stories of migrant sex work, cross-Border movement and violence. Canadian Woman Studies/Les Cahiers de la Femme, 25 (1/2), 61-66.

Downe, Pamela J. 2007. Strategic stories and reflexive interruptions: Narratives of a "safe home" amidst cross-border sex work. Qualitative Inquiry, 13 (4), 554-572.

Doyal, Lesley. 1995. What Makes Women Sick: Gender and the Political Economy of Health, New Brunswick NJ: Rutgers University Press.

DuBard, Annette \& Mark W. Massing. 2007. Trends in Emergency Medicaid Expenditures for Recent and Undocumented Immigrants, JAMA 297 (10): 1085-1092

Dunn, James \& Isabel Dyck. 2000. 'Social determinants of health in Canada's immigrant population: Results from the National Population Health Survey,' Social Science \& Medicine 51(11): 1573-1593.

Durand, Jorge. 2015. 'De programas bilaterales y visas unilaterales. Seis tesis sobre el trabajo migrante temporal.' En: Sara Lara Flores, Jorge Pantaleón y Sánchez Gómez Martha (Eds.) Hacia el Otro Norte: Mexicanos en Canadá (Pp: 75-88). Buenos Aires, ARG: CLACSO

Durkheim, Emile. 1998 [1895]. The Rules of Sociological Method. New York, NY: The Free Press.

Dussel, Enrique. 2006. 20 Tesis de Política. Distrito Federal, MEX: CREFAL-Siglo XXI.

Duxbury, Linda \& Christopher Higgins. 2013. Revisiting Work-Life Issues in Canada: The 2012 National Study on Balancing Work and Caregiving in Canada. Retrieved from: https://sprott.carleton.ca/wp-content/uploads/2012-National-Work-Key-Findings-1.pdf

Duxbury, Linda \& Mari Halinski. 2014. 'When more is less: An examination of the relationship between hours in telework and role overload.; Work 48(1): 91-103

Echeverria, Bolivar. 2010. Modernidad y Blanquitud. Distrito Federal, MEX: UNAM-ERA

Edwards, Ryan \& Francesc Ortega. 2016. The Economic Contribution of Unauthorized Workers: An Industry Analysis. Cambridge, MA: National Bureau of Economic Research. Retrieved from: www.nber.org/papers/w22834 
Elgersma, Sandra. 2014. Temporary Foreign Workers. Background Paper (Publication No. 201479-E). Library of Parliament-Government of Canada. Retrieved from: https://lop.parl.ca/Content/LOP/ResearchPublications/2014-79-e.pdf

Emerson, Robert M., Rachel I. Fretz \& Linda L. Shaw. 1995. Writing Ethnographic. Fieldnotes. Chicago, IL: University of Chicago Press

Fanon, Franz. 2008 [1952]. Black Skins, White Masks. New York, NY: Grove Press

Fairclough, Norman. 2003. Analysing Discourse. Textual analysis for social research. New York, NY: Routledge.

Fekete, Liz. 2005. 'The deportation machine: Europe, asylum and human rights.' Race \& Class, 47(1): 64-78

Fortier, Craig. 2013. 'No One Is Illegal Movements in Canada and the Negotiation of CounterNational and Anti-colonial Struggles from within the Nation-State.' In: Luin Golding \& Patricia Landolt (Eds.) Producing and Negotiating Non-citizenship: Precarious Legal Status in Canada (Pp: 274-290). Toronto, ON: University of Toronto Press.

Foster, John Bellamy, Brett Clark \& Richard York. 2010. The Ecological Rift: Capitalism's War on the Earth. New York, NY: Monthly Review Press

Foucault, Michel. 2003 [1997]. Society must be defended. London, UK: Penguin.

Farmer, Paul. 2005. Pathologies of Power. Health, Human Rights and the New War on the Poor. Berkeley and Los Angeles: University of California Press.

Ferris, Elizabeth. 1998. Uprooted!: Refugees and Forced Migrants. New York, NY: Friendship Press

Fraser, Nancy \& Axel Honneth. 2004. Redistribution or Recognition? A Political-Philosophical Exchange. New York, NY: Verso.

Fraser, Nancy. 1997. Iustitia Interrupta: Reflexiones críticas desde la posición 'postsocialista.' Santa Fé de Bogotá, COL: Siglo del Hombre Editores.

Fraser, Steven. 1991. Labor Will Rule: Sidney Hillman and the Rise of American Labor. New York, NY: The Free Press.

Fromm, Eric. 2002 [1955]. The Sane Society. New York, NY: Routledge

Fudge, Judy \& Leah F. Vosko. 2001. 'By Whose Standards? Reregulating the Canadian Labour Market.' Economic and Industrial Democracy, 22 (3): 271-310

Fudge, Judy \& Leah F. Vosko. 2003. 'Gendered Paradoxes and the Rise of Contingent Work: Towards a Transformative Feminist Political Economy of the Labour Market.' In: Wallace 
Clement and Leah F. Vosko (Eds.) Changing Canada: Political Economy as Transformation (Pp:183-213). Montreal and Kingston: McGill-Queen's University Press

Fudge, Judy, Eric Tucker \& Leah Vosko. 2002. The legal concept of employment: Marginalizing workers. Report for the Law Commission of Canada. Ottawa, ON

Fudge, Judy. 2016. 'Migrant Domestic Workers in British Columbia, Canada: Unfreedom, Trafficking and Domestic Servitude.' In: Joanna Howe \& Rosemary Owens (Eds.) Temporary Labour Migration in the Global Era: The Regulatory Challenges (Pp:151-172). Oxford and Portland, OR: Bloomsbury.

Fuller, Sylvia \& Leah F. Vosko. 2008. 'Temporary Employment and Social Inequality in Canada: Exploring Intersections of Gender, Race and Immigration Status.' Social Indicators Research, 88 (1):31-50

Garrett, P. Michael. 2010. 'Recognizing the Limitations of the Political Theory of Recognition: Axel Honneth, Nancy Fraser and Social Work.' The British Journal of Social Work, 40 (5): 1517 1533

Gastaldo, Denisse, Christine Carrasco \& Lilian Magalhães. 2012. Entangled in a web of exploitation and solidarity: Latin American undocumented workers in the Greater Toronto Area. Toronto, ON: SSP-CAIS. Retrieved from:

www.migrationhealth.ca/undocumented-workers-ontario/summary-findings

Gebhardt, Dirk. 2014. Building Inclusive Cities: Challenges in the Multilateral Governance of Immigrant Integration in Europe. Washington, DC: Migration Policy Institute

Gebhardt, Dirk. 2016. When the State Takes Over: Civic Integration Programmes and the Role of Cities in Immigrant Integration. Journal of Ethnic and Migration Studies 42(5): 742-58.

Gibney, Matthew. 2008. 'Asylum and the Expansion of Deportation in the United Kingdom.' Government and opposition, 43(2) 146-167.

Glen, Patrick J. 2013. Health Care and the Illegal Immigrant. Health Matrix. Journal of LawMedicine, 23 (1): 197-236

Goldring, Luin, Carolina Berinstein \& Judith Bernhard. 2009. 'Institutionalizing precarious migratory status in Canada.' Citizenship Studies, 13 (3):239-265

Goldring, Luin \& Patricia Landolt. 2013. 'The Social Production of Non-Citizenship:The Consequences of Intersecting Trajectories of Precarious Legal Status and Precarious Work.' In: L. Goldring \& P. Landolt (eds.) Producing and Negotiating Non-Citizenship: Precarious Legal Status in Canada (Pp: 154-174). Toronto, ON: University of Toronto Press.

Golsch, Katrin. 2005. The Impact of Labour Market Insecurity on the Work and Family Life of Men and Women. Frankfurt, DE: Peter Lang. 
González Casanova, Pablo. 2017. Explotación, colonialismo y lucha por la democracia en América Latina. Mexico, DF: AKAL

Gunn, Richard \& Adrian Wilding. 2014. Marx and Recognition. Heathwood Institute and Press. Retrieved from:

www.thiswasnottheplan.com/wp-content/uploads/2016/05/marx_and_recognition_nov_14.pdf

Gunn, Richard. 1994. Marxism and Contradiction. Common Sense, 15.

Hansen, Alvin H. 1942. After the War-Full Employment. Post-War Planning. National Defense Planning Board. Retrieved from:

https://palmm.digital.flvc.org/islandora/object/fau:4624/datastream/OBJ/view/After_the_war-_full_employment.pdf

Harvey, David. 1989. The Condition of Postmodernity: An Enquiry into the Origins of Cultural Change. New York, NY: Blackwell Publishing.

Harvey, David. 2000. Spaces of Hope. Berkeley and Los Angeles, CA: University of California

Harvey, David. 2003. The New Imperialism. New York, NY: Oxford University Press.

Harvey, David. 2005. A Brief History of Neoliberalism. Oxford, NY: Oxford University Press.

Hegel, Georg Wilhelm Friedrich. 1977[1807]: Phenomenology of Spirit. Boston, MA: Oxford University Press [Translation by A.V. Miller]

Heller, Agnes. 2018 [1976]. Theory of Need in Marx. New York, NY: Verso Books

Hennebry, Jenna. 2009. 'Mobile Vulnerabilities, Transnational Risks: Temporary Agricultural Migrants in Ontario.' International Settlement Canada 22(3): 10-15

Hennebry, Jenna. 2010. 'Not Just a Few Bad Apples: Structural Vulnerability, Health Risks and Temporary Migration in Canada.' Canadian Issues / Thèmes canadiens, March.

Hersi, Abdi M. 2014. Discourses concerning immigrant integration: a critical review. European Scientific Journal. Special Edition (August 2014).

Higgins, Christopher, Linda Duxbury \& Mark Julien. 2014. 'The relationship between work arrangements and work-family conflict.' Work, 48(1):69-81

Higgs, David. 1982. The Portuguese in Canada. Toronto, ON: Canadian Historical Association

Holmes, Seth. 2013. Fresh Fruit, Broken Bodies: Migrant Farmworkers in the United States. Berkeley and Los Angeles: University of California Press.

Holstein, Jafer \& James Gubrium. 1995. The active interview. Thousand Oaks, CA: Sage. 
Hollibaugh, Amber. 2001. 'They Are Everywhere. But We Refuse to See Them.' Queers Without Money. Village Voice, June: 20-26

Honneth, Axel. 1993. The Critique of Power: Reflective Stages in a Critical Social Theory. Boston, MA: MIT Press

Honneth, Axel. 1995. The Struggle for Recognition. The Moral Grammar of Social Conflicts. Cambridge, UK: Polity Press.

Horkheimer, Max \& Theodor W. Adorno. 2002 [1947]. Dialectic of Enlightenment. Stanford, CA: Stanford University Press.

Horkheimer, Max. 1976. 'Traditional and Critical Theory.' In: Paul Connerton (Ed.) Critical Sociology (Pp: 206-224). New York, NY: Penguin Books

Horkheimer, Max. 1982. Critical Theory. New York, NY: Seabury Press.

Ibbitson, John. Dec 2014. Bootstrap Immigrants: Assessing the Conservative Transformation of Canada's Immigration Policy. Policy Brief. Centre for International Governance Innovation. Retrieved from: www.cigionline.org/sites/default/files/pb_no52.pdf

International Labour Organization. 2011. World of Work Report. Geneva, SW: International Labour Organization (International Institute for Labour Studies)

Jackson, Andrew \& Govind Rao. 2016. The Unhealthy Canadian Workplace. In: Dennis Raphael (Ed.) Social Determinants of Health: Canadian Perspectives (Pp: 150-170). Toronto, ON: Canadian Scholars Inc.

Jameson, Fredric. 1969. 'Walter Benjamin, or Nostalgia.' Salmagundi, 10/11: 52-68

Jameson, Fredric. 1997. 'Culture and Finance Capital.' Critical Inquiry, 24 (1): 246-265

Jameson, Fredric. 2011. Representing Capital: A Reading of Volume One. New York, NY: Verso Books

Jennifer, Elrick. 2007. Focus Migration: Country profile: Canada. Ottawa, ON: Bundeszentrale für politische Bildung \& Hamburgisches WeltWirtschaftsInstitut (HWWI).

Jimenez, Marina. March 28, 2017. '200,000 illegal immigrants toiling in Canada's underground economy.' The Globe and Mail. Retrieved from:

www.theglobeandmail.com/news/national/200000-illegal-immigrants-toiling-in-canadasunderground-economy/article18437108/

Jones, Terry-Ann \& Eric Mielants (Ed.). 2016. Mass Migration in the World System. Past, Present and Future. New York, NY: Routledge 
Kathleen, Schwartzman. 2016. 'The US-Mexico Commodity Labour Exchange'. In: Terry-Ann Jones \& Eric Mielants (Eds.) Mass Migration in the World System. Past, Present and Future (Pp: 13-21). New York, NY: Routledge

Khandor, Erika, Jean McDonald, Peter Nyers \& Cynthia Wright. 2004. The Regularization of NonStatus Immigrants in Canada 1960-2004: Past Policies, Current Perspectives, Active Campaigns. Toronto, ON: Independient Booklet.

Klein, Naomi. 2014. This Changes Everything. Capitalism vs. The Climate. New York, NY: Simon \& Schuster

Landolt, Patricia \& Goldring, Luin. 2013. 'The Social production of Non-citizenship: The Consequences of Intersecting Trajectories of Precarious Legal Status and Precarious Work.' In: Luin Golding \& Patricia Landolt (Eds.) Producing and negociating Non-citizenship: Precarious Legal Status in Canada (Pp:154-175). Toronto, ON: University of Toronto Press.

Lapavistas, Costas. 2013. Profiting without Producing. How Finance Exploits Us All. New York, NY: Verso Books

Lars, Hansson. 2016. 'Branch Migration: Finnish Migration to Sweden. The Pulp and paper Industry.' In: Terry-Ann Jones \& Eric Mielants (Eds.) Mass Migration in the World System. Past, Present and Future (Pp: 13-21). New York, NY: Routledge

Lawrence, Bonita. 2004. 'Real' Indians and Others. Mixed-Blood Urban Native Peoples and indigenous Nationhood. Vancouver, BC: University of British Columbia Press

LEGER et.al. 2013. 'La politique provinciale et fédérale au Québec. Enquête d'Opinion'. Le Devoir (October 12, 2016). Retrieved from:

www.ledevoir.com/documents/pdf/sondage12octobre.pdf

Lemaitre, Georges. 2007. The Integration of Immigrants into the Labour Market: The Case of Sweden.Paris, FR: OECD Publishing

Lewchuk, Wayne, Alice deWolff, Andy King and Michael Polanyi. 2006. 'The Hidden Costs of Precarious Employment: Health and the Employment Relationship.' In: Precarious Work in Canada, Leah Vosko ed. (pp. 141-162). McGill-Queen's University Press: Montreal-Kingston.

Lewchuk, Wayne, Marlea Clarke and Alice de Wolff. 2011. Working Without Commitments: The Health Effects of Precarious Employment. Montreal and Kingston: McGill-Queen's University Press.

Li, Peter S. 2003. Deconstructing Canada's discourse of immigrant integration.

Journal of International Migration and Integration / Revue de l'integration et de la migration internationale, 4 (3)

Liebig, Thomas. 2007. The Labour Market Integration of Immigrants in Denmark (OECD paper No. 50). Paris, FR: OECD Publishing 
Lowry, Michelle \& Peter Nyers. 2003. “ "No One Is Illegal”: The Fight for Refugee and Migrant Rights in Canada.' Refuge, 21 (3): 66-72

Lukacs, Georg. 1971 [1920]. History \& Class Consciousness. Cambridge, MA: The MIT Press

Luke, Paul. January 11 2014. 'Longer hours, more stress: The new reality in the Canadian workplace'. The Province. Retrieved from:

www.theprovince.com/travel/longer+hours+more+stress+reality+canadian+workplace/9374213/ story.html

Luxton, Meg \& Kate Bezanson. 2006. 'Social reproduction and Feminist Political Economy.' In: Meg Luxton \& Kate Bezanson (Eds.) Social Reproduction: Feminist Political Economy Challenges Neo-Liberalism (Pp: 3-10). Montreal \& Kingston: McGill—Queen's University Press

Malkki, Liisa. 1992. National geographic: The rooting of peoples and the territorialization of national identity among scholars and refugees. Cultural Anthropology, 7(1),22-44.

Mandel, Ernest. 1975. Late Capitalism. London, UK: Lowe \& Brydone Printers Limited

Manokha, Ines. 2004. 'Modern Slavery and Fair-Trade Products: Buy One and Set Someone Free,' in C. van der Anker (Ed.) The Political Economy of New Slavery (Pp: 217-34). New York, NY: Palgrave Macmillan.

Marcus, George. 1995. "Ethnography of the World System: The Emergence of Multi-Sited Ethnography." Annual Review of Anthropology. 24: 95-117

Marcuse, Herbert. 1974 [1955]. Eros and Civilization: A Philosophical Inquiry into Freud. Boston, MA: Beacon Press

Marcuse, Herbert. 1960. A Note on Dialectic. (Preface to Reason and Revolution: Hegel and the Rise of Social Theory) (Pp: vii-xvi). Boston, MA: Beacon Press.

Marcuse, Herbert. 1965. Repressive Tolerance. In: Robert Paul Wolff, Barrington Moore Jr. \& Herbert Marcuse. A Critique of Pure Tolerance. Boston, MA: Beacon Press.

Marmot, Michael. 2005. 'Social determinants of health inequalities.' Lancet (365): 1099-1104

Marmot, Michael. 2015. Status Syndrome. How Your Place on the Social Gradient Directly Affects Your Health. London, UK: Bloomsbury

Marmot, Michael. 2016. The Health Gap. London, UK: Bloomsbury

Marmot, Michael. 2018. "Inclusion health: addressing the causes of the causes." The Lancet. 391. Retrieved from: www.thelancet.com/action/showPdf?pii=S0140-6736\%2817\%2932848-9 
Marshall, Thomas Humphrey. 1950. Citizenship and Social Class: And Other Essays. Cambridge, UK: University Press.

Martig, Alexis et Francine Saillant. 2017. 'Présentation: L'esclavage moderne: une question anthropologique?' Anthropologie et Sociétés, 41 (1): 9-27

Martig, Alexis. 2017. 'Domination et servitude dans le Brésil rural contemporain: le 'travail esclave' rural migrant.' Anthropologie et Sociétés, 41 (1): 69-90

Martín, Iván, et.al. 2016. From Refugees to Workers: Mapping Labour-Market Integration Support Measures for Asylum Seekers and Refugees in EU Member States, Volume 1: Comparative Analysis and Findings. Florence, IT: Migration Policy Centre \& European University Institute. Retrieved from :

www.bertels-mann-

stiftung.de/fileadmin/files/user_upload/Studie_NW_From_Refugees_to_Workers_Vol1.pdf.

Marx, Karl \& Friedrich Engels. 2010 [1843]. Collected works. Volume 3. March 1843-August 1844. London, UK: Lawrence \& Wishart

Marx, Karl. 1938 [1891]. Critique of the Gotha Programme. New York, NY: International Publishers Co.

Marx, Karl. 1970 [1843]. Critique of Hegel's Philosophy of Right. Cambridge, MA: Cambridge University Press

Marx, Karl. 1975. Early Writings. New York, NY: Penguin Books.

Marx, Karl. 1977 [1939]. Grundrisse. Foundations of the Critique of Political Economy. New York, NY: Penguin Books.

Marx, Karl. 1990. Capital. A Critique of Political Economy. Vol I. London, UK: Penguin Books.

McDonough, Peggy. 2001. "Work and Health in the Global Economy." In Armstrong, Hugh, Armstrong, Pat \& David Coburn (eds). Unhealthy Times: Political Economy Perspectives on Health and Care in Canada, 223-46, Don Mills, ON: Oxford University Press.

McIntosh, Peggy. 2004. 'White Privilege: Unpacking the Invisible Knapsack.' In Paula S. Rothenberg (Ed.) Race, Class, and Gender in the United States (Pp. 188-192). New York, NY: Worth Publishers.

Melançon, Jérôme. 2016. 'Liberty, Equality, Laicity: Québec's Charter of Values and the Reframing of Politics.' Canadian Political Science Review, 9:3, 35-71.

Mezzadra, Sandro. 2015. The proliferation of borders and the right to escape. In Y. Jansen, R. Celikates, \& J. de Bloois (Eds.), The Irregularization of Migration in Contemporary Europe: 
Detention, Deportation, Drowning (Pp:121-135). London, UK: Rowman \& Littlefield International

Migration Policy Institute. 2017. Profile of the Unauthorized Population: United States. Retrieved from: www.migrationpolicy.org/data/unauthorized-immigrant-population/state/US

Miers, Suzanne. 2003. Slavery in the Twentieth Century: The Evolution of a Global Problem. Walnut Creek, CA: Alta Mira Press

Minister of Education. Dec. 3, 2004. 'Clarification of section 49.1 of the Education Act: Education of persons unlawfully in Canada.' Policy/Program Memorandum No 136. Retrieved from: www.edu.gov.on.ca/extra/eng/ppm/136.pdf

Minsky, Amy. June 2017. 'Hate crimes against Muslims in Canada increase 253\% over four years'. Global News. Retrieved from:

https://globalnews.ca/news/3523535/hate-crimes-canada-muslim/

Minsky, Hyman P. 1989. 'Money Manager Capitalism.' In: Hyman P. Minsky Archive. Paper 13. Retrieved from: http://digitalcommons.bard.edu/hm_archive/13

Minsky, Hyman P. 1990. 'Money manager capitalism, fiscal independence, and international monetary reconstruction.' In: Miklos Szabo-Pelsoczi (Ed.) The Future of the Global Economic and Monetary System. Budapest: HU: Institute for World Economics of the Hungarian Academy of Sciences.

Mize, Ronald L. \& Alicia Swords. 2011. Consuming Mexican Labor: From the Bracero Program to NAFTA. Toronto, ON: University of Toronto Press.

Mize, Ronald L. 2008. 'Interrogating Race, Class, Gender and Capitalism Along the U.S.-Mexico Border: Neoliberal Nativism and Maquila Modes of Production.' Race, Gender \& Class, 15 (1/2): $134-155$

Molnar Diop, Petra. 2014. 'The 'Bogus' Refugee: Roma Asylum Claimants and Discourses of Fraud in Canada's Bill C-31.' Refuge 30 (1): 67-80

Molnar, Petra \& Stephanie J. Silverman. Nov 2017. 'Migrants are dying in Canadian detention centres. The government needs to act.' Maclean's. Retrieved from: www.macleans.ca/opinion/migrants-are-dying-in-canadian-detention-centres-the-governmentneeds-to-act/

Muntaner, Carles \& John Lynch. 1999. Income inequality, social cohesion, and class relations: A critique of Wilkinson's neo-Durkheimian research program. International Journal of Health Services, 29:59-82

Muntaner, Carles, Ng, Edwin, Prins, Seth J., Bones-Rocha, Katia, Espelt, Albert \& Haejoo. 2015. Social class and mental health: testing exploitation as a relational determinant of depression. International journal of health services: planning, administration, evaluation, 45(2), 265-84. 
Muntaner, Carles, Ng, Edwinet, Vanroelen, Christope, Christ, Sharon \& William W. Eaton. 2013. 'Social stratification, social closure, and social class as determinants of mental health disparities.' In: Aneshensel, C. S. Phelan, Jo C. \& Bierman, A. (eds.) Handbook of the Sociology of Mental Health (Pp: 205-227). New York, NY: Springer.

Muntaner, Carles, Rai, Nanky, Ng, Edwin \& Haejoo Chung. 2012. Social class, politics, and the spirit level: Why income inequality remains unexplained and unsolved. International Journal of Health Services, 42(3):369-381

National Conference of State Legislatures. 2016. 'States Offering Driver's Licenses to Immigrants.' Retrieved from: http://www.ncsl.org/research/immigration/states-offering-driver-slicenses-to-immigrants.aspx

Navarro, Vicente. (2009). What We Mean by Social Determinants of Health. International Journal of Health Services, 39(3), 423-441.

Navarro, Vicente. 2001. The Political Economy of Social Inequalities: Consequences for Health and Quality of Life. New York, NY: Baywood Publishing Co.

New York Times. Dec. 2016. Life Expectancy in U.S. Declines Slightly, and Researchers Are Puzzled. Retrieved from: www.nytimes.com/2016/12/08/health/life-expectancy-us-declines.html

Newbold, Bruce \& Jeff Danforth. 2003. 'Health status and Canada's immigrant population.' Social Science \& Medicine, 57(10):1981-1995

Newland, Kathleen \& Carylanna Taylor. 2010. Heritage Tourism and Nostalgia Trade: A Diaspora Niche in the Development Landscape. Washington, DC: Migration Policy Institute

Ng, Edward, Kevin Pottie \& Denise Spitzer. 2011. 'Limited Official Language Proficiency and Decline in Self-Reported Health Status: A Dynamic View from the Longitudinal Survey of Immigrants to Canada.' Health Reports 22(4): 1-9.

$\mathrm{Ng}$, Edward. 2014. The healthy immigrant effect and mortality rates. Health Reports, 22 (4). Retrieved from: www.statcan.gc.ca/pub/82-003-x/2011004/article/11588-eng.htm

Ngai, Mae. 2003. 'The strange career of the illegal alien: Immigration restriction and deportation policy in the United States, 1921-1965.' Law and History Review, 21(01):69-108.

Nizan, Rachel. 2004. 'Child Labour in Latin America: Issues and Policies in Honduras.' In: Christien Van der Anker (Ed.) The Political Economy of New Slavery (Pp: 137-157). New York, NY: Palgrave Macmillan

Nyers, Peter. 2003. 'Abject Cosmopolitanism: The Politics of Protection in the Anti-Deportation Movement.' Third World Quarterly 24(6): 1069-1093. 
Nyers, Peter. 2006. 'Taking Rights, Mediating Wrongs: Disagreements over the Political Agency of Non-Status Refugees.' In: Jef Huysmans, Andrew Dobson \& Raia Prokhovnik (Eds.) The Politics of Protection: Sites of Insecurity and Political Agency (Pp: 48-67). London, UK: Routledge.

Nyers, Peter. 2010. 'No One Is Illegal Between City and Nation.' Studies in Social Justice 4:(2)

OECD. 2015. In It Together: Why Less Inequality Benefits All. Paris, FR: OECD Publishing. Downloaded from:

www.keepeek.com//Digital-Asset-Management/oecd/employment/in-it-together-why-lessinequality-benefits-all_9789264235120-en\#page4

OECD. 2009. The Labour Market Integration of Immigrants and their children in Norway

(OECD Social, Employment and Migration Working papers no.94) Paris, FR: OECD Publishing

Orozco, 2008. Testing Identity. Trends in Migrant Demand for Home-Country Goods. Washington, DC: USAID. Retrieved http://archive.thedialogue.org/PublicationFiles/DNA\%20Paper\%20Series\%20\%20Tasting\%20Identity_11-18-08-Summary_FINAL.pdf

Otero, Gerardo \& Kerry Preibisch. 2015. Citizenship and Precarious Labour in Canadian Agriculture. Ottawa, ON: Canadian Centre for Policy Alternatives. Retrieved from: www.policyalternatives.ca/sites/default/files/uploads/publications/BC\%20Office/2015/11/CCPA -BC_CitizenshipPrecariousLabourCdnAgri_web.pdf

Pantaleón, Jorge \& Lucio Castracani. 2017. 'Travail, morale et dépendance personnelle: les ouvriers agricoles mexicains et guatémaltèques dans les fermes québécoises.' Anthropologie et Sociétés, 41(1): 91-106

Park, Agustine, S. J. 2013. 'Racial-Nationalism and Representations of Citizenship: The Recalcitrant Alien, the Citizen of Convenience and the Fraudulent Citizen.' Canadian Journal of Sociology, 38(4): 557-578.

Parliament of Canada. 2009. Temporary Foreign Workers and Non Status Workers. Report of the Standing Committee on Citizenship and Immigration. 40th Parliament, 2nd Session. Ottawa: House of Commons-Canada.

PEPSO. 2013. It's More than Poverty: Employment Precarity and Household Well-being. McMaster

PEPSO. 2017. The Precarity Penalty: The impact of employment precarity on individuals, households and communities — and what to do about it. PEPSO-McMaster-United Way

Perez, Claudio. 2002. "Health status and health behaviour among immigrants" Supplement to Health Reports, Vol. 13. Statistics Canada. Retrieved from: http:/www.statcan.gc.ca/pub/82-003s/2002001/pdf/82-003-s2002005-eng.pdf 
PEW Research Center. May 2006. Modes of Entry for the Unauthorized Migrant Population. Fact Sheet. Retrieved from: www.pewhispanic.org/2006/05/22/modes-of-entry-for-the-unauthorizedmigrant-population/

PEW Research Center (November 3, 2016) Size of U.S. Unauthorized Immigrant Workforce Stable After the Great Recession. Retrieved from: www.pewhispanic.org/2016/11/03/size-of-u-sunauthorized-immigrant-workforce-stable-after-the-great-recession/

Piore, Michael. 1979. Birds of Passage. Migrant Labor and Industrial Societies. Cambridge, MA: Cambridge University Press.

Porter, John. 1970. The Vertical Mosaic: An Analysis of Social Class and Power in Canada. Toronto, ON: University of Toronto Press.

Pratt, Anna, 2005. Securing Borders. Detention and Deportation in Canada. Vancouver, BC: University of British Columbia Press

Preibisch, Kerry. 2007. 'Local Produce, Foreign Labor: Labor Mobility Programs and Global Trade Competitiveness in Canada.' Rural Sociology, 72 (3): 418-449

Priebisch, Kerry. 2015. 'Los trabajadores migrantes y los cambios en los regímens laborales en la produccion agrícola contemporánea de Canadá.' En: Sara Lara Flores, Jorge Pantaleón y martha Sánchez Gómez (Eds.) Hacia el Otro Norte: Mexicanos en Canadá (Pp: 115-137). Buenos Aires, ARG: CLACSO

Proudhon, Pierre-Joseph. 2010 [1840]. What is Property?: An Inquiry Into the Principle of Right and of Government. Auckland, NZ: The Floating Press.

Proudhon, Pierre-Joseph. 1849. The State. Its Nature, Object, and Destiny. Panarchy.

Public Safety Canada. 2017. Integrated Border Enforcement Teams (IBET). (Date modified: 201709-18). Retrieved from:

www.publicsafety.gc.ca/cnt/brdr-strtgs/brdr-lw-nfrcmnt/ntgrtd-brdr-nforcmnt-tms-en.aspx

Quirk, Joel. 2008. Unfinished Business: A Comparative Study of Historical and Contemporary Slavery. Paris, FR: UNESCO.

Radio-Canada \& CROP. 2017. Les canadiens, le populisme et la xénophobie. Rapport presénté par CROP Retrieved from:

http://ici.radio-canada.ca/nouvelles/special/2017/03/sondage-crop/Sondage\%20CROP-RadioCanada.pdf

Radio-Canada. 2017b. 'Sondage CROP/Radio-Canada: Une majorité de Canadiens exprime des craintes face à l'immigration.' RadioCanada. Retrieved from:

http://ici.radio-canada.ca/nouvelles/special/2017/03/sondage-crop/canadiens-tolerance-religionimmigrants-identite-culture/ 
Raphael, Dennis. 2001. "From increasing poverty to societal disintegration: how economic inequality affects the health of individuals and communities", in Armstrong H, Armstrong P, Coburn D, editors. Unhealthy Times: Political Economy Perspectives on Health and Care in Canada, 223-46, Don Mills, ON: Oxford University Press.

Raphael, Dennis. 2002. Poverty, Income Inequality, and Health in Canada. Toronto, ON: The CSJ Foundation for Research and Education.

Raphael, Dennis (ed). 2009. Social Determinants of Health: Canadian Perspectives. Toronto, ON: Canadian Scholars' Press.

Raphael, Dennis. 2011. Poverty in Canada: Implications for health and quality of life, 2nd edition. Toronto, ON: Canadian Scholars' Press.

Raphael, Dennis (ed). 2016. Social Determinants of Health: Canadian Perspectives. Toronto, ON: Canadian Scholars Inc.

Raphael, Dennis (ed.). 2017. Immigration, Public Policy, and Health: Newcomer Experiences in Developed Nations. Toronto, ON: Canadian Scholars' Press

Reid-Musson, Emily. 2017. 'Grown Close to Home ${ }^{\mathrm{TM}}$ : Migrant Farmworker (Im)mobilities and Unfreedom on Canadian Family Farms.' Annals of the American Association of Geographers, 107 (3):716-730

Reimer, Bill. 2000. The Informal Economy in Rural Canada. Presentation to The Canadian Employment Research Forum, July 30. Retrieved from: www.researchgate.net/profile/Bill_Reimer/publication/228539278_The_Informal_Econo

Reimer, Bill. 2006. 'The Informal Economy in Non-Metropolitan Canada.' Canadian Review of Sociology/Revue canadienne de sociologie, 43: 23-49.

Reitz, Jeffrey G. 2007. "Immigrant Employment Success in Canada, Part I: Individual and Contextual Causes". International Migration and Integration 8 (2007): 11-36

Resnick Stephen \& Richard Wolff. 1982. Marxist epistemology: The critique of economic determinism. Social Text, 6:31-72.

Rystad, Göran. 1990. The Uprooted: forced migration as an international problem in the postwar era. Lund, SW: Lund University Press

Roediger, David R. 2007. The Wages of whiteness: race and the making of the American working class. New York, NY: Verso

Roman, Richard \& Edur Velasco Arregui. 2013. Continental Crucible: Big Business, Workers and Union in the Transformation of North America. Toronto, ON: Fernwood Publishing 
Roth, S., Newman, E., Pelcovitz, D., Van der Kolk, B.A., \& Mandel, F.S. 1997. 'Complex PTSD in victims exposed to sexual and physical abuse: Results from the DSM-IV field trial for posttraumatic stress disorder.' Journal of Traumatic Stress, 10(4): 539-555.

Rousseau, Cécile, ter Kuile, Marie, Muñoz, Sonia, Nadeau, Lucie, Ouimet, Marie-Jo, Kirmayer, Laurence \& François Crépeau. 2008. Health Care Access for Refugees and Immigrants with Precarious Status: Public Health and Human Right Challenges. Canadian Journal of Public Health, 99 (4): 290-292

Rummery, Kirstein. 2002. Disability, Citizenship and Community Care: A Case for Welfare Rights? Hampshire, UK: Ashgate publishing Limited.

Ruiz-Casares, Mónica et al. 2010. 'Right and access to healthcare for undocumented children: Addressing the gap between international conventions and disparate implementations in North America and Europe.' Social Science \& Medicine, 70 (2):329-336.

Ruiz-Casares, Mónica et al. 2012. 'Access to Health Care for Undocumented Migrant Children and Pregnant Women: The Paradox Between Values and Attitudes of Health Care Professionals.' Maternal and Child Health Journal, 17(2):292-298.

Saad, Samia. 2013. 'The Cost of Invisibility: The Psychosocial Impact of Falling Out of Status.' In: L. Goldring \& P. Landolt (eds.) Producing and Negotiating Non-Citizenship: Precarious Legal Status in Canada (Pp:137-153). Toronto, ON: University of Toronto Press.

Sakamoto, Izumi \& Zhou, Yanqiu Rachel. 2005. 'Gendered nostalgia: The experiences of Chinese new skilled immigrants in Canada'. In Vijay Agnew (Ed.), Diaspora, memory, identity: A search for home, (Pp: 209-229). Toronto, ON: University of Toronto Press.

Sassen, Saskia. 1988. The Mobility of Labor and Capital. A Study in International Investment and Labor Flow. Cambridge, MA: Cambridge University Press.

Sassen, Saskia. 1999. Guests and Aliens. New York, NY: The New Press

Sassen, Saskia. 2010. 'A Savage Sorting of Winners and Losers: Contemporary Versions of Primitive Accumulation' Globalizations, 7 (1): 23-50.

Sassen, Saskia. 2014. Expulsions. Brutality and Complexity in the Global Economy. Cambridge, MA: Harvard University Press.

Scott, James C. 1986. 'Everyday forms of peasant resistance.' The Journal of Peasant Studies, 13 (2): $5-35$

Scott, James C. 1990. Domination and the arts of resistance: Hidden transcripts. New Haven \& London, UK: Yale University Press.

Scott, James C. 2008. Weapons of the week: Everyday forms of peasant resistance. New Haven \& London, UK: Yale University Press. 
Sears, Alan. 2006. 'Creating and sustaining communities of struggle. The infrastructure of dissent.' New Socialist: $32-33$

Sears, Alan. 2014. The Next New Left: A Story of the Future. Black Point, NS: Fernwood Publishing.

Shalla, Vivian \& Wallace Clement (eds.). 2007. Work in Tumultuous Times. Critical Perspectives. Montreal and Kingston: McGill-Queen's University Press

Shalla, Vivian. 2007. "Theoretical Reflections on Work: A Quarter-Century of Critical Thinking." (3-29) In: Vivian Shalla \& Wallace Clement (Eds.) Work in Tumultuous Times. Critical Perspectives. Montreal and Kingston: McGill-Queen's University Press

Silverman, Stephanie J. 2014. 'In the Wake of Irregular Arrivals: Changes to the Canadian Immigration Detention System.' Refuge, 30 (2): 27-34

Silverman, Stephanie J., Julianna Beaudoin \& Efrat Arbel. February 2013. 'Why Is There No Refuge for Roma Refugees?' Huffington Post. Retrieved from: www.huffingtonpost.ca/stephaniej-silverman/roma-refugees-canada-immigration_b_2346160.html

Silverstein, Paul A. 2004. Of rooting and uprooting: Kabyle habitus, domesticity, and structural nostalgia. Ethnography, 5 (4), 553-578.

Simich, Laura, Fei, Wu \& Sonja Nerad. 2007. Status and Health Security: An Exploratory Study of Irregular Immigrants in Toronto. Canadian Journal of Public Health, 98(5):369-373

Simmons, Alan. 2015. 'Transformación de la política internacional de migración de Canadá. Implicaciones para México.' En: Sara Lara Flores, Jorge Pantaleon y Martha Sánchez Gómez (Coords.) Hacia el otro norte. Mexicanos en Canadá. Buenos Aires, ARG: CLACSO.

Smith, Dorothy \& William Carroll. 2010. "YYou are here" Interview with Dorothy Smith.' Socialist Studies, the Journal of the Society for Socialist Studies/Etudes socialistes: Revue de la Société d'études socialistes, 6(2):9-37

Smith, Dorothy. 2007. 'The relations of ruling: a feminist inquiry.' Studies in Cultures, Organizations and Societies, 2 (2): 171-190.

Spitzer, Denise. 2011a. 'Work, Worries and Weariness: Towards an Embodied and Engendered Migrant Health.' In: Denise Spitzer (Ed.) Engendering Migrant Health: Canadian Perspectives (Pp: 23-39). Toronto: University of Toronto Press.

Spitzer, Denise. 2011b. 'Engendering Migrant Health in Canada.' In: Denise Spitzer (Ed.) Engendering Migrant Health: Canadian Perspectives (Pp:3-20). Toronto, ON: University of Toronto Press. 
Spitzer, Denise. 2012. 'Oppression and Im/migrant Health in Canada.' In: E. McGibbon (Ed.) Oppression and Health (Pp: 113-122). Halifax, NS: Fernwood Publishing.

Spoormaker V.I. Schredl, M \& J. van den Bout. 2006. 'Nightmares: from anxiety symptom to sleep disorder.' Sleep Medical Review, 10(1):19-31.

Standing, Guy. 2011. The Precariat: The New Dangerous Class. London, UK: Bloomsbury Academic.

Stasiulis, Daiva. 2013. 'Worrier Nation: Quebec's Value Codes for Immigrants.' Politikon: South African Journal of Political Studies, 40 (1): 183-209.

Statistics Canada. 2016.The underground economy in Canada, 2013 (Released: 2016-06-20). Retrieved from: www.statcan.gc.ca/daily-quotidien/160620/dq160620b — eng.htm

Statistics Canada. 2013. Canada - Temporary foreign workers present on December $1^{\text {st }}$ by province or territory and urban area, 2008-2012. Retrieved on December 02, 2014 from: http://www.cic.gc.ca/english/resources/statistics/facts2012-preliminary/04.asp

Statistics Canada. 2017. Police-reported hate crimes, 2015. Retrieved from: www.statcan.gc.ca/daily-quotidien/170613/dq170613b-eng.htm?HPA=1

Stewart, M., Shizha, E., Makwarimba, E., Spitzer, D., Khalema, E., and Nsaliwa, C. 2011. 'Challenges and Barriers to Services for Immigrant Seniors in Canada: "You are among others, but you feel alone".' International Journal of Migration, Health and Social Care, 7(1): 16-32.

Stone, Laura. Nov 12, 2017. Federal Budget 2016. Inside Trudeau's budget: Read the highlights. The Globe \& Mail, Ottawa. Retrieved from: www.theglobeandmail.com/news/politics/insidetrudeaus-budget-read-thehighlights/article29336681/

Teixeira, Carlos \& Victor M. P. Da Rosa (cords). 2009. The Portuguese in Canada. Diasporic Challenges and Adjustment. Toronto, ON: University of Toronto Press

Teixeira, Carlos. 2009. New immigrant settlement in a mid-sized city: a case study of housing barriers and coping strategies in Kelowna, British Columbia. The Canadian Geographer 3: 323-339.

Thobani, Sunera. 2007. Exalted Subjects: Studies in the Making of Race and Nation in Canada. Toronto, ON: University of Toronto Press.

Thorpy, Michael J. 2012. 'Classification of Sleep Disorders.' Neurotherapeutics, 9(4): 687-701.

Thörnquist, Annette \& Engstrand, Åsa.-Karin. (Eds.). 2011. Precarious employment in perspective: Old and new challenges to working conditions in Sweden. Bryssel, SZ: Peter Lang Publishing Group

Tomilson, Frances \& Egan Sue. 2002. 'From Marginalization to (Dis)Empowerment: Organizing Training and Employment Services for Refugee,' Human Relations 55 (8): 1019-1043 
Torpey, John. 2000. The Invention of the Passport. Surveillance, Citizenship and the State. Cambridge: Cambridge University Press.

Trinkoff, Alison M, Johantgen, Meg, Muntaner, Carles \& Rong Le. 2005. Staffing and worker injury in nursing homes. American Journal of Public Health, 95(7):1220

Twinam, Ann. 2015. Purchasing Whiteness: Pardos, Mulattos, and the Quest for Social Mobility in the Spanish Indies. Stanford, CA: Stanford University Press.

United Nations. 2011. The Global Social Crisis. Report on the World Situation 2011. New York, NY: United Nations.

United Nations. Secretary-General (1995).'The relationship between the enjoyment of human rights, in particular, international labour and trade union rights, and the working methods and activities of transnational corporations." Background document prepared by the SecretaryGeneral, in: Eco-nomic and Social Council. Commission on Human Rights. Sub-Commission on Prevention of Discrimination and Protection of Minorities (ed.): Forty-seventh session. Item 8 of the provisional agenda: The realization of Economic, Social and Cultural Rights, 24 July 1995 (E/CN.4/Sub.2/1995/11). New York: United Nations, 1995.

US Department of Justice. 2003. 'Integrated Border Enforcement Teams Now Cover Canada-U.S. Border from Coast to Coast.' Memorandum released on November 19, 2003. Retrieved from: www.justice.gov/archive/opa/pr/2003/November/03_ag_640.htm

Valiani, Salimah. 2012. Rethinking Unequal Exchange. The Global Integration of Nursing Labour Markets. Toronto, ON: University of Toronto Press.

Valiani, Salimah. 2016. 'Global Integration of Nursing Labour Markets: The U.S Instance' In: Terry-Ann Jones \& Eric Mielants (Eds.) Mass Migration in the World System. Past, Present and Future (Pp: 81-101). New York, NY: Routledge

Van der Anker, Christien (ed.) 2004. The Political Economy of New Slavery. New York, NY: Palgrave Macmillan

Van der Kolk, B.A., Perry, J.C., \& Herman, J.L. 1991. 'Childhood origins of self-destructive behavior.' American Journal of Psychiatry, 148: 1665-1671.

Van der Kolk, Bessel A., Susan Roth, David Pelcovitz, Susanne Sunday \& Joseph Spinazzola. 2005. 'Disorders of Extreme Stress: The Empirical Foundation of a Complex Adaptation to Trauma.' International Society for Traumatic Stress Studies, 18 (5): 389-399

Verduzco, Gustavo. 2015. El PTAT y los programas de trabajadores temporales. Una visión crítica. En: Sara Lara Flores, Jorge Pantaleón y Martha Sánchez Gómez (Eds.) Hacia el Otro Norte: Mexicanos en Canadá (Pp: 89-114). Buenos Aires, ARG: Université de MontrealCLACSO 
Villegas, Paloma. 2013. 'Negotiating the Boundaries of Membership: Healthcare Providers, Access to Social Goods and Immigration Status.' In Luin Golding \& Patricia Landolt (Eds.) Producing and negociating Non-citizenship: Precarious Legal Status in Canada. Toronto, ON: University of Toronto Press

Vosko, Leah F., Nancy Zuchewich \& Cynthia Cranford. 2003. Precarious jobs: A new typology of employment. Statistics Canada, Perspectives on Labour and Income, 4 (10)

Vosko, Leah. 2000. Temporary Work: The gendered rise of a precarious employment relationship. Toronto, ON: University of Toronto Press

Vosko, Leah. 2003. 'Gender differentiation and the standard/non-standard employment distinction in Canada, 1945 to the present.' In: Danielle Juteau (Ed.) Social Differentiation in Canada: Patterns and processes (Pp: 25-80). Toronto, ON: University of Toronto Press.

Vosko, Leah. F. 2007. 'Gendered Labour Market Insecurities: Manifestations of Precarious Employment in Different Locations.' In Vivian Shalla \& Wallace Clement (Eds.) Work in Tumultuous Times. Montreal and Kingston: McGill-Queen's University Press.

Wacquant, Loïc. 2007. Urban Outcasts: A Comparative Sociology of Advanced Marginality. Malden, MA: Polity Press

Wallerstein, Immanuel. 2005. La Crisis Estructural del Capitalismo. San Cristobal de las Casas, MX: CIDECI-Universidad de la Tierra.

Wallerstein, Immanuel. 2016. 'Free Flows and real Obstacles. Who wants laissez faire?' In: Jones, Terry-Ann \& Eric Mielants (eds.) Mass Migration in the World System. Past, Present and Future. (Pp: 13-21). New York, NY: Routledge

Walters, William. 2002. 'Deportation, Expulsion and the International Police of Aliens.' Citizenship Studies, 6(3): 265-92

Walters, William. 2004. 'Secure Borders, Safe Haven, Domopolitics.' Citizenship Studies, 8(3): $237-260$

Walters, William. 2006. 'Border/Control.' European Journal of Social Theory, 9(2): 187-204

Walters, William. 2008. 'Acts of Demonstration: Mapping the Territory of (Non)Citizenship.' In: E. Isin and G. Neilson (Eds.) Acts of Citizenship (Pp: 182-207). London: UK: Zed Books.

Walters, William. 2008. 'Anti-Illegal Immigration Policy: The EU Case.' In Christina Gabriel \& Helene Pellerin (Eds.) Governing International Labour Migration (Pp: 43-59). London, UK: Routledge.

Warskett, Rosemary. 2007. 'Remaking the Canadian Labour Movement: Transformed Work and Transformed Labour Strategies.' In: Viviane Shalla \& Wallace Clement (Eds.) Work in Tumultuous Times. Montreal and Kingston: McGill-Queen's University Press. 
Weber, Max. 1992 [1930]. The Protestant Ethic and the Spirit of Capitalism. New York, NY: Routledge.

Weber, Max. 2013 [1922]. Economy and Society. An Outline of Interpretative Sociology. Berkeley and Los Angeles, CA: University of California Press.

Weeks, Kathi. 2011. The Problem with work: Feminism, Marxism, Antiwork Politics and Postwork Imaginaries. Durham, NC: Duke University Press.

Weiner, Myron. 1996. 'Determinants of Immigrant Integration: An International Comparative Analysis.' In: Carmon N. (eds) Immigration and Integration in Post-Industrial Societies.

Migration, Minorities and Citizenship. London, UK: Palgrave Macmillan

Williams, Raymond. 1975. The Country and the City. London, UK: Oxford University Press.

Williams, Raymond. 1977. Marxism and Literature. Oxford, UK: Oxford University Press.

World Health Organization. 1993. The ICD-10 Classification of Mental and Behavioural Disorders. Clinical descriptions and diagnostic guidelines. New York, NY: WHO

Wright, Cynthia. 2003. 'Moments of Emergence: Organizing by and with Undocumented and Non-Citizen People in Canada after September 11. Refuge, 21(3):5-15

Wright, Cynthia. 2006. 'Against Illegality: New Directions in Organizing By and With Non-Status People in Canada.' In: Caelie Frampton (ed.) Sociology for Changing the World: Social Movements/Social Research, Halifax, NS: Fernwood

Yerris, Kristin. 2014. "“Pensando mucho" ("thinking too much"): embodied distress among grandmothers in Nicaraguan transnational families,' Cultural medical Psychiatry, 38(3) 473-98. 